Renata Alves de Toledo

\title{
Estudo eletroquímico e desenvolvimento de novas metodologias eletroanalíticas para a determinação de antidepressivos tricíclicos e neurotransmissores
}

Tese apresentada ao Instituto de Química de São Carlos, da Universidade de São Paulo para obtenção do título de Doutor em Ciências (Área de Concentração: Química Analítica)

Orientador: Prof. Dr. Luiz Henrique Mazo

São Carlos - SP

2006 
“O valor das coisas não está no tempo em que elas duram, mas na intensidade com que acontecem. Por isso existem momentos inesquecíveis, coisas inexplicáveis e pessoas incomparáveis"

Fernando Pessoa 


\section{DEDICO ...}

Ao Eu Superior, o grande Arquiteto do Universo

Aos meus queridos pais, João e Zélia e ao meu irmão Beto.

Não há palavras no mundo capazes de traduzir o meu agradecimento e a minha gratidão em ter vocês sempre ao meu lado... Meus maiores agradecimentos a vocês que me deram, e dão até hoje, oportunidades e incentivos para o meu crescimento pessoal e profissional.

Ao Ricardo, meu marido e meu amigo. Minha gratidão por sua compreensão, carinho e incansável apoio em todos os momentos de minha vida.

À todos os amigos que me incentivaram a caminhar, quer pela palavra sincera ou por um gesto carinhoso.... Todos vocês são especiais! 


\section{AGRADECIMENTOS}

Ao Prof. Dr. Luiz Henrique Mazo, pela orientação neste trabalho, pela confiança em mim depositada, pelo exemplo de simplicidade e de humildade. Meus sinceros agradecimentos.

Ao Dr. Mauro Coelho dos Santos pela co-orientação e pela ajuda inestimável na execução deste trabalho. Aprendi muito com você, pois me ensinou a ter pensamentos positivos e ver o lado bom das coisas.

Á Dra. Káthia Maria Honório pela amizade e pela elaboração dos cálculos químico-quânticos. Serei sempre grata.

Ao Sr. João Tiengo pelo profissionalismo na elaboração de todos os materiais de que necessitei.

Aos amigos do GMEME: Prof. Dr. Luiz Alberto Avaca, Prof. Dr. Sergio Antonio Spinola Machado, André, Andrea, Andressa, Alexandra, Álvaro, Cláudia, Deborah, Djenaine, Fabiano, Giancarlo, Gustavo, Hugo, Inês, Josiane, Katlin, Lídia, Marcelina, Marcelo, Mariah, Marisa, Michele, Milena, Murilo, Rafael, Raquel, Robson, Sônia, Valber, pela ajuda e excelente convívio por todos esses anos. A presença de vocês me ensina a cada dia a valorizá-los, percebendo o quanto a amizade e a companhia de vocês são essenciais para mim.

Às bibliotecárias Lia, Wilneide, Eliana, Sônia, Solange, Vitória e Regina pela atenção, amizade e acima de tudo pelo bom humor.

Á Maria Sílvia de Guzzi Plepis e à Andréia Cristina Cardozo de Moraes do Serviço de Pós-Graduação.

À FAPESP (Processo 01/14629-0) pelo apoio financeiro. 


\section{SUMÁRIO}

LISTA DE ILUSTRAÇÕES................................................................ i

LISTA DE TABELAS ......................................................................... $\mathrm{x}$

LISTA DE SÍMBOLOS E ABREVIATURAS ......................................... xii

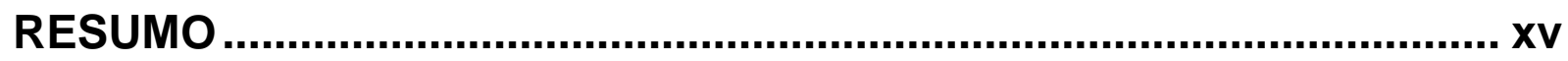

ABSTRACT ....................................................................................... xvii

\section{CAPÍTULO I - INTRODUÇÃO}

\section{I.1- A DEPRESSÃO E O PAPEL DOS ANTIDEPRESSIVOS ................... 1}

I.1.1 - Estudo mecanístico da reação de oxidação da imipramina............................................

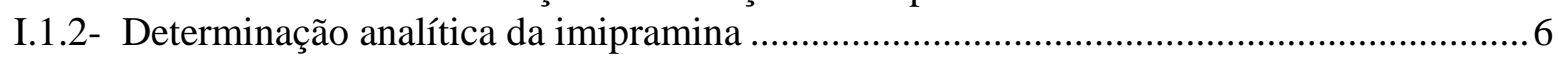

I.2- NEUROTRANSMISSORES ........................................................ 11

I.3- ELETRODOS COMPÓSITOS......................................................... 17

I.4- TÉCNICAS VOLTAMÉTRICAS .................................................... 19

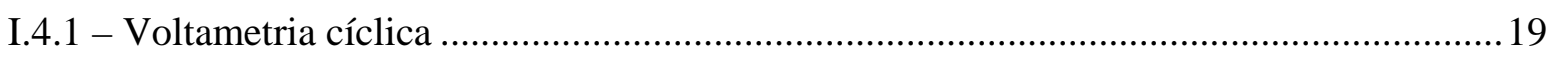

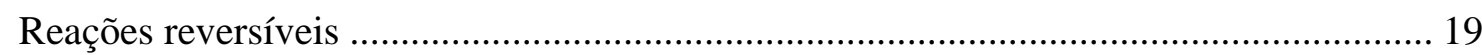

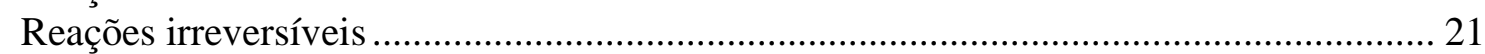

I.4.2- Voltametria de onda quadrada …………………………………………………...22

I.5- CÁLCULOS QUÍMICO-QUÂNTICOS ............................................. 26

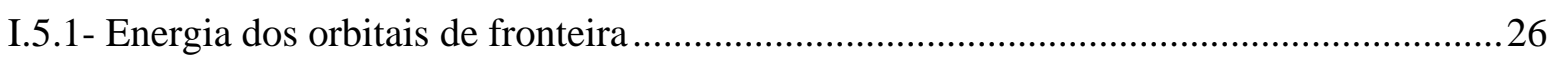

I.5.2- Superfícies de potencial eletrostático.......................................................................22

I.6- ESPECTROMETRIA DE MASSA COM IONIZAÇÃO POR ELECTROSPRAY ....................................................................... 29

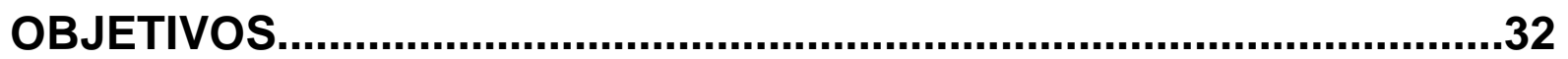




\section{CAPÍTULO II - MATERIAIS E MÉTODOS}

II.1- CÉLULAS ELETROQUÍMICAS .................................................... 35

II.2- REAGENTES E SOLUÇÕES................................................... 36

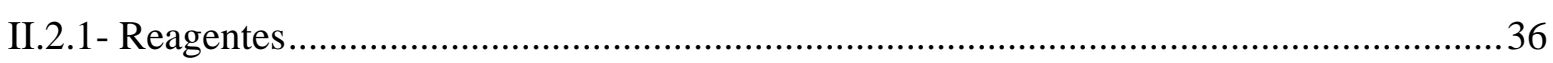

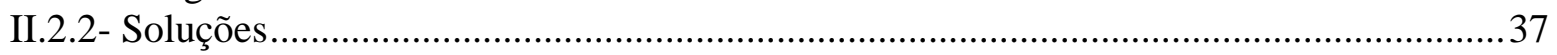

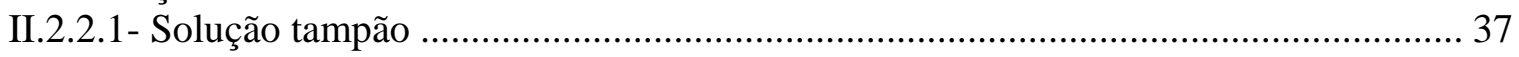

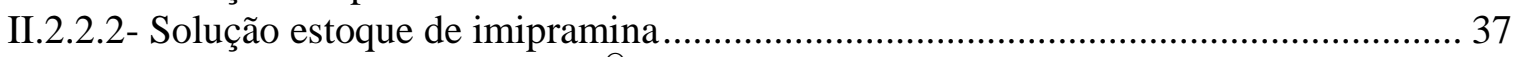

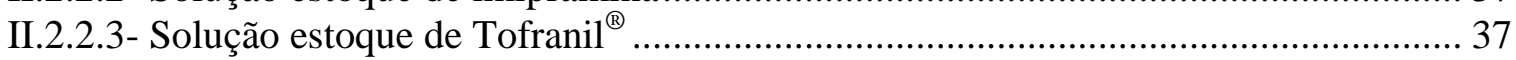

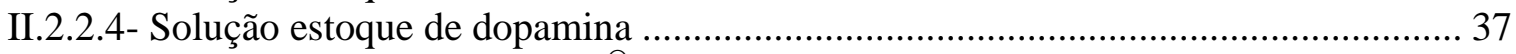

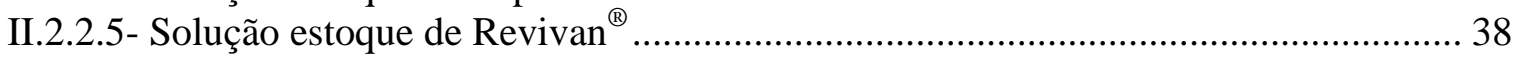

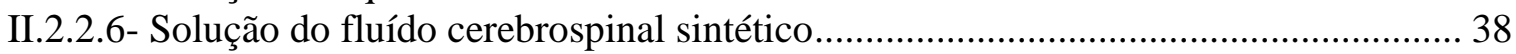

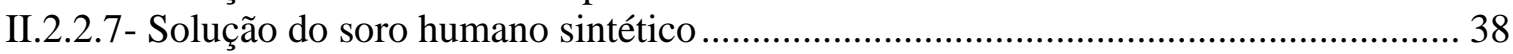

II.3- ELETRODOS ................................................................................ 39

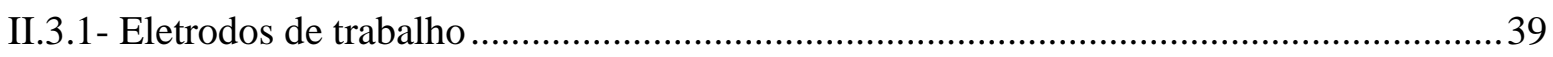

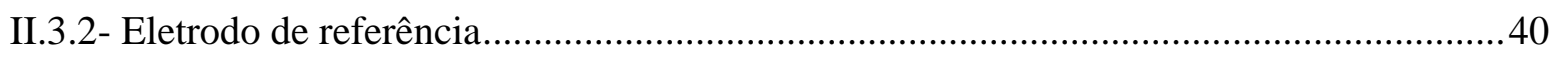

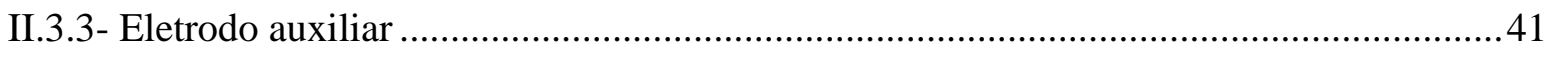

II.4- METODOLOGIA ........................................................................ 41

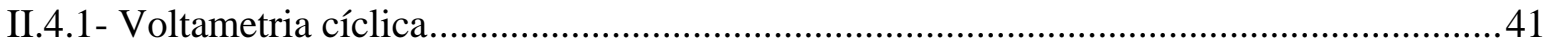

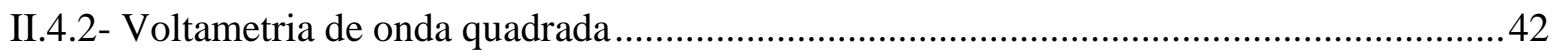

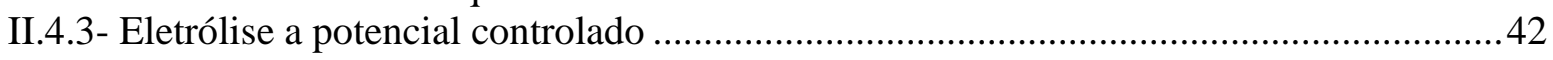

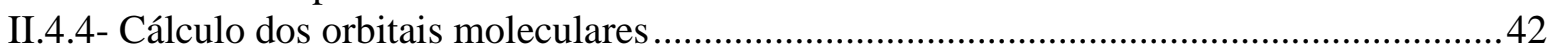

II.4.5- Espectrometria de massa com ionização por electrospray ……...................................43

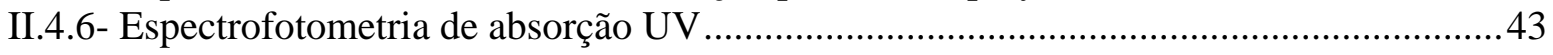

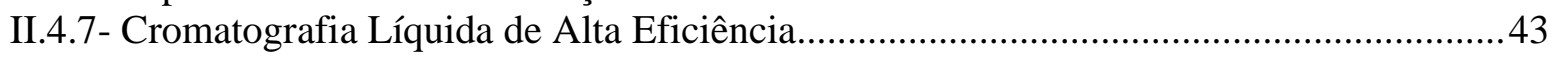

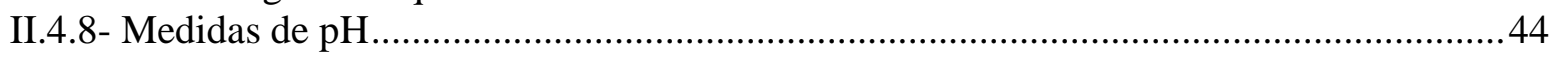

\section{CAPÍTULO III - RESULTADOS E DISCUSSÃO}

III.1- ESTUDO VOLTAMÉTRICO DA IMIPRAMINA (50)....................... 46

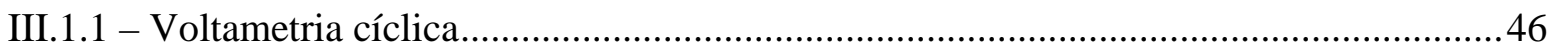

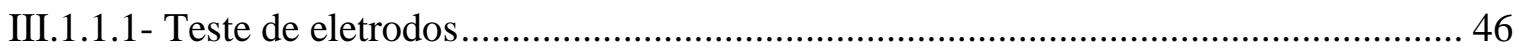

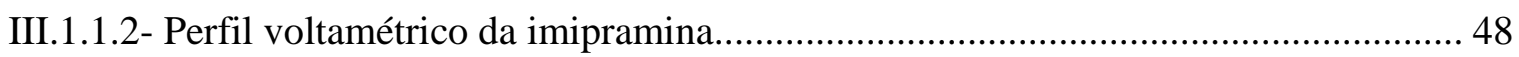

III.1.1.3- Variação da velocidade de varredura .......................................................... 49

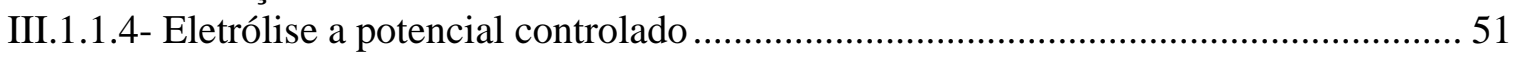

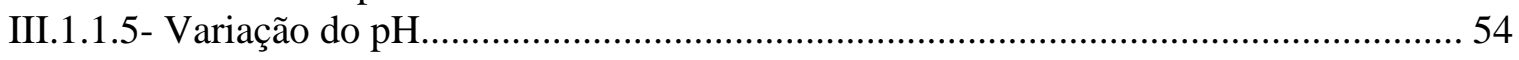

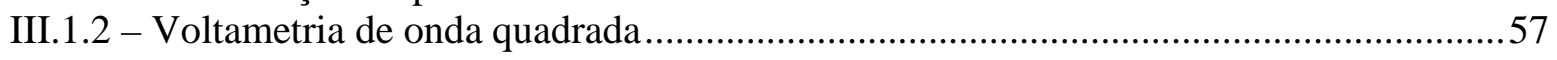

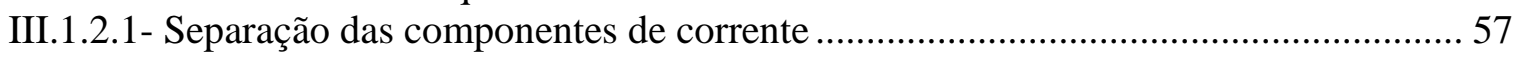

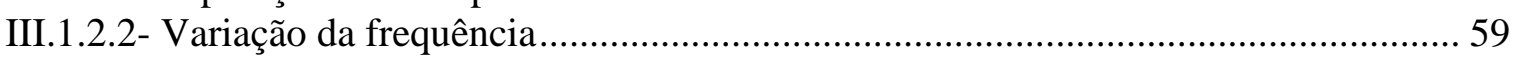


III.2- DETERMINAÇÃO ANALÍTICA DA IMIPRAMINA EM

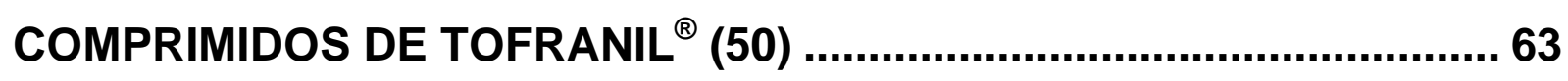

III.2.1 - Otimização dos parâmetros experimentais .................................................................6 63

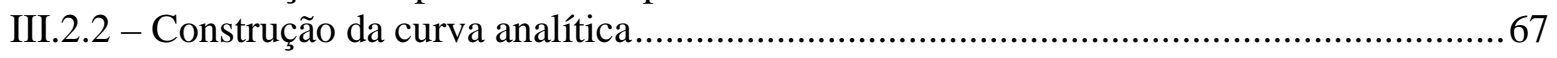

III.3- DETERMINAÇÃO ANALÍTICA DE IMIPRAMINA EM AMOSTRA DE SORO SINTÉTICO (58)................................................................. 75

III.4- ESTUDO QUÍMICO-QUÂNTICO DA IMIPRAMINA (50) .................. 81

III.5- ESTUDO VOLTAMÉTRICO DA DOPAMINA ................................ 94

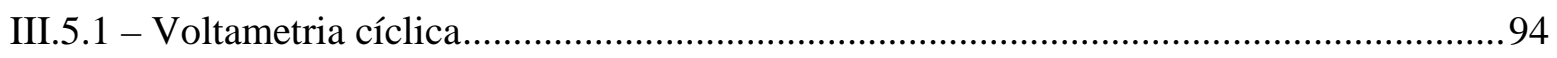

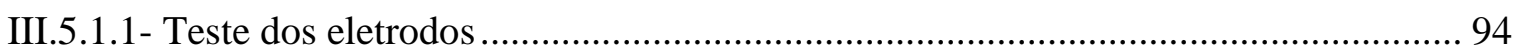

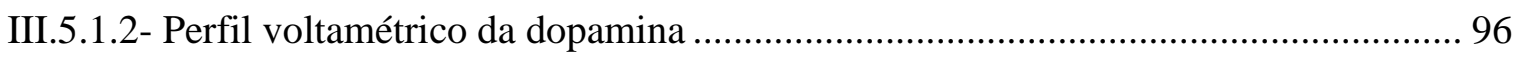

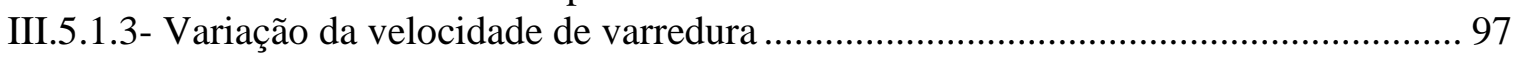

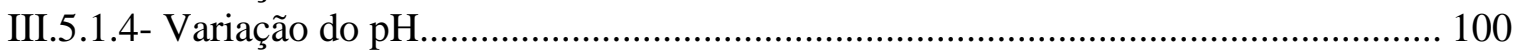

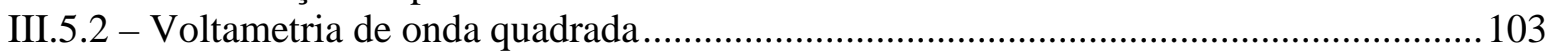

III.5.2.1 - Separação das componentes de corrente ............................................................. 103

III.6- DESENVOLVIMENTO DE METOdologia ANALÍtica PARA A DETERMINAÇÃO DE DOPAMINA EM FLUÍDO CEREBROSPINAL

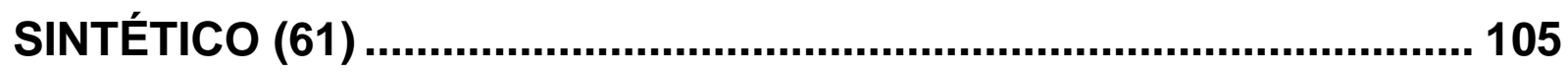

III.6.1 - Otimização dos parâmetros experimentais ...........................................................105

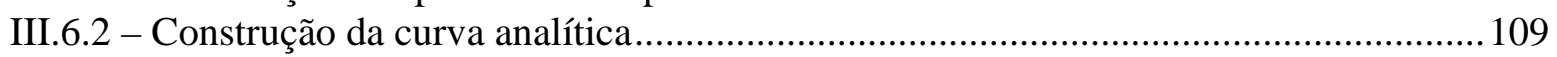

III.6.3 - Análise de dopamina em solução de fluído cerebrospinal sintético...........................116

III.7- DETERMINAÇÃO ANALÍTICA DA DOPAMINA EM AMPOLAS DE

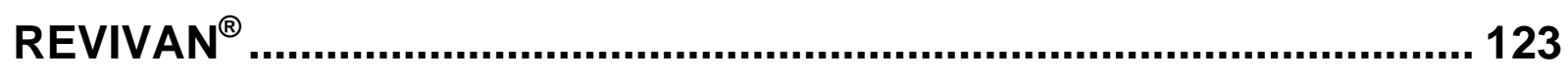

III.8- ESTUDO QUÍMICO-QUÂNTICO DA DOPAMINA ......................... 129

CONCLUSÕES................................................................................134

REFERÊNCIAS BIBLIOGRÁFICAS..................................................137 


\section{LISTA DE ILUSTRAÇÕES}

Figura 1 - Bloqueio da recaptação de serotonina por molécula de antidepressivo. 3

Figura 2 - Estrutura da imipramina. 4

Figura 3 - Acoplamento dos radicais cátion imipramina na posição 2. .5

Figura 4 - Estrutura da dopamina.

Figura 5 - Etapas da biossíntese da dopamina.

Figura 6 - Captação e recaptação da dopamina na fenda sináptica.

Figura 7 - Forma de aplicação do potencial em voltametria de onda quadrada. .23

Figura 8 - Voltamogramas de onda quadrada para: (A) Sistemas reversíveis; (B) Sistemas irreversíveis. I1 - corrente reversa; 12 - corrente direta; $\Delta \mathrm{l}$ - corrente resultante. $(\Delta \mathrm{I}=\mathrm{I} 2-\mathrm{I} 1)$.

Figura 9 - Representação da célula eletroquímica: (I) experimentos voltamétricos e (II) experimentos de eletrólise a potencial controlado, mostrando (A) Eletrodo auxiliar, (B) Eletrodo de trabalho e $(\mathrm{C})$ Eletrodo de referência.

Figura 10 - Representação da construção do eletrodo compósito.

Figura 11 - Voltamogramas cíclicos: (-) tampão BR $0,10 \mathrm{~mol} \mathrm{~L}^{-1}(\mathrm{pH} 7,0)$ e $(-)$ solução de imipramina $2,34 \times 10^{-4} \mathrm{~mol} \mathrm{~L}^{-1}$ em tampão BR $0,10 \mathrm{~mol} \mathrm{~L}^{-1}(\mathrm{pH} \mathrm{7,0)}$. Eletrodos de trabalho: (I) ouro; (II) platina; (III) carbono vítreo e (IV) compósito grafitepoliuretana. $v=100 \mathrm{mV} \mathrm{s}^{-1}$.

Figura 12 - Voltamogramas cíclicos: $(-) 1^{\circ}$ ciclo e $(-) 2^{\circ}$ ciclo de uma solução de imipramina $1,06 \times 10^{-4} \mathrm{~mol} \mathrm{~L}^{-1}$ em tampão $\mathrm{BR} 0,10 \mathrm{~mol} \mathrm{~L}^{-1}(\mathrm{pH} 7,0)$. Eletrodo de trabalho: compósito grafite-poliuretana. $v=100 \mathrm{mV} \mathrm{s}^{-1}$. 48 
Figura 13 - (I) Voltamogramas cíclicos de uma solução de imipramina 2,34 $\times 10^{-4} \mathrm{~mol} \mathrm{~L}^{-1}$ em tampão BR 0,10 mol L-1 $(\mathrm{pH} \mathrm{7,0).} \mathrm{Velocidades:}(-)$ 10, $(-)$ 20, (-) 50, (-) 100, (-) 200 e (-) $500 \mathrm{mV} \mathrm{s}^{-1}$. Eletrodo de trabalho: compósito grafite-poliuretana. (II) Gráficos de $I_{p} v s$. v para: ( $\bullet$ pico de oxidação da imipramina $(R=0,9992)$ e $(\bullet)$ pico de redução do dímero $(R=0,9994)$. 49

Figura 14 - Gráficos de $\log (v)$ vs. $\log \left(I_{p}\right)$ para: (ש) pico de oxidação da imipramina $(\theta=$ $0,71$ e $R=0,9967)$ e $(\bullet)$ pico de redução do dímero $(\theta=0,70$ e $R=0,9941)$.

Figura 15 - (I) Decaimento da corrente com o tempo. Eletrodo de trabalho: placa de platina $\left(A_{\text {geo }}=4,20 \mathrm{~cm}^{2}\right)$. (II) Voltamogramas cíclicos de uma solução de imipramina $2,34 \times 10^{-4} \mathrm{~mol} \mathrm{~L}^{-1}$ em tampão BR $0,10 \mathrm{~mol} \mathrm{~L}^{-1}(\mathrm{pH} 7,0),(-)$ antes da eletrólise e $(-)$ após 1200 s de eletrólise. Eletrodo de trabalho: compósito grafite-poliuretana. 52

Figura 16 - Variação de $\log (\mathrm{I})$ em função do tempo na eletrólise a potencial controlado

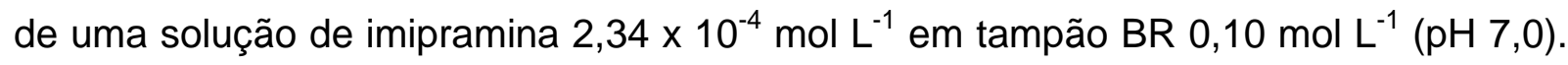
Eletrodo de placa de platina $\left(\mathrm{A}_{\text {geo }}=4,20 \mathrm{~cm}^{2}\right) . \mathrm{E}=10 \mathrm{mV}$ e $\mathrm{t}=1200 \mathrm{~s}$. $\theta=6,09 \times 10^{-4} \mathrm{~s}^{-1}$ e $\mathrm{R}=0,9932$. 53

Figura 17 - Voltamogramas cíclicos de uma solução de imipramina $2,34 \times 10^{-4} \mathrm{~mol} \mathrm{~L}^{-1}$ em tampão BR 0,10 mol L-1. Valores de pH: $(-)$ 3,0; $(-)$ 5,0; $(-)$ 7,0 e (-) 9,0. Eletrodo de trabalho: compósito grafite-poliuretana. $v=50 \mathrm{mV} \mathrm{s}^{-1}$. .54

Figura 18 - Gráficos de $\mathrm{E}_{\mathrm{p}}$ vs. pH: (匹) pico de oxidação da imipramina $(\mathrm{R}=0,9971$ e $\theta=$ $40 \mathrm{mV} / \mathrm{pH}) ;(\bullet)$ pico de redução do dímero $(\mathrm{R}=0,9996$ e $\theta=59 \mathrm{mV} / \mathrm{pH})$. .56

Figura 19 - Voltamogramas de onda quadrada de uma solução de imipramina $2,34 \times 10^{-4} \mathrm{~mol} \mathrm{~L}^{-1}$ para (I) imipramina e (II) dímero, mostrando as componentes de corrente $(-)$ resultante, $(-)$ direta e $(-)$ reversa. Eletrodo de trabalho: compósito grafite-poliuretana. $f=100 \mathrm{~s}^{-1}, a=50 \mathrm{mV}$ e $\Delta \mathrm{E}_{\mathrm{i}}=2 \mathrm{mV}$ 58 
Figura 20 - Voltamogramas de onda quadrada de uma solução de imipramina $2,34 \times 10^{-4} \mathrm{~mol} \mathrm{~L}^{-1}$ para (I) imipramina e (II) dímero. Valores de freqüência: $(-)$ 10, ( ()

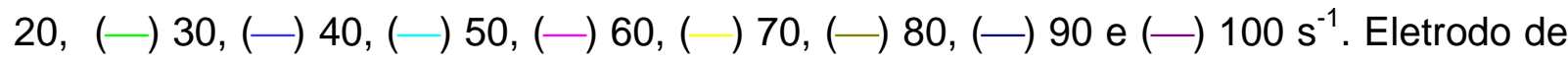
trabalho: compósito grafite-poliuretana. $a=50 \mathrm{mV}$ e $\Delta \mathrm{E}_{\mathrm{i}}=2 \mathrm{mV}$. 59

Figura 21 - Curvas (I) $I_{p}$ vs. f para: ( $\left.\square\right)$ imipramina $(R=0,9975)$ e $(\bullet)$ dímero. (II) $I_{p} v s$. $f^{1 / 2}$ para: $(\square)$ imipramina e $(\bullet)$ dímero $(R=0,9994)$.

Figura 22 - Curva $E_{p} v s$. $\log (f)$ para a imipramina: $(R=0,9991$ e $\theta=94,63)$. 62

Figura 23 - Voltamogramas de onda quadrada de uma solução de imipramina $2,25 \times 10^{-4} \mathrm{~mol} \mathrm{~L}^{-1}$ em tampão BR $0,10 \mathrm{~mol} \mathrm{~L}^{-1}(\mathrm{pH} 7,0)$. Valores de incremento: ( -1 , $(-)$ 2, ( $)$ 3, ( $)$ 4, ( ) 5, ( 6 e ( ) $7 \mathrm{mV}$. Eletrodo de trabalho: compósito grafitepoliuretana. $f=100 \mathrm{~s}^{-1}$ e $a=50 \mathrm{mV}$. 64

Figura 24 - Voltamogramas de onda quadrada de uma solução de imipramina $2,25 \times 10^{-4} \mathrm{~mol} \mathrm{~L}^{-1} \mathrm{em}$ tampão BR $0,10 \mathrm{~mol} \mathrm{~L}^{-1}(\mathrm{pH} \mathrm{7,0)}$. Valores da amplitude: $(-10$, $(\rightarrow)$ 20, $(-)$ 30, $(-)$ 40, $(-)$ 50, $(-) 100$ e ( ) 200 mV. Eletrodo de trabalho: compósito grafite-poliuretana. $f=100 \mathrm{~s}^{-1}$ e $\Delta \mathrm{E}_{\mathrm{i}}=2 \mathrm{mV}$. 65

Figura 25 - Curva $I_{p} v s$. a de uma solução de imipramina $2,25 \times 10^{-4} \mathrm{~mol} \mathrm{~L}^{-1}$ em tampão BR $0,10 \mathrm{~mol} \mathrm{~L}^{-1}(\mathrm{pH} 7,0)$. Eletrodo de trabalho: compósito grafite/poliuretana. $f=100 \mathrm{~s}^{-1}$ e $\Delta E_{i}=2 \mathrm{mV} . R=0,9978$ e $\partial \mathrm{I}_{\mathrm{p}} / \partial a=1,19 \times 10^{-3} \mathrm{~A} \mathrm{~V}^{-1}$ 66

Figura 26 - (I) Voltamogramas de onda quadrada variando-se a concentração de imipramina adicionada. Concentrações: $(-)$ branco, $(-)$ 3,04, $(-)$ 6,02, $(-)$ 8,94,

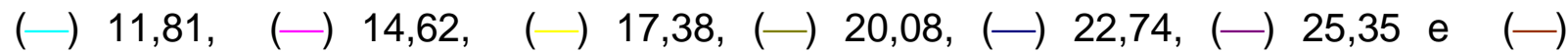
$27,91 \times 10^{-7} \mathrm{~mol} \mathrm{~L}^{-1}$. Eletrodo de trabalho: compósito grafite-poliuretana. $f=100 \mathrm{~s}^{-1}$, $a=50 \mathrm{mV}$ e $\Delta \mathrm{E}_{\mathrm{i}}=2 \mathrm{mV}$. (II) curva analítica ( $\mathrm{n}=10$ e $\left.\mathrm{R}=0,9988\right)$. 
Figura 27 - Voltamogramas de onda quadrada para diferentes concentrações de imipramina. $\mathrm{C}_{\mathrm{IMI}}$ adicionada: $(-)$ medicamento, $(-)$ 2,97, $(-)$ 5,88, $(-)$ 8,74 e $(-)$ $11,53 \times 10^{-7} \mathrm{~mol} \mathrm{~L}^{-1}$ com eletrodo compósito grafite-poliuretana. $f=100 \mathrm{~s}^{-1}, a=50 \mathrm{mV} \mathrm{e}$ $\Delta \mathrm{E}_{\mathrm{i}}=2 \mathrm{mV}$. Inserido: curva de recuperação aparente $(\mathrm{R}=0,9960)$.

Figura 28: (I) Cromatogramas obtidos para diferentes injeções de imipramina. $\mathrm{C}_{\mathrm{IMI}}$ : (一)

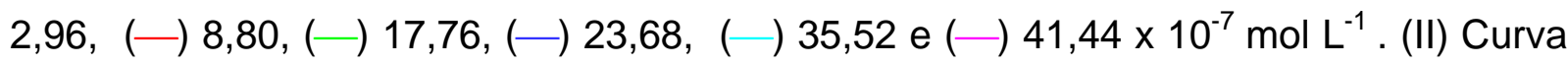
analítica $(R=0,9991)$. Fase móvel: $70 \% A C N / 30 \%$ tampão acetato de amônio $0,10 \mathrm{~mol} \mathrm{~L}^{-1}(\mathrm{pH} 5,0)$. Volume injetado: $20 \mu \mathrm{L}$. Detecção: $220 \mathrm{~nm}$.

Figura 29 - Cromatogramas para diferentes concentrações de imipramina. $\mathrm{C}_{\mathrm{IMI}}$

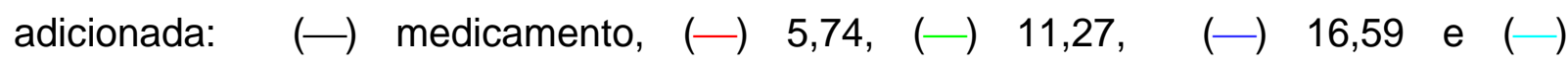
$21,72 \times 10^{-7} \mathrm{~mol} \mathrm{~L}^{-1}$. Fase móvel: $70 \% \mathrm{ACN} / 30 \%$ tampão acetato de amônio $0,10 \mathrm{~mol} \mathrm{~L}^{-1}(\mathrm{pH} 5,0)$. Volume injetado: $20 \mu \mathrm{L}$. Detecção: $220 \mathrm{~nm}$. Inserido: curva de recuperação aparente $(R=0,9960)$. 74

Figura 30 - (I) Voltamogramas de onda quadrada variando-se a concentração de imipramina adicionada em amostra de soro humano sintético ( $\mathrm{pH} 7,6)$. Concentrações: $(-)$ branco, $(-)$ 6,53, (-) 12,94, (-) 19,22, ( ) 25,38, (-) 31,43, ( ) 37,36, ( ) 43,18 e $\left(-48,89 \times 10^{-7} \mathrm{~mol} \mathrm{~L}^{-1}\right.$. Eletrodo de trabalho: compósito grafite-poliuretana. $f=100 \mathrm{~s}^{-1}, a=50 \mathrm{mV}$ e $\Delta \mathrm{E}_{\mathrm{i}}=2 \mathrm{mV}$. (II) curva analítica $(\mathrm{n}=10$ e $\mathrm{R}=0,9988)$. 76

Figura 31 - Voltamograma de onda quadrada de uma mistura de imipramina $\left(6,21 \times 10^{-7} \mathrm{~mol} \mathrm{~L}^{-1}\right)$ e desipramina $\left(5,23 \times 10^{-7} \mathrm{~mol} \mathrm{~L}^{-1}\right)$ em amostra de soro humano sintético (pH 7,6). ( Curva experimental, $(-$ Curva obtida após deconvolução, $(-)$ Pico de oxidação da desipramina e (-) Pico de oxidação da imipramina. Eletrodo de trabalho: compósito grafite-poliuretana. $f=100 \mathrm{~s}^{-1}, a=50 \mathrm{mV}$ e $\Delta \mathrm{E}_{\mathrm{i}}=2 \mathrm{mV}$. 78 
Figura 32 - (I) Voltamogramas de onda quadrada variando-se a concentração de imipramina em amostra de soro humano sintético $(\mathrm{pH} 7,6):(-)$ 2,97, $(-)$ 4,29, $(-)$ $6,21,(-) 7,65$ e $(-) 9,04 \times 10^{-7} \mathrm{~mol} \mathrm{~L}^{-1}$. Concentração de desipramina: $5,23 \times 10^{-7} \mathrm{~mol} \mathrm{~L}^{-1}$. Eletrodo de trabalho: compósito grafite-poliuretana. $f=100 \mathrm{~s}^{-1}$, $a=50 \mathrm{mV}$ e $\Delta \mathrm{E}_{\mathrm{i}}=2 \mathrm{mV}$. (II) Curva analítica $(\mathrm{R}=0,9938)$. 80

Figura 33 - Molécula de imipramina com os átomos numerados de acordo com a Tabela VII. .83

Figura 34 - Representação gráfica do HOMO e LUMO para a molécula de imipramina.

Figura 35 - Voltamograma cíclico de uma solução de amitriptilina 2,10 $\times 10^{-4} \mathrm{~mol} \mathrm{~L}^{-1} \mathrm{em}$ tampão BR $0,10 \mathrm{~mol} \mathrm{~L}^{-1}(\mathrm{pH} \mathrm{7,0)}$. Eletrodo de trabalho: compósito grafite-poliuretana. Estrutura da amitriptilina inserida. 86

Figura 36 - Voltamogramas de onda quadrada de uma solução de imipramina $6,96 \times 10^{-4} \mathrm{~mol} \mathrm{~L}^{-1}$ em tampão BR $0,10 \mathrm{~mol} \mathrm{~L}^{-1}(\mathrm{pH} 7,0)$. Tempos de eletrólise: (一) 0 , $(\rightarrow)$ 30, $(-)$ 60, $(-) 90$ e $(-) 120$ minutos. Eletrodo de trabalho compósito grafitepoliuretana.

Figura 37 - ESI-MS espectros: (I) solução de imipramina antes da eletrólise e (II) ampliação do ESI-MS na região acima de $\mathrm{m} / \mathrm{z}=283,4 \ldots .$. Erro! Indicador não definido.

Figura 38 - ESI-MS espectros: (I) solução eletrolisada e (II) ampliação do ESI-MS na região acima de $\mathrm{m} / \mathrm{z}=303,2$. Erro! Indicador não definido.

Figura 39 - ESI-MS espectros para: (I) filme eletrodepositado e (II) ampliação do ESIMS na região acima de $\mathrm{m} / \mathrm{z}=301,0$.

Figura 40 - Proposta de mecanismo para a oxidação da imipramina. 93 
Figura 41 - Voltamogramas cíclicos: (-) tampão BR $0,10 \mathrm{~mol} \mathrm{~L}^{-1}(\mathrm{pH} \mathrm{2,0)} \mathrm{e} \mathrm{(一)}$ solução de dopamina $1,54 \times 10^{-4} \mathrm{~mol} \mathrm{~L}^{-1}$ em tampão BR $0,10 \mathrm{~mol} \mathrm{~L}^{-1}$ (pH 2,0). Eletrodos de trabalho: (I) ouro; (II) platina; (III) carbono vítreo e (IV) compósito grafitepoliuretana. $v=100 \mathrm{mV} \mathrm{s}^{-1}$. 95

Figura 42 - Voltamogramas cíclicos: $(-) 1^{\circ}$ ciclo e $(-) 2^{\circ}$ ciclo de uma solução de dopamina $\quad 1,54 \times 10^{-4} \mathrm{~mol} \mathrm{~L}^{-1}$ em tampão BR $0,10 \mathrm{~mol} \mathrm{~L}^{-1}(\mathrm{pH} 2,0)$. Eletrodo de trabalho: compósito de grafite- poliuretana. $v=100 \mathrm{mV} \mathrm{s}^{-1}$. 96

Figura 43 - Voltamogramas cíclicos de uma solução de dopamina $1,54 \times 10^{-4} \mathrm{~mol} \mathrm{~L}^{-1} \mathrm{em}$ tampão BR 0,10 mol L-1 $(\mathrm{pH} \mathrm{2,0).} \mathrm{Velocidades:}(-)$ 10, $(-)$ 20, $(-)$ 50, $(-)$ 100, $(-)$ 200 e $(-) 500 \mathrm{mV} \mathrm{s}^{-1}$. Eletrodo de trabalho: compósito grafite-poliuretana. 97

Figura 44 - Gráficos de : (I) $I_{p}$ vs. v para: (ロ) pico de oxidação da dopamina $(R=0,9996)$ e $(\bullet)$ pico de redução da dopamina $(R=0,9997)$. (II) $I_{p} v s . v^{1 / 2}$ para: pico de oxidação da dopamina e $(\bullet)$ pico de redução da dopamina. .99

Figura 45 - Gráficos de $\log (v)$ vs. $\log \left(I_{p}\right)$ para: (ロ) pico de oxidação da dopamina $(R=0,9974$ e $\theta=0,96)(\bullet)$ pico de redução da dopamina $(R=0,9963$ e $\theta=0,99) \ldots . .100$

Figura 46 - Voltamogramas cíclicos de uma solução de dopamina $1,54 \times 10^{-4} \mathrm{~mol} \mathrm{~L}^{-1} \mathrm{em}$ tampão BR 0,10 mol L-1. Valores de pH: $(-)$ 2,0, (-) 3,0, (-) 4,0, (-) 5,0, (-) 6,0, (-) 7,0, ( ) 8,0 e (-) 9,0. Eletrodo de trabalho: compósito grafite-poliuretana. $\mathrm{v}=100 \mathrm{mV} \mathrm{s}^{-1}$ 101

Figura 47 - Gráficos de $E_{p}$ vs. pH para: (ש) pico de oxidação da dopamina $(R=0,9967$ e $\theta=50,13 \mathrm{mV} / \mathrm{pH})(\bullet)$ pico de redução da dopamina $(\mathrm{R}=0,9998$ e $\theta=53,44 \mathrm{mV} / \mathrm{pH})$ 
Figura 48 - Voltamogramas de onda quadrada de uma solução de dopamina $1,54 \times 10^{-4} \mathrm{~mol} \mathrm{~L}^{-1}$, mostrando as componentes de corrente $(-)$ resultante, $(-)$ direta e $(-)$ reversa. Eletrodo de trabalho: compósito grafite-poliuretana. $f=50 \mathrm{~s}^{-1}, a=50 \mathrm{mV}$ e $\Delta \mathrm{E}_{\mathrm{i}}=2 \mathrm{mV}$. 104

Figura 49 - (I) Voltamogramas de onda quadrada de uma solução de dopamina $1,24 \times 10^{-4} \mathrm{~mol} \mathrm{~L}^{-1}$ em tampão BR $0,10 \mathrm{~mol} \mathrm{~L}^{-1}(\mathrm{pH} 7,4)$. Valores de freqüência: $(-) 5$, $(-)$ 10, (-) 20, (-) 30, (-) 40, (-) $50 \mathrm{e} \mathrm{(} \mathrm{)} 60 \mathrm{~s}^{-1}$. (II) Curva $\mathrm{I}_{\mathrm{p}}$ vs. $f$ para o pico de oxidação da dopamina. Eletrodo de trabalho: compósito grafite-poliuretana. $a=50 \mathrm{mV}$ e $\Delta \mathrm{E}_{\mathrm{i}}=2 \mathrm{mV}$. 106

Figura 50 - Voltamogramas de onda quadrada de uma solução de dopamina $1,24 \times 10^{-4} \mathrm{~mol} \mathrm{~L}^{-1}$ em tampão BR $0,10 \mathrm{~mol} \mathrm{~L}^{-1}(\mathrm{pH} \mathrm{7,4)}$. Valores de incremento: $(-)$, (-) 2, (-) 3 e $(-) 7 \mathrm{mV}$. Eletrodo de trabalho: compósito grafite-poliuretana. $f=60 \mathrm{~s}^{-1}$ $\mathrm{e} a=50 \mathrm{mV}$ 108

Figura 51 - Voltamogramas de onda quadrada de uma solução de dopamina $1,24 \times 10^{-4} \mathrm{~mol} \mathrm{~L}^{-1}$ em tampão BR $0,10 \mathrm{~mol} \mathrm{~L}^{-1}(\mathrm{pH} 7,4)$. Valores da amplitude: $(-)$ 10, $(-)$ 20, (-) 30, (-) 40, (-) 50 e (-) 100 mV. Eletrodo de trabalho: compósito grafitepoliuretana. $f=60 \mathrm{~s}^{-1}$ e $\Delta \mathrm{E}_{\mathrm{i}}=2 \mathrm{mV}$. 109

Figura 52 - (I) Voltamogramas de onda quadrada variando-se a concentração de dopamina adicionada. Concentrações: $(-)$ branco, $(-)$ 5,20, $(-)$ 10,37, (-) 15,52, $(-)$ 20,63, (-) 25,71, ( ) 30,76, (-) 35,79, (-) 40,78, (-) 45,74 e (一) $50,68 \times 10^{-6} \mathrm{~mol} \mathrm{~L}^{-1}$. Eletrodo de trabalho: compósito grafite-poliuretana. $f=60 \mathrm{~s}^{-1}$, $a=50 \mathrm{mV}$ e $\Delta \mathrm{E}_{\mathrm{i}}=2 \mathrm{mV}$. (II) curva analítica $(\mathrm{n}=10$ e $\mathrm{R}=0,9997)$. 110

Figura 53 - Etapas eletroquímicas e possíveis etapas químicas para a reação de oxidação da dopamina. 113 
Figura 54 - (I) Espectros de absorção óptica de uma solução estoque de dopamina $2,0 \times 10^{-3} \mathrm{~mol} \mathrm{~L}^{-1}$ em tampão BR $0,10 \mathrm{~mol} \mathrm{~L}^{-1}(\mathrm{pH} \mathrm{7,4)}$, variando-se a concentração de dopamina adicionada. Concentrações: $(-)$ branco, $(-)$ 1,63, $(-)$ 3,23, $(-)$ 4,80, $(-)$ 6,37, (-) 7,88, ( ) 9,39, (-) 10,87, (-) 12,33, (-) 13,77 e (-) 15,19 x 10 $0^{-5} \mathrm{~mol} \mathrm{~L}^{-1}$. cubeta de $1,00 \mathrm{~cm}$ de caminho óptico (II) curva analítica ( $n=10$ e $R=0,9998)$..... 114

Figura 55 - Voltamogramas de onda quadrada (I) Dopamina; (II) Ácido ascórbico e (III) Dopamina + ácido ascórbico. Concentração das soluções: Dopamina $\left(5,20 \times 10^{-6} \mathrm{~mol} \mathrm{~L}^{-1}\right)$ e ácido ascórbico $\left(1,21 \times 10^{-3} \mathrm{~mol} \mathrm{~L}^{-1}\right)$ em solução de fluído

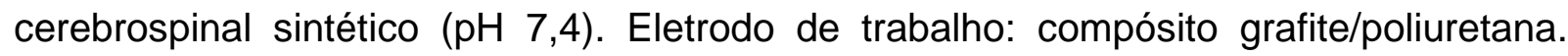
$f=60 \mathrm{~s}^{-1}, a=50 \mathrm{mV}$ e $\Delta \mathrm{E}_{\mathrm{i}}=2 \mathrm{mV}$

Figura 56 - Voltamogramas de onda quadrada variando-se a concentração de ácido ascórbico adicionada. Concentrações: $(-)$ 0,4, $(-)$ 0,8, $(-) 1,2, \quad(-)$ ) 1,8 e (-) $2,2 \times 10^{-3} \mathrm{~mol} \mathrm{~L}^{-1}$. Concentração de dopamina igual a $5,60 \times 10^{-6} \mathrm{~mol} \mathrm{~L}^{-1}$. Eletrodo de trabalho: compósito grafite-poliuretana. $f=60 \mathrm{~s}^{-1}, a=50 \mathrm{mV}$ e $\Delta \mathrm{E}_{\mathrm{i}}=2 \mathrm{mV}$. Inserido: curva analítica $(\mathrm{n}=5$ e $\mathrm{R}=0,9987)$. 118

Figura 57 - Voltamogramas de onda quadrada variando-se a concentração de dopamina adicionada. Concentrações: $(-)$ 6,61, (-) 10,91, (-) 15,36 (-) 19,71 e (-) $24,04 \times 10^{-6} \mathrm{~mol} \mathrm{~L}^{-1}$. Concentração de ácido ascórbico igual a $1,55 \times 10^{-3} \mathrm{~mol} \mathrm{~L}^{-1}$. Eletrodo de trabalho: compósito grafite-poliuretana. $f=60 \mathrm{~s}^{-1}, a=50 \mathrm{mV}$ e $\Delta \mathrm{E}_{\mathrm{i}}=2 \mathrm{mV}$. Inserido: curva analítica ( $\mathrm{n}=5$ e $\mathrm{R}=0,9993)$

Figura 58 - Voltamogramas de onda quadrada variando a concentração de dopamina adicionada em tampão BR $0,1 \mathrm{~mol} \mathrm{~L}^{-1}(\mathrm{pH} 2,0)$. (I) Concentrações: $(-)$ branco, $(-)$ 1,58, $(-)$ 3,14, $(-)$ 4,66, $(-)$ 6,15, (-) 7,62, $($ ) 9,06, $(-)$ 10,47, (-) 11,85, (一)

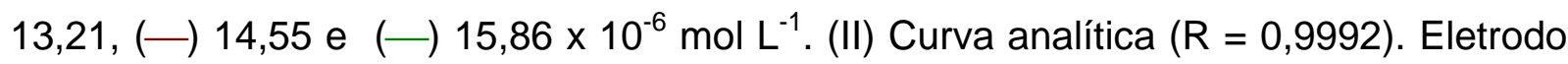
de trabalho: compósito grafite-poliuretana. 124 
Figura 59 - (I) Espectros de absorção óptica variando-se a concentração de dopamina adicionada. Concentrações: $(-)$ branco, $(-)$ 1,59, ( ) 3,15, ( $\longrightarrow$ 4,69, $(-)$ 6,20, (

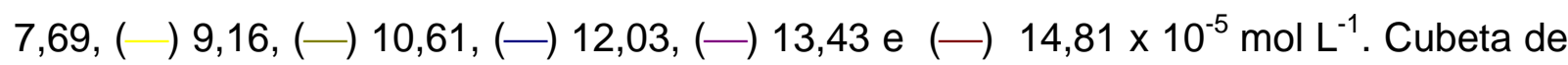
$1,00 \mathrm{~cm}$ de caminho óptico (II) curva analítica ( $\mathrm{n}=10$ e $\mathrm{R}=0,9997)$. 125

Figura 60 - Voltamogramas de onda quadrada para diferentes concentrações de dopamina. $C_{\text {DOPA }}$ adicionada: $(-)$ medicamento, $(-)$ 1,58, $(-)$ 3,13, $(-)$ ) 4,65 e $(-)$ $6,14 \times 10^{-6} \mathrm{~mol} \mathrm{~L}^{-1}$ com eletrodo compósito grafite-poliuretana. $f=60 \mathrm{~s}^{-1}, a=50 \mathrm{mV} \mathrm{e}$ $\Delta \mathrm{E}_{\mathrm{i}}=2 \mathrm{mV}$. Inserido: curva de recuperação aparente $(\mathrm{R}=0,9968)$. 127

Figura 61 - Espectros de absorção óptica para diferentes concentrações de dopamina. $C_{\text {DOPA }}$ adicionada: $(-)$ medicamento, $(-)$ 1,58, $(\rightarrow) 3,12, \quad(\rightarrow) 4,60$ e $(\rightarrow)$ $6,15 \times 10^{-5} \mathrm{~mol} \mathrm{~L}^{-1}$. Cubeta de $1,00 \mathrm{~cm}$ de caminho óptico. Inserido: curva de recuperação aparente $(R=0,9997)$. 128

Figura 62 - Representação do mapa de potencial eletrostático a $-10 \mathrm{kcal} \mathrm{mol}^{-1}$ (em malhas) e a $-50 \mathrm{kcal} \mathrm{mol}^{-1}$ (sólido em azul). 129

Figura 63 - Molécula de dopamina com os átomos numerados de acordo com a Tabela $\mathrm{X}$ 131

Figura 64 - Representação gráfica do HOMO e LUMO para a molécula dopamina. 132 


\section{LISTA DE TABELAS}

Tabela I - Características dos sistemas eletroquímicos, estudados com a técnica de voltametria de onda quadrada, quanto ao grau de reversibilidade ao se relacionar $I_{p}$ e $E_{p}$

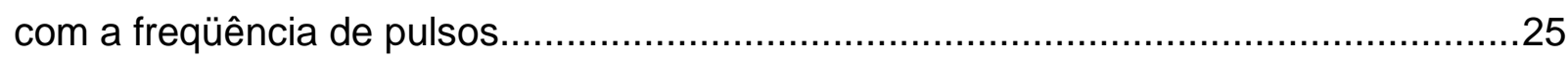

Tabela II - Procedência e pureza dos reagentes utilizados. .....................................36

Tabela III - Valores de corrente de pico $\left(I_{p}\right)$ e dos potenciais de pico $\left(E_{p}\right)$ para a oxidação da imipramina e redução do dímero......

Tabela IV - Valores de corrente $\left(I_{p}\right)$ e potencial $\left(E_{p}\right)$ de pico para: (I) oxidação da imipramina; (II) redução do dímero.

Tabela V - Valores de corrente $\left(I_{p}\right)$ e potencial $\left(E_{p}\right)$ de pico para: (I) imipramina; (II) dímero.

Tabela VI - Valores de concentração de imipramina adicionada e a média das correntes de pico referentes à curva analítica.

Tabela VII - Cálculo das cargas atômicas derivadas do potencial eletrostático para a molécula imipramina no estado fundamental e após oxidação.

Tabela VIII - Valores de corrente $\left(I_{p}\right)$ e potencial $\left(E_{p}\right)$ de pico para: (I) oxidação da dopamina; (II) redução da dopamina e a diferença entre potencial de pico anódico e catódio $\left(\Delta \mathrm{E}_{\mathrm{p}}\right)$ para o par redox.

Tabela IX - Valores de corrente $\left(I_{p}\right)$ e potencial $\left(E_{p}\right)$ de pico para: (I) oxidação e (II) redução da dopamina.

Tabela $X$ - Valores de corrente de pico $\left(I_{p}\right)$ em função da freqüência para a oxidação da dopamina.

Tabela XI - Valores de concentração de dopamina adicionada e a média das correntes de pico referentes à curva analítica. 
Tabela XII - Valores de concentração de dopamina adicionada e a média das absorbâncias referentes à curva analítica.............................................................115

Tabela XIII - Principais constituintes do plasma e do fluído cerebrospinal de um adulto saudável.

Tabela XIV - Cálculo das cargas atômicas derivadas do potencial eletrostático para a molécula dopamina no estado neutro e duplamente ionizado. 


\section{LISTA DE SÍMBOLOS E ABREVIATURAS}

A - Área do eletrodo $\left(\mathrm{cm}^{2}\right)$

$\mathrm{A}_{\text {geo }}$ - Área geométrica do eletrodo $\left(\mathrm{cm}^{2}\right)$

AA - Ácido ascórbico

Abs - Absorbância

AVOLM - Analisador Voltamétrico

$\alpha$ - Coeficiente de transferência de carga

BDD - Eletrodo de diamante dopado com boro

C - Concentração

GPU - Eletrodo compósito de grafite-poliuretana

HPLC - Cromatografia Líquida de Alta Eficiência

D - Coeficiente de difusão $\left(\mathrm{cm}^{2} \mathrm{~s}^{-1}\right)$

DA - Dopamina

E - Potencial

$E^{0}$ - Potencial padrão de eletrodo

$E_{p}$ - Potencial de pico

$E_{p a}$ - Potencial de pico anódico

$\mathrm{E}_{\mathrm{pc}}$ - Potencial de pico catódico

$E_{p / 2}$ - Potencial de pico a meia altura

ECE - Mecanismo eletroquímico/químico/eletroquímico

ESI-MS - Espectrometria de massa com ionização por electrospray

$\Delta \mathrm{E}_{\mathrm{I}}$ - Incremento de varredura $(\mathrm{mV})$

a - Amplitude (mV) 
$\Delta \mathrm{E}_{\mathrm{p} / 2}$ - Largura de meia-onda $(\mathrm{mV})$

$\phi$ - Diâmetro do eletrodo

$f$ - Freqüência $\left(\mathrm{s}^{-1}\right)$

F - Constante de Faraday $\left(9,648 \times 10^{4} \mathrm{C} \mathrm{mol}^{-1}\right)$

$\Gamma$ - Quantidade do analito adsorvida na superfície do eletrodo $\left(\mathrm{mol} \mathrm{cm}^{-2}\right)$

HOMO - Orbital molecular de mais alta energia ocupado

HPLC - Cromatografia Líquida de Alta Eficiência

I - Corrente

11 - Corrente resultante

12 - Corrente direta

$I_{p}$ - Corrente de pico

$\mathrm{I}_{\mathrm{pa}}$ - Corrente de pico anódica

$\mathrm{I}_{\mathrm{pc}}$ - Corrente de pico catódica

IMI - Imipramina

$\Delta \mathrm{l}$ - Corrente resultante

k - Constante de velocidade da reação

LD - Limite de detecção

LQ - Limite de quantificação

LUMO - Orbital molecular de mais baixa energia desocupado

$\lambda$ - Comprimento de onda $(\mathrm{nm})$

n - Número de elétrons

$\mathrm{N}$ - Número de mols

Q - Carga (C) 
$\theta$ - Coeficiente angular

$\sigma$ - Desvio padrão da média dos brancos

$P$ - número de prótons

PM3 - Parametric Model 3

$\mathrm{R}$ - Coeficiente de correlação

RSD - Desvio padrão relativo

SWV - Voltametria de onda quadrada

$\mathrm{t}$ - Tempo (s)

$v$ - Velocidade de varredura de potencial 


\section{RESUMO}

Neste trabalho, são abordados os estudos eletroquímicos e químico-quânticos, bem como o desenvolvimento de metodologias analíticas para o antidepressivo tricíclico imipramina e para o neurotransmissor dopamina. Os experimentos foram realizados em solução tampão Britton Robinson (BR) $0,10 \mathrm{~mol} \mathrm{~L}^{-1}$ no $\mathrm{pH}$ de melhor resposta analítica para os referidos compostos. Com base nos parâmetros eletroquímicos extraídos das técnicas de voltametria cíclica e de onda quadrada, utilizando-se um eletrodo de grafitepoliuretana (GPU), foi possível diagnosticar o grau de reversibilidade das reações, a presença ou não de processos de adsorção e também o número de prótons e elétrons envolvidos nas reações eletroquímicas. Quanto aos cálculos químico-quânticos, a representação gráfica do HOMO (orbital molecular de mais alta energia ocupado) e os cálculos das cargas atômicas derivadas do potencial eletrostático forneceram uma estimativa do provável sítio de oxidação dos compostos. Os resultados indicaram que a reação de oxidação da imipramina é irreversível e dependente da adsorção do reagente na superfície do eletrodo, ocorrendo a formação subseqüente de um dímero em uma etapa química posterior à transferência de dois elétrons e um próton. O provável sítio de oxidação da molécula abrange a região do átomo de nitrogênio do anel, salientando que após a transferência de dois elétrons há uma deslocalização de cargas pelo anel aromático, fato este que sugere a formação do dímero na posição 2. Paralelamente, experimentos de eletrólise a potencial controlado foram realizados com o objetivo de gerar produtos de reação para serem analisados pela técnica de espectroscopia de massa com ionização por electrospray (ESI-MS). Tomando-se por base os resultados obtidos pelas técnicas voltamétricas, pelos cálculos químico-quânticos e pelos espectros de massa, foi sugerido o provável mecanismo de oxidação da imipramina nas condições estudadas. A metodologia analítica desenvolvida para a imipramina é rápida, sensível e exata para a análise de rotina em comprimidos de Tofranil $^{\circledR}$. A sensibilidade alcançada pela metodologia permitiu ainda a análise direta de concentrações plasmáticas terapêuticas do antidepressivo e de seu metabólito (desipramina) em amostra de soro humano sintético. No entanto, a seletividade da metodologia ficou comprometida pela proximidade dos potenciais de pico dos dímeros formados após a 
oxidação da imipramina (-41 mV) e da desipramina (23 mV). A aplicação de um método matemático de deconvolução (Origin 6.0) tornou possível a determinação simultânea da imipramina e da desipramina. A dopamina, por sua vez, é oxidada a dopamina orto quinona em um processo reversível com a adsorção de reagente e produto na superfície do eletrodo. $O$ processo envolve a participação de dois elétrons e dois prótons. A metodologia analítica desenvolvida para a dopamina foi aplicada na análise de rotina em ampolas de Revivan ${ }^{\circledR}$ com boa exatidão e precisão. Além disso, a sensibilidade e a seletividade alcançadas pela metodologia resultaram na determinação de dopamina em fluído cerebrospinal sintético. A separação dos picos de oxidação da dopamina $\left(E_{p}=200 \mathrm{mV}\right)$ e do ácido ascórbico $\left(E_{p}=40 \mathrm{mV}\right)$ deve-se, provavelmente, às interações eletrostáticas favoráveis entre a superfície do eletrodo de GPU e o ânion ascorbato. De maneira geral, os resultados obtidos foram bastante satisfatórios para as determinações pretendidas, concluindo que o eletrodo de GPU é um material promissor para a análise de moléculas de interesse biológico.

Palavras-chave: imipramina, dopamina, eletrodo compósito de grafite-poliuretana, voltametria de onda quadrada, determinação analítica. 


\section{ABSTRACT}

In this work, the electrochemical and quantum-chemical studies are discussed, as well as the development of analytical methodologies for the imipramine tricyclic antidepressant and for the dopamine neurotransmitter. Experiments were performed in $0.10 \mathrm{~mol} \mathrm{~L}^{-1}$ Britton Robinson (BR) buffer solution at the best analytical response $\mathrm{pH}$ for the mentioned compounds. From the electrochemical parameters extracted of cyclic and square wave voltammetric techniques, using a graphite-polyurethane electrode (GPU), it was possible to diagnose the reactions reversible degree, the presence or not of adsorptions processes and also the number of protons and electrons involved in the electrochemical reactions. Concerning to the quantum-chemical calculations, the graphic representation of HOMO (Highest Occupied Molecular Orbital) and the calculation of the atomic charge derived from electrostatic potential provided an estimation of the probable oxidation sites of the compounds. The results indicated that the oxidation reaction of imipramine is reversible and dependent of the reagent adsorption at the electrode surface, occuring the formation of a dimer in a chemical step after the transference of two electrons and one proton. The probable oxidation site of the molecule includes the nitrogen atom region of the ring, emphasizing that after the transference of the two electrons there is a deslocalization of the charges though the aromatic ring, suggesting the formation of the dimeric specie at postion 2. At the same time, experiments of controlled potential electrolysis were carried out in order to generate reaction products to be analysed by electrospray ionization mass espectrosmmetry (ESI-MS). From the results obtained by voltammetric techniques, by quantum-chemical calculations and by mass spectroscopy, it was suggested a probable mechanism for the imipramine oxidation in the studied conditions. The analytical methodology developed for imipramine is fast, sensible and accurate for routine analysis in Tofranil ${ }^{\circledR}$ tablets. The reached sensibility also allowed the direct analysis of therapeutical plasmatic concentrations of the antidepressant and its methabolic (desipramine) in synthetic human serum sample. However, the selectivity of the methodology was compromised by the peak potentials proximity of the dimers formed after the oxidation of imipramine $(-41 \mathrm{mV})$ and of desipramine $(23 \mathrm{mV})$. The application of a deconvolution mathematical 
method (Origin 6.0) permitted the simultaneous analysis of imipramine and desipramine. On the other hand, dopamine is oxidized to dopamine ortho-quinone in a reversible process with the adsorption of reagent and product at the electrode surface. The process involves the participation of two electrons and two protons. The analytical methodology developed for dopamine was applied in the routine analysis in Revivan ${ }^{\circledR}$ injections with good accuracy and precision. Besides that, the sensitivity and the selectivity reached by the methodology resulted in the determination of dopamine in synthetic cerebrospinal fluid. The separation of the oxidation peaks of dopamine $\left(E_{p}=200 \mathrm{mV}\right)$ and of ascorbic acid $\left(E_{p}=40 \mathrm{mV}\right)$ is probably due to the favorable electrostatic interactions between the GPU electrode surface and the ascorbate anion. In general way, the obtained results were very satisfatory for the desirable determinations, concluding that the GPU electrode is a promissing material for the analysis of biological interest molecules.

Keywords: imipramine, dopamine, graphite-polyurethane composite electrode, square wave voltammetry, analytical determination. 
CAPÍTULO I - INTRODUÇÃO 


\section{I.1- A DEPRESSÃO E O PAPEL DOS ANTIDEPRESSIVOS}

A depressão é um transtorno afetivo caracterizado por uma alteração psíquica e orgânica com conseqüentes modificações na maneira de avaliar a realidade e a vida. Homens e mulheres, de qualquer faixa etária, podem ser atingidos, porém as mulheres são duas vezes mais afetadas que os homens (1). Em crianças (2) e idosos (3) a doença tem características particulares, porém a ocorrência em ambos os grupos também é freqüente. Sabe-se que a depressão é acompanhada por alterações em substâncias no sistema nervoso central, mais precisamente os neurotransmissores noradrenalina e serotonina (4).

Os antidepressivos são drogas que aumentam o tônus psíquico, melhorando o humor e, conseqüentemente, a psicomotricidade de maneira global. De acordo com a literatura (5), os antidepressivos podem ser subdivididos em quatro grupos de substâncias:

1- Antidepressivos tricíclicos (ADT): Esta classe de compostos é constituída de aminas passíveis de oxidação eletroquímica contendo como parte aromática da molécula um triciclo com um anel central alifático de seis ou sete membros. Estes compostos têm o efeito de elevar o ânimo, com baixo risco de provocar dependência química, apesar de apresentarem risco de overdose considerável. A amitriptilina, imipramina, nortriptilina e a desipramina são exemplos característicos desta classe de substâncias. 
2- Inibidores da monoaminaoxidase (IMAO): Os antidepressivos desta classe promovem o aumento da disponibilidade de serotonina por meio da inibição de uma enzima responsável pela degradação deste neurotransmissor a nível intracelular, a monoaminaoxidase (MAO). Como exemplos, podem-se citar a moclolemida, a selegilina e a tranclipromina.

3- Inibidores seletivos da recaptacão de serotonina (ISRS): Estes antidepressivos caracterizam-se por não interferir ou interferir pouco nos demais neurotransmissores. Fluoxetina, nefazodona e paroxetina são alguns antidepressivos pertencentes a esta classe.

4- Antidepressivos atípicos: Estes antidepressivos não se enquadram nas classes anteriores dos tricíclicos, IMAOs e ISRS. A aminiptina, fluvoxamina e tianeptina são exemplos desta classe.

Acredita-se que o efeito antidepressivo ocorre por meio de um aumento da disponibilidade de neurotransmissores no sistema nervoso central, notadamente da serotonina, da noradrenalina e da dopamina. Este aumento de neurotransmissores na fenda dá-se por meio do bloqueio da recaptação da noradrenalina e da serotonina no neurônio pré-sináptico ou ainda, por meio da inibição da monoaminaoxidase (MAO) que é a enzima responsável pela inativação destes neurotransmissores (6). A Figura 1 apresenta a liberação e o bloqueio da recaptação da serotonina na fenda sináptica pela ação dos antidepressivos. 

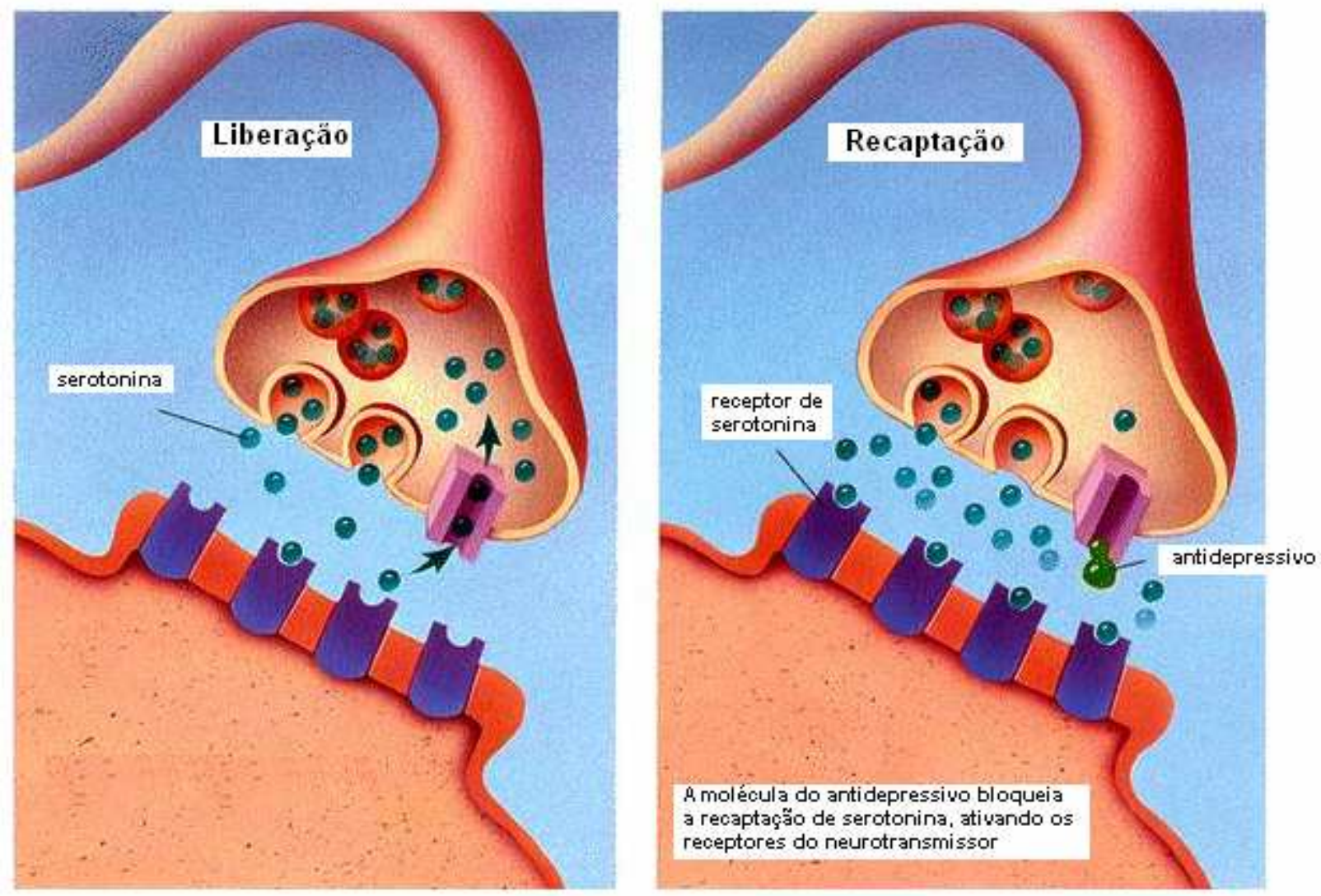

Figura 1 - Bloqueio da recaptação de serotonina por molécula de antidepressivo.

Os primeiros antidepressivos amplamente usados foram os tricíclicos, os quais se caracterizam pela grande eficácia, porém são responsáveis por causar muitos efeitos colaterais por afetarem substâncias químicas do cérebro não relacionadas com a depressão. Entre estes efeitos, pode-se citar a visão embaçada, boca seca, constipação, pressão arterial baixa, sonolência diurna e ganho de peso (3).

A imipramina, 10,11-dihidro-N,N-dimetil-5H-dibenz[b,f]azepina-5-propanamina, cuja estrutura é mostrada na Figura 2, foi o primeiro antidepressivo da classe dos tricíclicos utilizado no tratamento de várias formas de depressão, incluindo as endógenas, orgânicas e psicogênicas. 


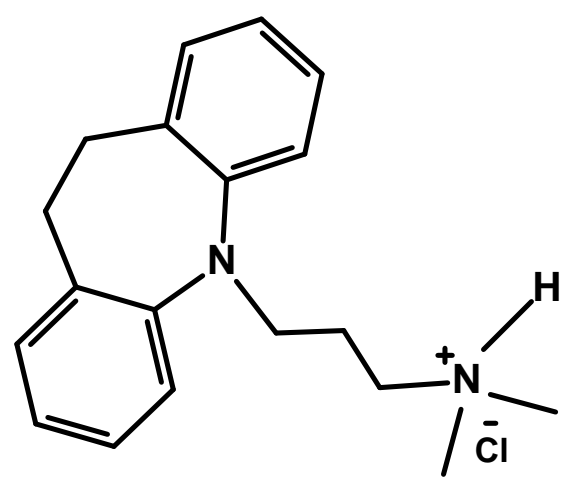

Figura 2 - Estrutura da imipramina.

Após passar pelo fígado, a imipramina é metabolizada pela perda de um grupo metila ligado ao nitrogênio da cadeia alifática gerando a desipramina, a qual também exibe atividade antidepressiva, tornando imprescindível o monitoramento terapêutico de ambas as moléculas em fluídos biológicos.

\section{I.1.1- Estudo mecanístico da reação de oxidação da imipramina}

O estudo mecanístico da reação de oxidação da iminobibenzila e de compostos relacionados, dentre eles a imipramina, foi abordado no trabalho de Frank e colaboradores por meio do acoplamento oxidativo de aminas aromáticas para formar uma variedade de derivados dimerizados (7). Segundo os autores, na primeira etapa da reação, ocorre a formação de um radical cátion com a perda de um elétron. Em uma etapa química posterior, de cinética muito rápida, há o acoplamento de dois radicais cátion na posição 2 com a perda de um próton por molécula de radical. A Figura 3 apresenta, de modo esquemático, o acoplamento dos radicais na referida posição (círculo em vermelho). 


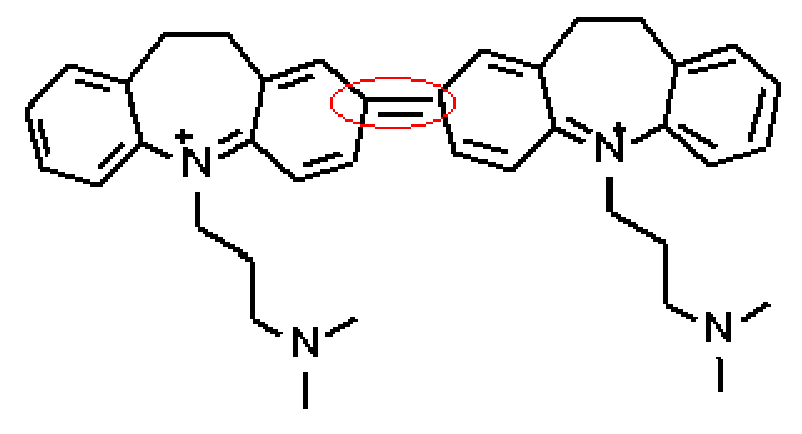

Figura 3 - Acoplamento dos radicais cátion imipramina na posição 2.

A velocidade da reação de acoplamento é tida como rápida, pois nenhuma evidência foi obtida para a redução do radical cátion durante a escala de tempo das medidas voltamétricas. Experimentos de eletrólise a potencial controlado $(E=0,90 \mathrm{~V})$ indicaram que mais de dois elétrons são necessários para a oxidação completa da molécula de imipramina. Especulações a respeito do mecanismo não foram abordadas, porém foi sugerido que a imipramina tem um comportamento similar ao dos outros compostos estudados.

Posteriormente, Bishop e Hussein realizaram um estudo eletroanalítico de antidepressivos tricíclicos, dentre eles a imipramina, em meio de ácido sulfúrico $0,10 \mathrm{~mol} \mathrm{~L}^{-1}$ com eletrodo de ouro (8). Neste trabalho, foi especulado um provável mecanismo da reação de oxidação da imipramina levando-se em consideração as condições experimentais em que o estudo foi realizado e também os resultados obtidos no trabalho de Frank e colaboradores (7). Segundo os autores, o fragmento ciclohepteno não é passível de oxidação, no entanto, a introdução de um heteroátomo (enxofre ou nitrogênio), que seja capaz de fornecer um elétron para a formação de um radical, confere eletroatividade ao antidepressivo. Assim, o provável mecanismo de oxidação da imipramina ocorre da seguinte forma: após a saída de um elétron do 
nitrogênio do anel, há a formação de um radical que reage com uma molécula de imipramina da solução, gerando o dímero. A reação de dimerização ocorre com a perda de dois prótons, mas não se sabe se a perda ocorre antes ou após o acoplamento. O dímero é mais facilmente oxidado que o monômero e o produto dicátion resulta da perda de dois elétrons por molécula de dímero.

No trabalho de Ivandini e colaboradores (9), é citado um provável mecanismo da reação de oxidação da imipramina, no entanto, os autores basearam-se somente nos estudos dos trabalhos anteriores, ou seja, nenhuma evidência que pudesse contribuir para o melhor entendimento da reação de oxidação do composto foi constatada.

Desta forma, verifica-se que os trabalhos da literatura que abordam alguns aspectos mecanísticos da imipramina sempre utilizam referências de trabalhos anteriores, os quais necessitam da aplicação de outras técnicas de geração e identificação de produtos de reação para assim complementar ou dar então um novo enfoque às especulações mecanísticas para a oxidação desta molécula.

\section{I.1.2- Determinação analítica da imipramina}

Em geral, a análise de fármacos deve englobar duas metas, a primeira diz respeito ao monitoramento terapêutico em fluídos biológicos e a segunda, ao desenvolvimento de metodologias de análise de rotina em formulações farmacêuticas comerciais. No caso dos antidepressivos tricíclicos, o monitoramento terapêutico é de extrema importância para avaliar se os níveis plasmáticos destes medicamentos estão dentro do intervalo terapêutico requerido, pois estes compostos apresentam uma estreita faixa terapêutica (50 a $\left.250 \mu \mathrm{g} \mathrm{L}^{-1}\right)(10)$, risco de toxicidade e metabólitos ativos. 
O monitoramento terapêutico e a análise em formulações farmacêuticas dos antidepressivos tricíclicos têm sido realizados aplicando-se as mais variadas técnicas analíticas, dentre elas a cromatografia líquida de alta eficiência com detecção ultravioleta (11), eletroquímica (12) e por fluorescência (13); cromatografia gasosa (14) e radio-imuno-ensaio (15). No entanto, as técnicas eletroanalíticas têm ocupado um lugar de destaque em razão de várias vantagens, dentre as quais podem-se citar a sensibilidade, rapidez e seletividade alcançadas quando se empregam eletrodos quimicamente modificados em conjunto com as técnicas de pulso, o que resulta, em alguns casos, na obtenção de limites de detecção tão baixos quanto aos alcançados pelas técnicas cromatográficas. Além disso, deve-se enfatizar a possibilidade de se trabalhar em diversas matrizes sem a necessidade de se efetuar um pré-tratamento da amostra.

No trabalho de Biryol e colaboradores (16), foi utilizada a técnica de voltametria cíclica com eletrodo de pasta de carbono modificado com poli(n-vinilimidazol) para a determinação de imipramina em formulações comerciais de Tofranil $^{\circledR}$. O eletrodo de pasta de carbono foi preparado pela mistura de $0,80 \mathrm{~g}$ de pó de grafite e 1,00 $\mathrm{ml}$ de óleo mineral. Para a modificação requerida, $50 \mathrm{mg}$ do polímero foi misturado à pasta de carbono para a análise de imipramina. A estabilidade e a reprodutibilidade do eletrodo foram averiguadas em solução de ácido sulfúrico $0,10 \mathrm{~mol} \mathrm{~L}^{-1}$ por meio de sucessivas ciclagens de potencial. Os resultados obtidos foram satisfatórios, porém, quando o mesmo teste foi realizado em uma solução do antidepressivo, observou-se um decréscimo gradual da corrente devido à adsorção de moléculas do composto na superfície do eletrodo. Posteriormente, o perfil voltamétrico da imipramina foi comparado com eletrodo de pasta de carbono não contendo o modificador. A 
sensibilidade analítica, bem como o perfil voltamétrico, foram superiores quando o modificador foi adicionado à pasta de carbono. A metodologia analítica desenvolvida foi utilizada para a determinação de imipramina em formulações farmacêuticas disponíveis comercialmente, nas quais as recuperações ficaram em torno de $100,7 \%$.

A detecção de imipramina também foi realizada utilizando eletrodos de carbono screen-printed modificados com filmes de polímeros de $\beta$-ciclodextrina $(\beta-C D P)$ ou $\beta$-ciclodextrina carboximetilado ( $\beta$-CDPA) em conjunto com a técnica de voltametria de pulso diferencial (17). Uma série de experimentos, que incluiu a seleção do $\mathrm{pH}$, do tempo e do potencial de pré-concentração, foi realizada para a otimização das condições experimentais. Os voltamogramas foram registrados em tampão fosfato $70 \times 10^{-3} \mathrm{~mol} \mathrm{~L}^{-1}(\mathrm{pH} 7,4)$ com uma etapa de pré-concentração do analito na superfície do eletrodo de 120 segundos no potencial de $-0,15 \mathrm{~V}$. Os resultados indicaram que a sensibilidade analítica para o eletrodo modificado com $\beta$-CDPA é maior que para o eletrodo de $\beta$-CDP, que por sua vez é ainda maior que para o eletrodo de carbono sem modificação. Uma explicação plausível para as diferentes sensibilidades alcançadas seria que nos filmes de $\beta$-CDP estão disponíveis somente sítios inclusos de $\beta$-CD ao passo que nos filmes de $\beta$-CDPA, sítios de inclusão como também de troca de íons no valor de $\mathrm{pH}$ estudado estão presentes. A existência de sítios de troca de íons deve-se aos grupos carboxílicos estarem dissociados e os analitos estarem protonados no valor de $\mathrm{pH}$ estudado. Os limites de detecção calculados para a imipramina, utilizando cada um dos eletrodos, foram iguais a $5,00 \times 10^{-7} \mathrm{~mol} \mathrm{~L}^{-1}(\beta-C D P)$ e $1,00 \times 10^{-7} \mathrm{~mol} \mathrm{~L}^{-1}(\beta-$ CDPA). 
O eletrodo de diamante dopado com boro foi utilizado para a detecção de antidepressivos tricíclicos, dentre eles a imipramina, em amostras de plasma sanguíneo (9). Os experimentos foram realizados em tampão fosfato $0,10 \mathrm{~mol} \mathrm{~L}^{-1}(\mathrm{pH} \mathrm{6,9)} \mathrm{com}$ eletrodo de diamante e também com eletrodo de carbono vítreo. O perfil voltamétrico da imipramina foi avaliado para os dois eletrodos, salientado que, com o eletrodo de diamante dopado com boro, obteve-se uma maior definição do pico de oxidação da imipramina, bem como do dímero formado em uma etapa química subseqüente à transferência eletrônica. No estudo da variação do pH, no intervalo de 2 a 11, constatou-se que os potenciais de pico deslocaram-se para valores menos positivos com o aumento do $\mathrm{pH}$. O coeficiente angular do gráfico de potencial de pico em função do $\mathrm{pH}$ é igual a $28 \mathrm{mV} / \mathrm{pH}$, o que está de acordo com um mecanismo envolvendo a participação de dois elétrons e um próton. Com alguns parâmetros eletroquímicos conhecidos, o mecanismo de oxidação da imipramina foi proposto, devendo mencionar que, de acordo com os autores, o nitrogênio do anel seria o provável sítio de oxidação. Esta suposição foi extraída apenas dos estudos da metiliminobibenzila e de alguns compostos relacionados (7) que apresentam estrutura similar à imipramina, ou seja, nenhuma nova evidência foi abordada pelos autores para confirmar o sítio de oxidação e também o acoplamento oxidativo para a formação do dímero. Em paralelo, foi realizada a detecção em fluxo da imipramina, e de outros antidepressivos tricíclicos, em amostras de sangue. O limite de detecção calculado foi de $3,00 \times 10^{-9} \mathrm{~mol} \mathrm{~L}^{-1}$ e a quantidade recuperada de imipramina foi igual a $90,9 \%(n=3)$.

O único trabalho na literatura, segundo o nosso conhecimento, no qual são empregados microeletrodos de fibra de carbono para a detecção de imipramina em urina e soro foi realizado por Ghoroghchian e colaboradores (18). O limite de detecção 
calculado foi de $1,00 \times 10^{-7} \mathrm{~mol} \mathrm{~L}^{-1}$. Uma das características inerentes à utilização de microeletrodos, a alta eficiência no transporte de massa, torna possível a análise de antidepressivos tricíclicos em baixas concentrações sem a necessidade de se efetuar uma etapa de pré-concentração do analito na superfície do eletrodo.

Pelos trabalhos descritos, verifica-se que a potencialidade dos eletrodos quimicamente modificados, para a análise de antidepressivos tricíclicos, foi pouco explorada, uma vez que estes compostos exibem pequena eletroatividade em superfícies eletródicas convencionais. Assim, a abordagem a ser realizada, neste trabalho, tanto para o estudo da oxidação eletroquímica da imipramina como também para o desenvolvimento de novas metodologias analíticas, torna-se devidamente justificada. 


\section{I.2- NEUROTRANSMISSORES}

Os neutransmissores são substâncias que existem naturalmente no cérebro e, como tais, servem para conduzir a transmissão de uma célula nervosa (neurônio) para outra. A dopamina (DA), 2-(3,4,dihidroxi-fenil)etilamina, cuja estrutura é mostrada na Figura 4, é um importante neurotransmissor do grupo das catecolaminas e é o precursor metabólico imediato da noradrenalina. Além disso, a dopamina é comumente empregada em unidades de emergência hospitalar como agente vasoconstritor e hipertensor.

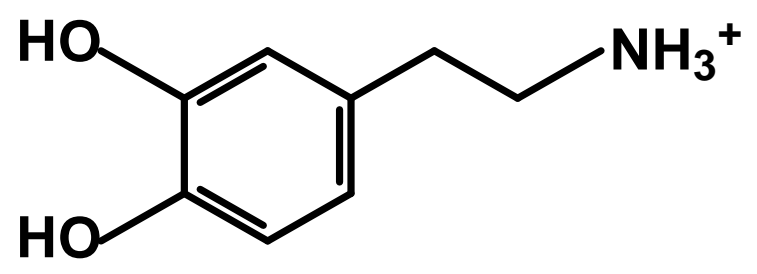

Figura 4 - Estrutura da dopamina.

A dopamina é sintetizada nos neurônios a partir do aminoácido tirosina, o qual é hidroxilado pela enzima tirosina hidroxilase a L-DOPA. Posteriormente, a L-DOPA é descarboxilada para formar a dopamina pela ação da enzima dopa carboxilase para então ser armazenada nas vesículas dos terminais pré-sinápticos. Na Figura 5, estão resumidas as etapas da biossíntese da dopamina. 
<smiles>[NH3+]C(C=O)Cc1ccc(O)cc1</smiles>

Tirosina<smiles>[NH3+]C(Cc1ccc(O)c(O)c1)C(=O)[O-]</smiles>

L-DOPA

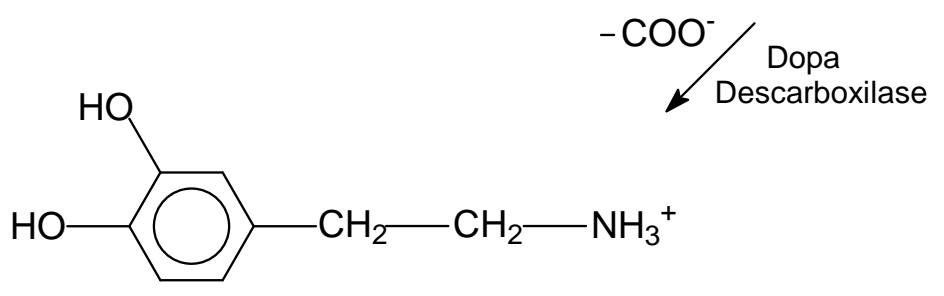

Dopamina

Figura 5 - Etapas da biossíntese da dopamina.

Quando chega um impulso elétrico na sinapse, as vesículas sinápticas direcionam-se para a periferia do neurônio e liberam o conteúdo da dopamina na fenda sináptica. A dopamina aí liberada atravessa essa fenda e se liga aos seus receptores específicos na membrana do próximo neurônio (pós-sináptico). Uma série de reações ocorre quando o neutrotransmissor ocupa seus receptores (receptores dopaminérgicos) no neurônio pós-sináptico: alguns íons entram e saem desse neurônio e algumas enzimas são liberadas ou inibidas. Após cumprir sua função (estimular o neurônio seguinte), a dopamina é recaptada novamente pelo neurônio pré-sináptico (o mesmo que a secretou) por meio de proteínas denominadas de transportadores de dopamina, as quais se localizam no neurônio pré-sináptico. A Figura 6 resume o processo de captação e recaptação da dopamina. 


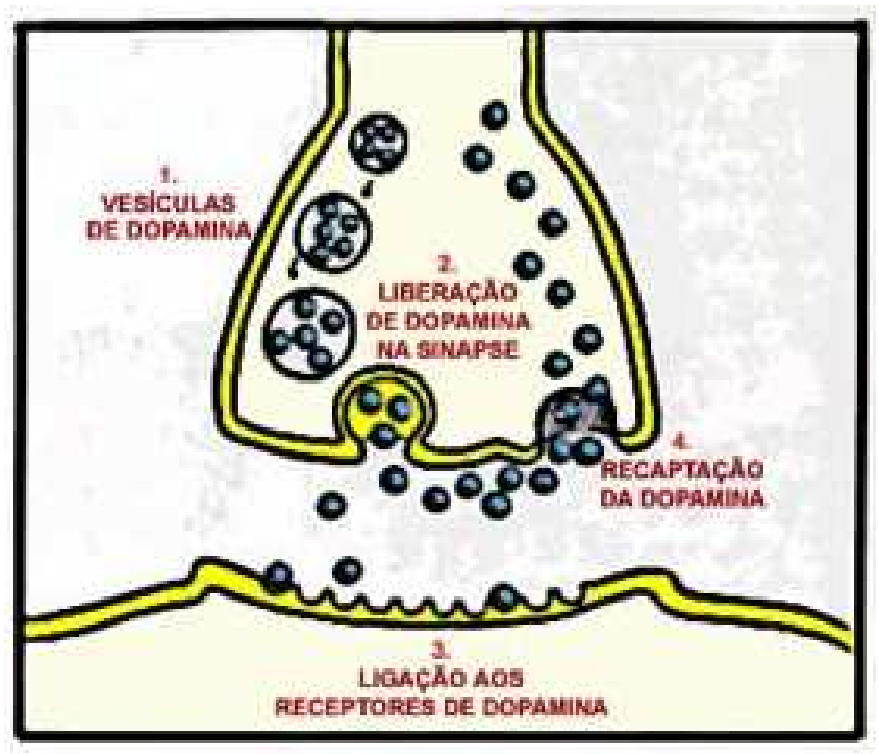

Figura 6 - Captação e recaptação da dopamina na fenda sináptica.

Recentemente, vários trabalhos têm surgido na literatura com o objetivo de explorar a modificação química da superfície de eletrodos sólidos convencionais para a determinação de neurotransmissores em fluídos extracelulares do sistema nervoso central, em virtude do fato de muitas doenças, dentre elas o Mal de Pakinson e a depressão, estarem relacionadas com anormalidades no nível de dopamina nas sinapses dos neurônios (19). No entanto, o assunto ainda está longe de ser considerado concluído.

O emprego de eletrodos quimicamente modificados ou então de metodologias que conciliam o emprego de microeletrodos e da voltametria de varredura rápida estão voltados para o propósito de se eliminar a interferência do ácido ascórbico $\left(10^{-4}-10^{-3} \mathrm{~mol} \mathrm{~L}^{-1}\right)$, o qual coexiste com a dopamina $\left(10^{-8}-10^{-6} \mathrm{~mol} \mathrm{~L}^{-1}\right)$ no fluído cerebrospinal em concentrações elevadas e também por sofrer oxidação na mesma região de potenciais que o neurotransmissor. 
A determinação simultânea de dopamina e de ácido ascórbico foi estudada por Sun e colaboradores (20) com a utilização de um eletrodo de carbono vítreo modificado pela eletrodeposição de um filme de poli(vermelho neutro). A modificação catalisa a reação de oxidação de ambos os compostos, e relações lineares entre a corrente de pico e o aumento da concentração de dopamina $\left(E_{p}=265 \mathrm{mV}\right)$ e de ácido ascórbico $\left(E_{p}=186 \mathrm{mV}\right)$ foram obtidas nos intervalos de $5,00 \times 10^{-6}$ a $2,00 \times 10^{-4} \mathrm{~mol} \mathrm{~L}^{-1} \mathrm{e}$ $2,50 \times 10^{-5}$ a $1,00 \times 10^{-1} \mathrm{~mol} \mathrm{~L}^{-1}$, respectivamente. A determinação simultânea pôde ser realizada usando a diferença das correntes catalíticas referentes a cada composto. A metodologia foi aplicada em injeções de cloridrato de dopamina com recuperações entre $95,3 \%$ a $106,4 \%(n=10)$

A determinação simultânea dos neurotransmissores dopamina e serotonina e o estudo da interferência do ácido ascórbico foram realizados com eletrodo de pasta de carbono modificado com complexos de ftalocianinas de ferro (II) (21). Os complexos de ferro (II) testados foram: ftalocianina (II) (FePc), tetrasulfoftalocianina ([FeTSPc] ${ }^{-4}$ ) e tetraminoftalocianina ([FeTAPc]). Os resultados revelaram que o complexo ([FeTSPc] $\left.{ }^{-4}\right)$ exibiu atividade catalítica para a detecção de ambos os neurotransmissores pelo aumento da velocidade de transferência de elétrons. O limite de detecção para a determinação de dopamina ou de serotonina é de $10^{-6} \mathrm{~mol} \mathrm{dm}^{-3}$. A interferência do ácido ascórbico pôde ser eliminada pela interação eletrostática não favorável entre o ácido e o complexo de ferro, ambos carregados negativamente.

Raj e colaboradores (22) aplicaram a técnica de voltametria de onda quadrada com eletrodo de ouro modificado com monocamadas self-assembled (SAMs) de 2,2'ditiobisetancamina (CYST) e 6,6'-ditiobishexancamina (DTH) para a determinação simultânea de dopamina e ascorbato. Os eletrodos modificados com monocamadas 
catiônicas apresentaram muitas vantagens frente ao eletrodo de ouro sem modificação. A primeira deve-se ao decréscimo bem pronunciado do potencial de pico do ácido ascórbico $\left(\Delta \mathrm{E}_{\mathrm{p}}=450 \mathrm{mV}\right)$, o qual está relacionado com interações eletrostáticas mais favoráveis entre o ânion e os grupos terminais da monocamada os quais estão carregados positivamente. Desta forma, a dopamina é repelida da superfície do eletrodo por estar protonada. A separação dos potenciais de pico $\left(E_{p}=40 \mathrm{mV}\right.$ para o ácido ascórbico e $E_{p}=200 \mathrm{mV}$ para a dopamina) torna possível a detecção simultânea dos compostos sem o efeito catalítico do ácido ascórbico no produto de oxidação da dopamina. Curvas analíticas para ambos os compostos foram registradas simultaneamente no intervalo de 0,30 a $100 \times 10^{-6} \mathrm{~mol} \mathrm{~L}^{-1}(\mathrm{R}=0,998)$ para o ácido ascórbico e de 0,50 a $100 \times 10^{-6} \mathrm{~mol} \mathrm{~L}^{-1}(R=0,997)$ para a dopamina. Os limites de detecção foram calculados com sendo iguais a $0,30 \times 10^{-6} \mathrm{~mol} \mathrm{~L}^{-1}$ e $0,50 \times 10^{-6} \mathrm{~mol} \mathrm{~L}^{-1}$ para o ácido ascórbico e para a dopamina, respectivamente. A modificação da superfície do eletrodo resultou em uma maior sensibilidade e seletividade, além de minimizar os efeitos de desativação do eletrodo pela adsorção de produtos de reação.

O estudo eletroquímico da dopamina foi realizado por Zhao e colaboradores (23) pela eletrodeposição de filmes de ácido sulfosalicílico sobre eletrodo de carbono vítreo. A modificação do eletrodo resultou em um excelente efeito catalítico na oxidação da dopamina $\left(\Delta \mathrm{E}_{\mathrm{p}}=42 \mathrm{mV}\right)$ quando comparado com o eletrodo de carbono vítreo $\left(\Delta \mathrm{E}_{\mathrm{p}}=102 \mathrm{mV}\right)$. Curvas analíticas foram construídas para o composto em dois intervalos, primeiro de $5,50 \times 10^{-7}$ a $2,20 \times 10^{-5} \mathrm{~mol} \mathrm{~L}^{-1}(\mathrm{R}=0,9985)$ e o segundo de $2,20 \times 10^{-5}$ a $1,10 \times 10^{-4} \mathrm{~mol} \mathrm{~L}^{-1}(\mathrm{R}=0,9996)$. O desvio relativo padrão de dez varreduras foi igual a $1,8 \%$ para uma solução de dopamina a $1,10 \times 10^{-6} \mathrm{~mol} \mathrm{~L}^{-1}$, 
indicando que o eletrodo modificado tem uma excelente reprodutibilidade. $O$ limite de detecção, obtido por voltametria de pulso diferencial, foi de $5,00 \times 10^{-9} \mathrm{~mol} \mathrm{~L}^{-1}$. A interferência de compostos inorgânicos e orgânicos no sinal analítico da dopamina também foi estudada. Para o caso do ácido ascórbico, verificou-se que o eletrodo modificado separa os picos de oxidação de ambos os compostos por interações eletrostáticas. Como o polímero está carregado com carga negativa, este irá interagir mais favoravelmente com a dopamina. Porém, o efeito catalítico do ácido ascórbico no produto de oxidação da dopamina não foi estudado e provavelmente deverá ocorrer, uma vez que a dopamina é oxidada antes que o ácido ascórbico. A metodologia desenvolvida foi aplicada para a quantificação de dopamina em ampolas de injeção comerciais, e a recuperação ficou entre $97 \%$ e $108 \%$.

A determinação de dopamina, na presença de ácido ascórbico, foi realizada pela aplicação de um eletrodo de carbono vítreo contendo um filme de vermelho de acridina eletrodepositado (24). Os resultados indicaram que a separação dos picos de oxidação de ambos os compostos é alcançada por interações eletrostáticas favoráveis entre o filme e a dopamina. Curvas analíticas foram construídas no intervalo de 1,00 × $10^{-7}$ a $1,00 \times 10^{-4} \mathrm{~mol} \mathrm{~L}^{-1}$. O limite de detecção foi calculado e igual a $1,00 \times 10^{-9} \mathrm{~mol} \mathrm{~L}^{-1}$.

Como pode ser visto pelos artigos citados, muito já se tem publicado, porém os artigos quase se assemelham na utilização de eletrodepósitos visando somente a separação do interferente principal. Além disso, é raro observar um artigo que contenha a aplicação da metodologia desenvolvida em algum fluido, sintético ou não. Assim, na metodologia que será proposta, preocupar-se-á tanto com a separação do interferente como também na sua aplicação. Os resultados obtidos poderão ser satisfatórios, o que permitirá avaliar a possibilidade de miniaturização do sistema para aplicação in vivo. 


\section{I.3- ELETRODOS COMPÓSITOS}

A utilização de eletrodos sólidos para o estudo de reações eletroquímicas é muito vasta na literatura (25), no entanto, atualmente, observa-se um crescimento muito expressivo em estudos que tratam da modificação da superfície eletródica com o objetivo de melhorar a seletividade, sensibilidade, estabilidade e o tempo de vida do eletrodo.

A denominação eletrodo quimicamente modificado (EQM) foi inicialmente utilizada na eletroquímica por Moses e colaboradores (26), na década de 70, para designar eletrodos com espécies quimicamente ativas convenientemente imobilizadas na superfície desses dispositivos.

Um EQM consiste de duas partes, ou seja, o eletrodo base e uma camada do modificador químico. A forma de preparação de um eletrodo quimicamente modificado é determinada pelas características analíticas desejadas no sensor. O uso de camadas de agentes modificadores sobre a superfície do eletrodo base tem sido a forma mais comum de modificar a superfície de um eletrodo.

De maneira geral, os métodos mais importantes utilizados para a introdução de um agente modificador sobre o eletrodo base consistem na adsorção simples e rápida de compostos em uma ampla gama de eletrodos base, na ligação covalente a sítios específicos da superfície do eletrodo pela manipulação da reatividade dos grupos funcionais existentes nesta superfície, na eletrodeposição de policamadas de filmes poliméricos ou ainda na preparação de materiais compósitos que permitem a modificação interna do eletrodo (27). 
O eletrodo compósito resulta da combinação de dois ou mais componentes e pode ser definido, em geral, como um material consistindo de pelo menos uma fase condutora misturada à pelo menos uma fase isolante (28). Cada fase mantém suas características individuais, mas a mistura pode apresentar novas características físicas, químicas ou biológicas.

A crescente utilização de compósitos, baseados na fase condutora dispersa em matrizes poliméricas, tem levado a um importante avanço em análises eletroquímicas, principalmente no desenvolvimento de sensores (29). Este avanço está particularmente relacionado com as propriedades elétricas do grafite e também com a facilidade no manuseio dos polímeros, apresentando algumas vantagens quando comparados aos eletrodos clássicos, como o ouro e a platina, dentre elas, o grande intervalo de potenciais de trabalho; a melhoria na relação sinal/ruído, devido à baixa corrente residual, o que geralmente leva a limites de detecção mais baixos; a elevada resistência mecânica; a estabilidade em sistema de fluxo; o baixo custo e a simplicidade na preparação e renovação da superfície do eletrodo (30). 


\section{I.4- TÉCNICAS VOLTAMÉTRICAS}

\section{I.4.1 - Voltametria cíclica}

Facilidade de aplicação e versatilidade são os principais atributos responsáveis pela popularização da técnica de voltametria cíclica em diversas áreas de aplicação. Freqüentemente, a voltametria cíclica é o primeiro experimento a ser realizado quando se deseja estudar o comportamento eletroquímico de um composto ou a superfície de um eletrodo (31), pois permite mostrar rapidamente o comportamento redox de um sistema em um grande intervalo de potenciais.

As correntes e os potenciais de pico catódico e anódico são parâmetros eletroquímicos importantes para a caracterização de um sistema quanto à reversibilidade e a análise da ocorrência de reações homogêneas acopladas ao processo de eletrodo. Deve-se enfatizar, porém, que a técnica gera em muitas situações somente resultados qualitativos de diagnósticos das reações eletroquímicas. Medidas quantitativas mais precisas são comumente obtidas com o emprego de técnicas de pulso (32).

\section{Reacões reversíveis}

Para um sistema eletroquímico reversível, as espécies oxidadas e reduzidas são estáveis e a cinética do processo de transferência de elétrons é rápida. Assim, os voltamogramas cíclicos são caracterizados por apresentarem picos na varredura direta e reversa de potencial. A atividade (a) de ambas as espécies envolvidas no processo 
eletroquímico pode ser calculada pela equação de Nernst (equação 1), pois o potencial e a velocidade do processo de transferência de elétrons na superfície do eletrodo estão em equilíbrio.

$$
E=E^{0}-R T / n F \sum\left(v_{i} \ln a_{i}\right)
$$

onde $v_{i}$ são os números estequiométricos, positivos para os produtos (espécies reduzidas) e negativos para os reagentes (espécies oxidadas).

Neste tipo de reação, a velocidade de transferência de elétrons é sempre maior que o fluxo das espécies eletroativas do interior da solução para a superfície do eletrodo. A corrente de pico catódica do voltamograma é dada pela equação de Randles e Sevcik (equação 2).

$$
I_{p c}=-2,69 \times 10^{5} n^{3 / 2} A D^{1 / 2}[O]_{\infty} v^{1 / 2}
$$

onde $A$ é a área do eletrodo $\left(\mathrm{cm}^{2}\right), \mathrm{D}$ é o coeficiente de difusão $\left(\mathrm{cm}^{2} \mathrm{~s}^{-1}\right),[O]_{\infty}$ é a concentração da espécie eletroativa na forma oxidada no interior da solução $\left(\mathrm{mol} \mathrm{cm}^{-3}\right)$ e $v$ é a velocidade de varredura $\left(V^{-1}\right)$.

Existem vários critérios para diagnosticar se um sistema eletroquímico comportase reversivelmente ou não, dentre eles (33):

${ }^{*} I_{p}$ é proporcional a raiz quadrada da velocidade de varredura;

${ }^{*} E_{p}$ é independente da velocidade de varredura;

${ }^{*}\left|E_{p}-E_{p / 2}\right|=59 / n(m V)$;

${ }^{*}\left|I_{p a} / I_{p c}\right|=1$;

${ }^{*} E_{p a}-E_{p c}=59 / n(m V)$. 


\section{$\underline{\text { Reações irreversíveis }}$}

Em sistemas irreversíveis, não ocorre o equilíbrio Nernstiano, ou seja, a velocidade de transferência de elétrons não mantém o equilíbrio das espécies eletroativas na superfície do eletrodo. Conseqüentemente, a forma do voltamograma cíclico é modificada, podendo ocorrer a ausência de pico na varredura reversa de potencial. Porém, esta característica não significa que o sistema seja eletroquimicamente irreversível, pois uma reação química rápida acoplada ao processo de transferência eletrônica pode estar associada ao sistema eletroquímico, consumindo rapidamente a espécie formada na varredura direta.

Para sistemas irreversíveis, a corrente de pico catódica do voltamograma é dada pela equação 3:

$$
I_{p c}=-2,99 \times 10^{5} n\left(\alpha_{c} n\right)^{1 / 2} A[O]_{\infty} D^{1 / 2} v^{1 / 2}
$$

onde $\mathrm{n}$ é o número de elétrons transferidos e $\alpha_{c}$ é o coeficiente de transferência de carga catódico, que constitui uma medida da barreira de energia de ativação, aproximando-se de 0,5 para um condutor metálico e para um processo reversível simples de transferência de elétron.

Os critérios eletroquímicos para diagnosticar um sistema irreversível são (33) :

* Ausência de pico na varredura reversa de potencial;

${ }^{*} I_{p}$ é proporcional a raiz quadrada da velocidade de varredura;

* $E_{p}$ desloca-se de 30/n $\alpha(\mathrm{mV})$ para cada 10 vezes de aumento na velocidade de varredura;

${ }^{*}\left|E_{p}-E_{p / 2}\right|=48 / n \alpha m V$. 


\section{I.4.2- Voltametria de onda quadrada}

A técnica voltametria de onda quadrada foi desenvolvida em 1952 por Baker e no decorrer dos anos apresentou algumas modificações instrumentais aliadas ao desenvolvimento de novas teorias que foram responsáveis pelo estabelecimento da técnica para a análise de traços e na obtenção de dados relacionados à cinética e ao mecanismo de reações químicas sob as mais variadas condições (34). Dentre as vantagens desta técnica, pode-se citar a sua rapidez de aplicação frente a outras técnicas de pulso como a voltametria de pulso diferencial, excelente sensibilidade e diminuição das correntes residuais, menor consumo da espécie eletroativa e diminuição dos problemas associados ao bloqueio da superfície do eletrodo por produtos de reações (35).

A forma de aplicação do potencial de altura a (amplitude), como mostrado na Figura 7, varia de acordo com uma escada de potencial com largura $\Delta \mathrm{E}_{\mathrm{I}}$ (incremento de varredura) e duração 2t. As correntes são medidas no final dos pulsos diretos (a) e reversos (b) e a diferença entre elas resulta na corrente resultante $(\Delta \mathrm{l})$. 


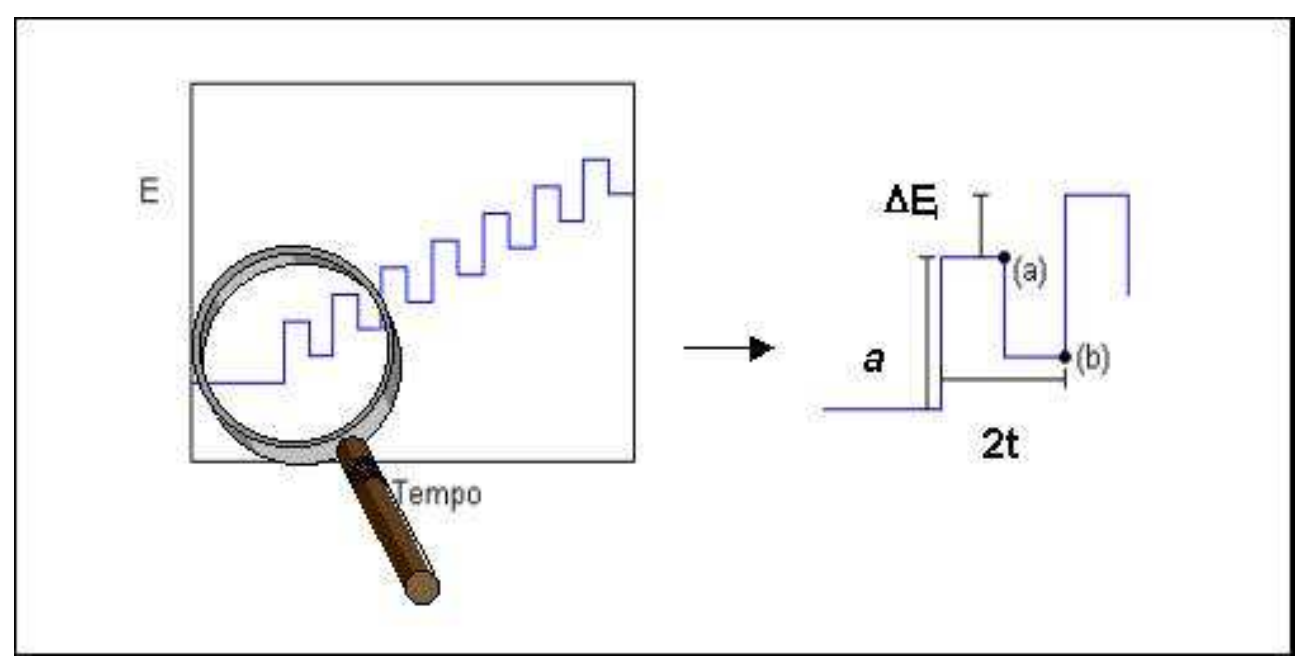

Figura 7 - Forma de aplicação do potencial em voltametria de onda quadrada.

Na Figura 8, são apresentados voltamogramas de onda quadrada típicos de sistemas reversíveis e irreversíveis com as correntes direta, reversa e resultante. A separação das correntes é uma ferramenta muito utilizada para diagnosticar o grau de reversibilidade de um sistema eletroquímico. Para sistemas reversíveis, quanto maior for a contribuição da corrente reversa, maior será a corrente resultante, pois ela é a diferença entre as correntes direta e reversa. Já para sistemas irreversíveis, a corrente reversa é mínima e, conseqüentemente, a sua contribuição para a intensidade da corrente resultante é desprezível. 


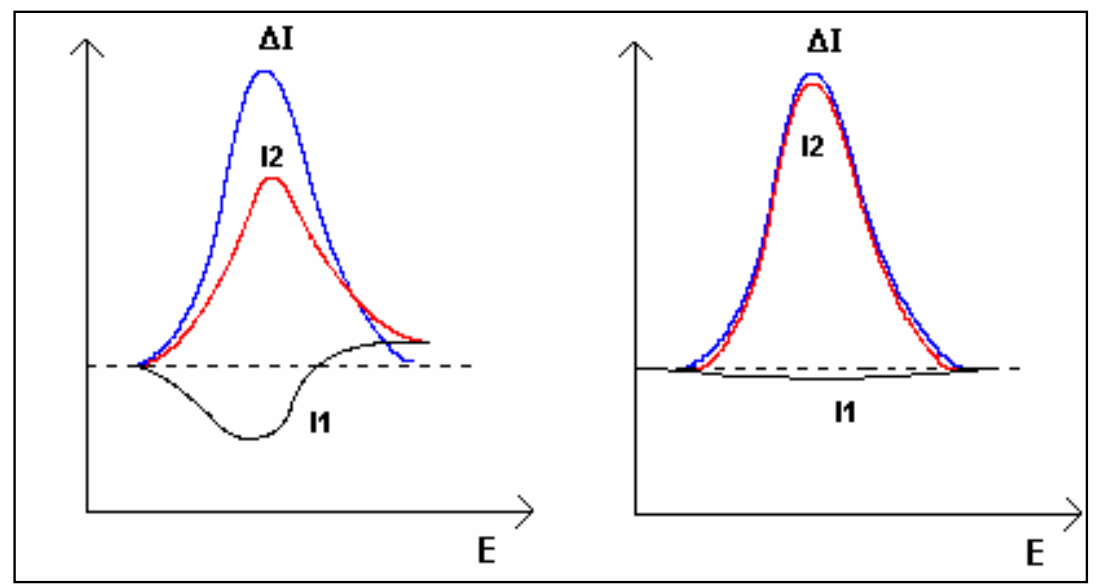

Figura 8 - Voltamogramas de onda quadrada para: (A) Sistemas reversíveis; (B) Sistemas irreversíveis. $\mathrm{I} 1$ - corrente reversa; $\mathrm{I} 2$ - corrente direta; $\Delta \mathrm{I}$ - corrente resultante. $(\Delta \mathrm{I}=\mathrm{I} 2-\mid \mathrm{I})$.

Os parâmetros eletroquímicos, corrente de pico $\left(I_{p}\right)$ e potencial de pico $\left(E_{p}\right)$, fornecem informações importantes quando relacionados com a freqüência de aplicação de pulsos de potencial (36). Para sistemas reversíveis, $I_{p}$ varia linearmente com a raiz quadrada da freqüência, por outro lado, varia linearmente com a freqüência para sistemas irreversíveis. Para sistemas quase-reversíveis, a relação entre $I_{p}$ e a freqüência não é linear. $O$ coeficiente angular $(\theta)$ dos gráficos de $E_{p} v s$. o logaritmo da freqüência, para sistemas reversíveis sem adsorção do produto, tem um valor de $-29 / n$ $\mathrm{mV}$ e com adsorção do produto e do reagente não há relação linear. Para sistemas irreversíveis, o coeficiente angular tem o valor de $-59 / \mathrm{n} \alpha \mathrm{mV}$. Na Tabela I, são resumidas as principais características dos sistemas eletroquímicos quanto ao grau de reversibilidade ao se relacionar $I_{p}$ e $E_{p}$ com a freqüência de aplicação de pulsos. 
Tabela I - Características dos sistemas eletroquímicos, estudados com a técnica de voltametria de onda quadrada, quanto ao grau de reversibilidade ao se relacionar $I_{p}$ e $E_{p}$ com a freqüência de pulsos.

\begin{tabular}{|c|c|c|}
\hline Sistema & Relação de f e $I_{p}$ & Relação de logf vs. $E_{p}$ \\
\hline Irreversível & $\mathrm{I}_{\mathrm{p}}=\mathrm{kf}$ & $\theta=-59 / \mathrm{n} \alpha \mathrm{mV}$ \\
\hline & & $\begin{array}{l}\text { Sem adsorção do produto: } \\
\qquad \theta=-29 / \mathrm{n} \mathrm{mV}\end{array}$ \\
\hline Reversível & $\mathrm{I}_{\mathrm{p}}=\mathrm{kf}^{1 / 2}$ & $\begin{array}{l}\text { Com adsorção do produto e } \\
\text { do reagente: } \\
\text { relação não é linear }\end{array}$ \\
\hline Quase-reversível & Não é linear & $\begin{array}{l}\text { Relação não } \\
\text { é linear }\end{array}$ \\
\hline
\end{tabular}

Um outro parâmetro utilizado para avaliar o grau de reversibilidade de um sistema eletroquímico é a largura de meia-onda $\left(\Delta \mathrm{E}_{\mathrm{p} / 2}\right)(36)$. Para sistemas irreversíveis com adsorção do produto, $\Delta \mathrm{E}_{\mathrm{p} / 2}$ é independente da amplitude dos pulsos se $\Delta \mathrm{E}_{\mathrm{a}}$ for maior que $20 \mathrm{mV}$. Para sistemas irreversíveis com adsorção do produto e do reagente, a independência da largura de meia-onda com a amplitude dos pulsos ocorre se $\Delta E_{a}$ for maior que $40 \mathrm{mV}$. Deste modo, considera-se a largura de meia-onda como sendo igual a $(63,5 \pm 0,5) / n \alpha$, podendo-se conseqüentemente avaliar o valor de $n \alpha$. 


\section{I.5- CÁLCULOS QUÍMICO-QUÂNTICOS}

\section{I.5.1- Energia dos orbitais de fronteira}

Os métodos que utilizam orbitais moleculares têm sido utilizados nos cálculos de diversos parâmetros de interesse químico e farmacológico e dentre estes parâmetros dois são bastante empregados em estudos das relações estrutura-atividade: a energia do HOMO ("Highest Occupied Molecular Orbital" - orbital molecular ocupado de mais alta energia) e a energia do LUMO ("Lowest Unoccupied Molecular Orbital” - orbital molecular desocupado de menor energia) (37). Estas energias medem a capacidade doadora e aceptora de elétrons de uma determinada molécula. Quanto maior a energia do HOMO, maior será a capacidade doadora da molécula e deste modo, a propensão da molécula em doar elétrons será maior; e quanto menor a energia do LUMO, menor será a resistência em aceitar elétrons (38).

Da Silva e colaboradores (39) realizaram um estudo químico-quântico e estatístico de 14 compostos biflavonóides com atividade anti-HIV. Alguns estudos de estrutura-atividade têm sido realizados em flavonóides, revelando que a atividade antiHIV destes compostos está relacionada com características eletrônicas, estéricas e hidrofóbicas dos substituintes da molécula. Neste estudo, a energia HOMO, a energia LUMO, o momento de dipolo $(\mu)$, o calor de formação $\left(\Delta \mathrm{H}_{\mathrm{f}}\right)$, a polarizabilidade molecular (POL), a energia total $\left(E_{T}\right)$ e a energia eletrônica $\left(E_{e l}\right)$ foram calculadas utilizando o método semi-empírico AM1 (Austin Model 1). Os resultados obtidos foram avaliados pelo emprego da análise de componente principais (PCA), análise hierárquica de agrupamento (HCA) e discriminante por passos (DAS). As variáveis HOMO, LUMO e A 
(área superficial) foram as responsáveis pela separação entre moléculas ativas e inativas. O comportamento dessas três variáveis pode ser útil quando se deseja obter novos compostos biflavonóides com alta atividade anti-HIV. Portanto, as energias do HOMO e do LUMO são propriedades importantes em estudos de moléculas com atividade biológica.

\section{I.5.2- Superfícies de potencial eletrostático}

A densidade eletrônica é uma função que fornece informações sobre a distribuição eletrônica probabilística contida na função de onda. Esta função pode ser medida experimentalmente por meio da técnica de difração de raios-X e também por cálculos teóricos. Sua determinação é de grande importância, encontrando aplicações em estudos de reatividade química, interações intermoleculares, similaridade molecular, dentre outras (40).

Existem várias maneiras de representar a densidade de carga de uma molécula: por meio de diagramas de contorno de um determinado plano da molécula ou por meio de superfícies de isovalores. A análise desses diagramas fornece informações importantes em relação à estrutura eletrônica da molécula. No trabalho de Castilho e colaboradores (41), foi utilizado o método semi-empírico PM3 com o objetivo de calcular a distribuição de carga na molécula de dipiridamol (DIP), um vasodilatador coronariano, e de seus derivados (RA14, RA25, RA47 e RA143) nos seus estados neutro e duplamente ionizados. Os resultados dos cálculos quânticos mostram que uma densidade eletrônica considerável aparece nos átomos de nitrogênio dos substituintes alifáticos e nos átomos de carbono e nitrogênio dos anéis pirimido-pirimidina, relevando 
que a remoção de um ou dois elétrons leva a mudanças significativas na densidade eletrônica em toda a molécula, mas apresenta mudanças somente em poucos sítios, especialmente nos átomos de nitrogênio dos substituintes alifáticos. Esses resultados mostram que o radical cátion DIP ${ }^{\bullet}$, formado pela oxidação de um elétron, está associado à remoção de um elétron desses nitrogênios. Esses resultados estão de acordo com a estequiometria para a reação de oxidação em solução aquosa (pH 3,0).

$\mathrm{Na}$ literatura, foi encontrado um trabalho que aborda a bioatividade de drogas tricíclicas neuroativas, como os antidepressivos, anticonvulsantes e antipsicóticos por meio de cálculos quânticos (42). A disposição espacial tem sido utilizada como um fator importante para a determinação da atividade farmacológica desses compostos. Esta hipótese foi utilizada para a análise da conformação teórica de moléculas representativas de cada classe. A comparação das estruturas otimizadas, utilizando o método semi-empírico AM1, indicou que uma correlação entre variáveis angulares usadas para definir a posição relativa dos anéis aromáticos no sistema tricíclico está intimamente relacionada com a atividade biológica de cada classe de composto. A análise dos momentos de dipolo também foi responsável por permitir tal separação, sugerindo, assim, a inclusão dos efeitos eletrônicos como parâmetros adicionais para avaliar a bioatividade de drogas neuroativas. 


\section{I.6- ESPECTROMETRIA DE MASSA COM IONIZAÇÃO POR ELECTROSPRAY}

A espectrometria de massa é uma técnica analítica que é usada para identificar compostos desconhecidos, quantificar materiais conhecidos e elucidar as propriedades químicas e estruturais das moléculas. A detecção de compostos pode ser conseguida para quantidades tão pequenas como 10-15 g para um composto de massa de 1000 Dalton. Isto significa que os compostos podem ser identificados em concentrações muito baixas (uma parte em 1012) em misturas quimicamente complexas. Os princípios científicos em que a técnica se baseia são simples. A essência da técnica envolve a geração de íons que são depois detectados. A sofisticação surge nos métodos que são usados para a geração desses mesmos íons e no modo de analisá-los (43).

Uma das técnicas de ionização em maior expansão é a electrospray, a qual passou por duas fases distintas de investigação e de desenvolvimento. A primeira decorreu antes de 1970 e centrou-se mais nos aspectos fundamentais do processo de produção de carga (44). A segunda fase se deu a partir de 1970 com destaque para o trabalho desenvolvido em 1984 por Yamashita e Fenn (45). A partir deste trabalho, houve um crescimento notório da técnica com o desenvolvimento e construção de fontes iônicas comercializáveis.

Há essencialmente quatro características que tornam esta técnica versátil em relação a outras técnicas de ionização. A primeira é a capacidade de produzir íons com número de cargas elevado, reduzindo assim a razão $\mathrm{m} / \mathrm{z}$ de tal modo que seja possível analisar compostos de elevada massa molecular de até centenas de kDa em praticamente todo o tipo de analisadores. Em segundo lugar, as amostras a serem 
analisadas devem ser introduzidas em solução, o que faz com que seja possível o acoplamento com muitas técnicas de separação. A terceira característica refere-se à baixa fragmentação do íon molecular e, por último, trata-se de uma técnica de ionização suave permitindo que as interações não covalentes entre moléculas que existem em solução sejam preservadas na fase gasosa (46). No entanto, um dos grandes problemas no electrospray é a falta de linearidade da intensidade do pico em função da concentração. A seção linear do electrospray trabalha em uma faixa de concentração de $10^{-6}$ a $10^{-3} \mathrm{~mol} \mathrm{~L}^{-1}$. Todavia, esta linearidade pode ser prejudicada se outros eletrólitos estiverem presentes na solução. 
OBJETIVOS 
Em razão da escassez de trabalhos na literatura que abordem aspectos mecanísticos da reação de oxidação da imipramina e a intensa exploração da modificação química da superfície de eletrodos para a determinação da dopamina, este trabalho tem por objetivo geral introduzir a utilização do eletrodo compósito grafitepoliuretana como uma alternativa para o estudo mecanístico e analítico destes compostos. A etapa experimental desta tese está dividida em 8 etapas:

1 - Estudo voltamétrico da imipramina: consiste em testes preliminares para verificar que material de eletrodo resulta no melhor perfil voltamétrico e, por conseguinte, em uma maior sensibilidade analítica. Com a escolha do eletrodo de trabalho, serão realizados experimentos para avaliar o grau de reversibilidade da reação, estimar o número de elétrons e prótons envolvidos e também verificar a presença ou não de processos de adsorção na superfície do eletrodo.

2 - Determinação analítica da imipramina em comprimidos de Tofranil $^{\circledR}$ : nesta etapa, será desenvolvida uma nova metodologia analítica pela aplicação do eletrodo de GPU e da técnica de voltametria de onda quadrada para análise de rotina em comprimidos de Tofranil $^{\circledR}$ no próprio eletrólito de suporte. A técnica de HPLC será empregada para avaliar a potencialidade da metodologia eletroanalítica desenvolvida.

\section{3 - Determinação analítica da imipramina em amostras de soro sintético: A} possibilidade de aplicação da metodologia GPU/SWV em amostra de soro sintético será avaliada em termos de sensibilidade e seletividade.

4 - Estudo mecanístico da reação de oxidação da imipramina: por meio do mapa de potencial eletrostático, da representação gráfica dos orbitais moleculares, do cálculo 
das cargas atômicas, de eletrólises a potencial controlado e da identificação dos produtos de eletrólise por espectrometria de massa com ionização por electrospray, especular o provável mecanismo da reação de oxidação da imipramina que poderá, no futuro, servir de base para o esclarecimento da ação biológica deste antidepressivo.

5 - Estudo voltamétrico da dopamina: este estudo será realizado da mesma maneira que o relatado para a molécula de imipramina (etapa 1).

6 - Desenvolvimento de metodologia analítica para a determinação de dopamina em fluído cerebrospinal sintético: uma nova metodologia analítica será desenvolvida pela utilização da técnica de voltametria de onda quadrada com eletrodo de GPU para a análise de dopamina. A sensibilidade e a seletividade serão diagnosticas para avaliar a possibilidade de aplicação do método em amostra de fluído cerebrospinal sintético.

7 - Determinação analítica da dopamina em ampolas de Revivan $^{\circledR}$ : aplicar a metodologia desenvolvida na etapa 6 para a análise de rotina de dopamina em ampolas do medicamento Revivan ${ }^{\circledR}$.

8 - Estudo químico-quântico da dopamina: apesar do mecanismo de oxidação da dopamina estar relatado na literatura, avaliar os possíveis sítios de oxidação e de redução da molécula pela aplicação de cálculos químico-quânticos. 
CAPÍTULO II - MATERIAIS E MÉTODOS 


\section{II.1- CÉLULAS ELETROQUÍMICAS}

Os experimentos de voltametria cíclica e de onda quadrada foram realizados em uma célula convencional de vidro Pyrex ${ }^{\circledR}$, como a representada na Figura 9 (I). A célula tem capacidade para $10 \mathrm{~mL}$ e é equipada com uma tampa em Teflon ${ }^{\circledR}$, contendo orifícios para o posicionamento dos eletrodos de trabalho, referência e auxiliar.

(I)

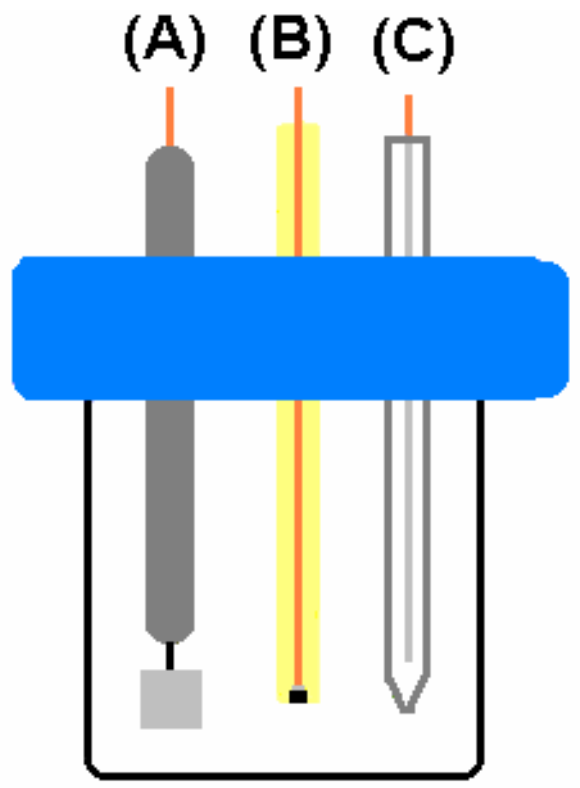

(II)

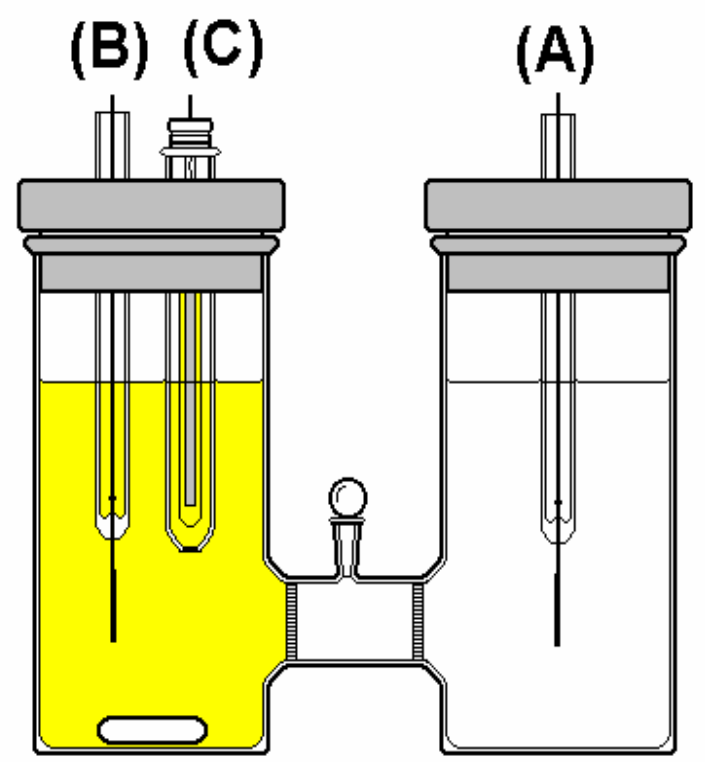

Figura 9 - Representação da célula eletroquímica: (I) experimentos voltamétricos e (II) experimentos de eletrólise a potencial controlado, mostrando (A) Eletrodo auxiliar, (B) Eletrodo de trabalho e (C) Eletrodo de referência.

Nos experimentos de eletrólise a potencial controlado, foi utilizada uma célula eletroquímica como a mostrada na Figura 9 (II), com dois compartimentos para $10 \mathrm{~mL}$, sendo um deles para o posicionamento do eletrodo auxiliar e o segundo contendo o eletrodo de trabalho e o de referência. Os dois compartimentos são separados por placas de vidro sinterizado de porosidade média. 


\section{II.2- REAGENTES E SOLUÇÕES}

\section{II.2.1- Reagentes}

Todos os reagentes utilizados nos experimentos são de pureza analítica (PA) e foram usados sem purificação prévia. Na Tabela II, são apresentadas as suas procedências. A água utilizada para a preparação das soluções foi purificada em sistema Milli-Q da Millipore ${ }^{\circledR}$.

Tabela II - Procedência e pureza dos reagentes utilizados.

\begin{tabular}{|c|c|c|c|}
\hline Reagentes & Fórmula química & Procedência & Pureza (\%) \\
\hline $\begin{array}{c}\text { Ácido acético } \\
\text { Ácido aspártico } \\
\text { Ácido bórico } \\
\text { Ácido ascórbico } \\
\text { Ácido fosfórico } \\
\text { Alanina } \\
\text { Álcool etílico absoluto anidro } \\
\text { Arginina } \\
\text { Cisteína } \\
\text { Bicarbonato de sódio } \\
\text { Cloreto de cálcio } \\
\text { Cloreto de potássio } \\
\text { Cloreto de sódio } \\
\text { Cloridrato de amitriptilina } \\
\text { Cloridrato de desipramina } \\
\text { Cloridrato de dopamina } \\
\text { Cloridrato de imipramina } \\
\text { Fenilalanina } \\
\text { Glicina } \\
\text { Glicose } \\
\text { Hidróxido de sódio } \\
\text { Histidina } \\
\text { Lisina } \\
\text { Nitrato de prata } \\
\text { Perclorato de sódio } \\
\text { Serina } \\
\text { Tirosina } \\
\text { Triptofano } \\
\text { Uréia }\end{array}$ & $\begin{array}{c}\mathrm{CH}_{3} \mathrm{COOH} \\
\mathrm{C}_{4} \mathrm{H}_{7} \mathrm{NO}_{4} \\
\mathrm{H}_{3} \mathrm{BO}_{3} \\
\mathrm{C}_{6} \mathrm{H}_{8} \mathrm{O}_{6} \\
\mathrm{H}_{3} \mathrm{PO}_{4} \\
\mathrm{C}_{3} \mathrm{H}_{7} \mathrm{NO}_{2} \\
\mathrm{C}_{2} \mathrm{H}_{5} \mathrm{OH} \\
\mathrm{C}_{6} \mathrm{H}_{14} \mathrm{~N}_{4} \mathrm{O}_{2} \\
\mathrm{C}_{3} \mathrm{H}_{7} \mathrm{NO}_{2} \mathrm{~S} \\
\mathrm{NaHCO}_{3} \\
\mathrm{CaCl} \mathrm{H}_{2} \\
\mathrm{KCl} \\
\mathrm{NaCl}_{\mathrm{C}_{20} \mathrm{H}_{23} \mathrm{~N} \mathrm{HCl}} \\
\mathrm{C}_{18} \mathrm{H}_{21} \mathrm{~N}_{2} \cdot \mathrm{HCl} \\
\mathrm{C}_{8} \mathrm{H}_{11} \mathrm{NO}_{2} \cdot \mathrm{HCl} \\
\mathrm{C}_{19} \mathrm{H}_{24} \mathrm{~N}_{2} \cdot \mathrm{HCl} \\
\mathrm{C}_{9} \mathrm{H}_{11} \mathrm{NO}_{2} \\
\mathrm{NH}_{2} \mathrm{CH}_{2} \mathrm{COOH} \\
\mathrm{C}_{6} \mathrm{H}_{12} \mathrm{O}_{6} \\
\mathrm{NaOH}_{4} \\
\mathrm{C}_{6} \mathrm{H}_{9} \mathrm{~N}_{3} \mathrm{O}_{2} \\
\mathrm{C}_{6} \mathrm{H}_{14} \mathrm{~N}_{2} \mathrm{O}_{2} \\
\mathrm{AgNO}_{3} \\
\mathrm{NaClO}_{4} \\
\mathrm{C}_{3} \mathrm{H}_{7} \mathrm{NO}_{3} \\
\mathrm{C}_{9} \mathrm{H}_{11} \mathrm{NO}_{3} \\
\mathrm{C}_{11} \mathrm{H}_{12} \mathrm{~N}_{2} \mathrm{O}_{2} \\
\mathrm{CH}_{4} \mathrm{~N}_{2} \mathrm{O}\end{array}$ & $\begin{array}{c}\text { Merck } \\
\text { Sigma } \\
\text { Reagen } \\
\text { Synth } \\
\text { Synth } \\
\text { Sigma } \\
\text { J.T. Baker } \\
\text { Aldrich } \\
\text { Merck } \\
\text { Merck } \\
\text { Merck } \\
\text { Merck } \\
\text { Synth } \\
\text { Sigma } \\
\text { Sigma } \\
\text { Sigma } \\
\text { Sigma } \\
\text { Aldrich } \\
\text { Aldrich } \\
\text { Riedel-de Haën } \\
\text { Synth } \\
\text { Sigma } \\
\text { Merck } \\
\text { Merck } \\
\text { Riedel-de Haën } \\
\text { Sigma } \\
\text { Synth } \\
\text { Aldrich } \\
\text { Sigma }\end{array}$ & $\begin{array}{l}99,8 \\
99,0 \\
98,0 \\
99,0 \\
85,0 \\
99,0 \\
99,9 \\
98,0 \\
99,0 \\
99,5 \\
99,0 \\
99,5 \\
99,9 \\
99,0 \\
99,0 \\
99,0 \\
99,0 \\
98,0 \\
98,5 \\
99,5 \\
97,0 \\
99,0 \\
99,0 \\
99,8 \\
99,0 \\
99,0 \\
98,0 \\
98,0 \\
99,5\end{array}$ \\
\hline
\end{tabular}




\section{II.2.2- Soluções}

\section{II.2.2.1- Solucão tampão}

A solução tampão Britton Robinson (BR) $0,10 \mathrm{~mol} \mathrm{~L}^{-1}$ foi preparada a partir dos ácidos acético $\left(0,04 \mathrm{~mol} \mathrm{~L}^{-1}\right)$, fosfórico $\left(0,04 \mathrm{~mol} \mathrm{~L}^{-1}\right)$ e bórico $\left(0,04 \mathrm{~mol} \mathrm{~L}^{-1}\right)$ e do perclorato de sódio $\left(0,10 \mathrm{~mol} \mathrm{~L}^{-1}\right)$. O valor de $\mathrm{pH}$ desejado em cada experimento foi ajustado pela adição de uma solução de hidróxido de sódio 1,00 mol L-1.

\section{II.2.2.2- Solucão estoque de imipramina}

A solução estoque de imipramina $3,10 \times 10^{-3} \mathrm{~mol} \mathrm{~L}^{-1}$ foi preparada em meio de etanol para total solubilização do composto e conservada sob a proteção da luz.

\section{$\underline{\text { II.2.2.3- Solução estoque de Tofranil }^{\circledR}}$}

A solução estoque de Tofranil $^{\circledR}$ foi preparada por meio da diluição, em etanol, de um comprimido para resultar em um estoque contendo nominalmente $3,16 \times 10^{-3} \mathrm{~mol} \mathrm{~L}^{-1}$ do princípio ativo.

\section{II.2.2.4- Solução estoque de dopamina}

A solução estoque de dopamina $2,08 \times 10^{-3} \mathrm{~mol} \mathrm{~L}^{-1}$ foi preparada pela solubilização da massa correspondente em tampão BR 0,10 mol L-1 $(\mathrm{pH} 2,0$ e pH 7,0). 


\section{II.2.2.5- Solução estoque de Revivan ${ }^{\circledR}$}

A solução estoque de $\operatorname{Revivan}{ }^{\circledR}$ foi preparada por meio de diluição simples em tampão BR $0,10 \mathrm{~mol} \mathrm{~L}^{-1}(\mathrm{pH} \mathrm{2,0)}$ para resultar em um estoque contendo nominalmente $2,00 \times 10^{-3} \mathrm{~mol} \mathrm{~L}^{-1}$ do princípio ativo.

\section{II.2.2.6- Solucão do fluído cerebrospinal sintético}

A solução do fluído cerebrospinal sintético $(\mathrm{pH} 7,4)$ foi preparada de acordo com os constituintes majoritários propostos por Oser (47) e Zhang (48), adicionando 2,15 $\mathrm{g}$ de NaCl, 7,50 $\times 10^{-2} \mathrm{~g}$ de $\mathrm{KCl}, 8,20 \times 10^{-2} \mathrm{~g}$ de $\mathrm{CaCl}_{2}, 0,23 \mathrm{~g}$ de glicose, 0,44 $\mathrm{g}$ de $\mathrm{NaHCO}_{3}$ e 2,00 × $10^{-2} \mathrm{~g}$ de uréia em um balão volumétrico de $250 \mathrm{~mL}$.

\section{I1.2.2.7- Solucão do soro humano sintético}

As amostras de soro sintético $(\mathrm{pH} \mathrm{7,6)}$ foram preparadas de acordo com o proposto por Parham (49), adicionando $1,27 \mathrm{~g}$ de $\mathrm{NaCl}, 0,16 \mathrm{~g}$ de $\mathrm{NaHCO}_{3}, 2,6 \times 10^{-3} \mathrm{~g}$ de glicina, $3,50 \times 10^{-3} \mathrm{~g}$ de triptofano, $3,70 \times 10^{-3} \mathrm{~g}$ de tirosina, $3,20 \times 10^{-3} \mathrm{~g}$ de serina, $6,60 \times 10^{-3} \mathrm{~g}$ de fenilalanina, $9,10 \times 10^{-3} \mathrm{~g}$ de lisina, $6,30 \times 10^{-3} \mathrm{~g}$ de histidina, $2,90 \times 10^{-2} \mathrm{~g}$ de ácido aspártico, $1,00 \times 10^{-2} \mathrm{~g}$ de arginina e $9,10 \times 10^{-3} \mathrm{~g}$ de alanina. 


\section{II.3- ELETRODOS}

\section{II.3.1- Eletrodos de trabalho}

Vários eletrodos de trabalho foram utilizados, dentre eles o de ouro, de platina e de carbono vítreo com o objetivo de comparar a resposta analítica dos compostos estudados com o eletrodo compósito grafite-poliuretana (GPU).

Todos os eletrodos mencionados foram construídos no próprio laboratório e consistiram do isolamento do disco de platina $\left(\phi=0,50 \mathrm{~mm}, A_{\text {geo }}=1,96 \times 10^{-3} \mathrm{~cm}^{2}\right)$ e de ouro $\left(\phi=1,00 \mathrm{~mm}, \mathrm{~A}_{\text {geo }}=7,85 \times 10^{-3} \mathrm{~cm}^{2}\right)$ em um tubo de vidro, conectados a um fio de cobre com o auxílio de epóxido de prata. O cilindro de carbono vítreo $(\phi=5,00 \mathrm{~mm}$, $A_{\text {geo }}=0,19 \mathrm{~cm}^{2}$ ) foi inserido na extremidade de um tubo de Teflon ${ }^{\circledR}$ e o contato elétrico foi feito por um fio de cobre. Os eletrodos foram submetidos a um tratamento superficial prévio com lixa de granulação 1500, seguido do polimento com suspensões de alumina de 0,25 $\mu \mathrm{m}$ e 0,05 $\mu \mathrm{m}$ em uma politriz motorizada Struers modelo DPU-10 até se obter uma superfície espelhada, no caso do eletrodo de carbono vítreo.

O eletrodo compósito grafite(60\%) poliuretana foi construído pela conexão de tarugos de comprimento $1,00 \mathrm{~cm}$ e diâmetro $3,00 \mathrm{~mm}\left(A_{\text {geo }}=0,07 \mathrm{~cm}^{2}\right)$, cedido gentilmente pelo Prof. Dr. Éder Tadeu Gomes Cavalheiro, a um fio de cobre por meio de cola de epóxido de prata. O conjunto foi então inserido em um tubo de vidro de 0,40 cm de diâmetro e 7,00 cm de comprimento. A extremidade contrária ao compósito foi selada com um tarugo de Teflon $^{\circledR}$. Este artifício permitiu que a resina de poliéster fosse adicionada e preenchesse devidamente o interior do tubo, como mostrado na Figura 10. Após o processo de cura da resina, que durou 24 horas, o eletrodo pôde ser facilmente 
descolado do interior do tubo de vidro. O excesso de resina foi removido com uma lixa de granulação 600 para expor o compósito. O polimento foi feito em feltro umedecido com água, pois a utilização de suspensão de alumina promovia a adesão de partículas na superfície do eletrodo, tornando dispendiosa a etapa de polimento.

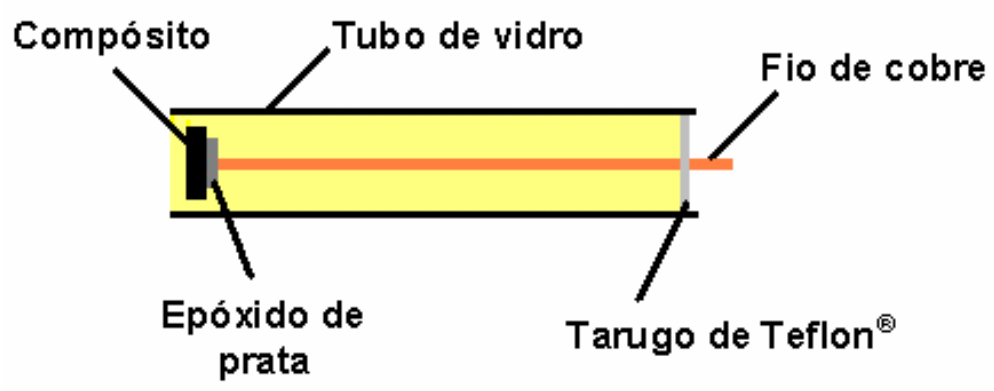

Figura 10 - Representação da construção do eletrodo compósito.

$\mathrm{Na}$ ausência de uma placa do compósito com área suficientemente grande para a realização do experimento de eletrólise a potencial controlado, optou-se por utilizar uma placa de platina de área geométrica igual a 4,20 $\mathrm{cm}^{2}$. A limpeza deste eletrodo foi feita em solução de ácido nítrico 1:1 pela polarização em potenciais suficientes para o desprendimento de $\mathrm{H}_{2}$ e $\mathrm{O}_{2}$.

\section{II.3.2- Eletrodo de referência}

O eletrodo de referência utilizado nos experimentos consistia de um fio de prata anodizado imerso em solução de $\mathrm{AgCl}$ e $\mathrm{KCl} 3,00 \mathrm{~mol} \mathrm{~L}^{-1}$ em meio aquoso $(\mathrm{Ag} / \mathrm{AgCl} / \mathrm{KCl})$. 


\section{II.3.3- Eletrodo auxiliar}

Como eletrodo auxiliar foi utilizada uma placa de platina de área $1,00 \mathrm{~cm}^{2}$.

\section{II.4- METODOLOGIA}

\section{II.4.1- Voltametria cíclica}

A técnica de voltametria cíclica foi empregada para o estudo preliminar da oxidação da imipramina e da dopamina. De início, os experimentos consistiram em testes com diferentes eletrodos, no intervalo de potencial adequado a cada um, com o intuito de avaliar a resposta voltamétrica. Com o eletrodo compósito foram variados os seguintes parâmetros: $\mathrm{pH}$ e velocidade de varredura. Nestes experimentos os voltamogramas cíclicos foram registrados no intervalo de -500 a $1100 \mathrm{mV}$ para a imipramina e de 0 a $800 \mathrm{mV}$ para a dopamina.

A instrumentação empregada consistiu de um Analisador polarográfico EG\&G Princeton Applied Research modelo 174 A conectado a um microcomputador IBM-PC, dotado de uma interface Analógica/Digital Digital/Analógica desenvolvida pelo próprio laboratório, sendo os experimentos realizados pelo uso do software AVOLM (analisador voltamétrico) em linguagem Visual Basic, também desenvolvido no grupo de pesquisa. A célula eletroquímica foi acondicionada no interior de uma gaiola de Faraday, construída com chapas de alumínio de 2,00 mm de espessura, para minimizar a captação de ruídos. 


\section{II.4.2- Voltametria de onda quadrada}

A técnica voltametria de onda quadrada foi utilizada para a extração de informações adicionais para o estudo da reação de oxidação da imipramina e da dopamina, bem como para o desenvolvimento de metodologia analítica. Os experimentos foram realizados com o eletrodo compósito e caracterizaram-se pelo estudo da variação dos parâmetros da técnica, dentre eles, a freqüência de aplicação dos pulsos de potencial, a amplitude e o incremento de varredura. Os voltamogramas de onda quadrada foram registrados no mesmo intervalo de potenciais que em voltametria cíclica.

O Potenciostato/Galvanostato EG\&G Princeton Applied Research modelo 283, com o software também proveniente da PAR foram empregados nos experimentos.

\section{II.4.3- Eletrólise a potencial controlado}

A técnica de eletrólise a potencial controlado foi empregada para a determinação do número de elétrons envolvidos na reação de oxidação da imipramina e também para gerar produtos de reação com o intuito de especular o mecanismo de oxidação deste antidepressivo. Para estes experimentos, utilizou-se o Potenciostato/Galvanostato EG\&G Princeton Applied Research modelo 283.

\section{II.4.4- Cálculo dos orbitais moleculares}

O método semi-empírico PM3 (Parametric Model 3), encontrado no programa computacional AMPAC 6.5, foi utilizado na otimização da geometria molecular da 
imipramina e da dopamina, bem como no cálculo das cargas atômicas derivadas do potencial eletrostático. A representação gráfica do HOMO (orbital molecular de mais alta energia ocupado), do LUMO (orbital molecular de mais baixa energia desocupado) e o mapa do potencial eletrostático foram calculados utilizando o programa Spartan 5.0.

\section{II.4.5- Espectrometria de massa com ionização por electrospray}

As medidas foram realizadas em um espectrômetro de massa Micromass Quattro LC (UK - England) equipado com um analisador quadrupolo triplo MS. Os dados foram coletados pela introdução direta da solução da amostra (Metanol/ $\mathrm{H}_{2} \mathrm{O}$ 70/30 v/v) dentro da fonte de íons.

\section{II.4.6- Espectrofotometria de absorção UV}

Os espectros de absorção óptica foram obtidos em um espectrofotômetro HITACHI U-2001 acoplado a um microcomputador IBM-PC com o software Spectracalc (Galactic Ind. Co.), sendo registrados no intervalo de 230 a $330 \mathrm{~nm}$ para a imipramina e de 250 a $330 \mathrm{~nm}$ para a dopamina. As cubetas utilizadas nos experimentos possuíam caminho óptico igual a $1,00 \mathrm{~cm}$.

\section{II.4.7- Cromatografia Líquida de Alta Eficiência}

As medidas foram realizadas em um cromatógrafo Shimadzu, contendo duas bombas modelo LC-10, com um detector SPD-10Avp e um forno CTO-10Asvp. A coluna utilizada foi a de marca Zorbax Eclipse XDB-C18 $(2,10 \mathrm{~mm} ; 150 \mathrm{~mm} ; 5 \mu \mathrm{m})$ Agilent Technologies. A fase móvel era constituída de uma mistura de $70 \%$ de acetonitrina e 
$30 \%$ de tampão acetato de amônio $0,10 \mathrm{~mol} \mathrm{~L}^{-1}(\mathrm{pH} 5,0)$. A vazão da fase móvel era de $1,00 \mathrm{~mL} \min ^{-1}$ e a detecção da imipramina foi realizada em $220 \mathrm{~nm}$. O volume de amostra injetado foi igual a $20 \mu \mathrm{L}$ e a temperatura do forno era de $40^{\circ} \mathrm{C}$.

\section{II.4.8- Medidas de pH}

Nas medidas de $\mathrm{pH}$, foi empregado um titulador automático da Methrom modelo 682 com um eletrodo de vidro. A calibração do aparelho é realizada diariamente, utilizando-se uma solução tampão citrato-ácido clorídrico ( $\mathrm{pH} 4,0)$ e uma solução tampão fosfato ( $\mathrm{pH} 7,0)$, ambas comerciais. 
CAPÍTULO III - RESULTADOS E DISCUSSÃO 


\section{III.1- ESTUDO VOLTAMÉTRICO DA IMIPRAMINA (50)}

\section{III.1.1 - Voltametria cíclica \\ III.1.1.1- Teste de eletrodos}

O estudo preliminar da reação de oxidação da imipramina consistiu em testes para avaliar o perfil voltamétrico com diferentes eletrodos e compará-los com o eletrodo compósito de grafite poliuretana, verificando assim a possibilidade de aplicação deste eletrodo no decorrer dos estudos voltamétricos, como também no desenvolvimento de metodologia analítica. Na Figura 11, são apresentados os voltamogramas cíclicos registrados com os seguintes eletrodos de trabalho: (I) ouro ( $\phi=1,00 \mathrm{~mm}, \mathrm{~A}_{\mathrm{geo}}=7,85 \mathrm{x}$ $\left.10^{-3} \mathrm{~cm}^{2}\right)$; (II) platina $\left(\phi=0,50 \mathrm{~mm}, \mathrm{~A}_{\text {geo }}=1,96 \times 10^{-3} \mathrm{~cm}^{2}\right)$; (III) carbono vítreo $\left(\phi=5,00 \mathrm{~mm}, A_{\text {geo }}=0,19 \mathrm{~cm}^{2}\right)$ e (IV) compósito grafite poliuretana $(\phi=3,00 \mathrm{~mm}$, $\left.A_{\text {geo }}=0,07 \mathrm{~cm}^{2}\right)$.

É possível observar que a oxidação da imipramina inicia-se na mesma região de potenciais para todos os eletrodos $(700 \mathrm{mV})$. No entanto, verifica-se que, para os eletrodos de ouro e de platina, a oxidação eletroquímica ocorre na mesma região de potenciais em que há a formação de seus respectivos óxidos, resultando na dificuldade de análise da reação de oxidação do composto. Quanto aos eletrodos de carbono vítreo e do compósito de grafite-poliuretana, respostas voltamétricas bem mais definidas na região de potenciais entre 700 a $1200 \mathrm{mV}$, além de um pico de redução em $44 \mathrm{mV}$ na varredura reversa de potencial, foram obtidos. Com base nesses resultados, o eletrodo 
compósito foi escolhido como eletrodo de trabalho por conciliar o melhor perfil voltamétrico e a maior sensibilidade analítica.
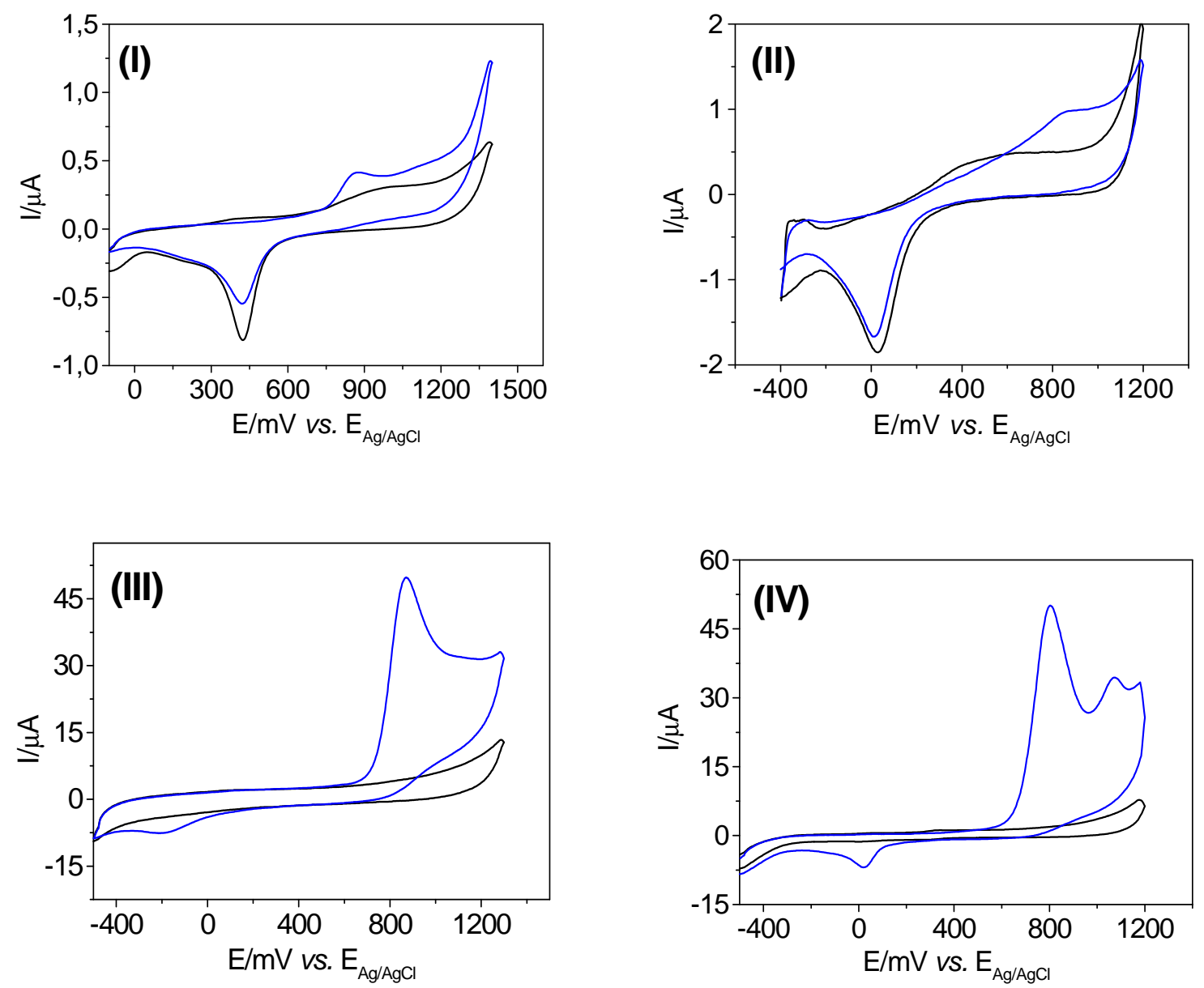

Figura 11 - Voltamogramas cíclicos: $(-)$ tampão $\mathrm{BR} \quad 0,10 \mathrm{~mol} \mathrm{~L}^{-1}(\mathrm{pH} 7,0)$ e $(-)$ solução de imipramina $2,34 \times 10^{-4} \mathrm{~mol} \mathrm{~L}^{-1}$ em tampão BR $0,10 \mathrm{~mol} \mathrm{~L}^{-1}(\mathrm{pH} \mathrm{7,0)}$. Eletrodos de trabalho: (I) ouro; (II) platina; (III) carbono vítreo e (IV) compósito grafite-poliuretana. $v=100 \mathrm{mV} \mathrm{s}^{-1}$. 


\section{III.1.1.2- Perfil voltamétrico da imipramina}

Com a escolha do eletrodo de trabalho, o perfil voltamétrico da imipramina foi registrado por meio de sucessivas ciclagens de potencial, como mostrado na Figura 12. No primeiro ciclo, na região de potenciais entre 700 a $1200 \mathrm{mV}$, é possível observar a presença de 2 picos, em $789 \mathrm{mV}$ e $1055 \mathrm{mV}$, respectivamente. O primeiro pico é atribuído à oxidação irreversível da imipramina (9) e o segundo, não relatado na literatura, pode estar relacionado possivelmente a um pós-pico de adsorção (51). Na varredura reversa de potencial, há um pico em $24 \mathrm{mV}$ atribuído à formação de um dímero (9), o qual é oxidado no segundo ciclo em $100 \mathrm{mV}$.

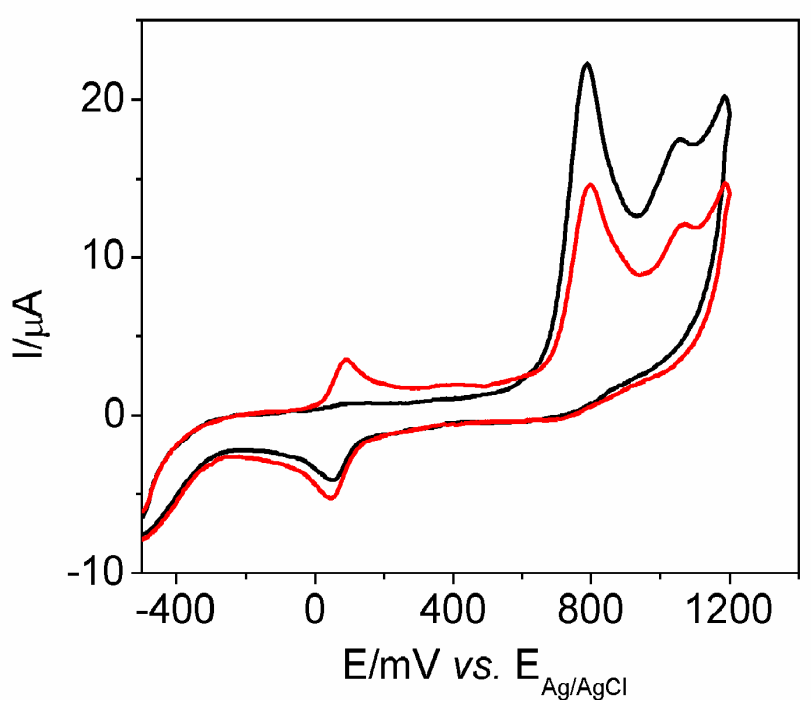

Figura 12 - Voltamogramas cíclicos: $(-) 1^{\circ}$ ciclo e $(-) 2^{\circ}$ ciclo de uma solução de imipramina $1,06 \times 10^{-4} \mathrm{~mol} \mathrm{~L}^{-1}$ em tampão $\mathrm{BR} 0,10 \mathrm{~mol} \mathrm{~L}^{-1}(\mathrm{pH} \mathrm{7,0)}$. Eletrodo de trabalho: compósito grafitepoliuretana. $\mathrm{v}=100 \mathrm{mV} \mathrm{s}^{-1}$. 


\section{III.1.1.3- Variação da velocidade de varredura}

O experimento de variação da velocidade de varredura foi realizado no intervalo de 10 a $500 \mathrm{mV} \mathrm{s}^{-1}$, com o objetivo de avaliar o grau de reversibilidade e a natureza do transporte do material eletroativo para a superfície do eletrodo. Na Figura 13, são apresentados os voltamogramas cíclicos de uma solução de imipramina 2,34 x 10-4 $\mathrm{mol} \mathrm{L}^{-1}$ em tampão BR $0,10 \mathrm{~mol} \mathrm{~L}^{-1}(\mathrm{pH} \mathrm{7,0)} \mathrm{em} \mathrm{diferentes} \mathrm{velocidades} \mathrm{de}$ varredura e a Tabela III contém os valores das correntes e dos potenciais de pico para a oxidação da imipramina e para o pico de redução do dímero. Com o objetivo de se evitar a passivação do eletrodo pela adsorção de produtos de reação, os voltamogramas cíclicos para diferentes velocidades de varredura foram obtidos efetuando-se o polimento em feltro umedecido com água a cada medida.
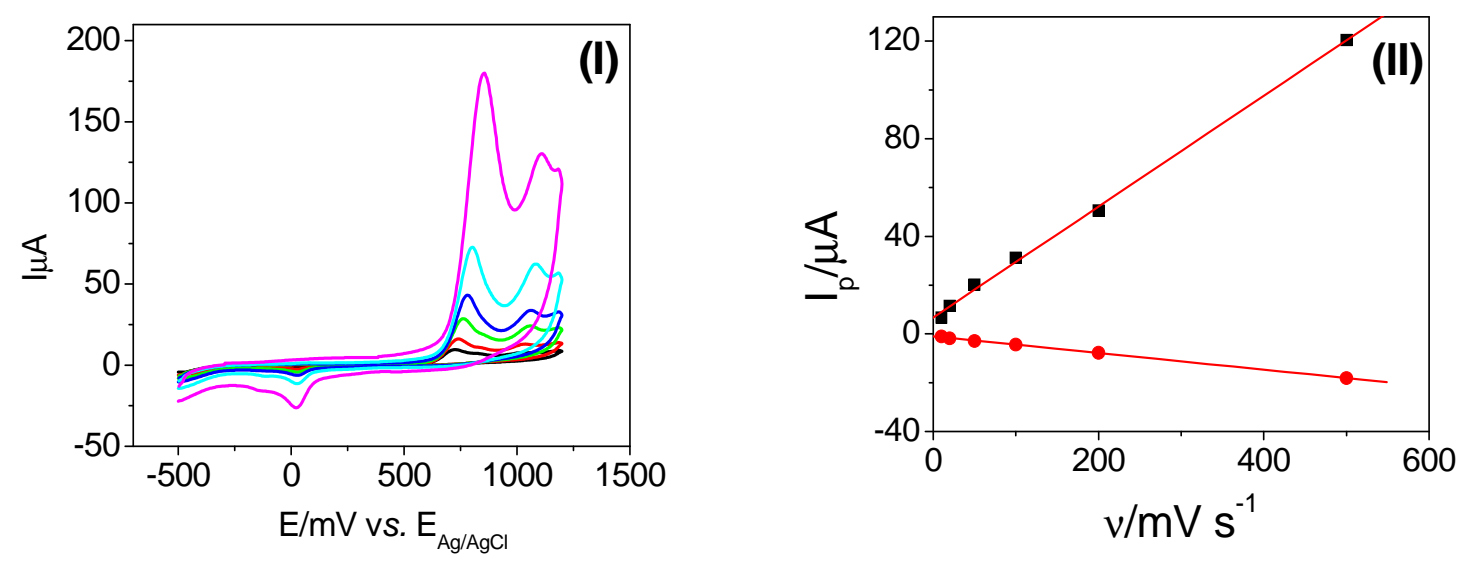

Figura 13 - (I) Voltamogramas cíclicos de uma solução de imipramina $2,34 \times 10^{-4} \mathrm{~mol} \mathrm{~L}^{-1} \mathrm{em}$ tampão BR

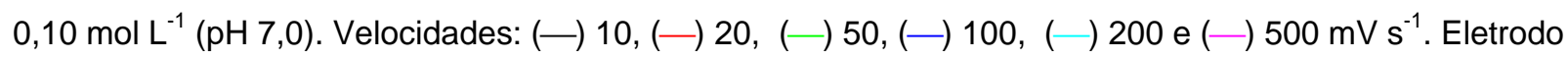
de trabalho: compósito grafite-poliuretana. (II) Gráficos de $I_{p} v s . v$ para: (-) pico de oxidação da imipramina $(R=0,9992)$ e $(\bullet)$ pico de redução do dímero $(R=0,9994)$. 
Tabela III - Valores de corrente de pico $\left(I_{p}\right)$ e dos potenciais de pico $\left(E_{p}\right)$ para a oxidação da imipramina e redução do dímero.

\begin{tabular}{c|c|c|c|c}
\hline$v$ & $I_{p} / \mu A$ & $E_{p} / m V$ & $I_{p} / \mu A$ \\
$\left(m^{\prime} ~ s^{-1}\right)$ & $(I M I)$ & $(I M I)$ & $E_{p} / m V$ \\
(DÍMERO) & (DÍMERO) \\
\hline 10 & 6,68 & 734 & $-1,01$ & 17 \\
20 & 11,49 & 741 & $-1,84$ & 20 \\
50 & 20,17 & 765 & $-2,96$ & 20 \\
100 & 31,17 & 791 & $-4,38$ & 24 \\
200 & 50,57 & 819 & $-7,71$ & 27 \\
500 & 120,45 & 857 & $-18,10$ & 27 \\
\hline
\end{tabular}

No intervalo de velocidade estudado, verificou-se que a imipramina se oxida irreversivelmente pela ausência de pico na varredura reversa de potencial e também pelo deslocamento dos potenciais de pico com o aumento da velocidade de varredura. Pelo critério $\left|E_{p}-E_{p / 2}\right|=48 / n \alpha$, foi possível calcular o valor de n $\alpha$ como sendo igual a 0,74, com $n$ referindo-se ao número de elétrons envolvidos na reação e $\alpha$ ao coeficiente de transferência de carga, que constitui uma medida da simetria da barreira de energia de ativação, aproximando-se de 0,50 para um condutor metálico e para um processo reversível simples de transferência de elétron (33).

Como foi registrada a primeira varredura para cada velocidade após o polimento em feltro, o pico de oxidação do dímero não foi detectado, desta forma, a constatação da reversibilidade do processo redox relativo ao dímero se deu pela pequena variação do potencial de pico com o aumento da velocidade de varredura. 
A natureza do transporte de massa que governa os processos redox estudados pôde ser conhecida pela relação existente entre $I_{p} v s . v$, as quais são mostradas na Figura 13 (II). A relação linear entre $I_{p} v s . v$, para ambos os processos, são indicativos de que a etapa determinante da velocidade é controlada pela adsorção de moléculas de imipramina e do dímero na superfície do eletrodo. Os valores dos coeficientes angulares $(\theta)$ dos gráficos de $\log \left(I_{p}\right)$ vs. $\log (v)$, mostrados na Figura 14, confirmam a natureza do transporte de massa, que segundo a literatura é igual a 0,50 para processos difusionais e aproxima-se de 1 para processos controlados por adsorção (52).

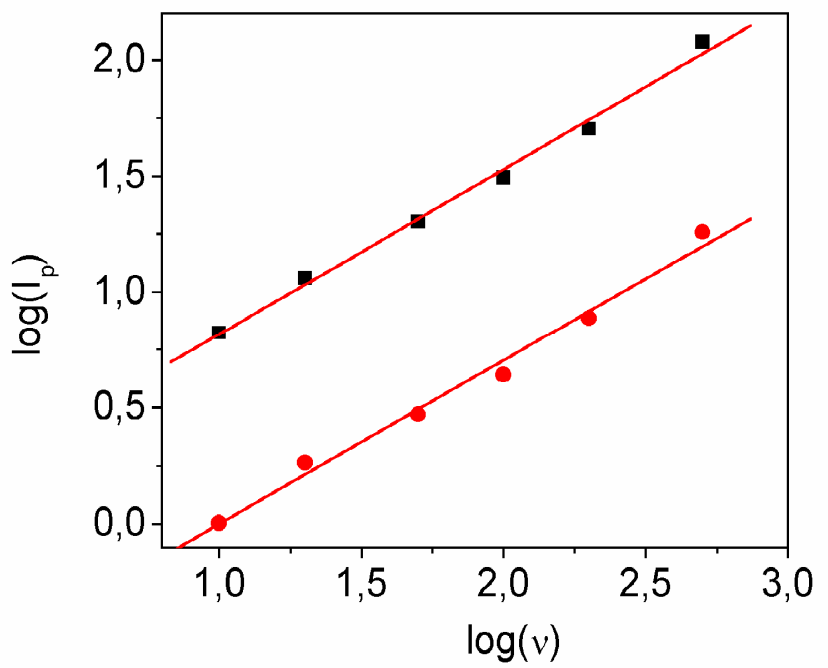

Figura 14 - Gráficos de $\log (v)$ vs. $\log \left(I_{p}\right)$ para: (匹) pico de oxidação da imipramina $(\theta=0,71$ e $R=0,9967) . e(\bullet)$ pico de redução do dímero $(\theta=0,70$ e $R=0,9941)$.

\section{III.1.1.4- Eletrólise a potencial controlado}

A técnica eletrólise a potencial controlado foi utilizada para determinar o número de elétrons envolvidos na oxidação da imipramina e conseqüentemente calcular o valor do coeficiente de transferência de carga $(\alpha)$. 
Os experimentos foram realizados à temperatura ambiente, em um potencial mais positivo $(E=1000 \mathrm{mV})$ do que o potencial de pico da imipramina $\left(E_{p}=810 \mathrm{mV}\right)$ determinado por voltametria cíclica. Na Figura 15 (I), é possível observar o decaimento da corrente com o tempo após a aplicação de potencial constante durante 1200 segundos.
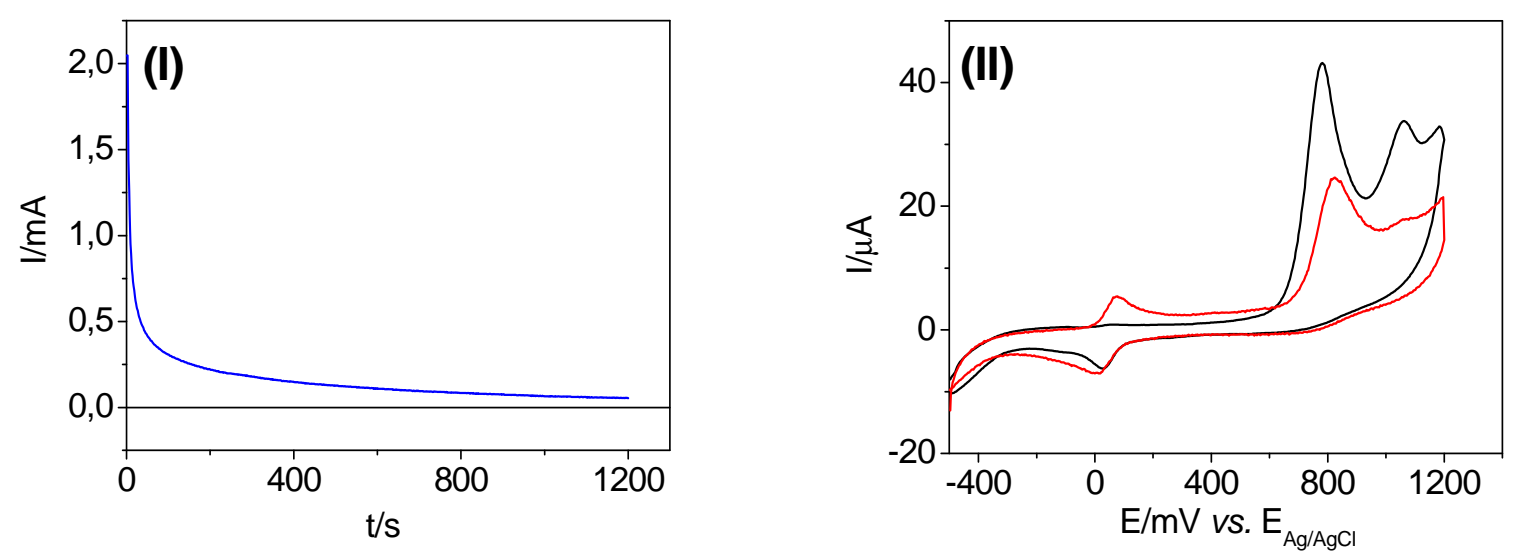

Figura 15 - (I) Decaimento da corrente com o tempo. Eletrodo de trabalho: placa de platina $\left(\mathrm{A}_{\text {geo }}=4,20 \mathrm{~cm}^{2}\right)$. (II) Voltamogramas cíclicos de uma solução de imipramina $2,34 \times 10^{-4} \mathrm{~mol} \mathrm{~L}^{-1} \mathrm{em}$ tampão BR 0,10 $\mathrm{mol} \mathrm{L}^{-1}(\mathrm{pH} 7,0),(-)$ antes da eletrólise e $(-)$ após $1200 \mathrm{~s}$ de eletrólise. Eletrodo de trabalho: compósito grafite-poliuretana.

$\mathrm{Na}$ Figura 15, são apresentados os voltamogramas cíclicos antes e após a eletrólise, mostrando o decaimento de corrente do pico referente à oxidação da imipramina, os quais foram utilizados para calcular a quantidade de imipramina eletrolisada durante 1200 segundos. No decorrer do experimento de eletrólise, foi constatada a mudança na coloração da solução de incolor para amarela devido a espécies geradas durante a reação de oxidação da imipramina. 
Após 1200 segundos de eletrólise, a carga resultante $(Q=0,19$ C) ficou bastante próxima da carga $(\mathrm{Q}=0,20 \mathrm{C})$ necessária para oxidar $1,03 \times 10^{-6}$ mols de imipramina em um processo envolvendo a transferência de 2 elétrons.

Deste modo, com o valor de $\alpha$ n conhecido $(0,74)$, o coeficiente de transferência de carga $(\alpha)$ pôde ser calculado e igual a 0,37. Este valor encontrado está de acordo com reações em que ocorrem mudanças na estrutura do reagente (52), o que pode estar associado com a formação do dímero.

O decaimento rápido da corrente durante os primeiros segundos de eletrólise deve-se ao bloqueio de sítios ativos do eletrodo de platina pela adsorção de moléculas de reagente e de produtos de oxidação. Na Figura 16, é apresentado o gráfico de log(I) em função do tempo.

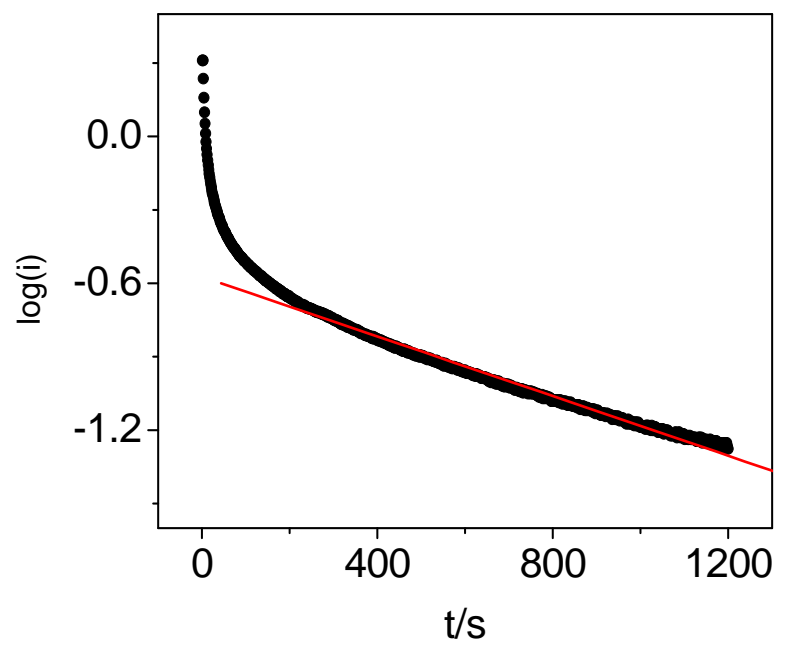

Figura 16 - Variação de $\log (l)$ em função do tempo na eletrólise a potencial controlado de uma solução de imipramina $2,34 \times 10^{-4} \mathrm{~mol} \mathrm{~L}^{-1}$ em tampão $\mathrm{BR} 0,10 \mathrm{~mol} \mathrm{~L}^{-1}(\mathrm{pH} 7,0)$. Eletrodo de placa de platina $\left(A_{\text {geo }}=4,20 \mathrm{~cm}^{2}\right) . E=10 \mathrm{mV}$ e $t=1200$ s. $\theta=6,09 \times 10^{-4} \mathrm{~s}^{-1}$ e $R=0,9932$.

A análise da relação $\log (\mathrm{I})$ vs. t mostra que em até 200 s após o início da eletrólise verifica-se um desvio da linearidade decorrente de complicações cinéticas da 
reação de eletrodo devido ao bloqueio da superfície por reagente e por produtos de reação. Por volta de $200 \mathrm{~s}$ observa-se um comportamento linear até $1200 \mathrm{~s}$, com constante de velocidade da reação $(\mathrm{k})$ igual a $6,09 \times 10^{-4} \mathrm{~s}^{-1}$.

\section{III.1.1.5- Variação do pH}

O estudo da variação do $\mathrm{pH}$ do meio foi realizado no intervalo de 2 a 11, com o objetivo de avaliar o número de prótons envolvidos na reação de oxidação da imipramina, bem como na redução do dímero formado na etapa química posterior à transferência de elétrons. A variação de $\mathrm{pH}$ também permitiu verificar em que valor ocorre maior resposta de corrente para fins analíticos. A Figura 17 apresenta os voltamogramas cíclicos em alguns valores de $\mathrm{pH}$ e a Tabela IV os valores de correntes e potenciais de pico para a oxidação da imipramina e a redução do dímero.

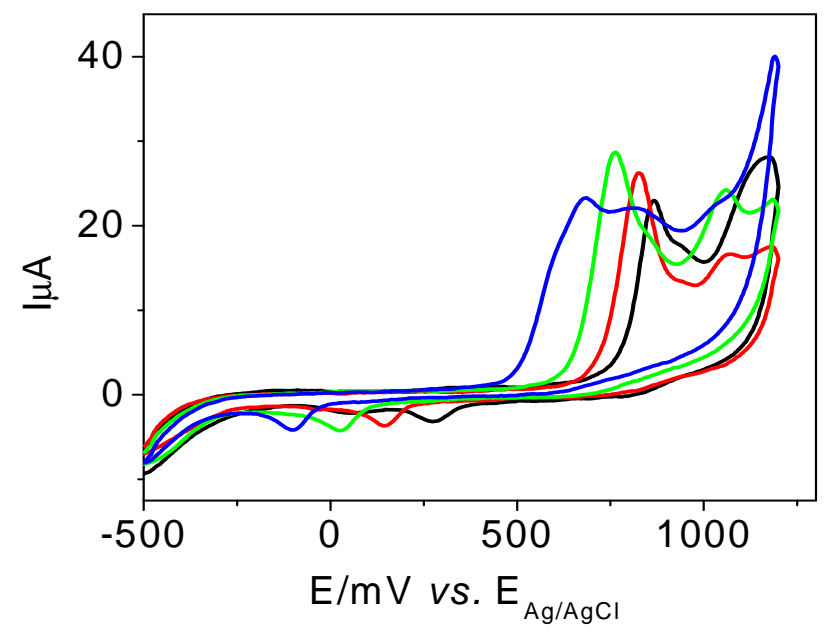

Figura 17 - Voltamogramas cíclicos de uma solução de imipramina $2,34 \times 10^{-4} \mathrm{~mol} \mathrm{~L}^{-1}$ em tampão BR 0,10 mol L-1. Valores de pH: (-) 3,0; ( - 5,0; ( ) 7,0 e ( - 9,0. Eletrodo de trabalho: compósito grafitepoliuretana. $v=50 \mathrm{mV} \mathrm{s}^{-1}$. 
Ao analisar a Figura 17, verifica-se que a partir de $\mathrm{pH} 9,0$ surgem ondas compostas, o que é um indicativo de mudança de mecanismo da reação, uma vez que nesta região de $\mathrm{pH}$ ocorre a desprotonação do sal de amônio gerando a amina correspondente. Assim, o par de elétrons livres do nitrogênio também passa a ser uma região com densidade de carga negativa e, portanto, passível de sofrer oxidação.

Tabela IV - Valores de corrente $\left(I_{p}\right)$ e potencial $\left(E_{p}\right)$ de pico para: (I) oxidação da imipramina; (II) redução do dímero.

\begin{tabular}{c|c|c|c|c}
\hline pH & $I_{p} / \mu A$ & $E_{p} / m V$ & $I_{p} / \mu A$ & $E_{p} / m V$ \\
$(I)$ & $(I)$ & $(I I)$ & $(I I)$ \\
\hline 2 & 14,14 & 867 & $-1,73$ & 272 \\
4 & 18,47 & 867 & $-2,55$ & 217 \\
5 & 19,13 & 826 & $-2,76$ & 143 \\
6 & 19,88 & 792 & $-3,29$ & 81 \\
7 & 20,41 & 761 & $-2,96$ & 27 \\
8 & 17,62 & 731 & $-2,62$ & -38 \\
9 & 15,36 & 648 & $-2,89$ & -102 \\
10 & 8,24 & 627 & $-2,72$ & -150 \\
11 & 6,25 & 639 & $-2,54$ & -182 \\
\hline
\end{tabular}


$\mathrm{Na}$ Tabela IV, verifica-se que os potenciais de pico deslocaram-se para valores menos positivos com o aumento do $\mathrm{pH}$, indicando que a transferência eletrônica é dependente do $\mathrm{pH}$ do meio.

$\mathrm{Na}$ Figura 18, observa-se que no intervalo de $\mathrm{pH}$ de 2 a 4 a transferência eletrônica é independente do pH do meio e que acima de 4 ocorre um deslocamento de $40 \mathrm{mV}$ para cada unidade de $\mathrm{pH}$. Quanto à redução do dímero, constata-se que, no intervalo de $\mathrm{pH}$ estudado, o potencial de pico é deslocado de $59 \mathrm{mV}$ por unidade de $\mathrm{pH}$.

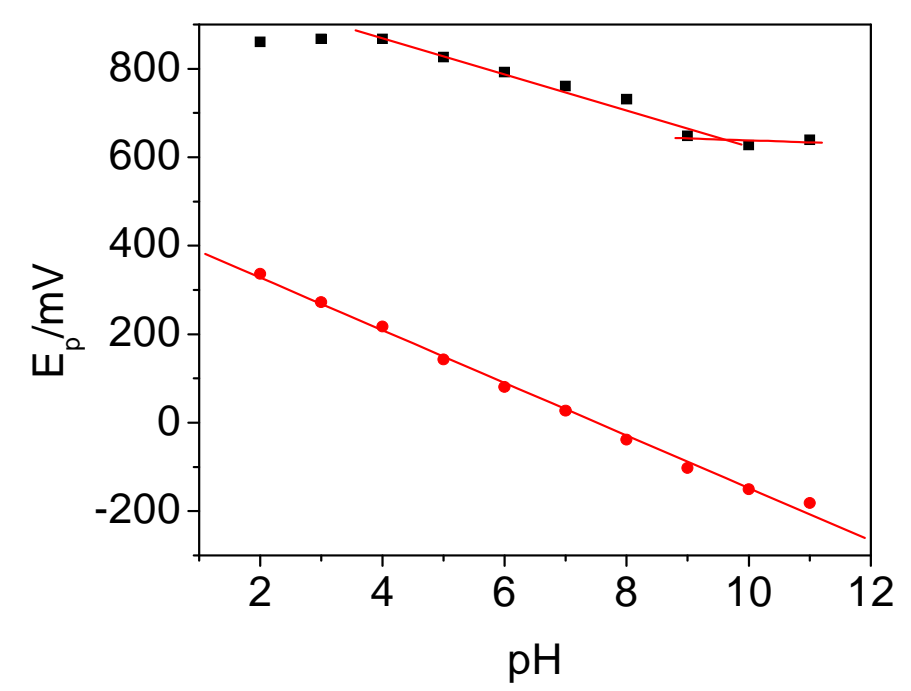

Figura 18 - Gráficos de $E_{p} v s . p H:(-)$ pico de oxidação da imipramina $(R=0,9971$ e $\theta=40 \mathrm{mV} / \mathrm{pH}) ;(\bullet)$ pico de redução do dímero $(\mathrm{R}=0,9996$ e $\theta=59 \mathrm{mV} / \mathrm{pH})$.

O número de prótons envolvidos na reação de oxidação da imipramina $(P)$ pôde ser calculado pela equação 4 .

$$
\Delta \mathrm{E}_{\mathrm{p}} / \Delta \mathrm{pH}=-59 \mathrm{P} / \mathrm{n} \alpha
$$


Como o valor de na já é conhecido $(0,74)$, o número de prótons pôde ser calculado em todo o intervalo de $\mathrm{pH}$ pelo coeficiente angular $(40 \mathrm{mV} / \mathrm{pH})$ do gráfico de $\mathrm{E}_{\mathrm{p}}$ vs. $\mathrm{pH}$, o qual corresponde ao termo $\Delta \mathrm{E}_{\mathrm{p}} / \Delta \mathrm{pH}$. Assim, obteve-se a participação de 1 próton $(P=0,51)$ por molécula de imipramina.

O número de prótons $(\mathrm{P})$ envolvidos na redução do dímero pôde ser calculado pela equação 5 .

$$
\Delta \mathrm{E}_{\mathrm{p}} / \Delta \mathrm{pH}=-59 \mathrm{P} / \mathrm{n}
$$

Como o coeficiente angular foi igual a $59 \mathrm{mV} / \mathrm{pH}$ para a redução do dímero, constata-se que estão envolvidos no processo redox do composto um número igual de prótons e elétrons.

Para fins analíticos, constatou-se que em $\mathrm{pH} 7,0$ foi obtido maior resposta de corrente para a reação de oxidação da imipramina, valor este utilizado no decorrer dos experimentos.

\section{III.1.2 - Voltametria de onda quadrada}

\section{III.1.2.1- Separação das componentes de corrente}

A corrente, em voltametria de onda quadrada, é uma resultante $(\Delta I)$ entre as correntes de varredura no sentido direto $\left(I_{d}\right)$ e as correntes de varredura, no sentido inverso $\left(I_{r}\right)$ (equação 6).

$$
\Delta I=I_{d}-I_{r}
$$


A separação das correntes é uma ferramenta utilizada para o diagnóstico do tipo de reação do sistema. Assim, o critério para analisar inicialmente o grau de reversibilidade é a separação da corrente resultante em suas três componentes. Nas Figuras 10 (I) e (II), é mostrada a separação das correntes para a imipramina e para o dímero, respectivamente.

Na Figura $19(\mathrm{I})$, pode-se observar que a intensidade de corrente resultante $(\Delta \mathrm{I})$ é muito próxima à intensidade da corrente direta $\left(I_{d}\right)$, o que indica que a contribuição da corrente reversa $\left(I_{r}\right)$ para a resultante é mínima, provocando uma variação quase insignificante ao final da análise. A quase coincidência de $\Delta \mathrm{l}$ e $\mathrm{I}_{\mathrm{d}}$ confirma $\mathrm{a}$ irreversibilidade da reação de oxidação da imipramina. A corrente resultante só não é coincidente com a corrente direta pela pequena contribuição de uma corrente reversa residual.
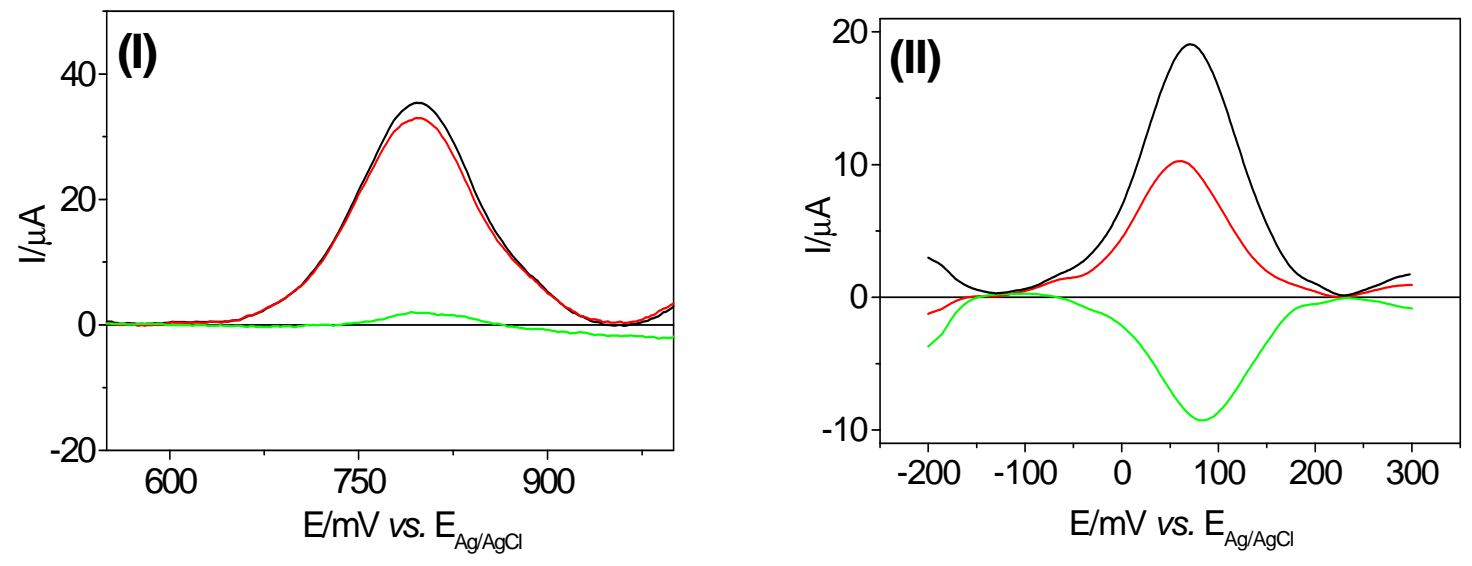

Figura 19 - Voltamogramas de onda quadrada de uma solução de imipramina $2,34 \times 10^{-4} \mathrm{~mol} \mathrm{~L}^{-1}$ para (I) imipramina e (II) dímero, mostrando as componentes de corrente $(-)$ resultante, $(-)$ direta e $(-)$ reversa. Eletrodo de trabalho: compósito grafite-poliuretana. $f=100 \mathrm{~s}^{-1}, a=50 \mathrm{mV}$ e $\Delta \mathrm{E}_{\mathrm{i}}=2 \mathrm{mV}$. 
A separação das componentes de corrente para o dímero, apresentada na Figura 19 (II), confirmou a reversibilidade do sistema pela contribuição da corrente reversa, aumentando significantemente a corrente resultante e deste modo a resposta analítica em termos de intensidade de corrente.

\section{III.1.2.2- Variação da freqüência}

A freqüência é uma das variáveis mais importantes em voltametria de onda quadrada, pois se mantendo constante a concentração, é ela quem determina a intensidade do sinal analítico. Nas Figuras 20 (I) e (II), é apresentado o estudo da variação da freqüência para a imipramina e para o dímero e, na Tabela $V$, são apresentados os valores de correntes e potenciais de pico para cada processo.
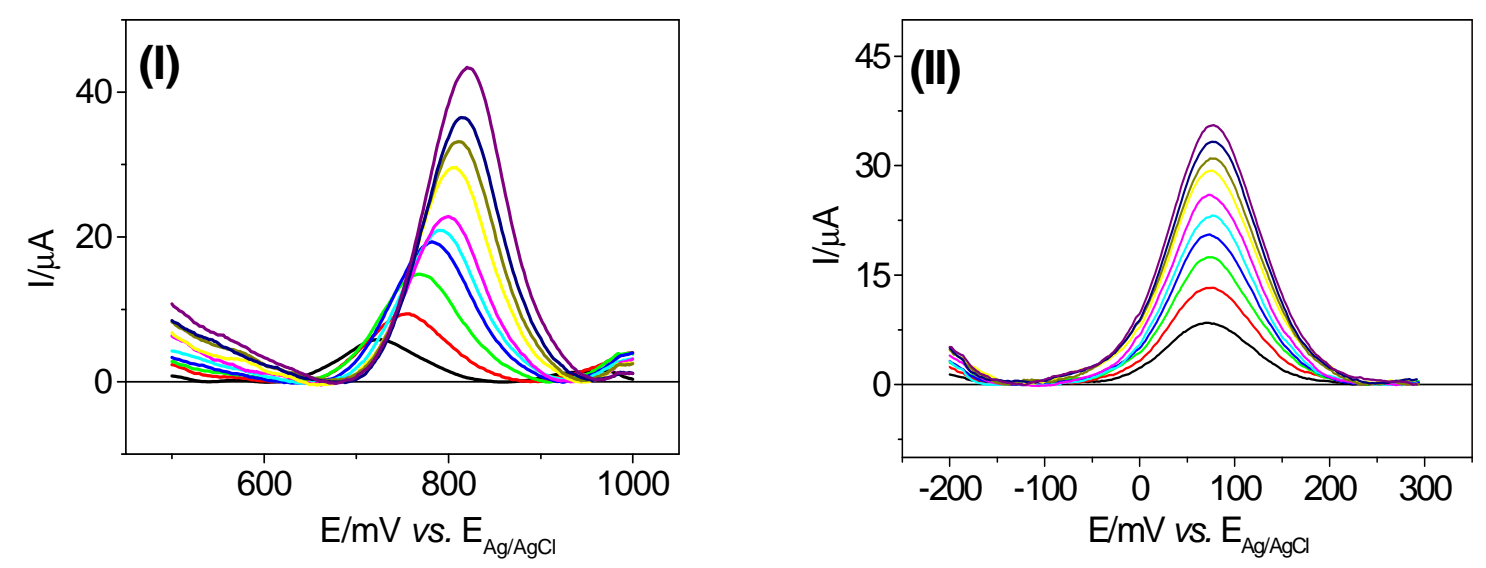

Figura 20 - Voltamogramas de onda quadrada de uma solução de imipramina $2,34 \times 10^{-4} \mathrm{~mol} \mathrm{~L}^{-1}$ para (I)

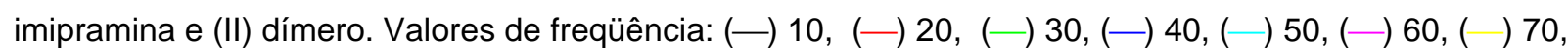
$(-)$ 80, $(-) 90$ e $(-) 100 \mathrm{~s}^{-1}$. Eletrodo de trabalho: compósito grafite-poliuretana. $a=50 \mathrm{mV}$ e $\Delta \mathrm{E}_{\mathrm{i}}=2 \mathrm{mV}$. 
Tabela V - Valores de corrente $\left(I_{p}\right)$ e potencial $\left(E_{p}\right)$ de pico para: (I) imipramina; (II) dímero.

\begin{tabular}{c|c|c|c|c}
\hline $\mathbf{f}$ & $I_{p} / \mu A$ & $E_{p} / m V$ & $I_{p} / \mu A$ & $E_{p} / m V$ \\
$\left(\mathbf{s}^{-1}\right)$ & $(I)$ & $(I)$ & $(I I)$ & $(I I)$ \\
\hline 10 & 5,82 & 726 & 8,46 & 72 \\
20 & 9,38 & 754 & 13,24 & 78 \\
30 & 14,84 & 770 & 17,47 & 72 \\
40 & 19,33 & 782 & 20,56 & 74 \\
50 & 21,91 & 790 & 23,17 & 76 \\
60 & 24,91 & 800 & 25,99 & 72 \\
70 & 29,62 & 808 & 29,35 & 76 \\
80 & 33,16 & 812 & 30,99 & 74 \\
90 & 36,47 & 814 & 33,28 & 76 \\
100 & 42,41 & 820 & 35,57 & 78 \\
\hline
\end{tabular}

Para a oxidação da imipramina, observou-se que o aumento da freqüência, nos quais os pulsos de potenciais são aplicados, provocou um aumento na intensidade de corrente de pico e um deslocamento dos potenciais para valores mais positivos. Quanto ao processo redox do dímero, também foram constatados um aumento na intensidade da corrente de pico e uma pequena variação dos potenciais com o aumento da freqüência.

O aumento na intensidade da corrente de pico em função da variação de freqüência de aplicação dos pulsos de potenciais é de grande importância em 
aplicações analíticas. Como foi visto anteriormente, a sensibilidade analítica é melhorada quando se trabalha com valores elevados de freqüência, ou seja, em $100 \mathrm{~s}^{-1}$. Assim, para a aplicação analítica, foram realizadas variações de outros parâmetros importantes em voltametria de onda quadrada, dentre eles, a amplitude de pulso (a) e o incremento de varredura $\left(\Delta \mathrm{E}_{\mathrm{i}}\right)$, com o objetivo de otimizá-los para a obtenção de maior sensibilidade nas análises.

As relações existentes entre a corrente de pico e a freqüência ou a raiz quadrada da freqüência fornecem informações quanto ao grau de reversibilidade e a existência ou não de processos de adsorção na superfície do eletrodo. Nas Figuras 21 (I) e (II), são apresentadas tais relações para a imipramina e para o dímero.
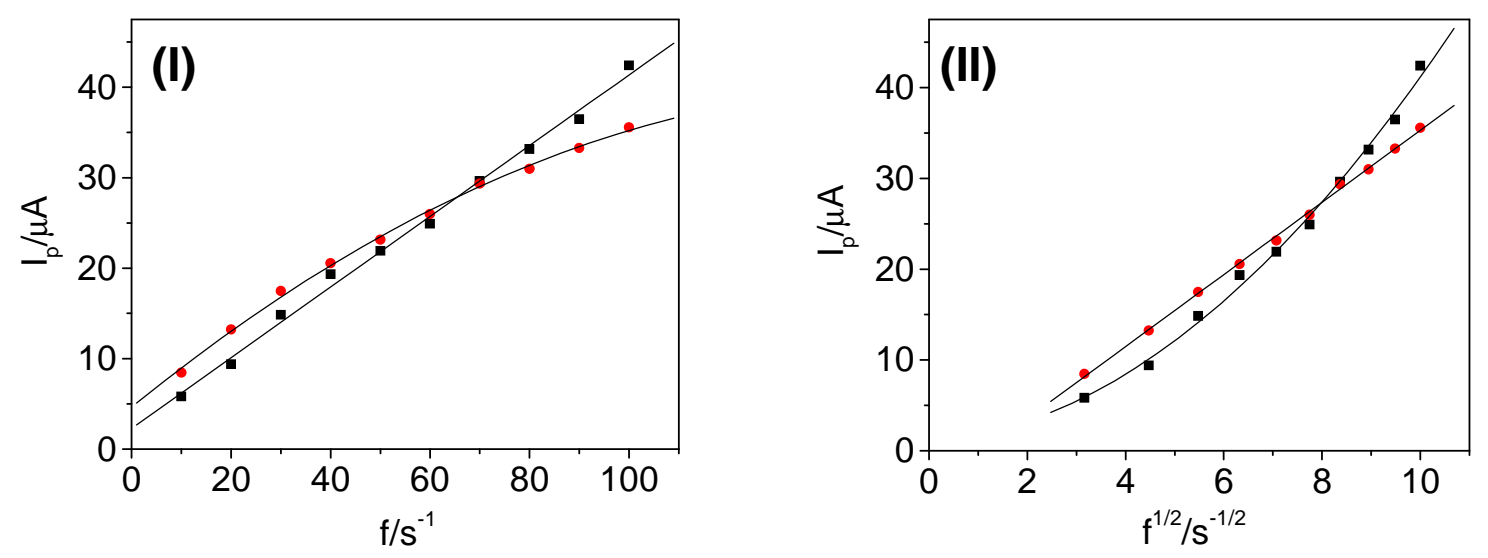

Figura 21 - Curvas (I) $I_{p} v s . f$ para: $(\square)$ imipramina $(R=0,9975)$ e $(\bullet)$ dímero. (II) $I_{p} v s . f^{1 / 2}$ para: imipramina e $(\bullet)$ dímero $(\mathrm{R}=0,9994)$.

Como pode ser observado, a linearidade entre $I_{p} v s$. $f$ e a não linearidade entre $I_{p}$ vs. $f^{1 / 2}$ confirmam a irreversibilidade da reação de oxidação da imipramina, bem como a adsorção de reagente na superfície do eletrodo. Para o processo redox do dímero, a inversão das relações também comprovam a reversibilidade da reação. 
Além das informações extraídas acima, o coeficiente angular $(\theta)$ da relação entre $E_{p}$ vs. $\log (f)$, para processos irreversíveis, permite calcular, pela equação de Lovric (equação 7), o valor de $\alpha$ e assim confirmá-lo com o obtido por voltametria cíclica. $\mathrm{Na}$ Figura 22, é mostrada a relação linear entre $E_{p}$ e $\log (f)$ para o pico de oxidação da imipramina.

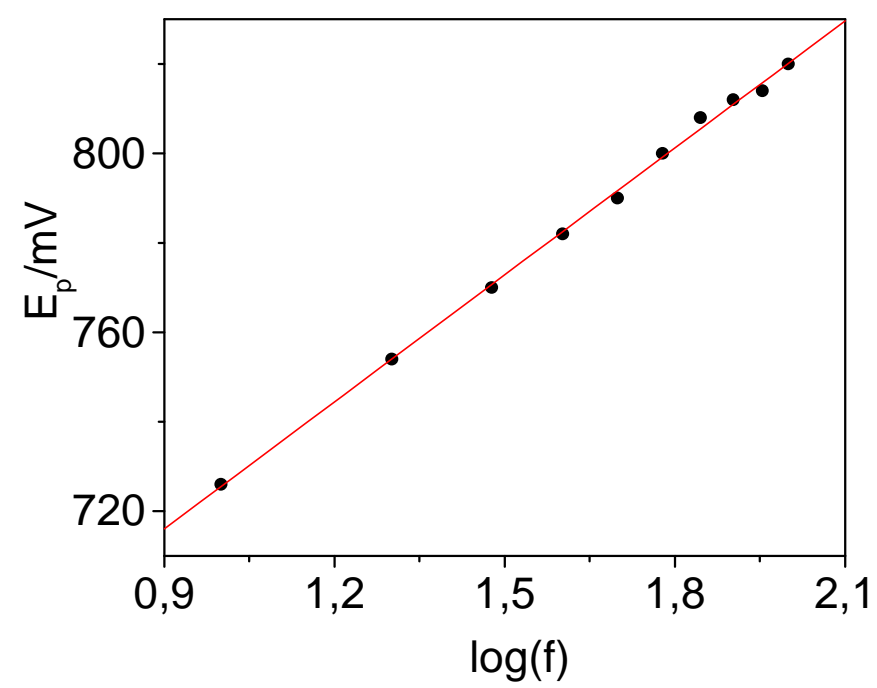

Figura 22 - Curva $E_{p} v s$. log(f) para a imipramina: $(R=0,9991$ e $\theta=94,63)$.

$$
\Delta \log (f) / \Delta \mathrm{E}_{\mathrm{p}}=-59 / \alpha \mathrm{n}
$$

Ao aplicar a equação 7 , o valor de $\alpha$ n calculado foi igual a 0,62 , o qual está relativamente próximo do valor calculado por voltametria cíclica $(0,74)$. 


\section{III.2- DETERMINAÇÃO ANALÍTICA DA IMIPRAMINA EM COMPRIMIDOS DE TOFRANIL ${ }^{\circledR}(50)$}

\section{III.2.1 - Otimização dos parâmetros experimentais}

O desenvolvimento de metodologia analítica para a determinação de imipramina em formulação farmacêutica comercial foi realizado pela utilização do eletrodo de GPU em conjunto com a técnica voltametria de onda quadrada. A primeira etapa consistiu na otimização dos parâmetros experimentais que resultassem em maior sensibilidade analítica.

Os resultados da seção III.1.2.2 revelaram que a separação das componentes de corrente para o dímero é interessante para fins analíticos em dois aspectos, primeiro pela sensibilidade analítica alcançada na corrente resultante e segundo pelo baixo potencial onde a reação ocorre, o qual, comparando-se ao pico de oxidação da imipramina, previne a ocorrência de interferência de outros compostos eletroativos eventualmente presentes na matriz a ser analisada. Desta forma, o par redox do dímero foi escolhido para o desenvolvimento de metodologia analítica.

Com o pH $(7,0)$ e a freqüência de aplicação dos pulsos de potenciais $\left(100 \mathrm{~s}^{-1}\right)$ otimizados, os parâmetros restantes da técnica de voltametria de onda quadrada foram avaliados com o intuito de se obter maior sensibilidade analítica. Na Figura 23, são apresentados os voltamogramas de onda quadrada de uma solução de imipramina $2,25 \times 10^{-4} \mathrm{~mol} \mathrm{~L}^{-1}$ ao variar o incremento de varredura de $1 \mathrm{a} 7 \mathrm{mV}$. 


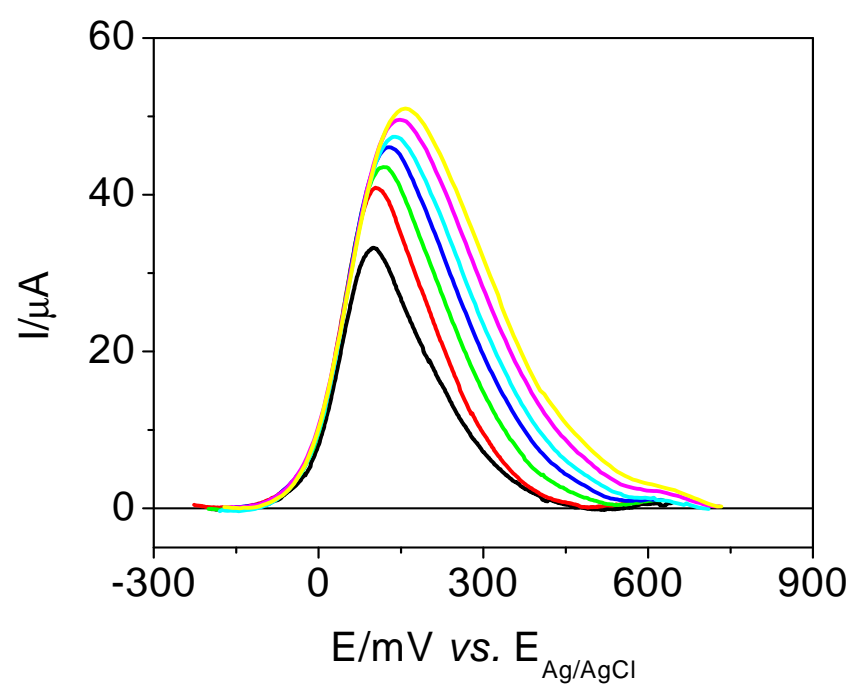

Figura 23 - Voltamogramas de onda quadrada de uma solução de imipramina $2,25 \times 10^{-4} \mathrm{~mol} \mathrm{~L}^{-1}$ em tampão BR $0,10 \mathrm{~mol} \mathrm{~L}^{-1}(\mathrm{pH} \mathrm{7,0)}$. Valores de incremento: $(-) 1,(-) 2,(-) 3$,

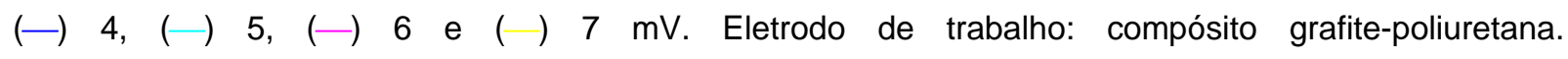
$f=100 \mathrm{~s}^{-1}$ e $a=50 \mathrm{mV}$.

Pela análise da Figura 23, verifica-se que ao variar o incremento de varredura de 1 a $7 \mathrm{mV}$ há um aumento da resposta de corrente, porém observa-se um alargamento dos picos, o qual está relacionado com a perda na seletividade. Desta forma, foi escolhido um incremento de $2 \mathrm{mV}$.

O último parâmetro a ser otimizado foi a amplitude dos pulsos de potencial, a qual foi variada no intervalo de 10 a $200 \mathrm{mV}$. Na Figura 23, são mostrados os voltamogramas de onda quadrada de uma solução de imipramina $2,25 \times 10^{-4} \mathrm{~mol} \mathrm{~L}^{-1}$ para diferentes valores de amplitude. 


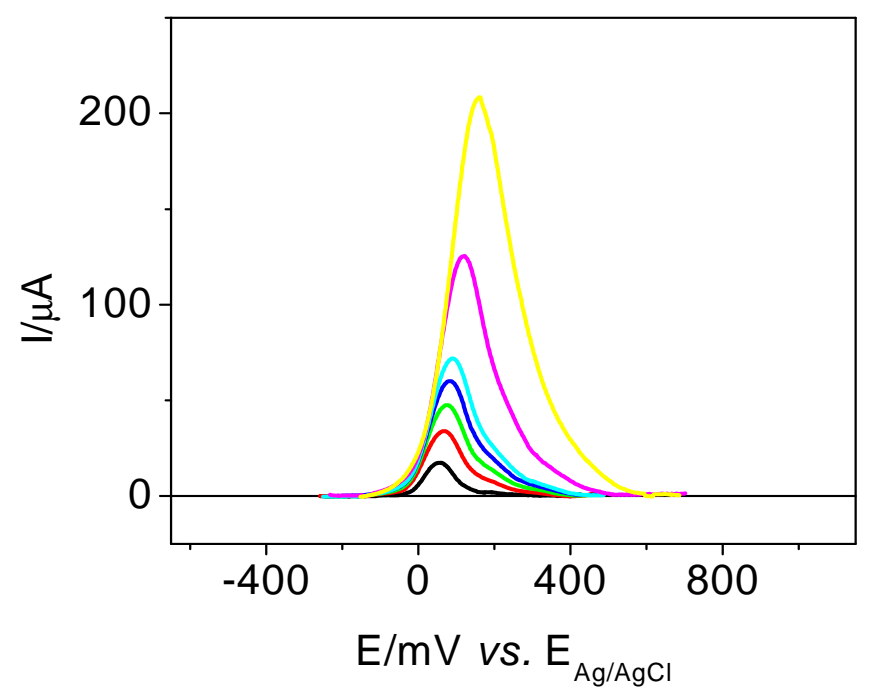

Figura 24 - Voltamogramas de onda quadrada de uma solução de imipramina $2,25 \times 10^{-4} \mathrm{~mol} \mathrm{~L}^{-1}$ em tampão BR 0,10 $\mathrm{mol} \mathrm{L}^{-1}(\mathrm{pH} \mathrm{7,0)}$. Valores da amplitude: $(-)$ 10, ( $\longrightarrow$ ) 20, ( $\longrightarrow) 30$, $\left(\rightarrow\right.$ 40, ( ) 50, ( $-100 \mathrm{e}\left(\right.$ ) $200 \mathrm{mV}$. Eletrodo de trabalho: compósito grafite-poliuretana. $f=100 \mathrm{~s}^{-1} \mathrm{e}$ $\Delta \mathrm{E}_{\mathrm{i}}=2 \mathrm{mV}$.

Ao variar este parâmetro, verifica-se que, para amplitudes maiores (200 mV), há uma melhoria na sensibilidade analítica, porém há um alargamento dos picos que resulta na perda de seletividade. Assim, optou-se por fixar a amplitude em $50 \mathrm{mV}$.

A concentração de moléculas de dímero adsorvidas na superfície do eletrodo $(\Gamma)$ pôde ser estimada de maneira similar a realizada por Lovric (53), segundo a equação 8.

$$
\partial \mathrm{I}_{\mathrm{p}} / \partial a=500 A \alpha n^{2} \mathrm{~F} f \Delta \mathrm{E}_{\mathrm{i}} \Gamma
$$

Em que $\partial \mathrm{I}_{\mathrm{p}} / \partial a$ é o coeficiente angular do gráfico $\mathrm{I}_{\mathrm{p}}$ vs. $a\left(1,19 \times 10^{-3} \mathrm{~A} \mathrm{~V}^{-1}\right)$, A é a área do eletrodo $\left(0,071 \mathrm{~cm}^{2}\right)$, $\alpha$ é o coeficiente de carga $(0,5)$, n é o número de elétrons (1), F 
é a constante de Faraday $\left(96500 \mathrm{Cmol}^{-1}\right), f$ é a freqüência $\left(100 \mathrm{~s}^{-1}\right), \Delta \mathrm{E}_{\mathrm{i}}$ é o incremento de varredura $\left(2 \times 10^{-3} \mathrm{~V}\right)$ e $\Gamma$ é a quantidade do analito adsorvido na superfície do eletrodo $\left(\mathrm{mol} \mathrm{cm}{ }^{-2}\right)$.

Na Figura 25, é apresentado o gráfico de corrente de pico $\left(I_{p}\right)$ vs. amplitude (a) referente ao par redox do dímero. O valor do coeficiente angular $\left(\partial \mathrm{I}_{\mathrm{p}} / \partial \mathrm{a}\right)$, utilizado no cálculo da quantidade do analito adsorvido na superfície do eletrodo, foi extraído da Figura 25 levando-se em consideração o intervalo linear de 10 a 50 mV.

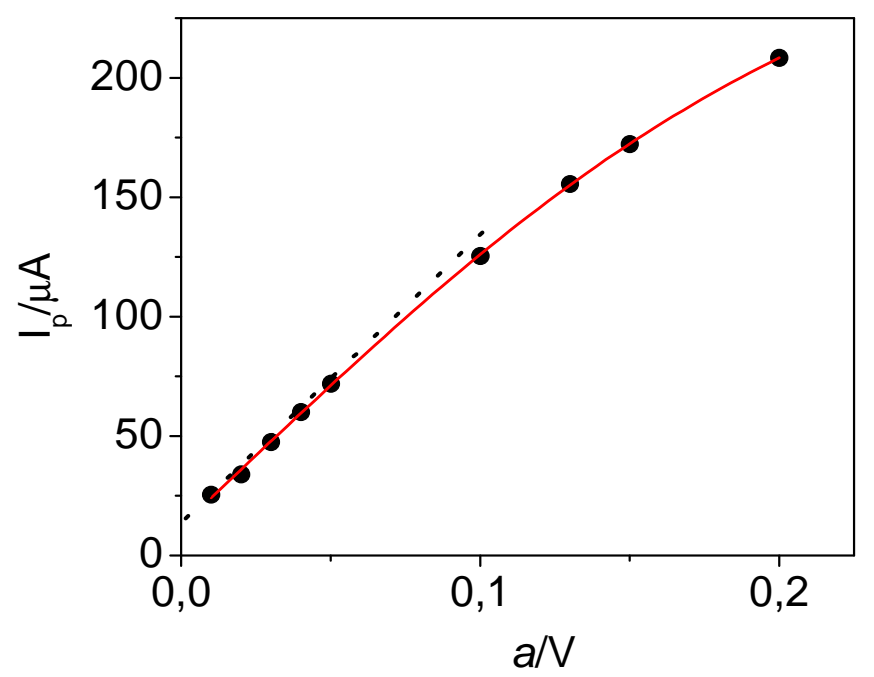

Figura 25 - Curva $I_{p}$ vs. a de uma solução de imipramina $2,25 \times 10^{-4} \mathrm{~mol} \mathrm{~L}^{-1}$ em tampão BR

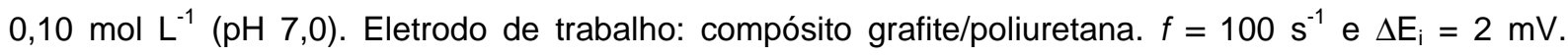
$\mathrm{R}=0,9978$ e $\partial \mathrm{I}_{\mathrm{p}} / \partial \mathrm{a}=1,19 \times 10^{-3} \mathrm{~A} \mathrm{~V}^{-1}$.

Ao aplicar a equação 8, verificou-se que a concentração de moléculas de dímero na superfície do eletrodo é igual a $3,74 \times 10^{-9} \mathrm{~mol} \mathrm{~cm}^{-2}$. 


\section{III.2.2 - Construção da curva analítica}

Após a otimização dos parâmetros experimentais, curvas analíticas $(n=3)$ para a imipramina foram construídas no intervalo de $3,04 \times 10^{-7} \mathrm{~mol}^{\mathrm{L}^{-1}}$ a $30,42 \times 10^{-7} \mathrm{~mol} \mathrm{~L}^{-1}$ pelo método de adição de padrão. Na Figura 26 (I), são mostrados os voltamogramas de onda quadrada registrados neste intervalo de concentração e a na Tabela VI, são apresentados os valores da média das correntes de pico para cada concentração.
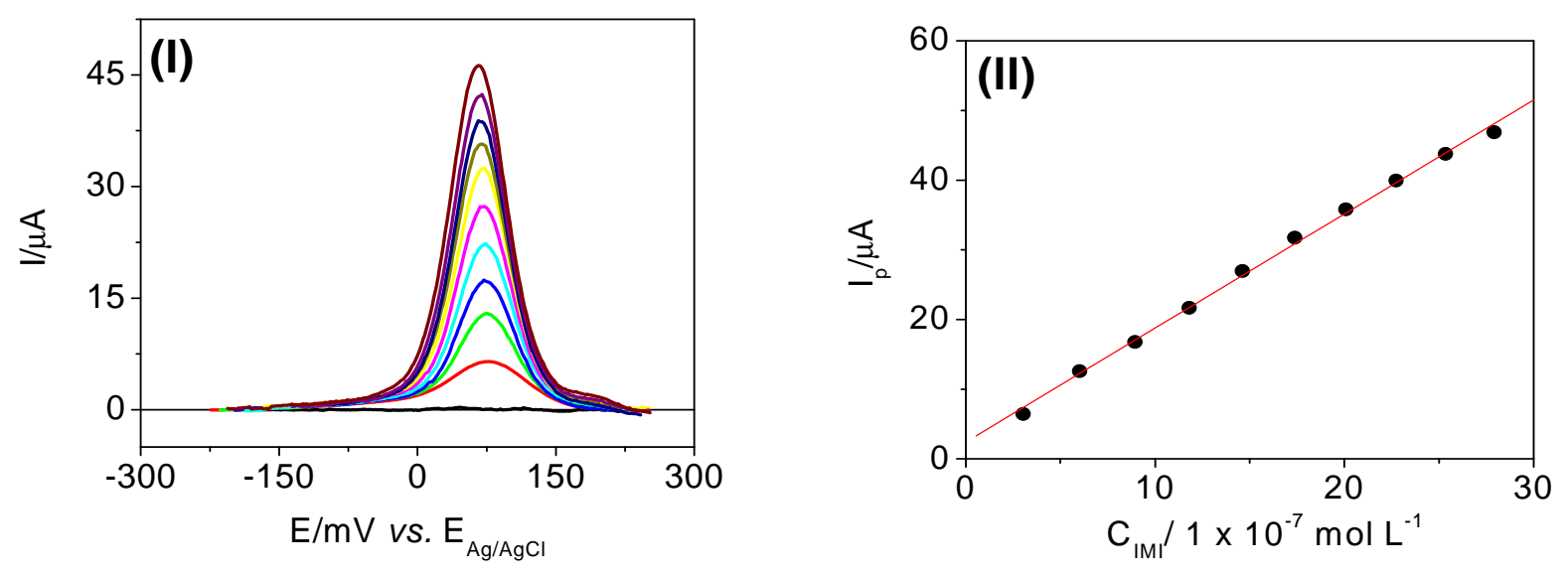

Figura 26 - (I) Voltamogramas de onda quadrada variando-se a concentração de imipramina adicionada. Concentrações: $(-)$ branco, $(-)$ 3,04, $(-)$ 6,02, $(-)$ 8,94, $(-)$ 11,81, $(-)$ 14,62, ( ) 17,38, ( ) 20,08,

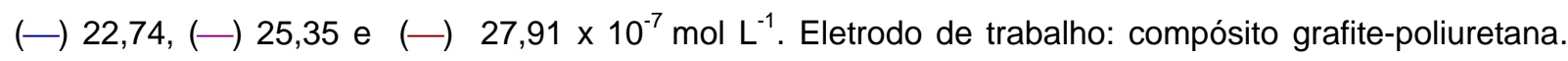
$f=100 \mathrm{~s}^{-1}, a=50 \mathrm{mV}$ e $\Delta \mathrm{E}_{\mathrm{i}}=2 \mathrm{mV}$. (II) curva analítica $(\mathrm{n}=10$ e $\mathrm{R}=0,9988)$. 
A equação da reta para a curva analítica (Figura 26 (II)) é dada pela equação 9, com o coeficiente de correlação igual a 0,9988.

$$
I_{p}(\mu A)=2,40 \times 10^{-6}+16,38 \times C_{I M I}\left(10^{-7} \mathrm{~mol} \mathrm{~L}^{-1}\right)
$$

Tabela VI - Valores de concentração de imipramina adicionada e a média das correntes de pico referentes à curva analítica.

\begin{tabular}{c|c}
\hline $\mathbf{C}_{\mathrm{IMI}} / \mathbf{1 0}^{-7} \mathrm{~mol} \mathrm{~L}^{-1}$ & $\mathrm{I}_{\mathrm{p} \text { média }} / \mu \mathrm{A}$ \\
& \\
\hline 3,04 & 6,43 \\
6,02 & 12,59 \\
8,94 & 16,76 \\
11,81 & 21,67 \\
14,62 & 26,97 \\
17,38 & 31,73 \\
20,08 & 35,81 \\
22,74 & 39,96 \\
25,35 & 43,76 \\
27,91 & 46,88 \\
\hline
\end{tabular}

Para avaliar a sensibilidade da metodologia analítica, o limite de detecção (LD) e o limite de quantificação (LQ) foram convenientemente estabelecidos da seguinte maneira: o LD foi calculado de acordo com a equação 10 e o LQ ficou determinado como sendo a menor concentração do padrão na curva analítica (54). De acordo com a literatura, o limite de detecção é a menor valor de concentração do analito que pode ser detectada pelo método com baixa confiabilidade. O limite de quantificação, por sua vez, 
é a menor concentração que pode ser determinada com um nível aceitável de precisão e de exatidão. Desta forma, a diferença entre LD e LQ é a ordem de grandeza das incertezas associadas (55).

$$
L D=3 \sigma / \theta
$$

Com o termo $\sigma$ referindo-se ao desvio padrão da média dos brancos $(n=10)$ e $\theta$ ao coeficiente angular da curva analítica.

Desta maneira, o limite de detecção e o de quantificação obtidos foram iguais a $4,58 \times 10^{-9} \mathrm{~mol} \mathrm{~L}^{-1}\left(1,50 \mu \mathrm{g} \mathrm{L}^{-1}\right)$ e $3,04 \times 10^{-7} \mathrm{~mol} \mathrm{~L}^{-1}\left(97 \mu \mathrm{g} \mathrm{L}^{-1}\right)$, respectivamente.

A precisão da metodologia foi checada por meio de 10 medidas sucessivas de uma solução de imipramina $4,92 \times 10^{-7} \mathrm{~mol} \mathrm{~L}^{-1}$. Para a precisão intra-day (repetibilidade), a qual foi calculada por meio de análises sucessivas durante um dia ( $n=10$ ), o RSD foi igual a 1,3\%. A precisão inter-day (precisão intermediária) foi calculada por meio de análises em dias diferentes (RSD =2,4\%, para 6 dias diferentes).

A exatidão foi avaliada pelo cálculo do erro relativo (bias\%), o qual descreve o desvio dos resultados esperados nos experimentos de recuperação aparente de imipramina em comprimidos de Tofranil $^{\circledR}$ (25 mg de cloridrato de imipramina) no eletrólito de trabalho.

A recuperação aparente de imipramina foi realizada de acordo com o recomendado pela IUPAC (56). Foram realizadas cinco adições, sendo a primeira do medicamento $(\mathrm{V}=100 \mu \mathrm{L})$ e as restantes do padrão analítico $(\mathrm{V}=100 \mu \mathrm{L})$. Deve-se salientar que o intervalo de concentrações nos experimentos de recuperação aparente 
obedeceu àqueles da curva analítica. Na Figura 27, são apresentados os voltamogramas de onda quadrada registrados para a adição do medicamento e várias adições do padrão analítico, além da curva de recuperação aparente inserida $(R=$ 0,9960).

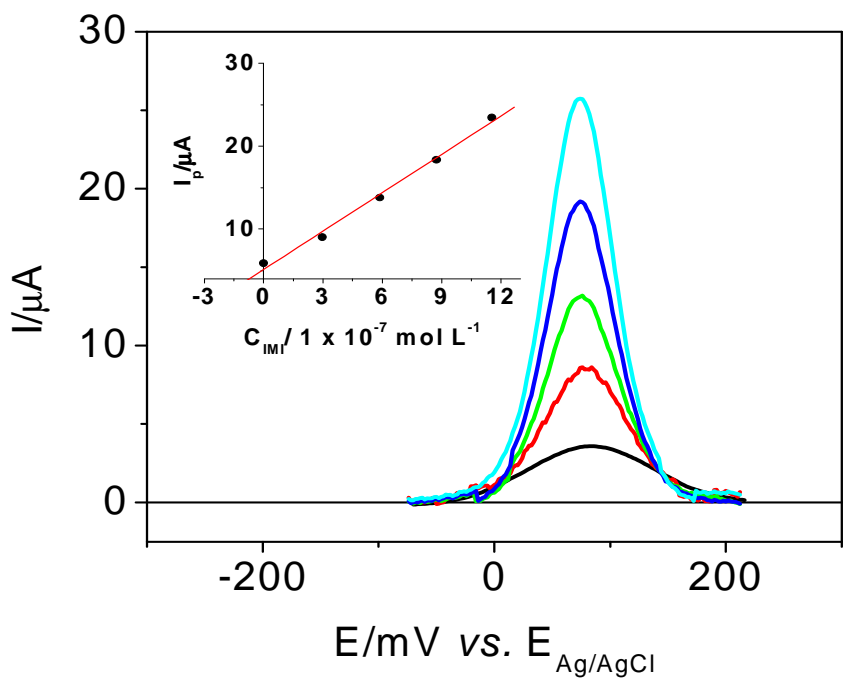

Figura 27 - Voltamogramas de onda quadrada para diferentes concentrações de imipramina. $\mathrm{C}_{\mathrm{IMI}}$ adicionada: $\left(-\right.$ medicamento, $(-)$ 2,97, $\left(-5,88,(-)\right.$ 8,74 e $(-) 11,53 \times 10^{-7} \mathrm{~mol} \mathrm{~L}^{-1}$ com eletrodo compósito grafite-poliuretana. $f=100 \mathrm{~s}^{-1}, a=50 \mathrm{mV}$ e $\Delta \mathrm{E}_{\mathrm{i}}=2 \mathrm{mV}$. Inserido: curva de recuperação aparente $(R=0,9960)$.

Como não foi realizado um estudo de interferentes, a quantidade de imipramina recuperada não pôde ser obtida diretamente da curva analítica. Deste modo, esta quantidade foi calculada pela extrapolação, no eixo $\mathrm{x}$, da reta do gráfico de $\mathrm{I}_{\mathrm{p}} v s$. $\mathrm{C}_{\mathrm{IMI}}$ (inserida na Figura 27). A extrapolação resulta na concentração da solução de medicamento recuperada e a porcentagem é conhecida pela relação existente entre a concentração adicionada da solução de medicamento (100\%) e a concentração encontrada por extrapolação. 


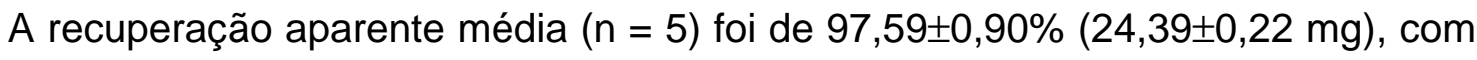
bias igual a $1,8 \%$. Na caixa de Tofranil $^{\circledR}$, está rotulado que cada comprimido contém $25 \mathrm{mg}$ de cloridrato de imipramina, assim, a quantidade de medicamento adicionada e recuperada pela metodologia analítica desenvolvida mostra-se coerente, revelando que não há interferência significativa da matriz desse medicamento na metodologia proposta.

Os resultados obtidos são bastante promissores para a análise de rotina deste medicamento, no entanto, deve-se averiguar se o método analítico é adequado ao uso pretendido. Por essa razão, foram realizados alguns experimentos com a técnica de cromatografia líquida de alta eficiência (HPLC) a fim de se avaliar o desempenho da metodologia eletroanalítica proposta. Dentre todas as técnicas aplicáveis para promover a análise dos antidepressivos tricíclicos, a técnica de HPLC foi escolhida por ser largamente utilizada para a análise desta classe de compostos em formulações farmacêuticas e em fluídos biológicos para a monitoração terapêutica.

A determinação cromatográfica da imipramina foi realizada após a otimização do sistema. A fase móvel utilizada foi acetonitrila/tampão acetato de amônio $0,10 \mathrm{~mol} \mathrm{~L}^{-1}$ $(\mathrm{pH} 5,0)$ na proporção $70 / 30 \mathrm{v} / \mathrm{v}$, com fluxo de $1,0 \mathrm{~mL}$ por minuto, forno a $40^{\circ} \mathrm{C}$ e comprimento de onda monitorado em 220 nm. Nas Figuras 28 (I) e (II), são apresentados os cromatogramas para diferentes concentrações de imipramina no intervalo de $2,96 \times 10^{-7}$ a $41,44 \times 10^{-7} \mathrm{~mol} \mathrm{~L}^{-1}$ e a curva analítica, respectivamente. 

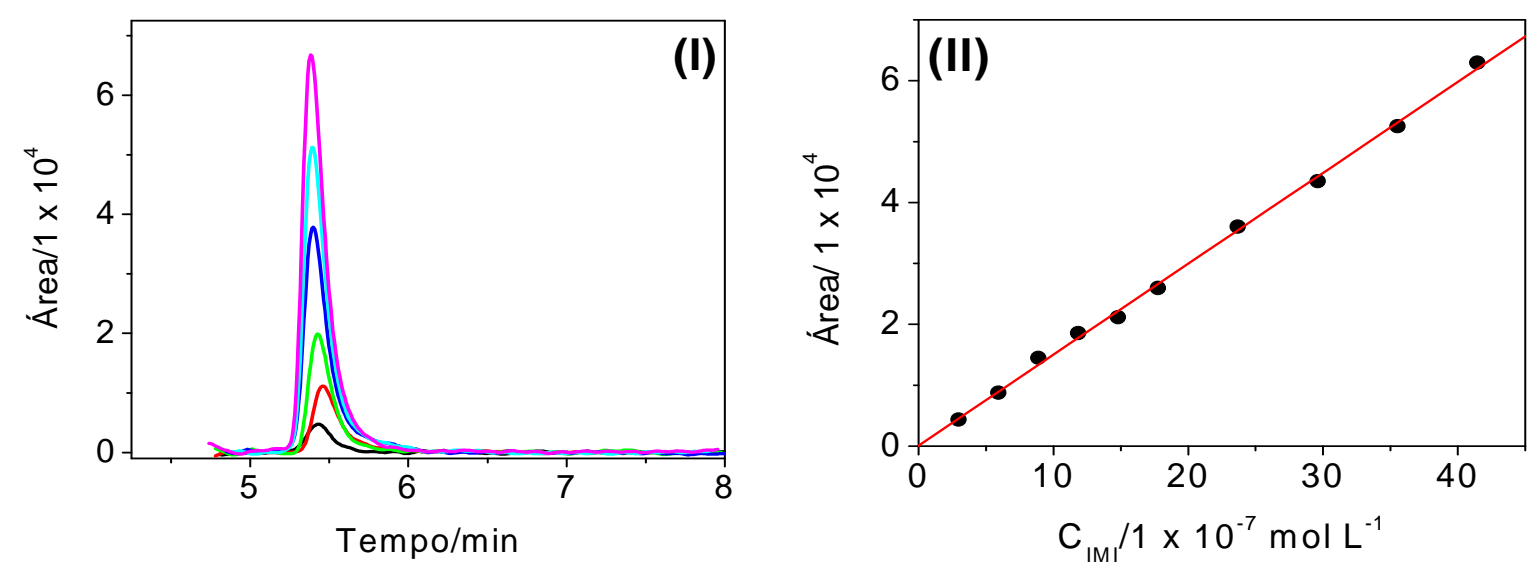

Figura 28: (I) Cromatogramas obtidos para diferentes injeções de imipramina. $\mathrm{C}_{\mid \mathrm{|M|}}$ : (一) 2,96,

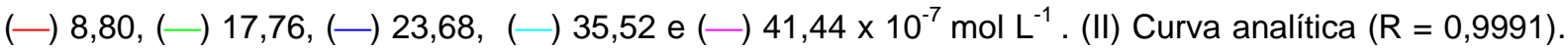
Fase móvel: 70 \% ACN / 30 \% tampão acetato de amônio $0,10 \mathrm{~mol} \mathrm{~L}^{-1}(\mathrm{pH}$ 5,0). Volume injetado: $20 \mu$ L. Detecção: 220 nm.

Pela Figura 28 (I), observa-se que o tempo de retenção da imipramina, nas condições experimentais estabelecidas, foi de 5,40 minutos.

A equação da reta para a curva analítica (Figura 28 (II)) é dada pela equação 11, com o coeficiente de correlação igual a 0,9991.

$$
\text { Área }=108,87+1,49 \times 10^{10} \mathrm{C}_{\mathrm{IMI}}
$$

O limite de detecção $\left(2,19 \times 10^{-8} \mathrm{~mol} \mathrm{~L}^{-1}\right.$ ou $\left.7 \mu \mathrm{g} \mathrm{L}^{-1}\right)$ foi calculado pelo método baseado nos parâmetros da curva analítica, de acordo com a equação 10, com o termo $\sigma$ referindo-se ao desvio padrão do menor valor que intercepta o eixo y na curva analítica (coeficiente linear da curva analítica), para uma média aritmética de três curvas, e $\boldsymbol{\theta}$ ao coeficiente angular da curva analítica. 
O limite de quantificação $\left(2,96 \times 10^{-7} \mathrm{~mol} \mathrm{~L}^{-1}\right.$ ou $\left.94 \mu \mathrm{g} \mathrm{L}^{-1}\right)$ ficou estabelecido como sendo o primeiro ponto da curva analítica.

Comparando-se o limite de quantificação alcançado com a metodologia proposta empregando SWV/GPU $\left(97 \mu \mathrm{g} \mathrm{L}^{-1}\right)$ e o obtido pelo HPLC $\left(94 \mu \mathrm{g} \mathrm{L}^{-1}\right)$, observa-se que ambas as metodologias podem ser empregadas na análise de rotina de medicamentos e também no monitoramento terapêutico, uma vez que a concentração terapêutica recomendada para muitos antidepressivos tricíclicos está no intervalo de 89 a $269 \mu \mathrm{g} \mathrm{L}^{-1}$, ao passo que os efeitos tóxicos para o organismo podem ocorrer se a concentração plasmática ultrapassar $444 \mu \mathrm{g} \mathrm{L}^{-1}(57)$.

A repetibilidade da metodologia foi avaliada para uma solução de imipramina na concentração de $3,62 \times 10^{-7} \mathrm{~mol} \mathrm{~L}^{-1}$, obtendo-se um RSD de $3,5 \%(n=10)$. A precisão intermediária foi calculada por meio de experimentos realizados em sete dias diferentes, nas mesmas condições experimentais que a repetibilidade, sendo que o RSD obtido foi igual a $4,6 \%$.

Ensaios de recuperação da imipramina em comprimidos de Tofranil $^{\circledR}$ também $^{-}$ foram realizados com a técnica de HPLC para finalizar o processo de investigação da confiabilidade dos resultados obtidos empregando a metolodogia SWV/GPU. Na Figura 29, são apresentados os cromatogramas para a injeção do medicamento e de diferentes concentrações do padrão de imipramina, além da curva de recuperação aparente inserida $(R=0,9986)$. 


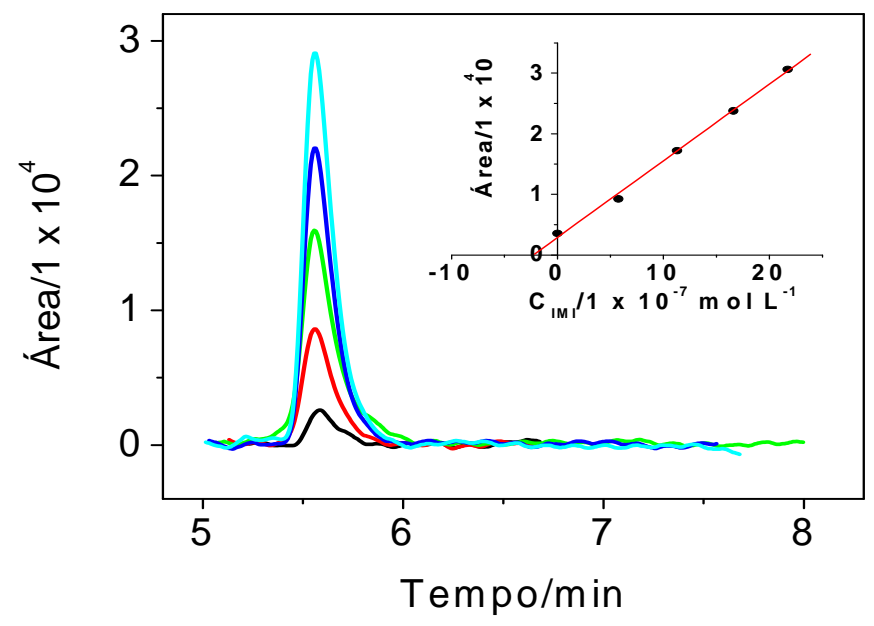

Figura 29 - Cromatogramas para diferentes concentrações de imipramina. $\mathrm{C}_{\mathrm{IMI}}$ adicionada: $(-)$ medicamento, $(-)$ 5,74, ( ) 11,27, (-) 16,59 e ( 30 \% tampão acetato de amônio $0,10 \mathrm{~mol} \mathrm{~L}^{-1}(\mathrm{pH} \mathrm{5,0)}$. Volume injetado: $20 \mu \mathrm{L}$. Detecção: $220 \mathrm{~nm}$. Inserido: curva de recuperação aparente $(R=0,9960)$.

A recuperação aparente média $(n=5)$ foi de $95,10 \pm 2,91 \%(23,72 \pm 0,71 \mathrm{mg})$, com bias igual a $2,3 \%$. Na caixa de Tofranil $^{\circledR}$, está rotulado que cada comprimido contém $25 \mathrm{mg}$ de cloridrato de imipramina, assim, a quantidade de medicamento adicionada e recuperada pela técnica de HPLC mostra-se coerente com o encontrado por SWV/GPU $(97,59 \pm 0,90 \%$ ou $24,39 \pm 0,22 \mathrm{mg})$, revelando que a metodologia eletroanalítica desenvolvida pode ser utilizada na análise de rotina desse medicamento. 


\section{III.3- DETERMINAÇÃO ANALÍTICA DE IMIPRAMINA EM AMOSTRA DE SORO SINTÉTICO}

Como pôde ser observado nos resultados da seção anterior, a metodologia analítica desenvolvida mostrou-se rápida, sensível, exata e precisa para a análise de rotina de imipramina em comprimidos de Tofranil $^{\circledR}$ no eletrólito puro. O limite de quantificação alcançado pela metodologia eletroanalítica $\left(97 \mu \mathrm{g} \mathrm{L}^{-1}\right)$ está dentro da concentração plasmática terapêutica da imipramina (75 a $\left.250 \mu \mathrm{g} \mathrm{L}^{-1}\right)(10)$, o que motivou o estudo para diagnosticar a viabilidade de aplicação direta desta metodologia em amostras de soro sintético humano sem efetuar uma etapa de pré-tratamento da amostra. Apesar da metodologia apresentar boa sensibilidade, a seletividade é um parâmetro extremamente importante nesta matriz, visto que se deve considerar o efeito do metabolito ativo (desipramina) no perfil voltamétrico da imipramina.

Inicialmente, os experimentos consistiram em diagnosticar a interferência dos constituintes do soro humano sintético previamente descritos na etapa experimental (seção II.2.2.7). Nenhuma interferência foi observada para a glicina [214], alanina [282], arginina [321], histidina [189], lisina [317], fenilalanina [290], serina [345], tirosina [123] e triptofano [180]. No entanto, o ácido aspártico [71] e a cisteína [60] foram os aminoácidos que apresentaram uma interferência considerável na intensidade do pico voltamétrico da imipramina, sugerindo a ocorrência de interações de natureza eletrostática com a superfície do eletrodo de GPU, uma vez que esses aminoácidos contêm regiões com densidade de carga negativa na molécula. Os valores entre 
colchetes estão relacionados com a razão molar do composto interferente para uma concentração de imipramina igual a $6,53 \times 10^{-7} \mathrm{~mol} \mathrm{~L}^{-1}$.

Em seguida, um estudo da variação da concentração da imipramina foi realizada em uma solução de soro humano sintético para determinar se a sensibilidade da metodologia é diminuída nessa matriz. Nas Figuras 30 (I) e (II), são apresentados os voltamogramas de onda quadrada registrados para várias adições de imipramina no intervalo de $6,53 \times 10^{-7}$ a $48,89 \times 10^{-7} \mathrm{~mol} \mathrm{~L}^{-1}$ e a curva analítica, respectivamente.
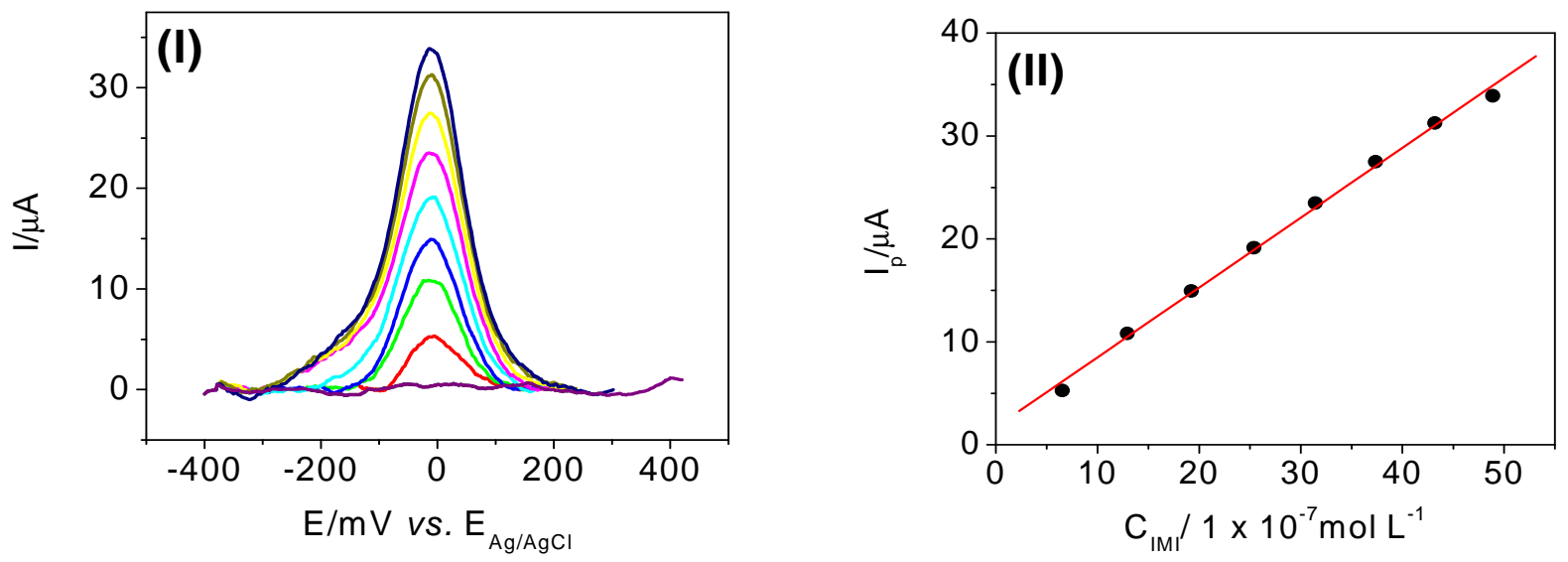

Figura 30 - (I) Voltamogramas de onda quadrada variando-se a concentração de imipramina adicionada em amostra de soro humano sintético $(\mathrm{pH} 7,6)$. Concentrações: $(-)$ branco, $(-)$ 6,53, $(-)$ 12,94, $(-)$ 19,22, ( $\left(\right.$ ) 25,38, (-) 31,43, ( ) 37,36, (-) 43,18 e $(-) 48,89 \times 10^{-7} \mathrm{~mol} \mathrm{~L}^{-1}$. Eletrodo de trabalho: compósito grafite-poliuretana. $f=100 \mathrm{~s}^{-1}, a=50 \mathrm{mV}$ e $\Delta \mathrm{E}_{\mathrm{i}}=2 \mathrm{mV}$. (II) curva analítica $(\mathrm{n}=10 \mathrm{e}$ $R=0,9988)$.

A equação da reta para a curva analítica (Figura 30 (II)) é dada pela equação 12, com o coeficiente de correlação igual a 0,9983.

$$
I_{p}(\mu A)=1,70 \times 10^{-6}+6,79 \times C_{\text {IMI }}\left(10^{-7} \mathrm{~mol} \mathrm{~L}^{-1}\right)
$$


Ao analisar o coeficiente angular da curva analítica em eletrólito puro $(16,38)$ e em soro humano sintético $(6,79)$, observa-se um decréscimo bem pronunciado da sensibilidade do método ocasionado pelo efeito da matriz, o qual é comprovado pelos menores valores dos limites de detecção $\left(5,3 \mu \mathrm{g} \mathrm{L}^{-1}\right)$ e de quantificação $\left(207 \mu \mathrm{g} \mathrm{L}^{-1}\right)$ alcançados. No entanto, o limite de quantificação alcançado nesta matriz ainda está no intervalo da concentração terapêutica plasmática da imipramina (75 a $\left.250 \mu \mathrm{g} \mathrm{L}^{-1}\right)(10)$.

A precisão da metodologia, aplicada em amostra de soro humano sintético, foi avaliada por meio de 10 medidas sucessivas de uma solução de imipramina $6,23 \times 10^{-7} \mathrm{~mol} \mathrm{~L}^{-1}$. Para a precisão intra-day (repetibilidade), o RSD foi igual a $1,9 \%$. A precisão inter-day (precisão intermediária) resultou em um RSD igual a 3,2\%.

A exatidão também foi checada por meio do cálculo do erro relativo (\%bias) nos experimentos de recuperação aparente de imipramina. O bias foi igual a $4,1 \%$, o qual indica que a metodologia apresenta uma boa exatidão.

Como foi realizado um estudo para diagnosticar a interferência de cada constituinte da matriz, a quantidade de imipramina recuperada pôde ser obtida diretamente da curva analítica (equação 12). A recuperação média $(n=5)$ foi igual a $90,34 \pm 3,62 \%(22,58 \pm 0,93 \mathrm{mg})$. As recuperações aparentes obtidas com a metodologia SWV/GPU em eletrólito puro $(97,59 \pm 0,90 \%$ ou $24,39 \pm 0,22 \mathrm{mg})$, com a técnica de HPLC $(95,10 \pm 2,91 \%$ ou $23,72 \pm 0,71 \mathrm{mg})$ e com a metodologia SWV/GPU em amostra de soro humano sintético $(90,34 \pm 3,62 \%$ ou $22,58 \pm 0,93 \mathrm{mg})$ são bastante satisfatórias e indicam que a metodologia eletroanalítica pode ser aplicada na análise direta de imipramina em amostra de soro humano sintético sem a interferência significativa dos constituintes desta matriz. 
Para finalizar o estudo nesta matriz, deve-se levar em consideração que a imipramina é metabolizada a desipramina, pela perda de um grupo metila da cadeia alifática, a qual também exibe atividade antidepressiva. Por isso, é crucial investigar se a metodologia eletroanalítica seja seletiva a ponto de separar o pico voltamétrico da imipramina e de seu metabólito. Os experimentos foram realizados levando-se em consideração a concentração plasmática terapêutica de ambas as espécies (75 a $250 \mu \mathrm{g} \mathrm{L}^{-1}$ para a imipramina e $175 \mu \mathrm{g} \mathrm{L}^{-1}$ para a desipramina).

Na Figura 31, é apresentado o voltamograma de onda quadrada de uma mistura de imipramina $\left(6,21 \times 10^{-7} \mathrm{~mol} \mathrm{~L}^{-1}\right.$ ou $\left.197 \mu \mathrm{g} \mathrm{L}^{-1}\right)$ e desipramina $\left(5,23 \times 10^{-7} \mathrm{~mol} \mathrm{~L}^{-1}\right.$ ou $\left.158 \mu \mathrm{g} \mathrm{L}^{-1}\right)$.

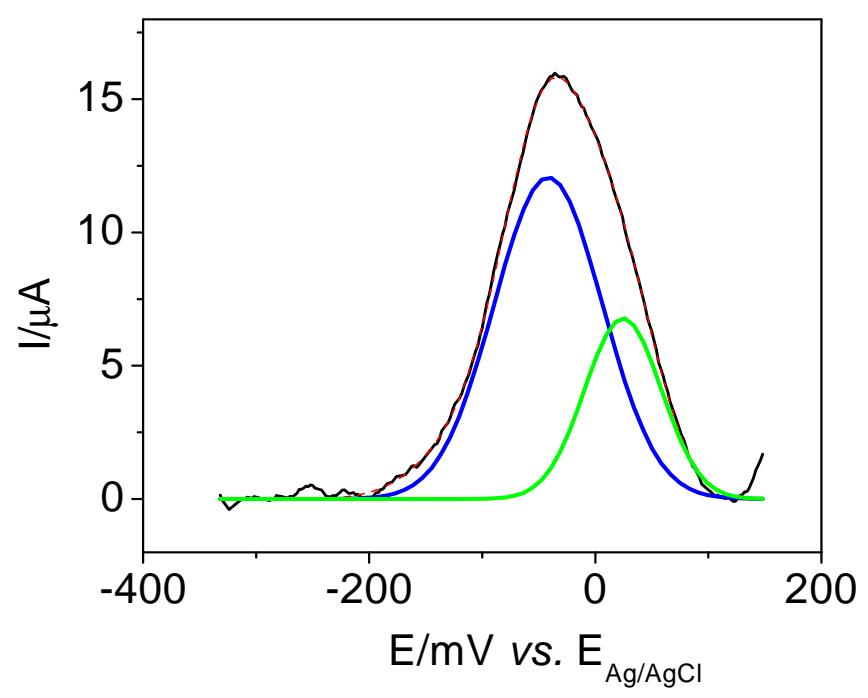

Figura 31 - Voltamograma de onda quadrada de uma mistura de imipramina $\left(6,21 \times 10^{-7} \mathrm{~mol} \mathrm{~L}^{-1}\right)$ e desipramina $\left(5,23 \times 10^{-7} \mathrm{~mol} \mathrm{~L}^{-1}\right)$ em amostra de soro humano sintético $(\mathrm{pH} 7,6)$. ( -$)$ Curva experimental, $(\rightarrow$ Curva obtida após deconvolução, $(-)$ Pico de oxidação da desipramina e $(-)$ Pico de oxidação da imipramina. Eletrodo de trabalho: compósito grafite-poliuretana. $f=100 \mathrm{~s}^{-1}, a=50 \mathrm{mV}$ e $\Delta \mathrm{E}_{\mathrm{i}}=2 \mathrm{mV}$. 
Como pode ser visto na Figura 31, o voltamograma da mistura apresentou um único pico com perfil alargado, indicando que há a sobreposição dos picos de oxidação de cada composto. O comprometimento da seletividade do método já era esperado, uma vez que a imipramina e a desipramina apresentam estruturas químicas bastante semelhantes e o mesmo sítio de oxidação (nitrogênio do anel). Por essa razão, tornouse necessário a utilização de um método matemático de deconvolução, utilizando o programa de computador Microcal Origin 6.0, para a separação dos picos voltamétricos. O procedimento de deconvolução do pico voltamétrico foi bem sucedido, possibilitando a separação dos dois picos referentes à oxidação do dímero formado após a oxidação da imipramina (-41 $\mathrm{mV})$ e da desipramina $(23 \mathrm{mV})$.

Com o intuito de avaliar se o tratamento matemático utilizado torna possível a determinação analítica da imipramina na presença de desipramina, curvas analíticas $(n=3)$ foram construídas obedecendo o intervalo da concentração plasmática de ambos os compostos. Nas Figuras 32 (I) e (II), são apresentados os voltamogramas de onda quadrada, após o tratamento matemático, no intervalo de concentração de $2,97 \times 10^{-7}$ a $9,04 \times 10^{-7} \mathrm{~mol} \mathrm{~L}^{-1}$ e a curva analítica, respectivamente. 

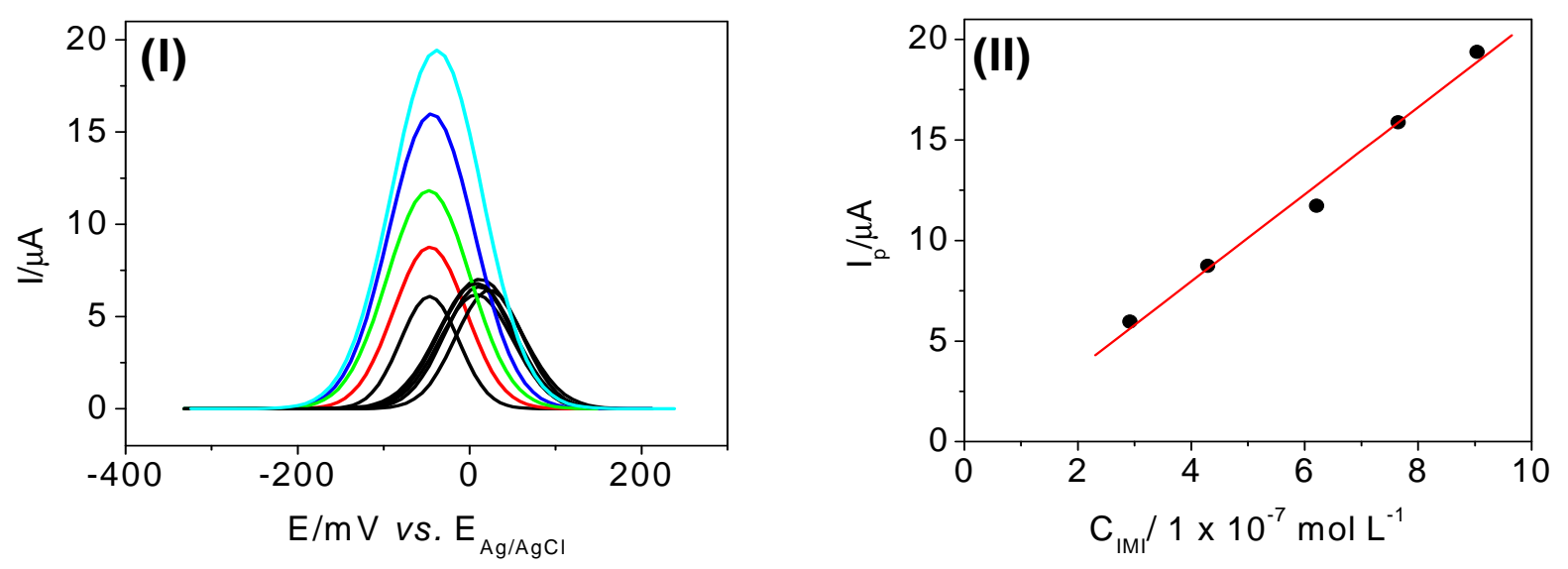

Figura 32 - (I) Voltamogramas de onda quadrada variando-se a concentração de imipramina em amostra de soro humano sintético $(\mathrm{pH} 7,6)$ : $(-)$ 2,97, (-) 4,29, (-) 6,21, ( $)$ 7,65 e (-) $9,04 \times 10^{-7} \mathrm{~mol} \mathrm{~L}{ }^{-1}$. Concentração de desipramina: $5,23 \times 10^{-7} \mathrm{~mol} \mathrm{~L}^{-1}$. Eletrodo de trabalho: compósito grafite-poliuretana. $f=100 \mathrm{~s}^{-1}, a=50 \mathrm{mV}$ e $\Delta \mathrm{E}_{\mathrm{i}}=2 \mathrm{mV}$. (II) Curva analítica $(\mathrm{R}=0,9938)$.

A equação da reta para a curva analítica (Figura 31 (II)) é dada pela equação 13, com o coeficiente de correlação igual a 0,9938.

$$
I_{p}(\mu A)=-6,98 \times 10^{-7}+21,65 \times C_{I M I}\left(10^{-7} \mathrm{~mol} \mathrm{~L}^{-1}\right)
$$

Os resultados obtidos com a metodologia eletroanalítica GPU/SWV são bastante satisfatórios para a determinação direta de imipramina tanto para a análise de rotina em comprimidos de Tofranil $^{\circledR}$, como também em outras matrizes tais como amostras de soro humano sintético. 


\section{III.4- ESTUDO QUÍMICO-QUÂNTICO DA IMIPRAMINA (50)}

Por meio das técnicas voltamétricas, foi possível extrair vários parâmetros importantes para o estudo do comportamento oxidativo da imipramina sobre eletrodo compósito de grafite-poliuretana, dentre eles, o grau da reversibilidade da reação, a presença ou não de processos de adsorção na superfície do eletrodo e o número de prótons e elétrons envolvidos na reação. No entanto, para o melhor entendimento do processo eletroquímico, foi realizado em paralelo um estudo químico-quântico com o objetivo de auxiliar na especulação do provável sítio de oxidação da molécula de imipramina.

A primeira etapa do estudo consistiu no cálculo das cargas atômicas derivadas do potencial eletrostático, apresentado na Tabela VII, para a molécula imipramina no estado fundamental (molécula com carga +1 ) e após a oxidação (molécula com carga +3). Por meio deste cálculo, foi possível avaliar a mudança de densidade eletrônica antes e após a oxidação da molécula. 
Tabela VII - Cálculo das cargas atômicas derivadas do potencial eletrostático para a molécula imipramina no estado fundamental e após oxidação.

\begin{tabular}{c|c|c}
\hline Átomo & Estado fundamental (carga $=++1)$ & Após oxidação (carga $=+3$ ) \\
\hline $1 C$ & $-0,20$ & $-0,35$ \\
$2 \mathrm{C}$ & $-0,13$ & 0,29 \\
$3 \mathrm{C}$ & $-0,07$ & 0,24 \\
$4 \mathrm{C}$ & $-0,16$ & $-0,13$ \\
$5 \mathrm{C}$ & 0,19 & 0,10 \\
$6 \mathrm{C}$ & $-0,27$ & $-0,23$ \\
$7 \mathrm{C}$ & $-0,09$ & $-0,17$ \\
$8 \mathrm{C}$ & $-0,12$ & $-0,32$ \\
$9 \mathrm{C}$ & $-0,03$ & 0,22 \\
$10 \mathrm{C}$ & 0,13 & $-0,25$ \\
$11 \mathrm{~N}$ & $-0,20$ & 0,50 \\
$12 \mathrm{C}$ & $-0,20$ & $-0,28$ \\
$13 \mathrm{C}$ & $-0,14$ & 0,16 \\
$14 \mathrm{C}$ & $-0,14$ & $-0,20$ \\
$15 \mathrm{C}$ & $-0,26$ & $-0,07$ \\
$16 \mathrm{C}$ & $-0,17$ & $-0,39$ \\
$17 \mathrm{C}$ & $-0,18$ & 0,06 \\
$18 \mathrm{C}$ & $-0,25$ & $-0,50$ \\
$19 \mathrm{~N}$ & 0,73 & 0,79 \\
$20 \mathrm{C}$ & $-0,54$ & $-0,53$ \\
$21 \mathrm{C}$ & $-0,47$ & $-0,50$ \\
\hline & & \\
\hline & & \\
\hline
\end{tabular}

Ao analisar a Tabela VII, verifica-se que a remoção de dois elétrons leva a mudanças significativas na densidade eletrônica, a qual é distribuída em toda a molécula,,porém apresentando mudanças perceptíveis somente em poucos sítios, dentre eles, no átomo de nitrogênio 11 e nos átomos de carbono 2,3,9,10,13 e 17. Na 
Figura 33, é apresentada a estrutura da molécula de imipramina com os átomos numerados de acordo com a Tabela VII.

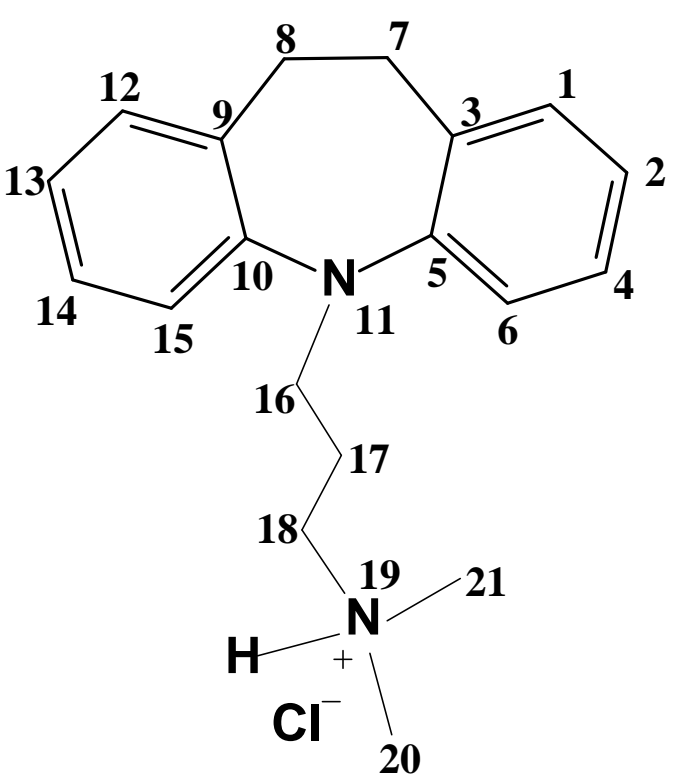

Figura 33 - Molécula de imipramina com os átomos numerados de acordo com a Tabela VII.

Para confirmar os resultados obtidos por meio do cálculo das cargas atômicas derivadas do potencial eletrostático, o orbital molecular de mais alta energia ocupado (HOMO) da molécula de imipramina foi representado graficamente na Figura 34. 


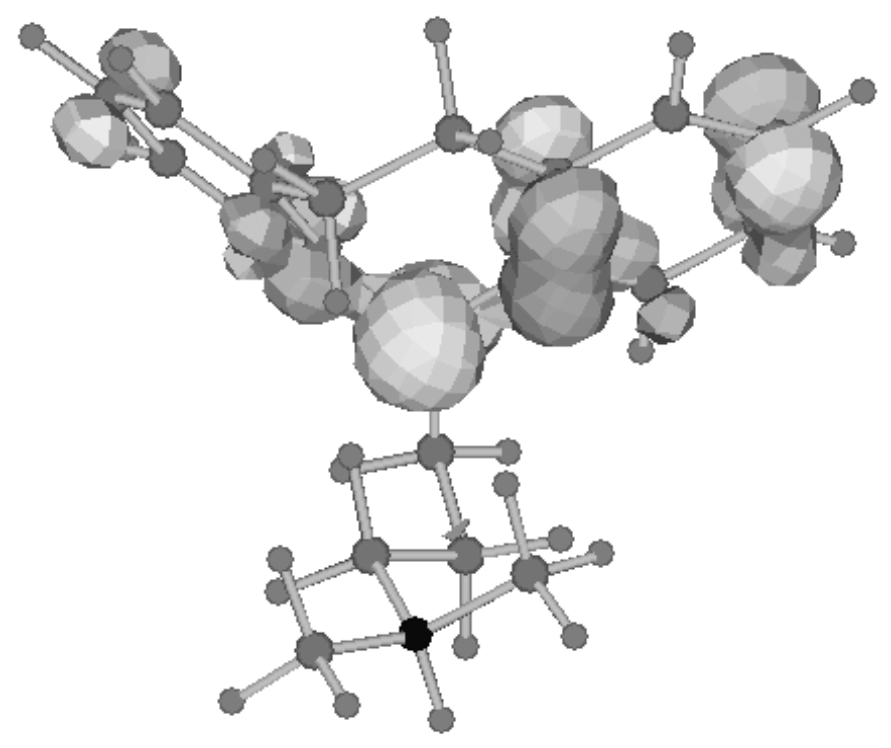

Figura 34 - Representação gráfica do HOMO e LUMO para a molécula de imipramina.

Pela análise do HOMO, orbital molecular de onde sairão os dois elétrons referentes à oxidação da imipramina, confirma-se que a região do átomo N11 é de extrema importância no processo de oxidação da molécula.

A formação do dímero na posição 2 , como relatada no trabalho de Frank e colaboradores (7), também foi evidenciada pelo cálculo das cargas atômicas que estão na Tabela VII. Pela confirmação da provável região de perda de elétrons, verificou-se que quando a molécula é oxidada, há uma deslocalização de carga entre os átomos de carbono do anel aromático, mais precisamente nos carbonos C2 e C6. 
A maior variação de densidade de carga ocorre no átomo de carbono $\mathrm{C2}$, o que indica que, provavelmente, é neste átomo que ocorre o acoplamento com outra molécula de imipramina para então gerar o dímero em uma etapa química posterior à transferência eletrônica.

A formação do dímero também foi averiguada pelos valores da variação dos calores de formação $\left(\Delta \mathrm{H}_{\mathrm{f}}\right)$ para a molécula no estado fundamental $\left(40,42 \mathrm{kcal} \mathrm{mol}^{-1}\right)$, após a oxidação $\left(482,71 \mathrm{kcal} \mathrm{mol}^{-1}\right)$ e para o dímero $\left(81,67 \mathrm{kcal} \mathrm{mol}^{-1}\right)$. Os resultados sugerem que, após a oxidação, a molécula de imipramina tende a formar o dímero em uma etapa química posterior, o qual é energeticamente mais favorável se comparado com a molécula triplamente ionizada.

Uma evidência experimental adicional para a formação do dímero está representada na Figura 35. A amitriptilina também é um antidepressivo da classe dos tricíclicos e sua estrutura, inserida na Figura 35, assemelha-se muito com a da imipramina, porém com a ausência do nitrogênio do anel. Pode-se observar que no voltamograma cíclico da amitriptilina não há pico referente à formação do dímero, ou seja, neste caso, a oxidação poderá ocorrer na dupla ligação da cadeia alifática (58). 


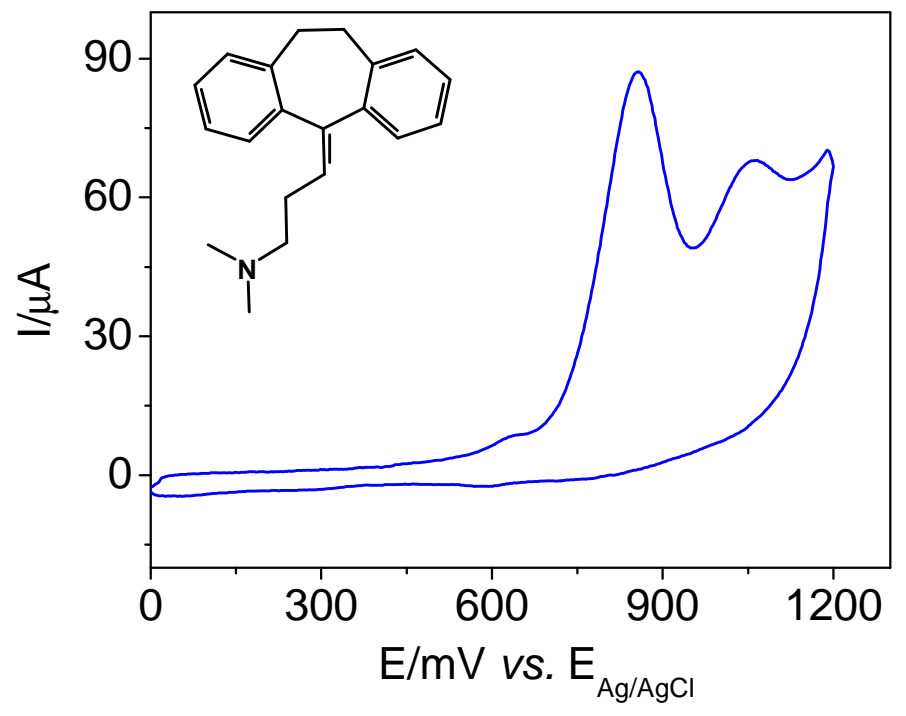

Figura 35 - Voltamograma cíclico de uma solução de amitriptilina $2,10 \times 10^{-4} \mathrm{~mol} \mathrm{~L}^{-1}$ em tampão BR $0,10 \mathrm{~mol} \mathrm{~L}^{-1}(\mathrm{pH} 7,0)$. Eletrodo de trabalho: compósito grafite-poliuretana. Estrutura da amitriptilina inserida.

Com o objetivo de identificar os produtos gerados durante a reação de oxidação da imipramina, foi realizado um experimento de eletrólise a potencial controlado para a obtenção de quantidades significativas de produtos para serem analisados por espectrometria de massa com ionização por electrospray (ESI-MS). Paralelamente, voltamogramas de onda quadrada também foram registrados durante a eletrólise para confirmar a formação do dímero ou então de outros produtos de reação.

A eletrólise foi realizada partindo-se de uma solução estoque de imipramina $6,96 \times 10^{-4} \mathrm{~mol} \mathrm{~L}^{-1}$ em tampão BR $0,10 \mathrm{~mol} \mathrm{~L}^{-1}(\mathrm{pH} 7,0)$. O potencial foi fixado em $1,0 \mathrm{~V}$ e os voltamogramas de onda quadrada foram registrados a cada 30 minutos com a finalidade de se acompanhar as possíveis mudanças ocorridas durante o processo de oxidação da imipramina. No decorrer da eletrólise, verificou-se a mudança de coloração 
da solução de incolor para marrom claro devido às espécies geradas na reação eletroquímica. Além desta mudança, foi observada a formação de um filme azul sobre a superfície do eletrodo de platina, o qual foi dissolvido em etanol com o auxílio de um banho de ultrassom.

Na Figura 36, são apresentados os voltamogramas de onda quadrada do dímero para os seguintes tempos de eletrólise: 0, 30, 60, 90 e 120 minutos, podendo-se observar que após 120 minutos cerca de $14 \%$ de imipramina foi eletrolisada.

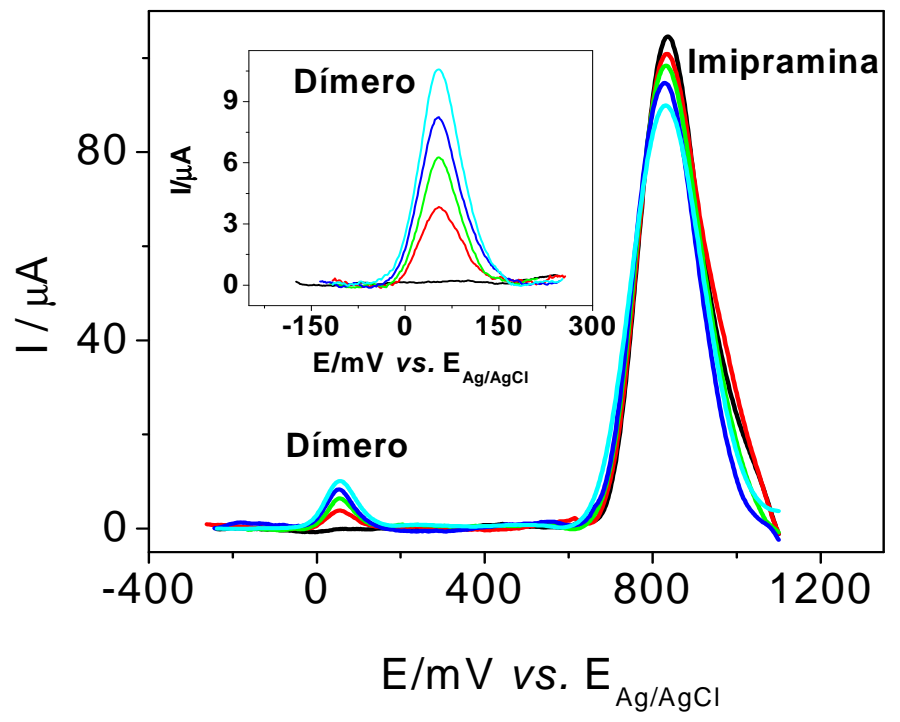

Figura 36 - Voltamogramas de onda quadrada de uma solução de imipramina $6,96 \times 10^{-4} \mathrm{~mol} \mathrm{~L}^{-1}$ em tampão BR $0,10 \mathrm{~mol} \mathrm{~L}^{-1}(\mathrm{pH} \mathrm{7,0)}$. Tempos de eletrólise: $(-)$, ( $(-) 30$, $(-) 60,(-) 90$ e $(-) 120$ minutos. Eletrodo de trabalho compósito grafite-poliuretana.

Os espectros de massa foram registrados tanto para a solução não eletrolisada (Figura 37 (I)), como também para a solução eletrolisada (Figura 38 (I)) e para a solução contendo o filme eletrodepositado (Figura 39 (I)). Com o intuito de confirmar as 
evidências experimentais e teóricas já discutidas, quanto à formação do dímero, os espectros de massa foram ampliados até a região com $\mathrm{m} / \mathrm{z}=580,0$, para então verificar a presença de picos que possam sugerir a fragmentação da molécula do dímero.

Os espectros de massa obtidos com ionização por electrospray são caracterizados por apresentarem poucos picos de fragmentação, uma vez que se trata de uma técnica de fragmentação branda. Embora seja normalmente considerada como uma fonte de ionização, o electrospray é, na realidade, um processo de transferência de íons pré-existentes em solução para a fase gasosa. Assim, muitos íons formados na fase gasosa mantêm exatamente a mesma estrutura e carga das espécies em solução (46). Na Figura 38 (I), que corresponde ao espectro de massa da solução eletrolisada, é observado um pico de íon majoritário em $\mathrm{m} / \mathrm{z}=281,4$, o qual pode ser atribuído à massa molar da imipramina que não foi eletrolisada $\left(281,4 \mathrm{~g} \mathrm{~mol}^{-1}\right)$, pois a eletrólise não foi exaustiva. Já para o filme adsorvido na superfície do eletrodo, há um pico de íon em $\mathrm{m} / \mathrm{z}=280,4$ (Figura $39(\mathrm{I})$ ), o qual pode estar relacionado com a formação do dímero. Para melhor visualização, as estruturas da imipramina e do dímero formado na reação eletroquímica estão representadas nas Figuras 38 (I) e 39 (I). 


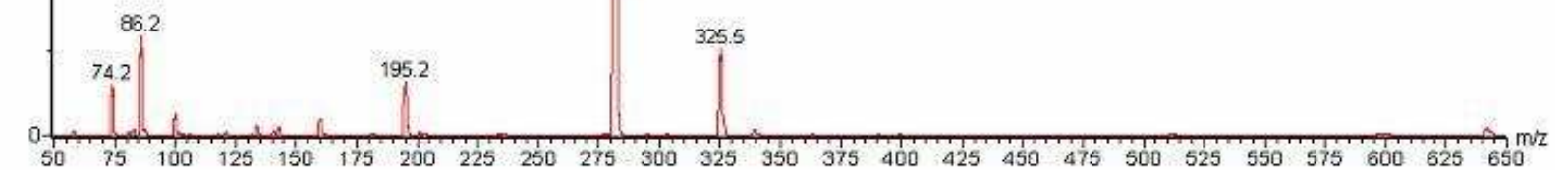

11/03/2005

mauro imipra 22 (0.599) $\mathrm{Cm}(19.30-(2.15+37.46)\}$

$100 \div 55283.4 \quad 325.5,3257$

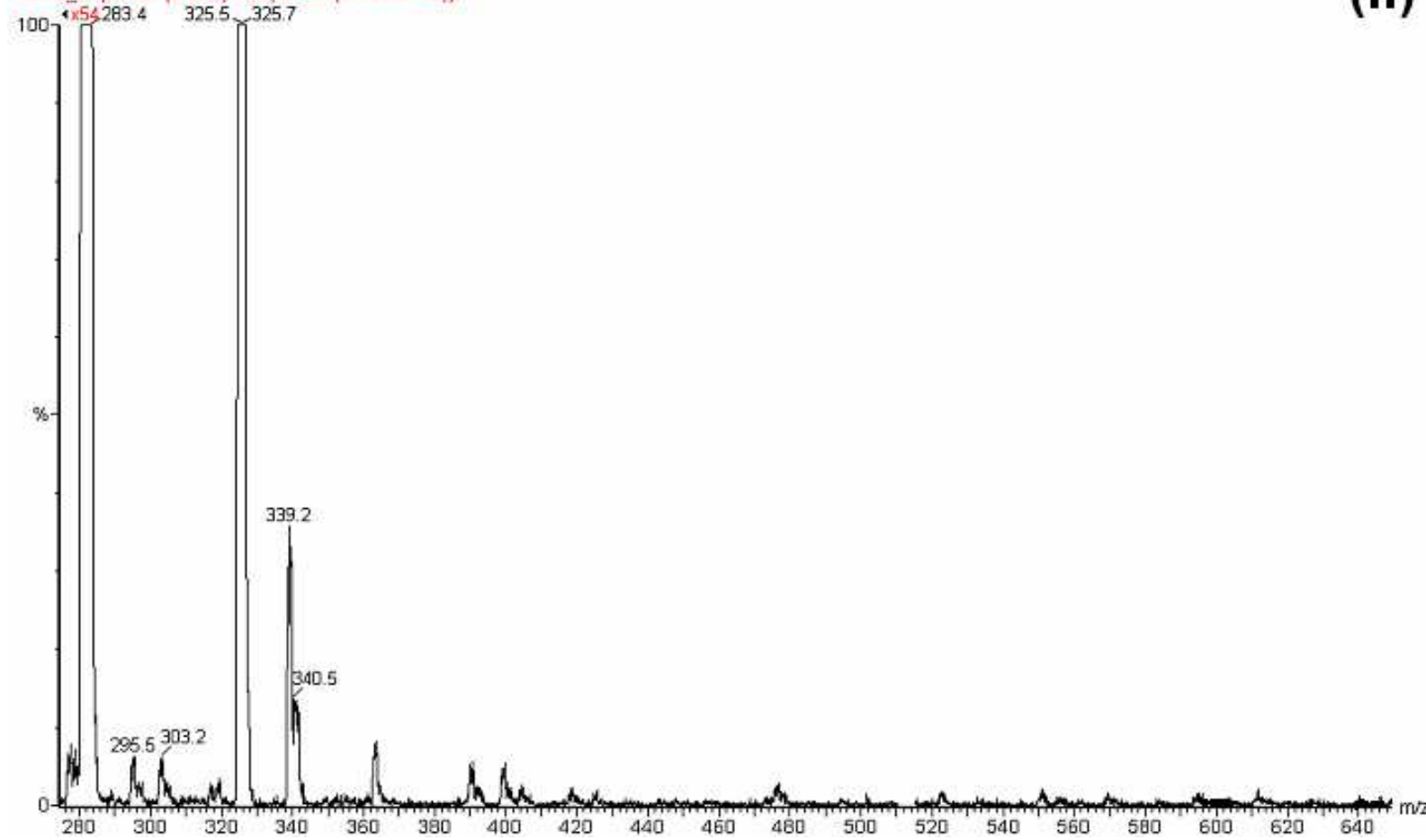

Figura 37 - ESI-MS espectros: (I) solução de imipramina antes da eletrólise e (II) ampliação do ESI-

MS na região acima de $\mathrm{m} / \mathrm{z}=283,4$. 
090904

maurofrasco2 56 (1.228) Sm (Mn, 3×0.80); Cm (49:80-(97:121+22:45))

100

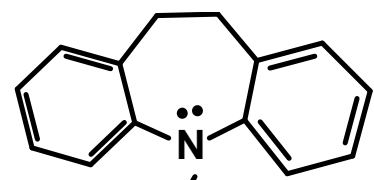

$\mathrm{M}=281,4 \mathrm{~g} \mathrm{~mol}^{-1}$

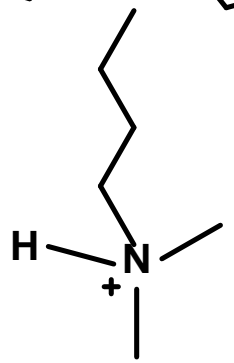

M $=281,4 \mathrm{gmol}^{-1}$

$$
\%
$$

090904

maurofrasco2 56 (1.228) Cn (Cen,2, 80.00, Ht); Sm (Mn, 3×0.80); Sm (Mn, 3×0.80); Cm (49:80-(97:121+22:45))

100

Figura 38 - ESI-MS espectros: (I) solução eletrolisada e (II) ampliação do ESI-MS na região acima de $\mathrm{m} / \mathrm{z}=303,2$. 


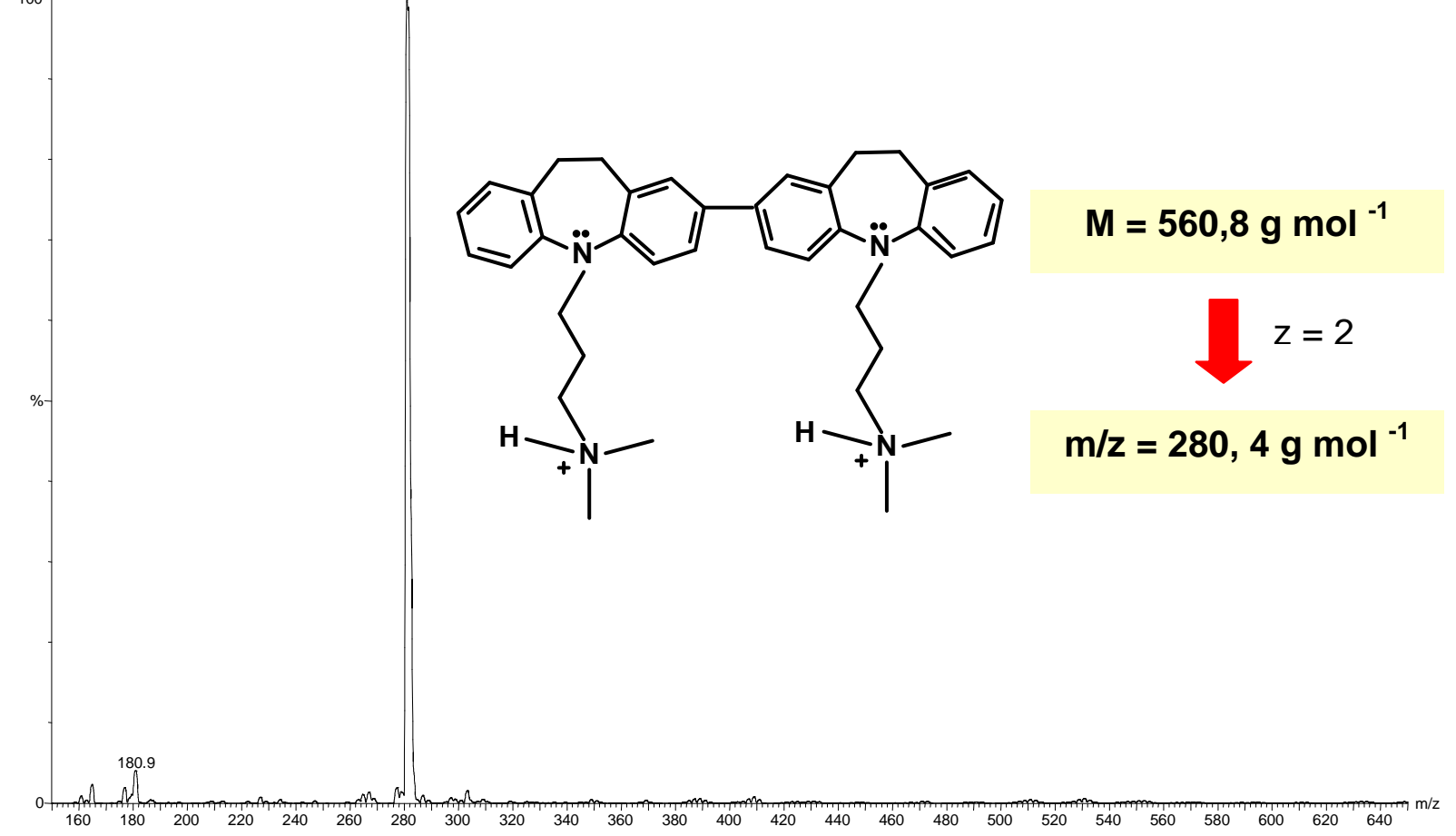

090904

maurofrasco1 51 (1.122) $\mathrm{Cn}(\mathrm{Cen}, 2,80.00, \mathrm{Ht})$; Sm (Mn, 3×0.80); Sm (Mn, 3×0.80); Cm (41:88-(113:133+20:35))

100303.2

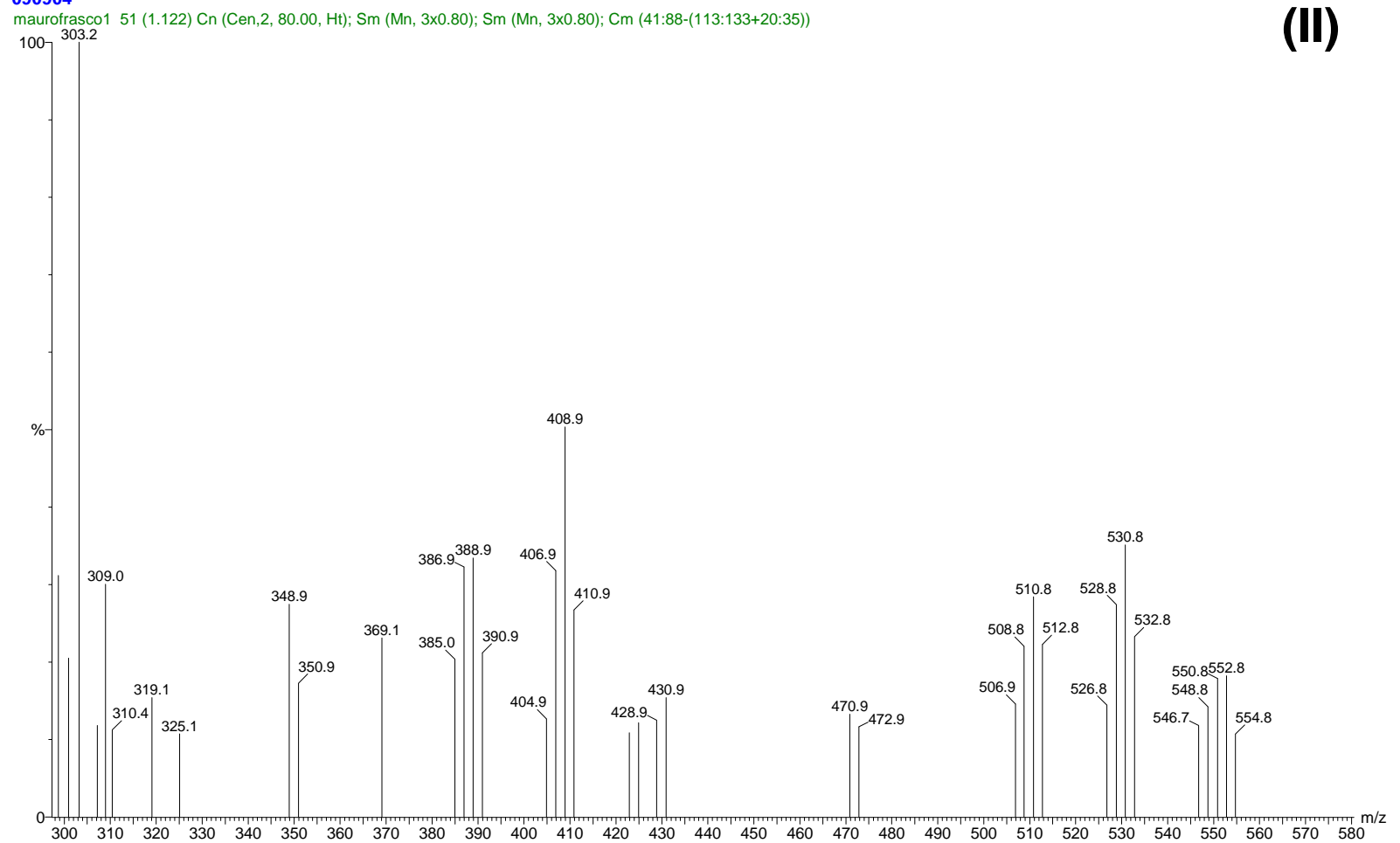

Figura 37 - ESI-MS espectros para: (I) filme eletrodepositado e (II) ampliação do ESI-MS na região acima de $m / z=301,0$. 
Pela análise dos espectros ampliados (54X), os quais correspondem às Figuras 38 (II) e 39 (II), observa-se que existem picos de íons com pequena intensidade na região de $\mathrm{m} / \mathrm{z}=500$, sugerindo que uma pequena fração da molécula do dímero é dissociada antes de alcançar o detector. Este fato pode ser explicado pela existência de um campo elétrico entre o cone de amostragem e as lentes que conduzirão os íons ao analisador de massas. Nesta região, as moléculas do dímero são aceleradas provocando a colisão entre elas e/ou entre o gás secante (nitrogênio) (46). Desta forma, a molécula do dímero poderá sofrer colisão e perder moléculas do solvente ou até mesmo sofrer processos de rearranjo intramolecular ou de fragmentação.

Um espectro de massa para a solução de imipramina foi registrado antes do experimento de eletrólise (Figura 37 (I)). A ausência de picos de íon na região de $\mathrm{m} / \mathrm{z}=$ 500 no espectro ampliado (Figura 37 (II)) confirma que os picos existentes nos espectros das Figuras 38 (II) e 39 (II) referem-se à molécula do dímero.

Em decorrência dos resultados obtidos nos estudos eletroquímicos, químicoquânticos e dos espectros de massa, chegou-se a um mecanismo para a oxidação eletroquímica da imipramina, o qual é apresentado na Figura 40. 


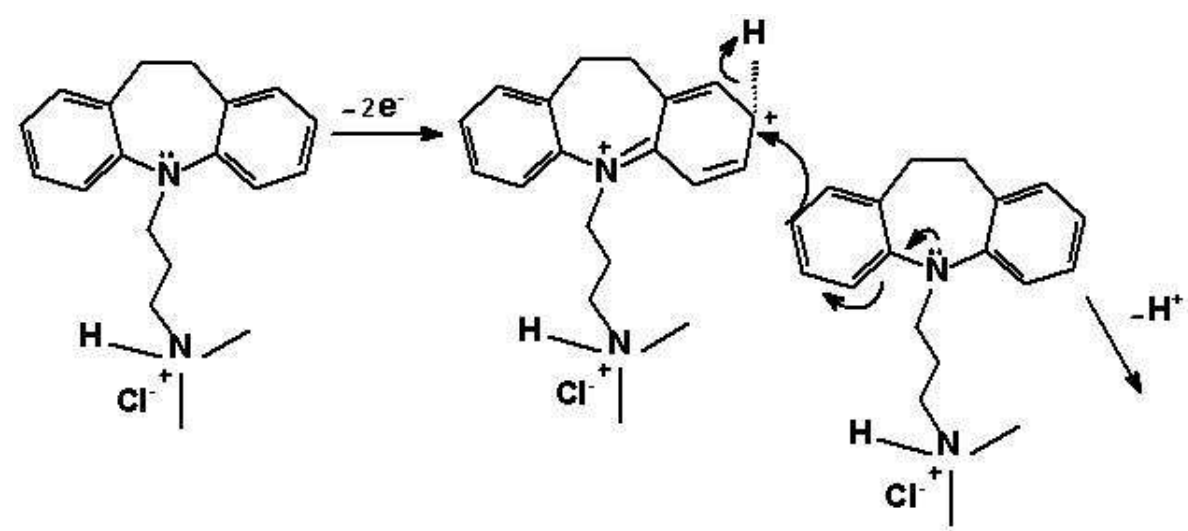

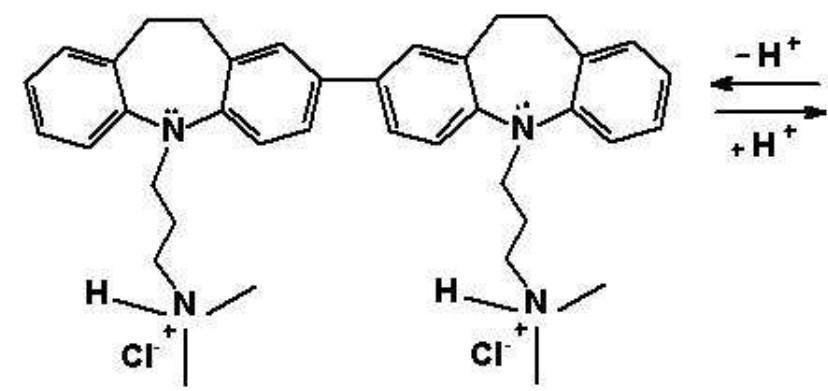

(2)

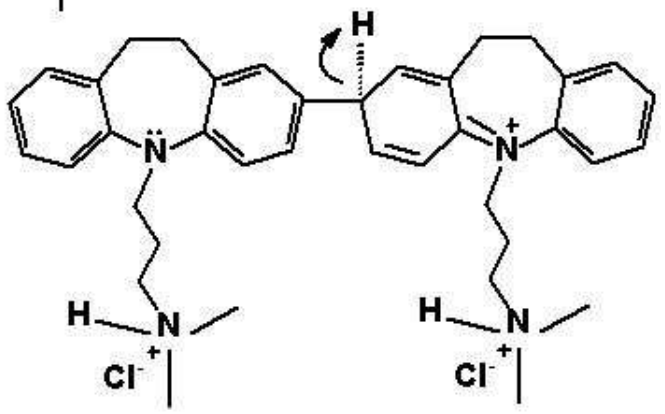

(1)

Figura 38 - Proposta de mecanismo para a oxidação da imipramina.

De acordo com a Figura 40, a imipramina é oxidada com a perda de dois elétrons e um próton. Em seguida, há uma deslocalização de carga positiva pelo anel aromático e um acoplamento entre o cátion e uma molécula em solução, formando a espécie (1), que por sua vez pode perder um próton e gerar a espécie (2). Pelos cálculos químicoquânticos, verifica-se que a espécie (2) apresenta uma entalpia de formação menor $\left(81,67 \mathrm{kcal} \mathrm{mol}^{-1}\right)$ que a espécie (1) $\left(246,31 \mathrm{kcal} \mathrm{mol}^{-1}\right)$, ou seja, o equilíbrio de desprotonação tende à formação da espécie (2) que é energicamente mais favorável. 


\section{III.5- ESTUDO VOLTAMÉTRICO DA DOPAMINA}

\section{III.5.1 - Voltametria cíclica}

\section{III.5.1.1- Teste dos eletrodos}

O estudo preliminar da reação de oxidação da dopamina também consistiu em testes para avaliar o perfil voltamétrico com diferentes eletrodos e compará-los com o eletrodo compósito de grafite-poliuretana. Na Figura 41, são apresentados os voltamogramas cíclicos registrados com os seguintes eletrodos de trabalho: (I) ouro $(\phi=1,00 \mathrm{~mm}) ;(\mathrm{II})$ platina $(\phi=0,50 \mathrm{~mm}) ;(\mathrm{III})$ carbono vítreo $(\phi=5,00 \mathrm{~mm})$ e (IV) compósito de grafite-poliuretana $(\phi=3,00 \mathrm{~mm})$.

Com exceção do eletrodo de platina, no qual não foi observada resposta eletroquímica, a oxidação da dopamina inicia-se na mesma região de potenciais para todos os outros eletrodos $(400 \mathrm{mV})$. O eletrodo compósito de grafite-poliuretana, mais uma vez, resultou em resposta voltamétrica bem mais definida e com maior intensidade de corrente na região de potenciais entre 400 a $600 \mathrm{mV}$ para o pico de oxidação e redução da dopamina. 

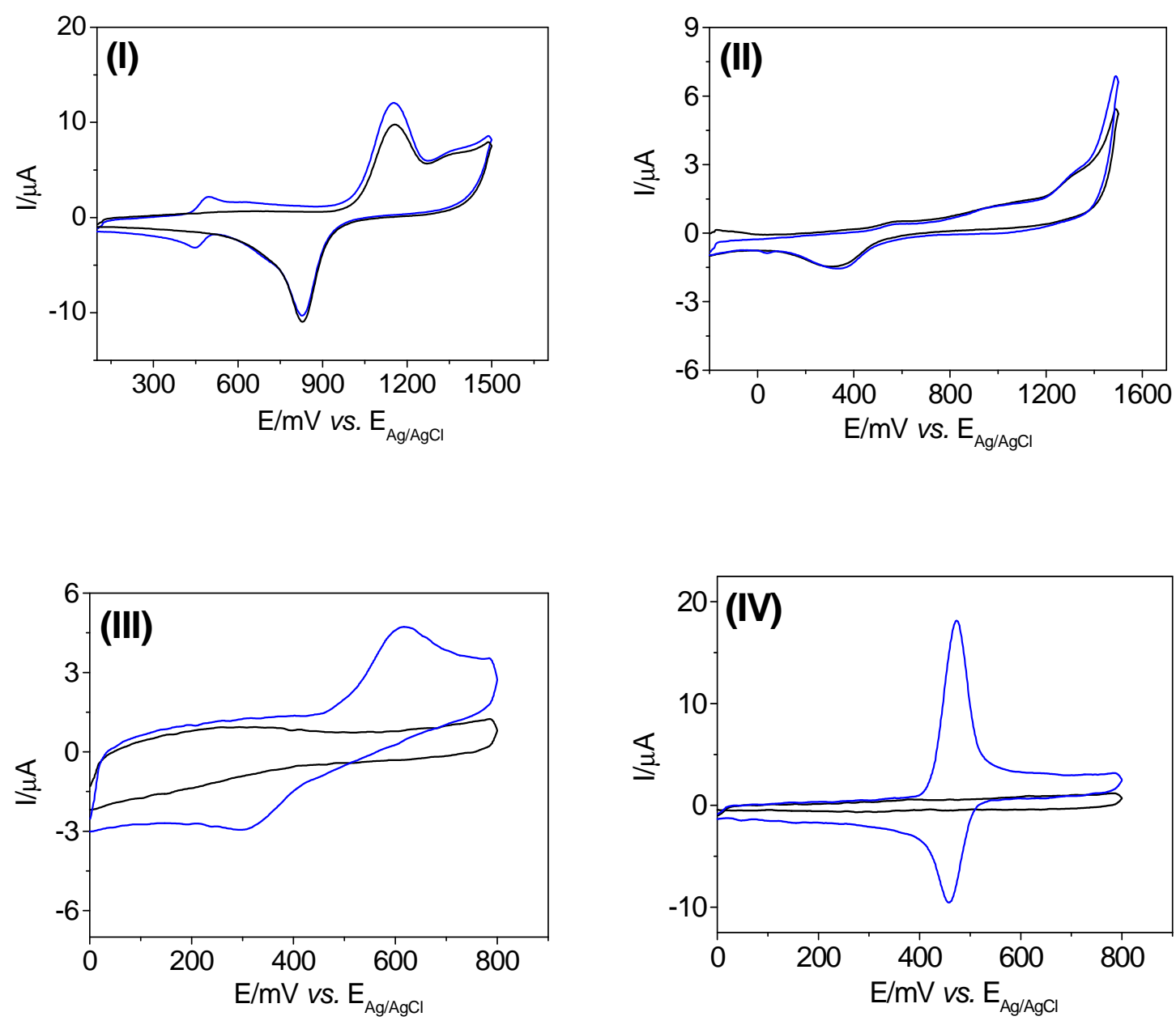

Figura 39 - Voltamogramas cíclicos: (-) tampão BR $0,10 \mathrm{~mol} \mathrm{~L}^{-1}(\mathrm{pH} 2,0)$ e (一) solução de dopamina $1,54 \times 10^{-4} \mathrm{~mol} \mathrm{~L}^{-1}$ em tampão BR $0,10 \mathrm{~mol} \mathrm{~L}^{-1}(\mathrm{pH} \mathrm{2,0)}$. Eletrodos de trabalho: (I) ouro; (II) platina; (III) carbono vítreo e (IV) compósito grafite-poliuretana. $v=100 \mathrm{mV} \mathrm{s}^{-1}$. 


\section{III.5.1.2- Perfil voltamétrico da dopamina}

Com a escolha do eletrodo de trabalho, o perfil voltamétrico da dopamina foi registrado por meio de sucessivas ciclagens de potencial, como mostrado na Figura 42. No primeiro ciclo, na região de potenciais entre 400 a $600 \mathrm{mV}$, pode-se observar 2 picos, em $477 \mathrm{mV}$ e $454 \mathrm{mV}$, referentes à oxidação e a redução da dopamina, respectivamente. Ao observar o segundo ciclo, verifica-se que a sobreposição dos voltamogramas é um indicativo de que não há problemas relacionados com a passivação do eletrodo, pela adsorção irreversível de moléculas de reagente e/ou de produto na superfície do eletrodo (bloqueio de sítios ativos na superfície), nas condições em que o experimento foi realizado.

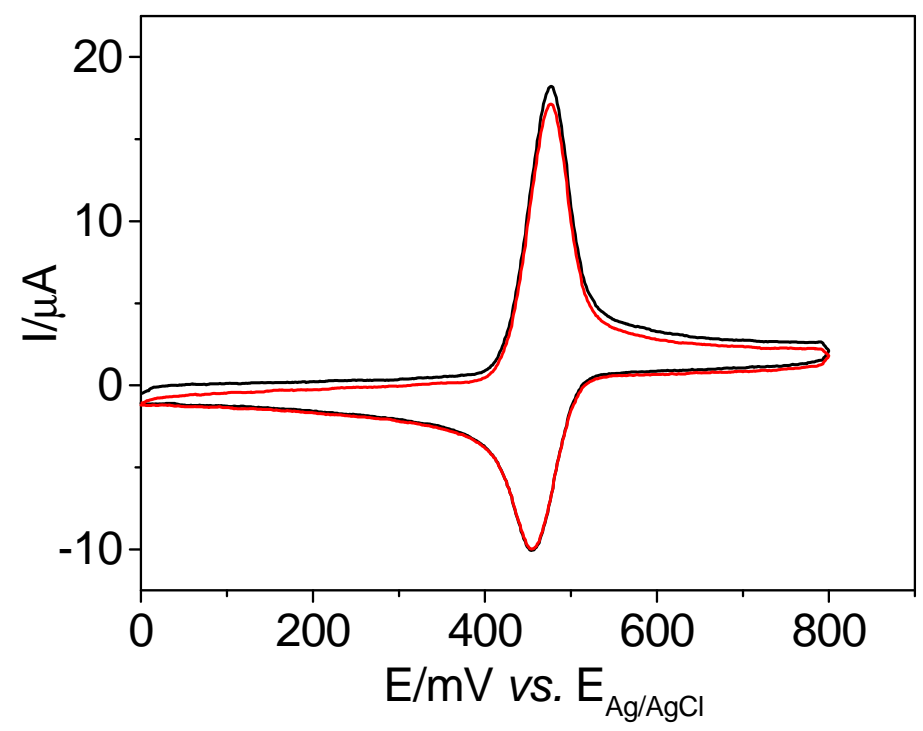

Figura 40 - Voltamogramas cíclicos: $(-) 1^{\circ}$ ciclo e $(-) 2^{\circ}$ ciclo de uma solução de dopamina $1,54 \times 10^{-4} \mathrm{~mol} \mathrm{~L}^{-1}$ em tampão BR $0,10 \mathrm{~mol} \mathrm{~L}^{-1}(\mathrm{pH} 2,0)$. Eletrodo de trabalho: compósito de grafitepoliuretana. $v=100 \mathrm{mV} \mathrm{s}^{-1}$. 


\section{III.5.1.3- Variação da velocidade de varredura}

A velocidade de varredura foi variada no intervalo de 10 a $500 \mathrm{mV} \mathrm{s}^{-1}$, com o objetivo de avaliar o grau de reversibilidade e a natureza do transporte do material eletroativo para a superfície do eletrodo. Na Figura 43, são apresentados os voltamogramas cíclicos, em diferentes velocidades de varredura, de uma solução de dopamina $1,54 \times 10^{-4} \mathrm{~mol} \mathrm{~L}^{-1}$ em tampão BR $0,10 \mathrm{~mol} \mathrm{~L}^{-1}(\mathrm{pH} 2,0)$ e na Tabela VIII, os valores das correntes e dos potenciais para os picos anódico e catódico da dopamina.

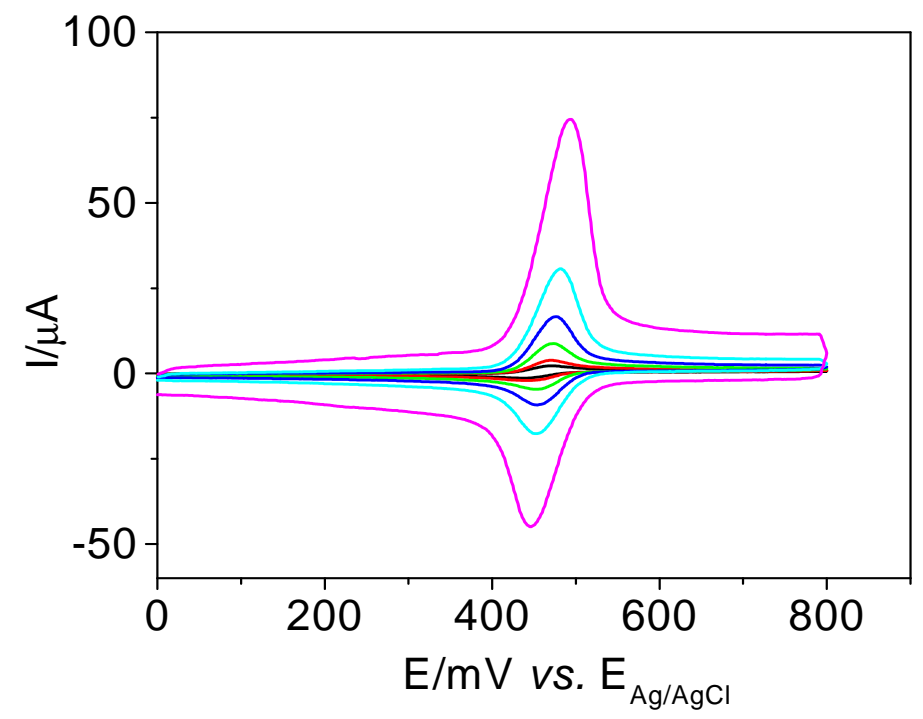

Figura 41 - Voltamogramas cíclicos de uma solução de dopamina $1,54 \times 10^{-4} \mathrm{~mol} \mathrm{~L}^{-1}$ em tampão BR

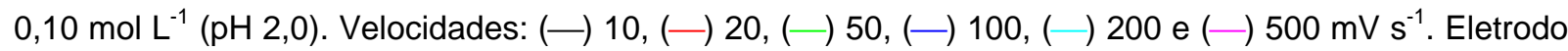
de trabalho: compósito grafite-poliuretana. 
Tabela VIII - Valores de corrente $\left(I_{p}\right)$ e potencial $\left(E_{p}\right)$ de pico para: (I) oxidação da dopamina; (II) redução da dopamina e a diferença entre potencial de pico anódico e catódio $\left(\Delta \mathrm{E}_{\mathrm{p}}\right)$ para o par redox.

\begin{tabular}{c|c|c|c|c|c}
\hline$v$ & $I_{p} / \mu A$ & $E_{p} / m V$ & $I_{p} / \mu A$ & $E_{p} / m V$ & $\Delta E_{p} / m V$ \\
$\left(m^{*} ~ s^{-1}\right)$ & $(I)$ & $(I)$ & $(I I)$ & $(I I)$ & \\
\hline 10 & 2,09 & 470 & $-1,10$ & 435 & 35 \\
20 & 3,62 & 470 & $-2,08$ & 442 & 28 \\
50 & 8,32 & 474 & $-4,38$ & 454 & 20 \\
100 & 15,94 & 476 & $-8,95$ & 454 & 22 \\
200 & 28,06 & 481 & $-17,63$ & 452 & 29 \\
500 & 67,17 & 493 & $-41,47$ & 445 & 48 \\
\hline
\end{tabular}

No intervalo de velocidade estudado, é possível observar uma pequena variação do potencial de pico com o aumento da velocidade de varredura, que é um indicativo da reversibilidade da reação de oxidação da dopamina. Pelo critério da variação do potencial de pico, $\Delta \mathrm{E}_{p}=\mathrm{E}_{\mathrm{pa}}-\mathrm{E}_{\mathrm{pc}}=59 / \mathrm{n}$, o número de elétrons envolvidos no processo redox pôde ser calculado $(n=2)$. A relação entre a corrente de pico anódica e catódica $\left(I_{p a} / I_{p c}=1\right)$, que para sistemas reversíveis simples é igual a um, não foi constatada na reação de oxidação da dopamina em virtude de, possivelmente, complicações cinéticas, ou então pela presença de reações homogêneas acopladas ao processo de eletrodo (59). Para identificar a presença de tais reações, critérios eletroquímicos para cada tipo de mecanismo, dentre eles, EC, CE, catalítico EC' e ECE (E representa uma transferência de elétron heterogênea na superfície do eletrodo e $C$, uma reação química homogênea em solução) foram aplicados. No entanto, a reação de oxidação da 
dopamina não se enquadrou em nenhum dos mecanismos citados, confirmando que a não igualdade das correntes catódicas e anódicas é um indicativo de complicações cinéticas.

A natureza do transporte de massa que governa o processo redox pôde ser conhecida pela relação existente entre $I_{p} v s . v$ e $I_{p} v s . v^{1 / 2}$, que são mostradas nas Figuras 44 (I) e (II).
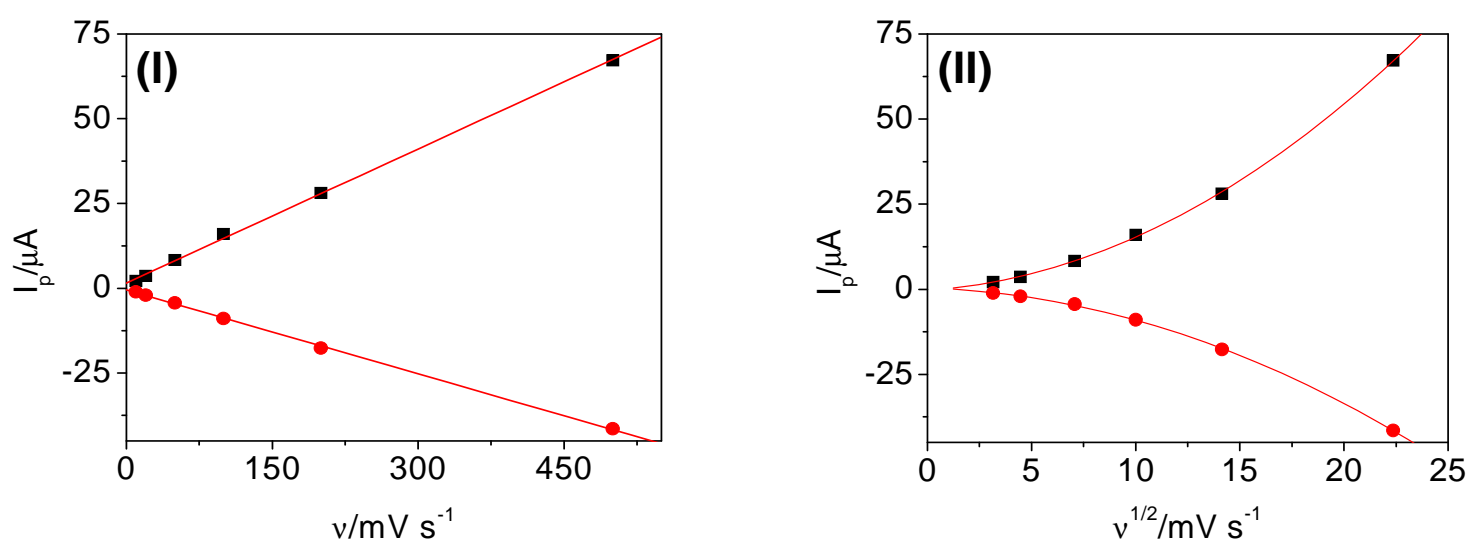

Figura 42 - Gráficos de : (I) $I_{p} v s$. v para: (অ) pico de oxidação da dopamina $(R=0,9996)$ e $(\bullet)$ pico de redução da dopamina $(R=0,9997)$. (II) $I_{p} v s . v^{1 / 2}$ para: ( $(\mathbf{)})$ pico de oxidação da dopamina e $(\bullet)$ pico de redução da dopamina.

A relação linear entre a corrente de pico e a velocidade de varredura e a não linearidade entre a corrente de pico e a raiz quadrada da velocidade de varredura, para o pico anódico e catódico da dopamina, são indicativos da adsorção de moléculas do reagente e/ou do produto na superfície do eletrodo. Os coeficientes angulares $(\theta)$ dos gráficos de $\log \left(I_{p}\right)$ vs. $\log (v)$, apresentados na Figura 45, confirmam a natureza do transporte de massa ( $\theta$ anódico $=0,96$ e $\theta$ catódico $=0,99)$, que, segundo a literatura, 
aproxima-se de 1 para processos limitados pela adsorção de material eletroativo na superfície do eletrodo (52).

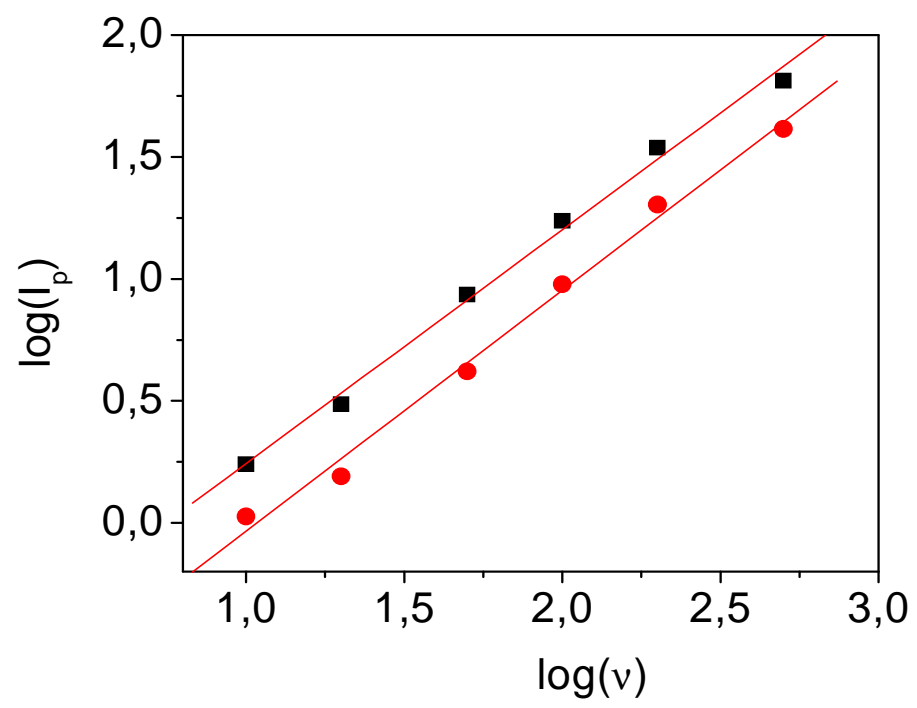

Figura 43 - Gráficos de $\log (v)$ vs. $\log \left(I_{p}\right)$ para: $(\mathbb{\square})$ pico de oxidação da dopamina $(R=0,9974$ e $\theta=0,96)$ $(\bullet)$ pico de redução da dopamina $(\mathrm{R}=0,9963$ e $\theta=0,99)$.

\section{III.5.1.4- Variacão do $\mathrm{pH}$}

O estudo da variação do $\mathrm{pH}$ do meio foi realizado no intervalo de 2 a 9, com o objetivo de avaliar o número de prótons envolvidos na reação de oxidação e redução da dopamina. Pela variação do $\mathrm{pH}$, foi possível constatar em que valor ocorre maior resposta de corrente para fins analíticos. Na Figura 46, são apresentados os voltamogramas cíclicos e na Tabela IX, os valores de correntes e potenciais de pico para a oxidação e redução da dopamina. 


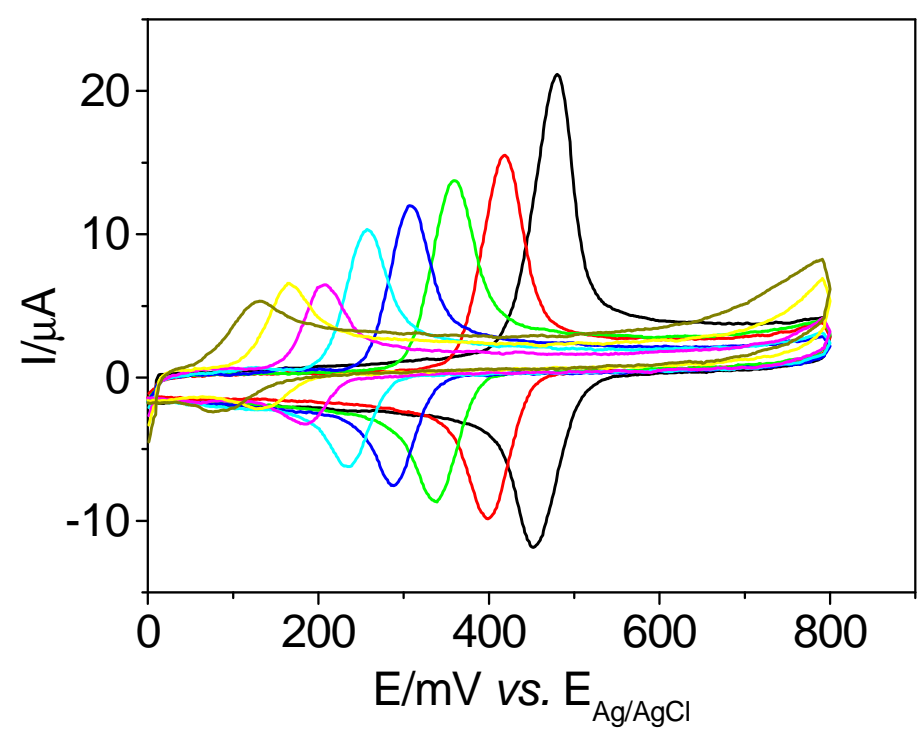

Figura 44 - Voltamogramas cíclicos de uma solução de dopamina $1,54 \times 10^{-4} \mathrm{~mol} \mathrm{~L}^{-1}$ em tampão BR

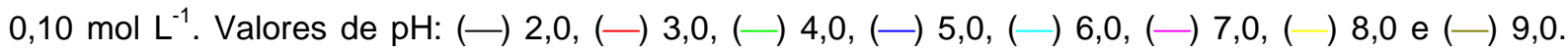
Eletrodo de trabalho: compósito grafite-poliuretana. $v=100 \mathrm{mV} \mathrm{s}^{-1}$.

Ao analisar os voltamogramas apresentados na Figura 46, verifica-se que os potenciais de pico deslocaram-se para valores menos positivos com o aumento do $\mathrm{pH}$, indicando que a transferência eletrônica é dependente da concentração hidrogeniônica do meio. As correntes de pico anódica e catódica apresentaram um decaimento progressivo com o aumento do $\mathrm{pH}$ e, desta forma, sugeriu-se que o meio ácido $(\mathrm{pH} 2,0)$ é interessante para fins analíticos devido à maior resposta de corrente para a oxidação da dopamina. 
Tabela IX - Valores de corrente $\left(I_{p}\right)$ e potencial $\left(E_{p}\right)$ de pico para: (I) oxidação e (II) redução da dopamina.

\begin{tabular}{c|c|c|c|c}
\hline $\mathrm{pH}$ & $\mathrm{I}_{\mathrm{p}} / \mu \mathrm{A}$ & $\mathrm{E}_{\mathrm{p}} / \mathrm{mV}$ & $\mathrm{I}_{\mathrm{p}} / \mu \mathrm{A}$ & $\mathrm{E}_{\mathrm{p}} / \mathrm{mV}$ \\
& $(\mathrm{I})$ & $(\mathrm{I})$ & $(\mathrm{II})$ & $(\mathrm{II})$ \\
\hline 2 & 18,88 & 480 & $-11,74$ & 452 \\
4 & 14,36 & 419 & $-9,87$ & 399 \\
5 & 12,6 & 359 & $-8,58$ & 339 \\
5 & 11,22 & 307 & $-7,36$ & 288 \\
6 & 9,44 & 257 & $-5,88$ & 236 \\
7 & 5,58 & 208 & $-2,76$ & 185 \\
8 & 3,61 & 166 & $-1,52$ & 129 \\
9 & 1,44 & 131 & $-1,44$ & 77 \\
\hline
\end{tabular}

$\mathrm{Na}$ Figura 47, é apresentado o deslocamento dos potenciais de pico com o pH para o processo redox da dopamina. No intervalo de $\mathrm{pH}$ estudado, ocorreu um deslocamento de aproximadamente $50 \mathrm{mV}$ por unidade de $\mathrm{pH}$ para o pico de oxidação da dopamina e de cerca de $53 \mathrm{mV}$ para o pico de redução. Como o número de elétrons já é conhecido ( $n=2$ ), o número de prótons pôde ser calculado, por meio da equação 5 , em todo o intervalo de $\mathrm{pH}$, pelo coeficiente angular dos gráficos de $\mathrm{E}_{\mathrm{p}} v s . \mathrm{pH}$. 


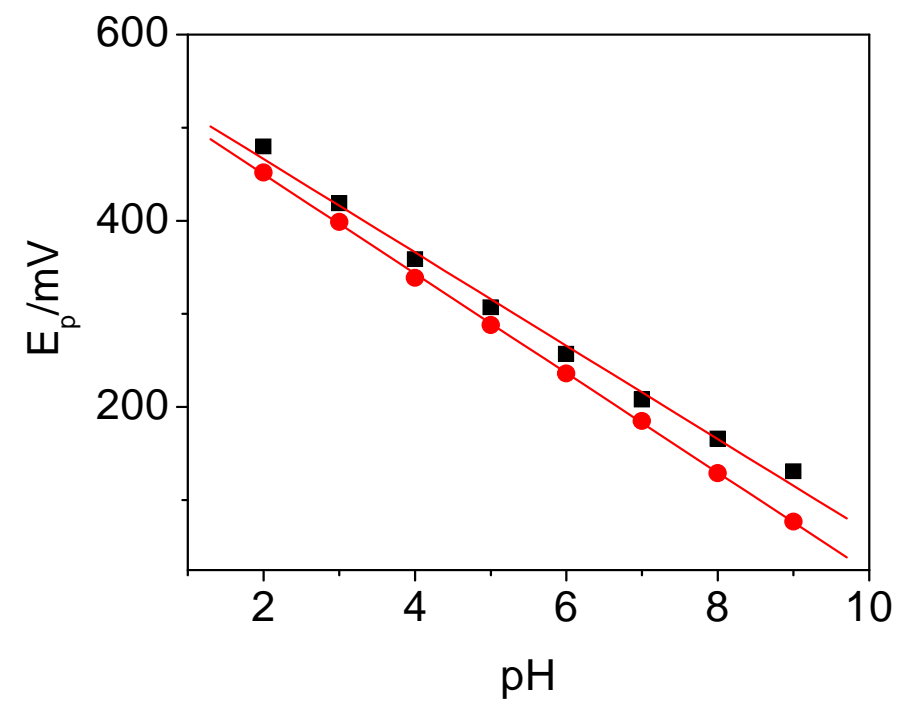

Figura 45 - Gráficos de $E_{p}$ vs. pH para: (ロ) pico de oxidação da dopamina $(R=0,9967$ e $\theta=50,13$ $\mathrm{mV} / \mathrm{pH})(\bullet)$ pico de redução da dopamina $(\mathrm{R}=0,9998$ e $\theta=53,44 \mathrm{mV} / \mathrm{pH})$.

Ao aplicar a equação 5, constatou-se que estão envolvidos 2 prótons durante a oxidação ou então a redução da molécula de dopamina.

\section{III.5.2 - Voltametria de onda quadrada}

\section{III.5.2.1- Separacão das componentes de corrente}

A separação da corrente resultante nas suas componentes direta e reversa, apresentada na Figura 48, também foi efetuada no estudo voltamétrico da oxidação da dopamina. 


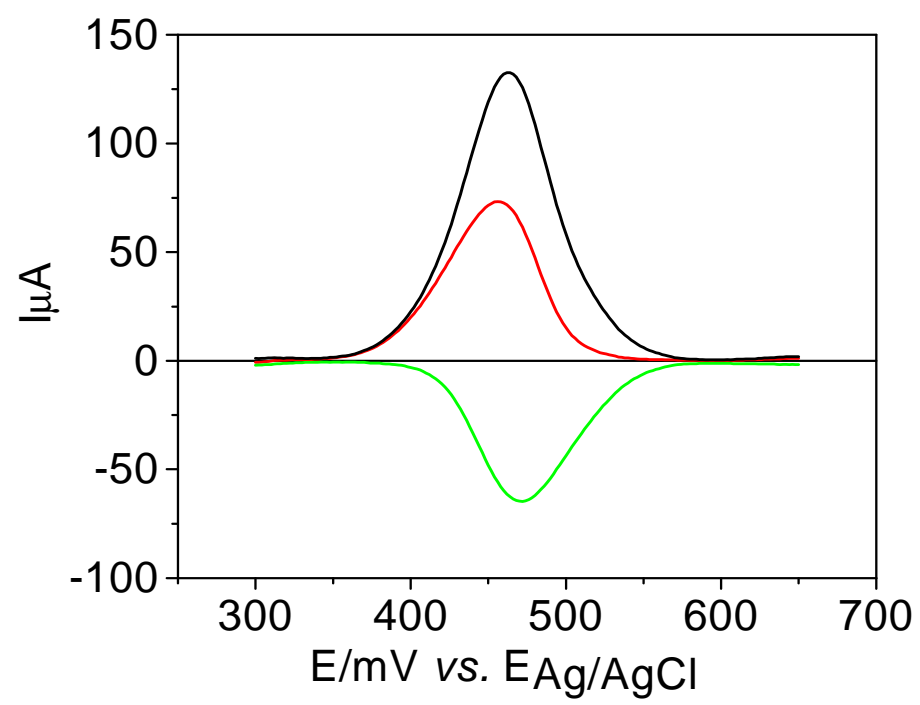

Figura 46 - Voltamogramas de onda quadrada de uma solução de dopamina $1,54 \times 10^{-4} \mathrm{~mol} \mathrm{~L}^{-1}$, mostrando as componentes de corrente $(-$ resultante, $(-)$ direta e $(-)$ reversa. Eletrodo de trabalho: compósito grafite-poliuretana. $f=50 \mathrm{~s}^{-1}, a=50 \mathrm{mV}$ e $\Delta \mathrm{E}_{\mathrm{i}}=2 \mathrm{mV}$.

A reversibilidade da reação foi confirmada pela contribuição da corrente reversa para a corrente resultante, a qual aumenta significantemente a resposta analítica em termos de intensidade de corrente. 


\section{III.6- DESENVOLVIMENTO DE METODOLOGIA ANALÍTICA PARA A DETERMINAÇÃO DE DOPAMINA EM FLUÍDO CEREBROSPINAL SINTÉTICO (60)}

\section{III.6.1 - Otimização dos parâmetros experimentais}

Para o desenvolvimento de uma metodologia analítica, deve-se atentar aos seguintes fatos: primeiro, a escolha da técnica analítica que seja sensível, permitindo assim a determinação de traços do composto, e segundo, a escolha do eletrodo de trabalho que seja seletivo ao analito de interesse, que apresente boa reprodutibilidade e estabilidade. No caso da dopamina, além da sensibilidade desejada, deve-se minimizar o efeito do principal interferente, o ácido ascórbico, que além de existir em concentrações elevadas no fluído cerebrospinal (cerca de $10^{3}$ vezes maior que a dopamina), é oxidado na mesma região de potenciais que o neurotransmissor. Assim, o desenvolvimento de eletrodos quimicamente modificados e a aplicação de técnicas de pulso tornam-se cruciais para a elaboração de uma nova metodologia analítica.

A técnica analítica utilizada foi a voltametria de onda quadrada pela excelente sensibilidade e rapidez frente a outras técnicas de pulso.

Apesar do estudo da variação do $\mathrm{pH}$ constatar que em $\mathrm{pH}$ 2,0 obteve-se maior resposta de corrente para fins analíticos, optou-se por trabalhar em condições que

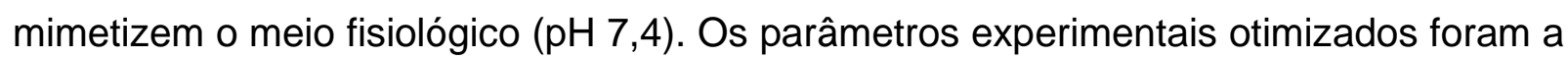
freqüência de aplicação dos pulsos de potenciais $(f)$, o incremento de varredura $\left(\Delta E_{i}\right)$ e a amplitude de pulso (a). 
$\mathrm{Na}$ Figura 49, é apresentada a variação da freqüência no intervalo de 5 a $60 \mathrm{~s}^{-1} \mathrm{e}$ na Tabela $X$ os valores de correntes de pico para a oxidação da dopamina.
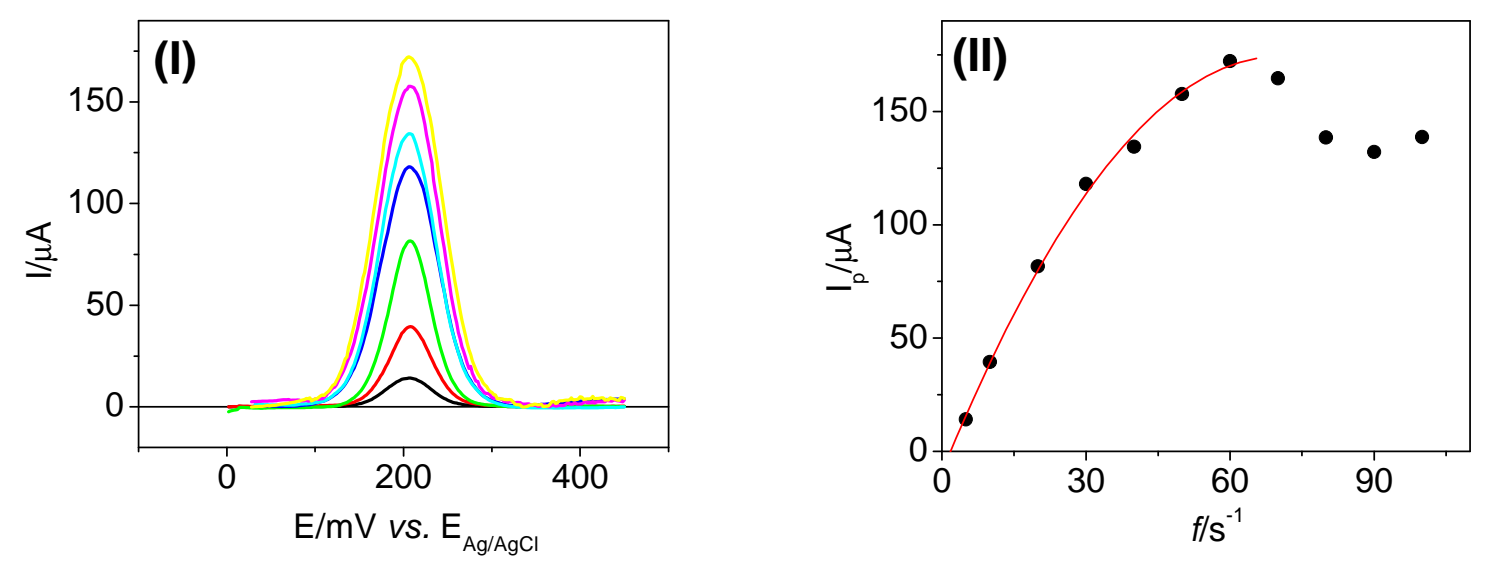

Figura 47 - (I) Voltamogramas de onda quadrada de uma solução de dopamina $1,24 \times 10^{-4} \mathrm{~mol} \mathrm{~L}^{-1}$ em tampão BR $0,10 \mathrm{~mol} \mathrm{~L}^{-1}\left(\mathrm{pH}_{7,4)}\right.$. Valores de freqüência: $(-) 5,(-) 10$,

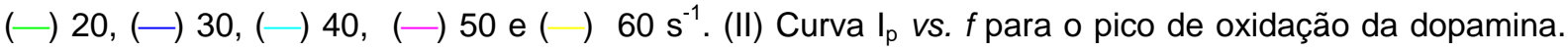
Eletrodo de trabalho: compósito grafite-poliuretana. $a=50 \mathrm{mV}$ e $\Delta \mathrm{E}_{\mathrm{i}}=2 \mathrm{mV}$.

Para valores de freqüência acima de $60 \mathrm{~s}^{-1}$ foi observado um decréscimo da corrente de pico causada provavelmente por problemas cinéticos com o produto formado após a perda de 2 elétrons e 2 prótons , formando a dopamina orto-quinona. A partir dessas evidências, foi escolhida a freqüência de $60 \mathrm{~s}^{-1}$ para a aplicação analítica.

A não linearidade do gráfico $I_{p}$ vs. $f$ (Figura 49 (II)) confirma a reversibilidade da reação de oxidação e também o processo de adsorção de reagente e produto na superfície do eletrodo (61). 
Tabela X - Valores de corrente de pico $\left(I_{p}\right)$ em função da freqüência para a oxidação da dopamina.

\begin{tabular}{c|c}
\hline$f / \mathbf{s}^{-1}$ & $I_{p} / \mu A$ \\
& \\
\hline 5 & 14,12 \\
10 & 39,47 \\
20 & 81,67 \\
30 & 118,06 \\
40 & 134,43 \\
50 & 157,71 \\
60 & 172,21 \\
70 & 164,64 \\
80 & 138,48 \\
90 & 132,18 \\
100 & 138,79 \\
\hline
\end{tabular}

$\mathrm{O}$ incremento de varredura foi variado no intervalo de 1 a $7 \mathrm{mV}$, mantendo-se constante a freqüência em $60 \mathrm{~s}^{-1}$ e a amplitude em $50 \mathrm{mV}$. Na Figura 50, são apresentados os voltamogramas de onda quadrada neste intervalo proposto. 


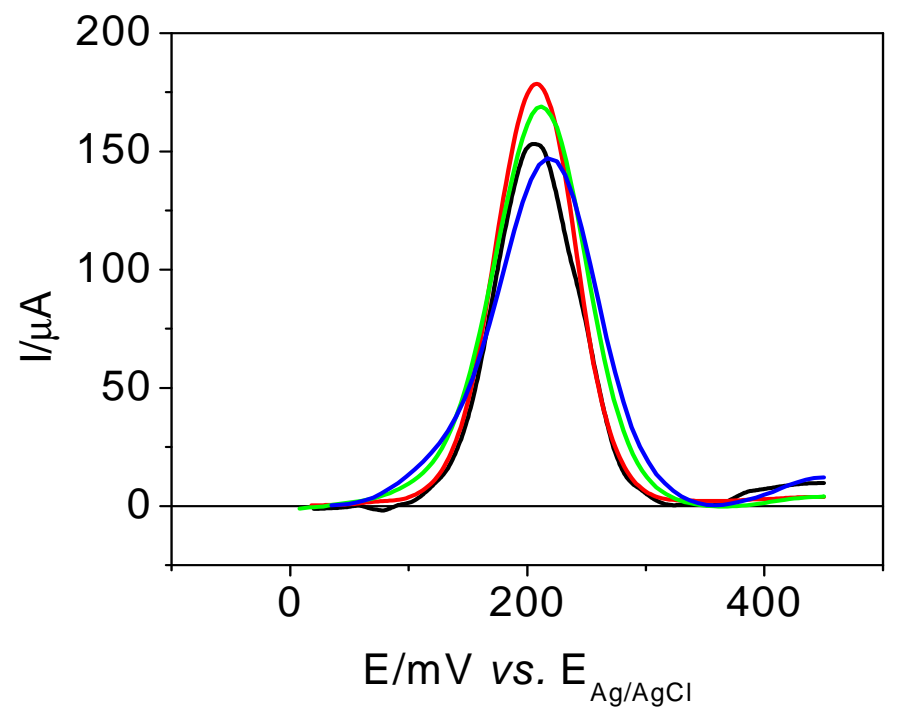

Figura 48 - Voltamogramas de onda quadrada de uma solução de dopamina

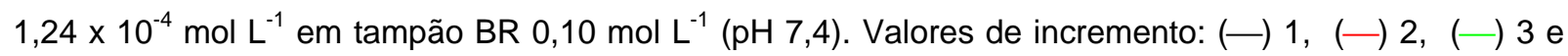
(一) $7 \mathrm{mV}$. Eletrodo de trabalho: compósito grafite-poliuretana. $f=60 \mathrm{~s}^{-1}$ e $a=50 \mathrm{mV}$.

Pela análise da Figura 50, verifica-se que, ao variar o incremento de varredura, há uma diminuição da corrente de pico e conseqüentemente uma perda na sensibilidade analítica. Assim, o incremento de varredura foi fixado em $2 \mathrm{mV}$ no decorrer dos experimentos.

O último parâmetro a ser otimizado foi a amplitude dos pulsos de potencial. Este estudo foi realizado no intervalo de 10 a $100 \mathrm{mV}$. Na Figura 51, são mostrados os voltamogramas de onda quadrada registrados, mantendo-se constante a freqüência $\left(60 \mathrm{~s}^{-1}\right)$ e o incremento de varredura $(2 \mathrm{mV})$. 


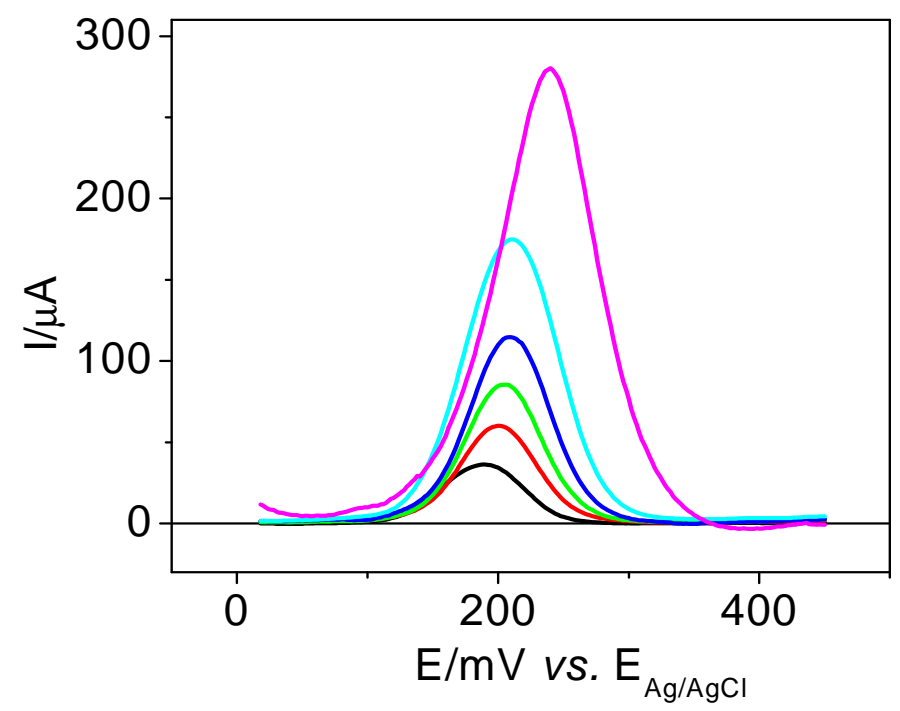

Figura 49 - Voltamogramas de onda quadrada de uma solução de dopamina $1,24 \times 10^{-4} \mathrm{~mol} \mathrm{~L}^{-1}$ em tampão BR $0,10 \mathrm{~mol} \mathrm{~L}^{-1}(\mathrm{pH} 7,4)$. Valores da amplitude: $(-)$ 10, $(-) 20$, $(\rightarrow)$ 30, $(-)$ 40, $\left(\rightarrow 50\right.$ e $(-) 100 \mathrm{mV}$. Eletrodo de trabalho: compósito grafite-poliuretana. $f=60 \mathrm{~s}^{-1} \mathrm{e}$ $\Delta \mathrm{E}_{\mathrm{i}}=2 \mathrm{mV}$.

É observado que, para amplitudes maiores (100 mV), há uma melhoria na sensibilidade analítica, porém verifica-se um alargamento dos picos que está associado com a perda na seletividade. Desta forma, optou-se por fixar a amplitude em $50 \mathrm{mV}$.

\section{III.6.2 - Construção da curva analítica}

Após a otimização dos parâmetros experimentais, curvas analíticas para a dopamina foram construídas no intervalo de $5,20 \times 10^{-6}$ a $50,68 \times 10^{-6} \mathrm{~mol} \mathrm{~L}^{-1}$, pelo método de adição de padrão, partindo-se de um estoque na concentração de $1,74 \times 10^{-3} \mathrm{~mol} \mathrm{~L}^{-1}$. 
As adições foram repetidas três vezes e a curva analítica foi construída por meio da média das correntes de pico vs. a concentração de dopamina adicionada. Nas Figuras 51 (I) e (II), são mostrados os voltamogramas de onda quadrada registrados no intervalo de concentração estudado e a curva analítica, respectivamente. Na Tabela XI, são apresentados os valores de concentração de dopamina adicionada e a média da corrente de pico para cada adição.
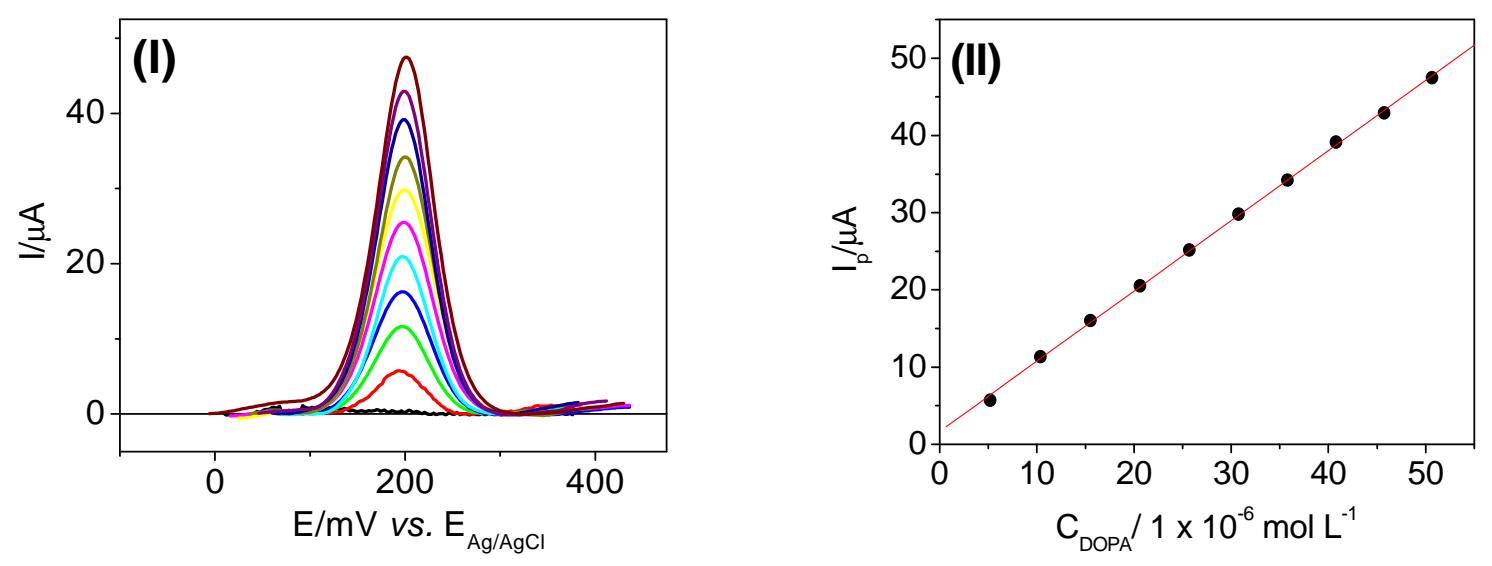

Figura 50 - (I) Voltamogramas de onda quadrada variando-se a concentração de dopamina adicionada. Concentrações: $(-)$ branco, $(-)$ 5,20, $(-)$ 10,37, $(-)$ 15,52, $(\rightarrow)$ 20,63, $(-)$ 25,71, ( ) 30,76, $\left(\rightarrow\right.$ 35,79, (-) 40,78, (-) 45,74 e $(-)$ 50,68 $\times 10^{-6} \mathrm{~mol} \mathrm{~L}^{-1}$. Eletrodo de trabalho: compósito grafitepoliuretana. $f=60 \mathrm{~s}^{-1}, a=50 \mathrm{mV}$ e $\Delta \mathrm{E}_{\mathrm{i}}=2 \mathrm{mV}$. (II) curva analítica ( $\mathrm{n}=10$ e $\left.\mathrm{R}=0,9997\right)$.

A equação da reta para a curva analítica (Figura 52 (II)) é dada pela equação 14, com o coeficiente de correlação igual a 0,9997.

$$
I_{p}(\mu A)=1,69 \times 10^{-6}+0,91 \times C_{\text {DOPA }}\left(\mu \mathrm{mol} \mathrm{L}^{-1}\right)
$$


Tabela XI - Valores de concentração de dopamina adicionada e a média das correntes de pico referentes à curva analítica.

\begin{tabular}{c|c}
\hline & \\
\hline & \\
& \\
& \\
& \\
\hline DOPA $/ 10^{-6} \mathrm{~mol}^{-1} / \mu A$ \\
\hline 5,20 & 5,75 \\
10,37 & 11,35 \\
15,52 & 16,05 \\
20,63 & 20,54 \\
25,71 & 25,20 \\
30,76 & 29,80 \\
35,79 & 34,22 \\
40,78 & 39,14 \\
45,74 & 42,93 \\
50,68 & 47,46 \\
\hline
\end{tabular}

Para avaliar a sensibilidade da metodologia analítica, o limite de detecção (LD) foi calculado de acordo com a equação 10 e o limite de quantificação (LQ) ficou estabelecido como o primeiro ponto da curva analítica. Assim, os valores de LD e o LQ foram iguais a $6,38 \times 10^{-8} \mathrm{~mol} \mathrm{~L}^{-1}(12,09 \mu \mathrm{g} / \mathrm{L})$ e $5,20 \times 10^{-6} \mathrm{~mol} \mathrm{~L}^{-1}(0,98 \mathrm{mg} / \mathrm{L})$, respectivamente.

A precisão da metodologia foi checada por meio do cálculo do desvio padrão relativo (RSD) para uma solução de dopamina de concentração igual a $9,90 \times 10^{-6} \mathrm{~mol} \mathrm{~L}^{-1}$. Para a precisão intra-day (repetibilidade), a qual foi calculada a partir de análises sucessivas durante um dia $(n=10$, com $n$ referindo-se ao número de medidas), o RSD foi igual a 1,9\%. A precisão inter-day (precisão intermediária) foi 
calculada em diferentes dias $(\mathrm{d}=10$, com d referindo-se ao número de dias) e resultou em um RSD igual a 2,3\%.

A exatidão da metodologia foi avaliada em termos do erro relativo (bias\%), o qual mede ao grau de concordância entre o resultado de uma medição e um valor verdadeiro do mensurando, nos experimentos de recuperação aparente. O valor de bias foi igual a 2,9\%, o qual indica boa exatidão.

A estabilidade do eletrodo de GPU foi determinada ao se comparar a corrente de pico de uma solução de dopamina igual a $19,8 \times 10^{-6} \mathrm{~mol} \mathrm{~L}^{-1}$ após sucessivas varreduras. Foi constatado que, ao término de 20 varreduras, a corrente decaiu cerca de $14 \%$. A avaliação do efeito de supressão do sinal analítico pela adsorção de moléculas dos reagentes e/ou produtos foi feita pela aplicação da técnica de voltametria cíclica. Foi verificado que o sinal analítico decresce vagarosamente com o número de ciclos e que este é totalmente suprimido após 500 ciclos. A fácil e rápida regeneração do eletrodo de GPU foi feita por meio da utilização de lixas d'agua de granulação 2000, mostrando que este eletrodo pode ser utilizado em aplicações analíticas mesmo com a adsorção do analito na superfície do eletrodo.

Como foi relatado na seção III.5.1.2, a passivação da superfície do eletrodo, pela adsorção irreversível do produto de reação da dopamina, não foi constatada em meio ácido. Porém, observa-se que, em meio neutro, a adsorção do produto de reação é mais evidenciada pela necessidade do polimento da superfície do eletrodo a cada experimento. Segundo a literatura, a dopamina oxida-se reversivelmente, de acordo com um mecanismo ECC (eletroquímico - químico - químico), a dopamina orto-quinona (62). Em uma etapa química posterior, a ciclização da dopamina orto-quinona (1) pode 
ocorrer com a perda de um próton, gerando a 5,5- dihidroxiindolina (2) e/ou a aminocroma (3), a qual pode sofrer polimerização e conseqüentemente bloquear a superfície do eletrodo. Como, em meio neutro, a velocidade da reação de ciclização é maior, a formação da 5,5- dihidroxiindolina é favorecida e conseqüentemente há o bloqueio da superfície do eletrodo. Na Figura 53, são resumidas as etapas eletroquímicas e químicas citadas acima.<smiles>C=C=C=C</smiles><smiles>COc1cc(CC[NH3+])ccc1O</smiles><smiles>C=C=C</smiles><smiles>[NH3+]CCC1=CC(=O)C(=O)C=C1</smiles>

(1)<smiles>CCCC1=CC(=O)C(=O)C=C1</smiles>

(1)<smiles></smiles><smiles>[NH3+]CCC1=CC(=O)C(=O)C=C1</smiles>

(1)<smiles>C=C</smiles><smiles>NCCC1=CC(=O)C(=O)C=C1</smiles>

polímero

Figura 51 - Etapas eletroquímicas e possíveis etapas químicas para a reação de oxidação da dopamina. 
Com a finalidade de obter-se resultados adicionais que confirmassem a sensibilidade da metodologia analítica desenvolvida, curvas analíticas também foram construídas com o emprego de outra técnica analítica. Como o composto apresenta uma banda de absorção óptica em $278 \mathrm{~nm}$, optou-se pela técnica de espectrofotometria de absorção no UV. Nas Figuras 54 (I) e (II), são mostrados os espectros de UV e a curva analítica $(n=3)$ construída por meio da média das absorbâncias vs. a concentração de dopamina adicionada no intervalo de $1,63 \times 10^{-5} \mathrm{~mol} \mathrm{~L}^{-1}$ a $15,19 \times 10^{-5}$ mol $\mathrm{L}^{-1}$. Na Tabela XII, são apresentados os valores de concentração de dopamina adicionada e a média das absorbâncias para cada adição.
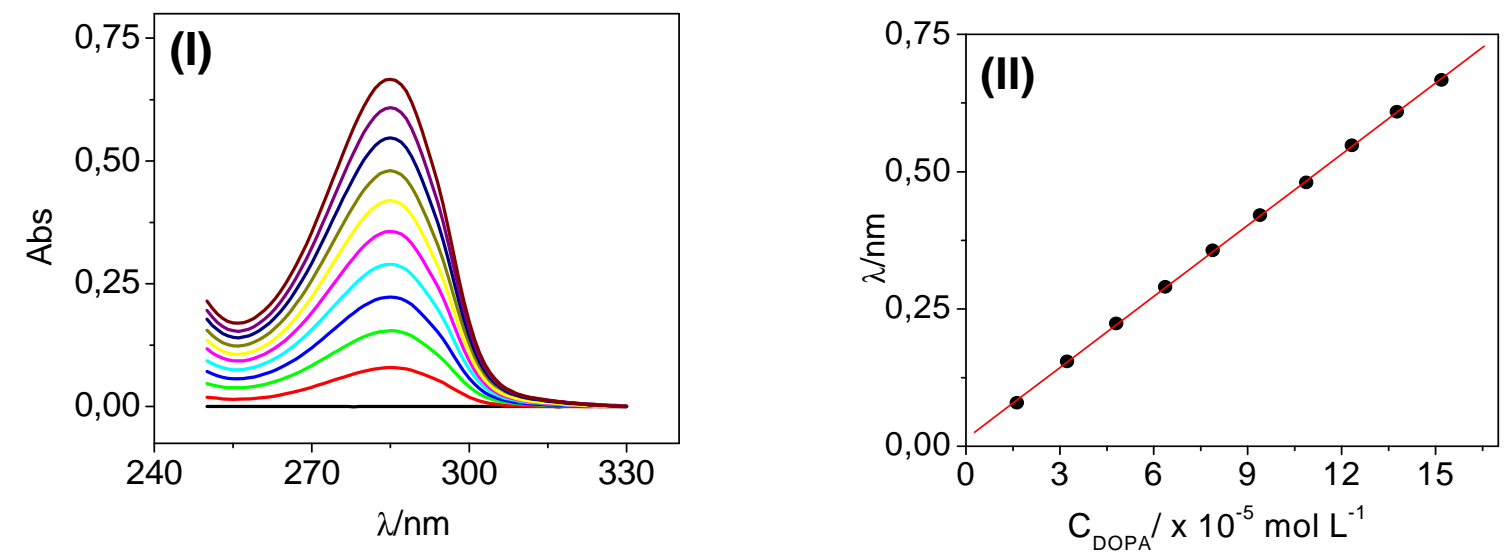

Figura 52 - (I) Espectros de absorção óptica de uma solução estoque de dopamina

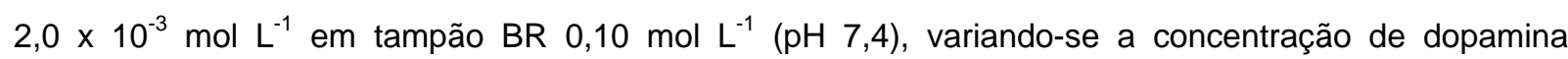
adicionada. Concentrações: $(-)$ branco, $\quad(\rightarrow)$ 1,63, $(\rightarrow)$ 3,23, $(-)$ 4,80, $(\rightarrow)$ 6,37,

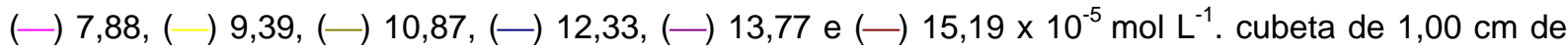
caminho óptico (II) curva analítica ( $\mathrm{n}=10$ e $\mathrm{R}=0,9998)$. 
Tabela XII - Valores de concentração de dopamina adicionada e a média das absorbâncias referentes à curva analítica.

\begin{tabular}{c|c}
\hline $\mathbf{C}_{\text {DOPA }} / \mathbf{1 0} \mathbf{~ m o l ~ L}^{-1}$ & Abs.média \\
& \\
\hline 1,63 & 0,08 \\
3,23 & 0,15 \\
4,80 & 0,22 \\
6,37 & 0,29 \\
7,88 & 0,35 \\
9,39 & 0,42 \\
10,87 & 0,48 \\
12,33 & 0,55 \\
13,77 & 0,61 \\
15,19 & 0,67 \\
\hline
\end{tabular}

A equação da reta para a curva analítica (Figura 56 (II)) é dada pela equação 15, com o coeficiente de correlação igual a 0,9998.

$$
\text { Abs }=0,01+4317,60 \times C_{\text {DOPA }}\left(10^{-5} \mathrm{~mol} \mathrm{~L}^{-1}\right)
$$

O limite de detecção ( $\mathrm{LD}=2,32 \times 10^{-6} \mathrm{~mol} \mathrm{~L}^{-1}$ ou $0,44 \mathrm{mg} \mathrm{L}^{-1}$ ) foi calculado pela aplicação da equação 16, utilizando os parâmetros da equação da curva analítica, ou seja, S é o intercepto em Y e $\theta$ é o coeficiente angular da curva analítica.

$$
\mathrm{LD}=3 \times \mathrm{S} / \boldsymbol{\theta}
$$

O limite de quantificação $\left(L Q=1,63 \times 10^{-5} \mathrm{~mol} \mathrm{~L}^{-1}\right.$ ou $\left.3,10 \mathrm{mg} \mathrm{L}^{-1}\right)$ ficou estabelecido como sendo o primeiro ponto da curva analítica. 
Como, pelo limite de quantificação é possível comparar técnicas diferentes, verifica-se que a metodologia empregando GPU/SWV apresenta uma maior sensibilidade $\left(40,37 \mu \mathrm{g} \mathrm{L}^{-1}\right)$ que a técnica espectrofotométrica $\left(3,10 \mathrm{mg} \mathrm{L}^{-1}\right)$, o que permite avaliar a potencialidade da metodologia eletroanalítica em uma solução de fluído cerebrospinal sintético com os possíveis interferentes, dentre eles, o ácido ascórbico.

\section{III.6.3 - Análise de dopamina em solução de fluído cerebrospinal sintético}

É de conhecimento na literatura, que o ácido ascórbico (AA) está presente no fluído extracelular do sistema nervoso central em altas concentrações (cerca de $10^{3}$ vezes maior que a dopamina) e, além disso, é oxidado na mesma região de potenciais que a dopamina (DA) na maioria dos eletrodos sólidos, tais como o eletrodo de carbono vítreo. Assim, fatores como a sensibilidade e a seletividade são essenciais para o desenvolvimento de metodologias analíticas para a determinação de dopamina.

Como a metodologia empregando GPU/SWV apresentou boa sensibilidade para a detecção de dopamina, a seletividade foi o segundo fator a ser analisado. Para efetuar este estudo, foi utilizada uma solução de fluído cerebrospinal sintético preparada de acordo como descrito na seção II.2.2.7.

Nas Figuras 55 (I) e (II), são apresentados os voltamogramas de onda quadrada de uma solução de dopamina $5,20 \times 10^{-6} \mathrm{~mol} \mathrm{~L}^{-1}$ e de ácido ascórbico $1,21 \times 10^{-3} \mathrm{~mol} \mathrm{~L}^{-1}$, respectivamente. A concentração de ambos os compostos está na 
ordem de grandeza de acordo com o observado após um estímulo elétrico nas sinapses dos neurônios (63).

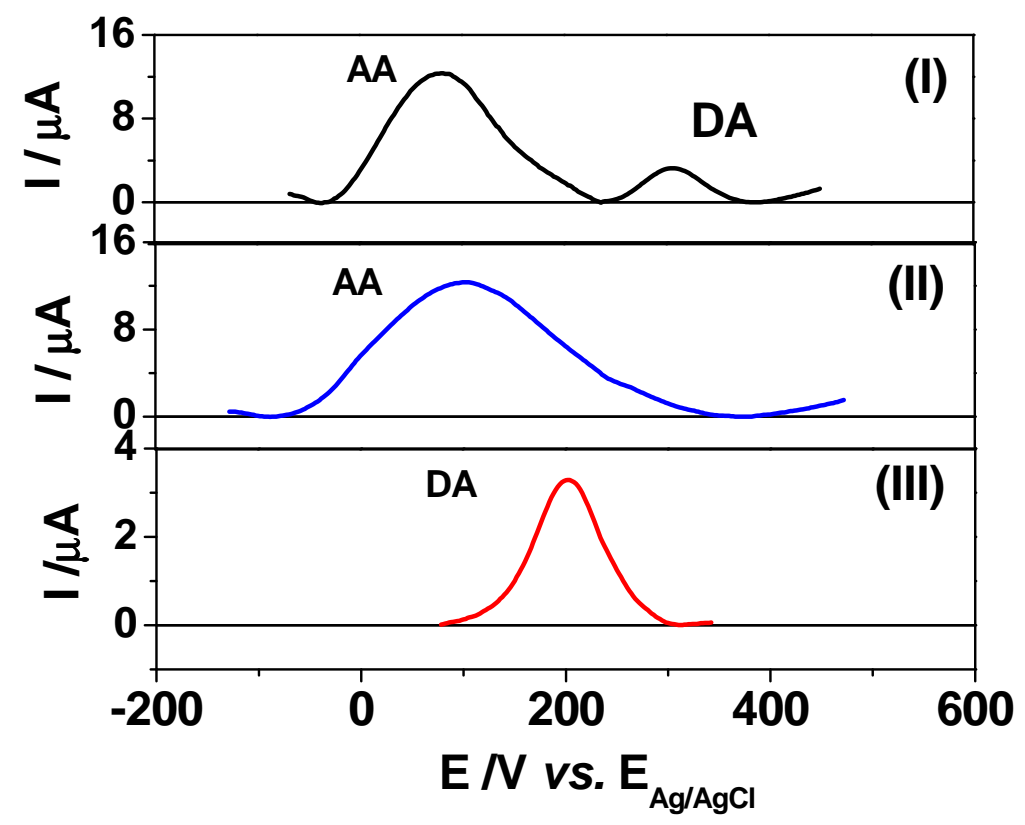

Figura 53 - Voltamogramas de onda quadrada (I) Dopamina; (II) Ácido ascórbico e (III) Dopamina + ácido ascórbico. Concentração das soluções: Dopamina $\left(5,20 \times 10^{-6} \mathrm{~mol}^{-1}\right)$ e ácido ascórbico $\left(1,21 \times 10^{-3} \mathrm{~mol} \mathrm{~L}^{-1}\right)$ em solução de fluído cerebrospinal sintético $(\mathrm{pH} 7,4)$. Eletrodo de trabalho: compósito grafite/poliuretana. $f=60 \mathrm{~s}^{-1}, a=50 \mathrm{mV}$ e $\Delta \mathrm{E}_{\mathrm{i}}=2 \mathrm{mV}$.

Pela análise da Figura 55 (I), pode-se observar que o eletrodo compósito separa a resposta eletroquímica da dopamina $\left(E_{p}=306 \mathrm{mV}\right)$ e do ácido ascórbico $\left(E_{p}=80 \mathrm{mV}\right)$, permitindo assim a análise simultânea de ambas as espécies. Porém, existem trabalhos na literatura, nos quais mesmo ocorrendo a separação dos picos de oxidação, há ainda a necessidade de se eliminar o efeito catalítico do AA na oxidação da DA $(22,64)$. Este efeito ocorre quando a DA é oxidada em potenciais mais positivos que o AA. Assim, o AA, atuando como antioxidante, reduz o produto dopamina orto- 
quinona a dopamina, e conseqüentemente observa-se um aumento do sinal analítico referente à oxidação da DA. Assim, como o AA é oxidado antes da DA, o efeito catalítico do AA na oxidação do neurotransmissor não é observada, pois as correntes de pico nas Figuras 55 (I) e (III) são muito similares.

Ao analisar as Figuras 55 (I) e (III), verifica-se que a presença de AA em solução deslocou o potencial de oxidação da DA para valores mais positivos $\left(\Delta \mathrm{E}_{\mathrm{p}}=100 \mathrm{mV}\right)$. Este deslocamento de potenciais pode ser melhor averiguado na Figura 56, em que se adicionou várias concentrações de $A A$, mas mantendo-se fixa a concentração de DA $\left(5,60 \times 10^{-6} \mathrm{~mol} \mathrm{~L}^{-1}\right)$.

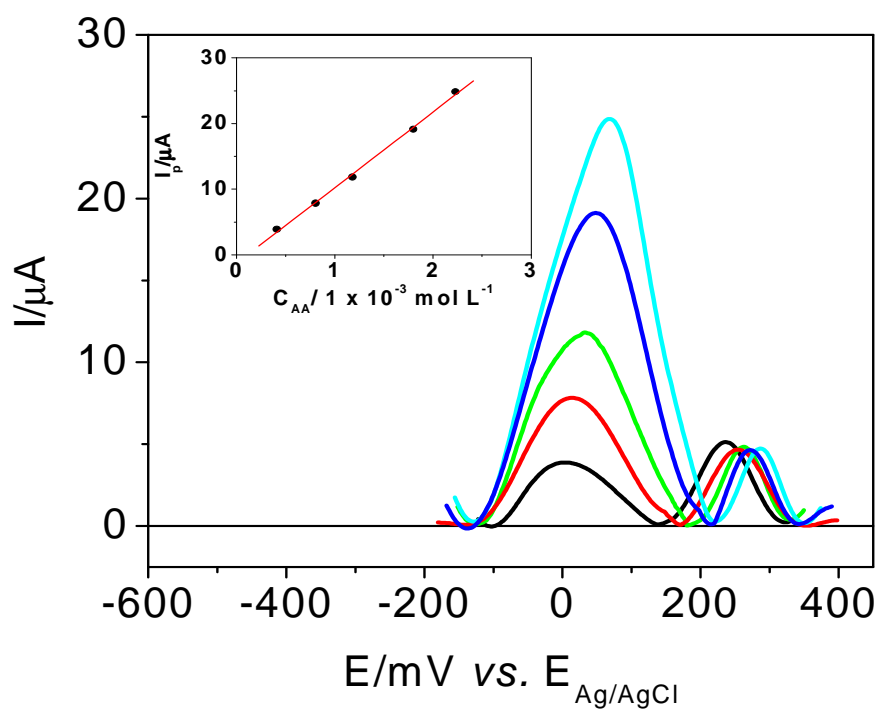

Figura 54 - Voltamogramas de onda quadrada variando-se a concentração de ácido ascórbico adicionada. Concentrações: $(-)$ 0,4, $\left(-\right.$ ) 0,8, $(\rightarrow)$ 1,2, $(-)$ 1,8 e $(-)$ 2,2 $\times 10^{-3} \mathrm{~mol} \mathrm{~L}^{-1}$. Concentração de dopamina igual a 5,60 $\times 10^{-6} \mathrm{~mol} \mathrm{~L}^{-1}$. Eletrodo de trabalho: compósito grafite-poliuretana. $f=60 \mathrm{~s}^{-1}, a=50 \mathrm{mV}$ e $\Delta \mathrm{E}_{\mathrm{i}}$ $=2 \mathrm{mV}$. Inserido: curva analítica $(\mathrm{n}=5$ e $\mathrm{R}=0,9987)$. 
É importante mencionar que este deslocamento já foi reportado na literatura, porém nenhuma explicação foi dada para este efeito (65). No entanto, duas hipóteses podem ser lançadas, a primeira, refere-se a mudanças na superfície do eletrodo de GPU ocasionadas pela adsorção irreversível de moléculas do produto da reação de oxidação do AA (ácido deidroascórbico). Assim, de alguma maneira não se teria mais a superfície de GPU, o que possivelmente provocaria o deslocamento do potencial de pico da DA para potenciais mais positivos.

A segunda hipótese, talvez a mais plausível, é a de que, como o meio não está tamponado, haveria uma mudança do $\mathrm{pH}$ na interface eletrodo-solução quando o $\mathrm{AA}$ fosse oxidado, pois neste processo ocorre a liberação de 2 elétrons e 2 prótons. Esta modificação do pH local seria considerável o suficiente para promover o deslocamento do potencial de pico da DA para valores mais positivos, uma vez que a concentração de AA na solução está cerca de 1000 vezes maior que a do neurotransmissor.

Em eletrodos sólidos comuns, o potencial de pico do AA estaria em torno de $350 \mathrm{mV} v s . \mathrm{E}_{\mathrm{Ag} / \mathrm{AgCl}} \mathrm{O}$ deslocamento, observado no eletrodo de $\mathrm{GPU}\left(\Delta \mathrm{E}_{\mathrm{p}} \approx 300 \mathrm{mV}\right)$, deve-se provavelmente a sítios ativos presentes na superfície do eletrodo compósito que interagem mais favoravelmente com a forma aniônica do $A A\left(\mathrm{pk}_{\mathrm{a}}=4,10\right)$ do que com a forma protonada do neurotransmissor $\left(\mathrm{pk}_{\mathrm{a}}=8,87\right)$.

A interferência de espécies orgânicas e inorgânicas foi estudada nas concentrações esperadas de acordo com a constituição do fluído cerebrospinal de um adulto saudável (47). Este fluído é formado pelo processo de secreção das células epiteliais do plexo coróide, sendo, portanto um ultrafiltrado do plasma sanguíneo. Por este fato, não contém bilirrubina, proteína, pouco colesterol e menos açúcar, mas a 
mesma quantidade de bicarbonato e mais cloreto. Na Tabela XIII, são apresentados os principais constituintes do plasma e do fluído cerebrospinal de um adulto saudável.

Tabela XIII - Principais constituintes do plasma e do fluído cerebrospinal de um adulto saudável.

\begin{tabular}{c|c|c}
\hline Constituintes & Plasma & Fluído cerebrospinal $^{*}$ \\
\hline Sódio & $300-355$ & $501-543$ \\
Potássio & $14-22$ & $8,5-11,5$ \\
Cálcio & $9-11,5$ & $3,9-5,1$ \\
Cloreto & $352-382$ & $418-452$ \\
Bicarbonato & $55,2-71,3$ & 48,3 \\
Albumina $(\mathrm{g} / 100 \mathrm{~mL})$ & $4,6-6,7$ & $0,0048-0,030$ \\
Globulina $(\mathrm{g} / 100 \mathrm{~mL})$ & $1,2-2,3$ & $0,0012-0,0086$ \\
Bilirrubina & $0,1-0,8$ & 0 \\
Uréia & $28-40$ & $7,4-16,0$ \\
Colesterol & $110-390$ & $0,24-0,50$ \\
Glicose & $60-95$ & $45-93$ \\
Fibrinogênio $(\mathrm{g} / 100 \mathrm{~mL})$ & $0,3-0,6$ & 0 \\
\hline
\end{tabular}

* Todos os valores em $\mathrm{mg} / 100 \mathrm{~mL}$, a menos que indicados de outra forma.

Nenhuma interferência pôde ser observada para a glicose [600], uréia [300], ácido ascórbico [220], bicarbonato [2500], cloreto de sódio [10150], cloreto de cálcio [350] e cloreto de potássio [500]. Os valores entre colchetes estão relacionados com a razão molar do composto interferente para uma concentração de dopamina igual a $8,80 \times 10^{-6} \mathrm{~mol} \mathrm{~L}^{-1}$.

Um estudo da variação da concentração de dopamina, na presença de ácido ascórbico, foi realizado em uma solução de fluído cerebrospinal sintético. Na Figura 57, são mostrados os voltamogramas de onda quadrada registrados para várias adições de 
dopamina no intervalo de $6,61 \times 10^{-6}$ a $24,04 \times 10^{-6} \mathrm{~mol} \mathrm{~L}^{-1}$ e também a curva analítica inserida $(R=0,9993)$.

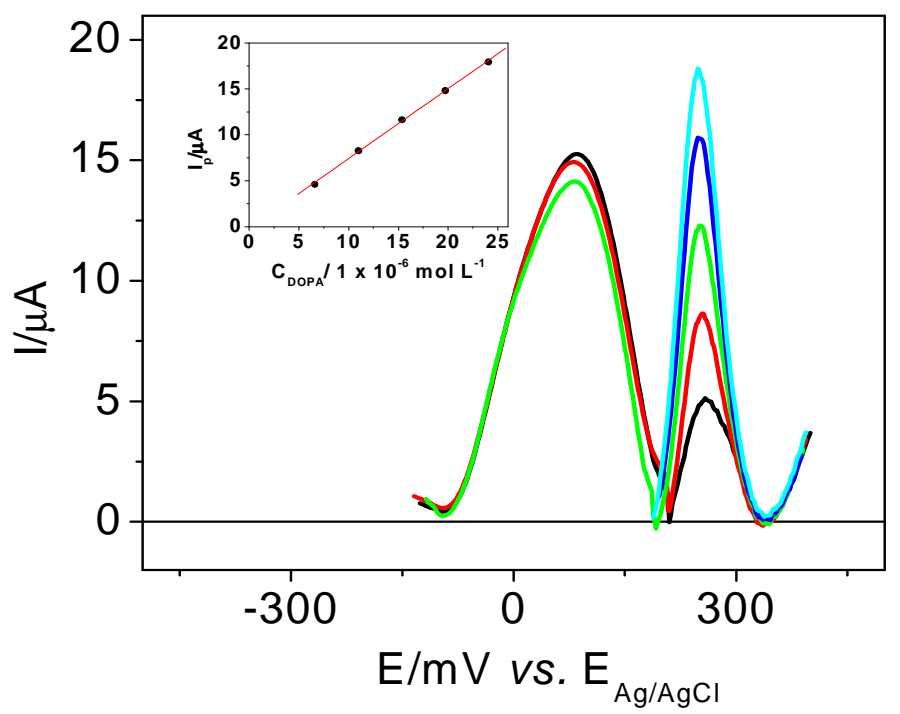

Figura 55 - Voltamogramas de onda quadrada variando-se a concentração de dopamina adicionada.

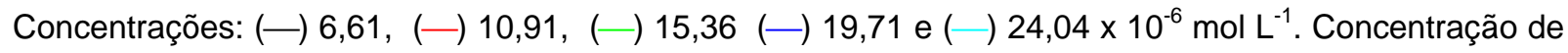
ácido ascórbico igual a $1,55 \times 10^{-3} \mathrm{~mol} \mathrm{~L}^{-1}$. Eletrodo de trabalho: compósito grafite-poliuretana. $f=60 \mathrm{~s}^{-1}$, $a=50 \mathrm{mV}$ e $\Delta \mathrm{E}_{\mathrm{i}}=2 \mathrm{mV}$. Inserido: curva analítica $(\mathrm{n}=5$ e $\mathrm{R}=0,9993)$.

A equação da reta para a curva analítica (Figura 57) é dada pela equação 17, com o coeficiente de correlação igual a 0,9998.

$$
I_{p}(\mu A)=-2,22 \times 10^{-7}+0,70 \times C_{D O P A}\left(\mu \mathrm{mol} \mathrm{L}^{-1}\right)
$$

A precisão da metodologia foi estimada de maneira similar ao descrito na seção III.6.2, partindo-se de uma solução de dopamina de concentração igual a 
$6,60 \times 10^{-6} \mathrm{~mol} \mathrm{~L}^{-1}$. A precisão intra-day (repetibilidade) apresentou um RSD de 2,4\%, ao passo que o RSD da precisão inter-day (precisão intermediária) foi igual a 3,2\%.

Experimentos de recuperação aparente $(n=5)$ foram realizados no intervalo de concentração do neurotransmissor no fluído cerebrospinal, partindo-se de uma concentração igual a $6,60 \times 10^{-6} \mathrm{~mol} \mathrm{~L}^{-1}(66)$. As recuperações ficaram em torno de 94,72 a $99,50 \%$ com RSD igual a $2,1 \%$.

A exatidão da metodologia aplicada em amostra de fluído cerebrospinal sintético foi avaliada em termos do erro relativo (bias\%), o qual descreve o desvio dos resultados esperados nos experimentos de recuperação aparente. Foi obtido um bias de 3,4\%, o qual indica a boa exatidão do método.

A proximidade dos valores das inclinações das curvas analíticas da Figura 52 II $(0,91)$, em eletrólito puro, e da Figura $57(0,70)$, em solução de fluído cerebrospinal sintético, confirmam, mais uma vez, que os constituintes do fluído cerebrospinal não interferem significantemente na resposta analítica da dopamina.

Os resultados obtidos indicam que a metodologia analítica desenvolvida pode ser aplicada com sucesso na análise de dopamina em amostra de fluído cerebrospinal sintético sem a interferência do ácido ascórbico e de outros constituintes desta matriz. A miniaturização do sistema, fator crucial para aplicação in vivo, será objeto de um estudo futuro. 


\section{III.7- DETERMINAÇÃO ANALÍTICA DA DOPAMINA EM AMPOLAS DE REVIVAN ${ }^{\circledR}$}

A potencialidade da aplicação da metodologia analítica para determinação de dopamina em fluído cerebrospinal sintético foi adequadamente abordada na seção anterior quanto à sensibilidade e à seletividade do eletrodo de GPU aliado à técnica de voltametria de onda quadrada. No entanto, a dopamina também pode ser quantificada em ampolas de Revivan ${ }^{\circledast}(50 \mathrm{mg})$, o qual é um medicamento de uso restrito hospitalar utilizado como estimulante cardíaco. Por essa razão, foi elaborada uma metodologia analítica de rotina para a determinação de dopamina em ampolas deste medicamento. Nos resultados da seção III.5.1.4, referente à variação do pH, observou-se que em pH 2,0 (tampão BR $0,10 \mathrm{~mol} \mathrm{~L}^{-1}$ ) $\circ$ composto apresenta um par redox com maior sensibilidade analítica, assim, optou-se por elaborar a metodologia analítica de rotina neste valor de $\mathrm{pH}$.

A técnica escolhida foi a voltametria de onda quadrada pela rapidez das análises. Os parâmetros experimentais da técnica, tais como a freqüência $(f)$, a amplitude (a) e o incremento de varredura $\left(\Delta \mathrm{E}_{\mathrm{i}}\right)$ foram otimizados em $\mathrm{pH}$ 2,0 e os valores obtidos para cada parâmetro ( $f=60 \mathrm{~s}^{-1}, a=50 \mathrm{mV}$ e $\Delta \mathrm{E}_{\mathrm{i}}=2 \mathrm{mV}$ ) não diferiram dos obtidos em $\mathrm{pH}$ 7,0. Assim, decidiu-se por omitir os voltamogramas referentes à otimização para não tornar a exposição dos resultados repetitiva.

Curvas analíticas da dopamina foram construídas no intervalo de $1,58 \times 10^{-6} \mathrm{~mol} \mathrm{~L}^{-1}$ a $15,86 \times 10^{-6} \mathrm{~mol} \mathrm{~L}^{-1}$. Nas Figuras 58 (I) e (II), são apresentados os 
voltamogramas de onda quadrada registrados neste intervalo de concentração e a curva analítica, respectivamente.
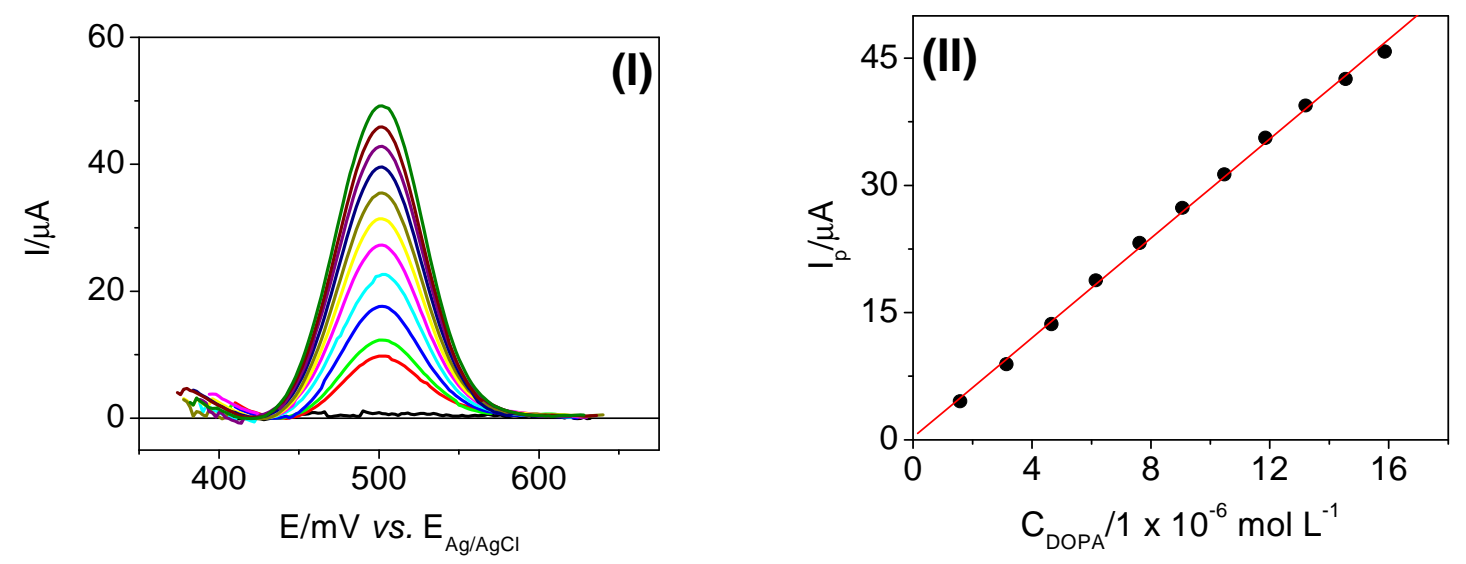

Figura 56 - Voltamogramas de onda quadrada variando a concentração de dopamina adicionada em tampão BR 0,1 mol L-1 (pH 2,0). (I) Concentrações: $(-)$ branco, $(-)$ 1,58, ( ) 3,14, ( -

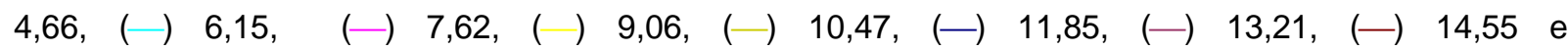
$\left(-15,86 \times 10^{-6} \mathrm{~mol} \mathrm{~L}^{-1}\right.$. (II) Curva analítica $(\mathrm{R}=0,9992)$. Eletrodo de trabalho: compósito grafitepoliuretana.

As adições foram repetidas três vezes e a curva analítica foi construída por meio da média das correntes de pico vs. a concentração de dopamina adicionada. A equação da reta para a curva analítica (Figura 58 (II)) é dada pela equação 18, com o coeficiente de correlação igual a 0,9992.

$$
I_{p}(\mu A)=2,96 \times 10^{-7}+2,93 \times C_{D O P A}
$$

O limite de detecção $\left(1,74 \times 10^{-8} \mathrm{~mol} \mathrm{~L}^{-1}\right.$ ou $\left.3,30 \mu \mathrm{g} \mathrm{L}^{-1}\right)$ foi calculado de acordo com a equação 10 e o de quantificação $\left(1,58 \times 10^{-8} \mathrm{~mol} \mathrm{~L}^{-1}\right.$ ou $\left.0,30 \mathrm{mg} \mathrm{L}^{-1}\right)$ ficou estabelecido como o primeiro ponto da curva analítica. 
A repetibilidade e a reprodutibilidade da metodologia analítica também foram avaliadas para concentrações de dopamina no intervalo da curva analítica, com coeficientes de variação iguais a 0,56\% $(n=10)$ e $1,03 \%$.

Com o objetivo de se obter resultados adicionais que mostrassem a sensibilidade da metodologia analítica desenvolvida, curvas analíticas para a dopamina também foram construídas com o emprego da técnica de espectrometria de absorção no UV, uma vez que o composto apresenta uma banda de absorção óptica em $278 \mathrm{~nm}$.

Nas Figuras 59 (I) e (II), são mostrados os espectros de UV e a curva analítica ( $n=3$ ) construída por meio da média das absorbâncias vs. a concentração de dopamina adicionada no intervalo de $1,59 \times 10^{-5} \mathrm{~mol} \mathrm{~L}^{-1}$ a $14,81 \times 10^{-5} \mathrm{~mol} \mathrm{~L}^{-1}$.
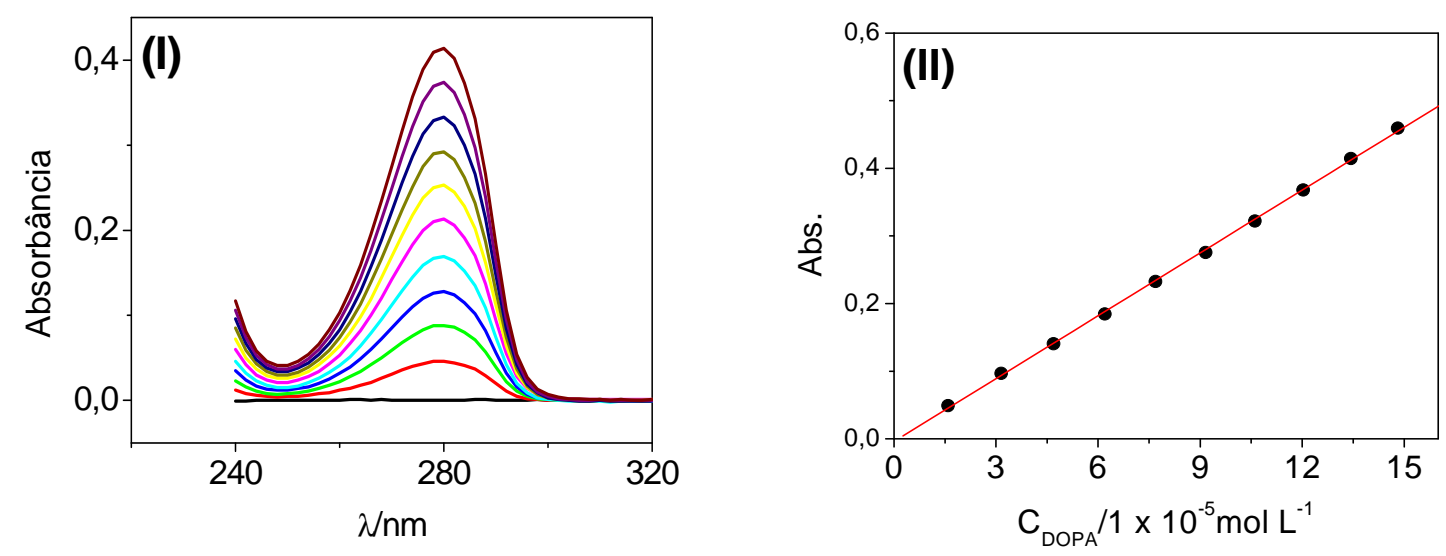

Figura 57 - (I) Espectros de absorção óptica variando-se a concentração de dopamina adicionada.

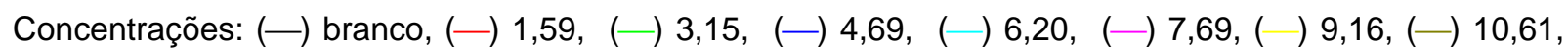
$\left(-12,03,(-)\right.$ 13,43 e $(-)$ 14,81 $\times 10^{-5} \mathrm{~mol} \mathrm{~L}^{-1}$. Cubeta de $1,00 \mathrm{~cm}$ de caminho óptico (II) curva analítica $(n=10$ e $R=0,9997)$. 
A equação da reta para a curva analítica (Figura 59 (II)) é dada pela equação 19, com o coeficiente de correlação igual a 0,9997.

$$
\text { Abs }=-3,91 \times 10^{-3}+3,09 \times 10^{3} \times C_{\text {DOPA }}
$$

O limite de detecção $\left(1,26 \times 10^{-6} \mathrm{~mol} \mathrm{~L}^{-1}\right.$ ou $\left.0,24 \mathrm{mg} \mathrm{L}^{-1}\right)$ foi calculado de acordo com a equação 16 e o de quantificação ficou estabelecido como sendo o primeiro ponto da curva analítica $\left(1,59 \times 10^{-5} \mathrm{~mol} \mathrm{~L}^{-1}\right.$ ou $\left.3,01 \mathrm{mg} \mathrm{L}^{-1}\right)$.

Como para a análise de rotina de fármacos não se necessita de uma sensibilidade considerável, uma vez que as condições de trabalho são para uma concentração do princípio ativo relativamente alta, verifica-se que tanto a metodologia eletroanalítica desenvolvida $\left(\mathrm{LQ}=0,30 \mathrm{mg} \mathrm{L}^{-1}\right)$ quanto a técnica espectrofotométrica $\left(L Q=3,01 \mathrm{mg} \mathrm{L}^{-1}\right)$ podem ser empregadas para a quantificação de dopamina em formulação farmacêutica. No entanto, os experimentos de recuperação mostrarão a potencialidade da técnica eletroanalítica frente aos possíveis interferentes, ou seja, os excipientes contidos na amostra do medicamento a ser analisado.

Os experimentos de recuperação aparente da dopamina, em ampolas de Revivan ${ }^{\circledR}$, foram realizados sem um pré-tratamento prévio da amostra, ou seja, as soluções estoque foram preparadas a partir das soluções injetáveis por meio de diluição simples em tampão BR $0,10 \mathrm{~mol} \mathrm{~L}^{-1}(\mathrm{pH} 2,0)$. Os experimentos de recuperação foram realizados pelo método de adição de padrão $(n=5)$, sendo a primeira adição do medicamento $\left(\mathrm{V}=20 \mu \mathrm{L}\right.$, partindo-se de um estoque $\left.2,0 \times 10^{-3} \mathrm{~mol} \mathrm{~L}^{-1}\right)$ e as restantes do padrão analítico $\left(\mathrm{V}=100 \mu \mathrm{L}\right.$, partindo-se de um estoque $\left.1,63 \times 10^{-4} \mathrm{~mol} \mathrm{~L}^{-1}\right)$. Na 
Figura 60, são apresentados os voltamogramas de onda quadrada e o gráfico de $I_{p} v s$. $\mathrm{C}_{\text {DOPA }}$ adicionada para o pico de oxidação da dopamina.

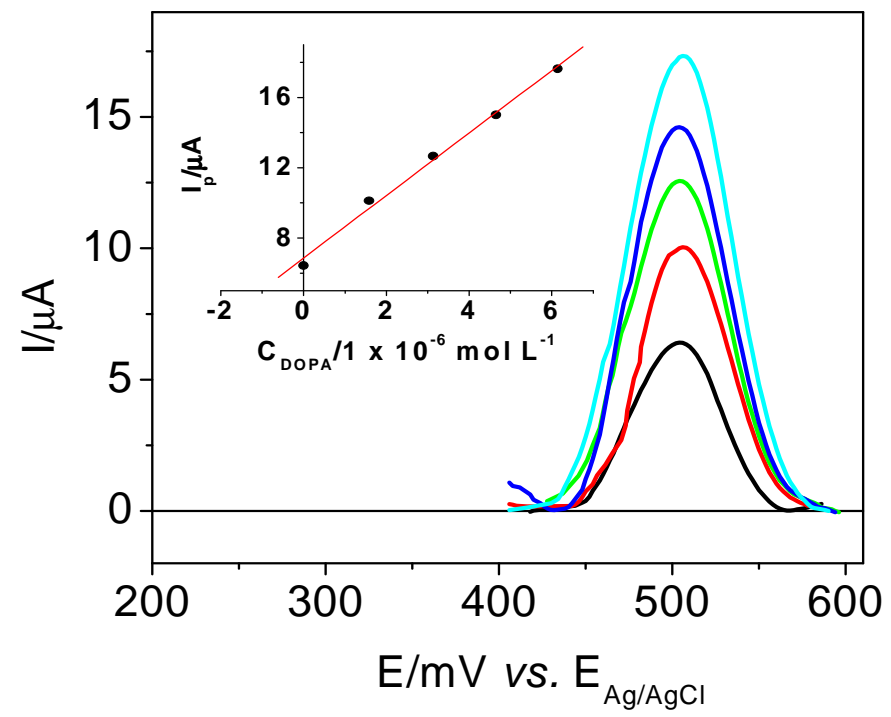

Figura 58 - Voltamogramas de onda quadrada para diferentes concentrações de dopamina. $\mathrm{C}_{\text {DOPA }}$ adicionada: $\left(-\right.$ medicamento, $(-)$ 1,58, $(-)$ 3,13, $(-)$ 4,65 e $(-)$ 6,14 $\times 10^{-6} \mathrm{~mol} \mathrm{~L}^{-1}$ com eletrodo compósito grafite-poliuretana. $f=60 \mathrm{~s}^{-1}, a=50 \mathrm{mV}$ e $\Delta \mathrm{E}_{\mathrm{i}}=2 \mathrm{mV}$. Inserido: curva de recuperação aparente $(R=0,9968)$.

A porcentagem média de dopamina encontrada foi igual a $96,60 \pm 1,31 \%$ $(9,72 \pm 0,14 \mathrm{mg})$. Na caixa de Revivan $^{\circledR}$, está rotulado que cada ampola contém $10 \mathrm{mg}$ de cloridrato de dopamina, indicando que a quantidade de medicamento adicionada e recuperada pela metodologia analítica desenvolvida mostra-se coerente com a informação prescrita pelo fabricante.

Os experimentos de adição e de recuperação aparente de dopamina também foram realizados pela aplicação da técnica de espectrofotometria de absorção no UV (Figura 61). As adições foram em número de 5 , sendo a primeira do medicamento 
$\left(\mathrm{V}=20 \mu \mathrm{L}\right.$, partindo-se de uma solução estoque de $\left.2,00 \times 10^{-3} \mathrm{~mol} \mathrm{~L}^{-1}\right)$ e as demais do padrão analítico ( $\mathrm{V}=20 \mu \mathrm{L}$, partindo-se de um estoque de $2,00 \times 10^{-3} \mathrm{~mol} \mathrm{~L}^{-1}$ )

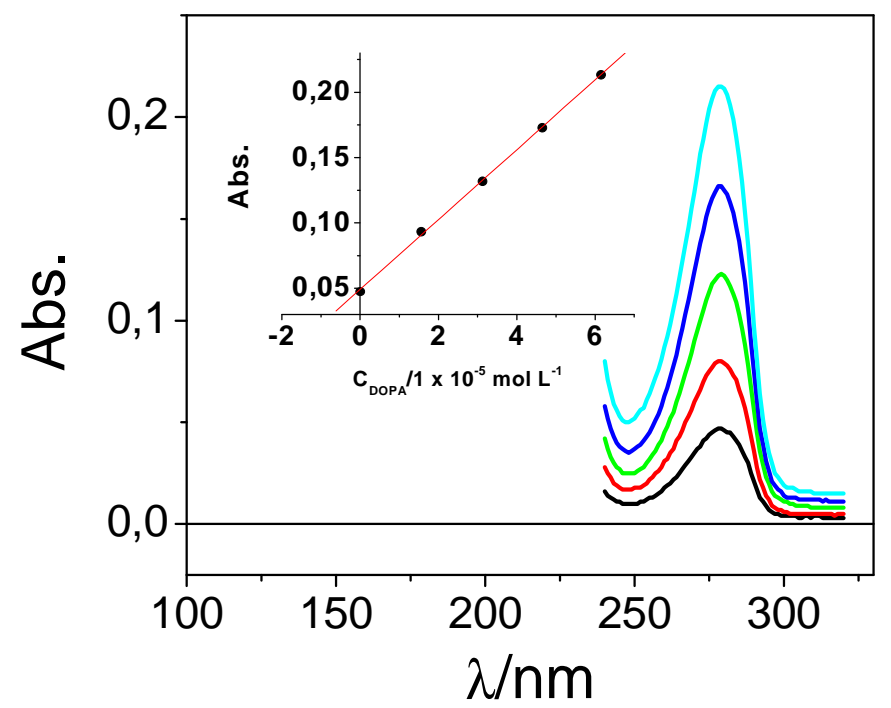

Figura 59 - Espectros de absorção óptica para diferentes concentrações de dopamina. $C_{D O P A}$ adicionada: $\left(\rightarrow\right.$ medicamento, $(-)$ 1,58, $(-)$ 3,12, $(-) 4,60$ e $(-)$ 6,15 $\times 10^{-5} \mathrm{~mol} \mathrm{~L}^{-1}$. Cubeta de $1,00 \mathrm{~cm}$ de caminho óptico. Inserido: curva de recuperação aparente $(R=0,9997)$.

A recuperação aparente média de dopamina foi igual a $107,59 \pm 1,30 \%$ $(10,76 \pm 0,09 \mathrm{mg})$. A quantidade do composto adicionada e recuperada pela metodologia analítica, empregando a técnica de espectrofotometria de absorção no UV, encontra-se um pouco superior ao estipulado pelo fabricante $(10 \mathrm{mg})$. Os excipientes contidos na formulação farmacêutica podem absorver na mesma região do espectro óptico da dopamina e, desta forma, poderão interferir na análise, porém, a quantidade recuperada encontra-se na faixa aceitável para análises de rotina (67). 


\section{III.8- ESTUDO QUÍMICO-QUÂNTICO DA DOPAMINA}

O estudo químico-quântico também foi realizado para a molécula de dopamina, apesar do mecanismo para a oxidação eletroquímica da dopamina já estar relatado na literatura (62). Na Figura 62, é apresentado o mapa de potencial eletrostático para a molécula de dopamina, mostrando que há uma considerável densidade de carga negativa, representada pelos círculos azuis, na região que compreende os átomos de oxigênio do anel aromático e do nitrogênio da cadeia alifática, o que sugeriria que estes átomos seriam os possíveis sítios de oxidação da molécula.

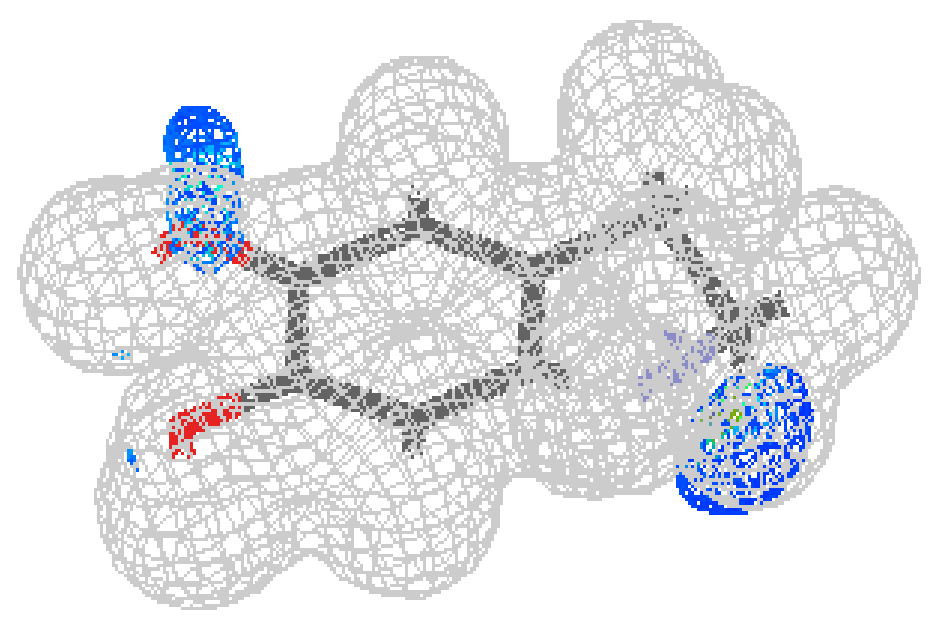

Figura 60 - Representação do mapa de potencial eletrostático a $-10 \mathrm{kcal} \mathrm{mol}^{-1}$ (em malhas) e a $-50 \mathrm{kcal} \mathrm{mol}^{-1}$ (sólido em azul).

Em seguida, foi realizado o cálculo das cargas atômicas derivadas do potencial eletrostático, apresentado na Tabela XIV, para a molécula de dopamina no estado neutro e duplamente ionizado. Por meio deste cálculo, foi possível avaliar a mudança de densidade eletrônica antes e após a oxidação da molécula. 
Tabela XIV - Cálculo das cargas atômicas derivadas do potencial eletrostático para a molécula dopamina no estado neutro e duplamente ionizado.

\begin{tabular}{|c|c|c|}
\hline Átomos & Dopamina & Dopamina +2 \\
\hline $\mathrm{C}_{1}$ & $-0,27$ & $-0,52$ \\
\hline $\mathrm{C}_{2}$ & 0,06 & 0,39 \\
\hline $\mathrm{C}_{3}$ & 0,08 & 0,46 \\
\hline $\mathrm{C}_{4}$ & 0,01 & 0,42 \\
\hline $\mathrm{C}_{5}$ & $-0,17$ & 0,21 \\
\hline $\mathrm{C}_{6}$ & $-0,27$ & $-0,51$ \\
\hline $\mathrm{O}_{7}$ & $-0,25$ & $-0,07$ \\
\hline $\mathrm{O}_{8}$ & $-0,26$ & $-0,15$ \\
\hline $\mathrm{C}_{9}$ & $-0,21$ & $-0,49$ \\
\hline $\mathrm{C}_{10}$ & 0,19 & 0,01 \\
\hline $\mathrm{N}_{11}$ & $-0,63$ & $-0,10$ \\
\hline $\mathrm{H}_{12}$ & 0,23 & 0,31 \\
\hline $\mathrm{H}_{13}$ & 0,16 & 0,10 \\
\hline $\mathrm{H}_{14}$ & 0,18 & 0,29 \\
\hline $\mathrm{H}_{15}$ & 0,27 & 0,34 \\
\hline $\mathrm{H}_{16}$ & 0.24 & 0,38 \\
\hline $\mathrm{H}_{17}$ & 0,05 & 0,21 \\
\hline $\mathrm{H}_{18}$ & 0,08 & 0,22 \\
\hline $\mathrm{H}_{19}$ & 0,02 & 0,06 \\
\hline $\mathrm{H}_{20}$ & 0,22 & 0,12 \\
\hline $\mathrm{H}_{21}$ & 0,23 & 0,14 \\
\hline $\mathrm{H}_{22}$ & 0,02 & 0,13 \\
\hline
\end{tabular}


Pela análise da Tabela XIV, verifica-se que a remoção de dois elétrons leva a mudanças significativas na densidade eletrônica, a qual é distribuída em toda a molécula, porém apresentando mudanças perceptíveis somente em poucos sítios, dentre eles, no átomo de carbono do anel $\left(\mathrm{C}_{2}, \mathrm{C}_{3}, \mathrm{C}_{4}, \mathrm{C}_{5}\right)$ e nos átomos de oxigênio $\left(\mathrm{O}_{7}\right.$ e $\mathrm{O}_{8}$ ). Na Figura 63, é mostrada a estrutura da molécula de dopamina com os átomos numerados de acordo com a Tabela XIV

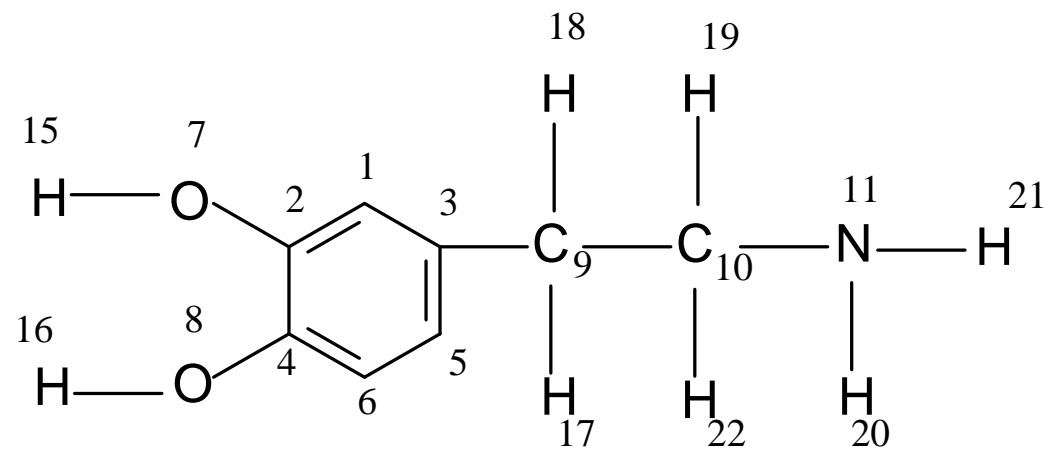

Figura 61 - Molécula de dopamina com os átomos numerados de acordo com a Tabela X.

Pelo cálculo das cargas atômicas para a molécula de dopamina ficou confirmado que, após a perda de dois elétrons e de dois prótons, há um rearranjo de cargas entre os átomos de carbono do anel aromático para formar a dopamina orto-quinona.

Com o intuito de confirmar as evidências constatadas até o momento, o orbital molecular de mais alta energia ocupado (HOMO) foi representado graficamente na Figura 64, juntamente com o orbital molecular de mais baixa energia desocupado (LUMO) da molécula de dopamina. 


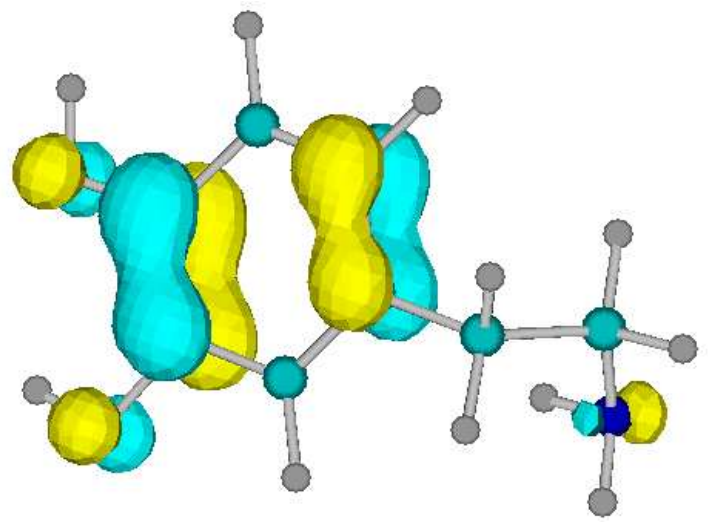

HOMO

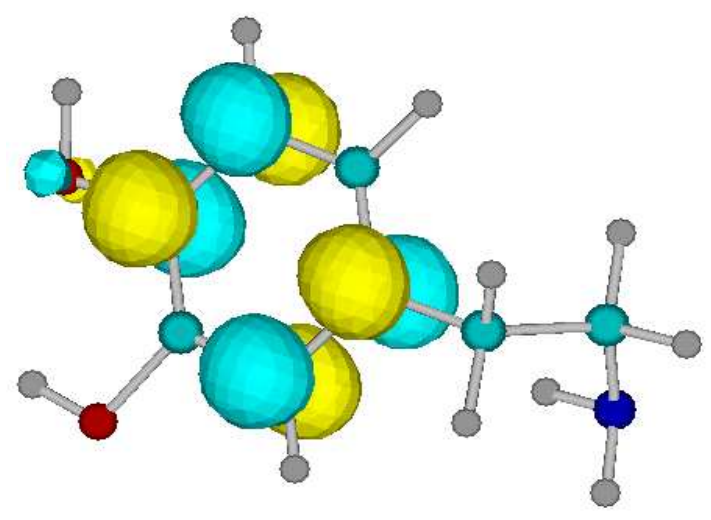

LUMO

Figura 62 - Representação gráfica do HOMO e LUMO para a molécula de dopamina

Pela análise do HOMO, orbital molecular pelo qual sairão os dois elétrons referentes à oxidação da dopamina, observa-se que os átomos que contribuem para a formação deste orbital molecular encontram-se na região que compreende o anel aromático $\left(\mathrm{C}_{2}, \mathrm{C}_{3}, \mathrm{C}_{4}, \mathrm{C}_{5}\right)$ e os átomos de oxigênio $\mathrm{O}_{7}$ e $\mathrm{O}_{8}$, o que está de acordo com o cálculo das cargas atômicas mencionado anteriormente. Quanto ao LUMO, orbital molecular no qual entrarão elétrons referentes à redução da dopamina, verifica-se que a região dos átomos de carbono dos anéis aromáticos contribui muito para a formação deste orbital molecular. 
CONCLUSÕES 
O eletrodo compósito a base de grafite-poliuretana (GPU) foi utilizado com sucesso para avaliar o comportamento eletroquímico e também para desenvolver novas metodologias analíticas para o antidepressivo tricíclico imipramina e para o neurotransmissor dopamina.

A interação do tipo hidrofóbica entre a superfície do eletrodo de GPU e a molécula de imipramina (anel tricíclico) resultou em uma resposta voltamétrica bem definida, o que tornou possível o estudo voltamétrico da reação de oxidação do composto até então pouco explorado na literatura. A partir da sensibilidade alcançada com o emprego da técnica de voltametria de onda quadrada (SWV), uma nova metodologia analítica foi desenvolvida para a análise de rotina de imipramina em comprimidos de Tofrani $^{\circledR}$ com rapidez, boa precisão e exatidão, enfatizando que a metodologia GPU/SWV pode ser utilizada como uma alternativa aos procedimentos cromatográficos usuais.

O limite de quantificação alcançado pela metodologia eletroanalítica (97 $\mu \mathrm{g} \mathrm{L}^{-1}$ ) está dentro da concentração plasmática terapêutica da imipramina (75 a $250 \mu \mathrm{g} \mathrm{L}^{-1}$ ), o que motivou o estudo para diagnosticar a viabilidade de aplicação direta desta metodologia em amostras de soro sintético humano sem efetuar uma etapa de prétratamento da amostra. A seletividade do método foi comprometida, uma vez que a imipramina e seu metabólito (desipramina) apresentam estruturas químicas praticamente idênticas e o mesmo sítio de oxidação (nitrogênio do anel). No entanto, a aplicação de um método matemático de deconvolução (Microcal Origin 6.0) foi bem sucedido para a separação dos picos voltamétricos, permitindo a determinação de imipramina na presença da desipramina. 
No desenvolvimento de metodologia analítica para a dopamina, o eletrodo de GPU foi crucial para separar os picos de oxidação do neurotransmissor e de seu principal interferente, o ácido ascórbico. Foi sugerido que esta separação esta relacionada com interações favoráveis entre o ácido ascórbico (forma aniônica) e os sítios ativos presentes na superfície do eletrodo de GPU.

Desta forma, conclui-se que os resultados alcançados são bastante promissores para a minituarização do sistema na tentativa de se determinar in vivo estas moléculas, bem como outras moléculas de interesse biológico, visto a rapidez, a sensibilidade, a exatidão e a simplicidade da metodologia GPU/SWV. 
REFERÊNCIAS BIBLIOGRÁFICAS 
1. PFIZER, laboratórios Ltda. Depressão em mulheres. Neurociência. Disponível em: <http:www.neurociência.com.br/buscaPaciente.asp?tópico=405\&material=558>Acesso em: 31 mar. 2003.

2. WELLER, E.B.; WELLER, R.A. Treatment options in the management of adolescent depression. Journal of Affective Disorders, v.61, p.S23-S28, 2000.

3. GARERI, P.; FALCONI, U.; FAZIO DE, P.; SARRO, GIOVAMBATTISTA DE. Conventional and new antidepressant drugs in the elderly. Progress in Neurobiology, v.61, p.353-396, 2000.

4. BAN, T.A. Pharmacotherapy of mental illness - A historical analysis. Progress in Neuro-Psychopharmacology \& Biological Psychiatry, v.25, p.709-727, 2001.

5. SUSSMAN, N.; STAHL, S. Uptade in phamacotherapy of depression. The American Journal of Medicine, v.101, suppl.6A, p.26S-36S, 1996.

6. BALLONE, G.J. - Antidepressivos Tricíclicos -1. PsiqWeb - Psiquiatria Geral. Disponível em <http://www.psiqweb.med.br/farmaco/tricic.html> Acesso em: 08 de nov. 2005.

7. FRANK, S.N.; BARD, A.J.; LEDWITH, A. Electrochemical oxidation of iminobibenzil and related compounds. Journal of Electrochemistry Society, v.122, n.7, p.898-904, 1975.

8. BISHOP, E.; HUSSEIN, W. Electroanalytical study of tricyclic antidepressants. Analyst, v.109, p.73-80, 1984. 
9. IVANDINI, T.A.; SARADA, B.V.; TERASHIMA, C.; RAO, T.N.; TRYK, D.A.; ISHIGURO, H.; KUBOTA, Y.; FUJISHIMA, A. Electrochemical detection of tricyclic antidepressant drugs by HPLC using highly boron-doped diamond electrodes. Journal of Electroanalytical Chemistry, v.521, p.117-126, 2002.

10. CANTÚ, M.D.; HILLEBRAND, S.; QUEIROZ, M.E.C.; LANÇAS, F.M.; CARRILHO, E. Validation of non-aqueous capillary electrophoresis for simultaneous determination of four tricyclic antidepressants in pharmaceutical formulations and plasma samples. Journal of Chromatography B, v.799, p.127-132, 2004.

11. YOO, S.D.; HOLLADAY, J.W.; FINCHER, T.K.; DEWEY, M.J Rapid microsample analysis of imipramine and desipramine by reversed-phase highperformance liquid chromatography with ultraviolet detection. Journal of Chromatography B, v.668, p.338-342, 1995.

12. CHEN, A.G.; WING, Y.K.; CHIU, H.; LEE, S.; CHEN, C.N.; CHAN, K. Simultaneous determination of imipramine, desipramine and their 2- and 10hydroxylated metabolites in human plasma and urine by high-perfoamnce liquid chromatography. Journal of Chromatography B, v.693, p.153-158, 1997.

13. REECE, P.A.; ZACEST, R.; BARROW, C.G. Quantification of imipramine and desipramine in plasma by high-performance-liquid-chromatography and fluorescence detection. Journal of Chromatography, v.163, n.3, p.310-314, 1979.

14. BAILEY, D.N.; JATLOW, P.I. Gás-chromatographic analysis for therapeutic concentrations of imipramine and desipramine in plasma, with use of a nitrogen detector. Clinical Chemistry, v.22, n.10, p.1697-1701, 1976. 
15. MASON, P.A.; ROWAN, K.M.; LAW, B.; MOFFAT, A.C.; KILNER, E.A.; KING, L.A. Development and evaluation of a radioimmunoassay for the analysis of body fluids to determine the presence of tricyclic antidepressant drugs. Analyst, v.109, p.12131215, 1984.

16. BIRYOL, I.; BENGI, U.; KÜÇÜKYAVUZ, Z. Voltammetric determination of imipramine hydrochloride and amitriptyline hydrochloride using a polymer-modified carbon paste electrode. Journal of Pharmaceutical and Biomedical Analysis, v.15, p.371-381, 1996.

17. FERANCOVÁ, A.; KORGOVÁ, E.; BUZINKAIOVÁ, T.; KUTNER, W.; STEPÁNEK, I.; LABUDA, J. Electrochemical sensors using screen-printed carbon electrode assemblies modified with the $\beta$-cyclodextrin or carboxymethylated $\beta$ cyclodextrin polymer films for determination of tricyclic antidepressive drugs. Analytica Chimica Acta, v.447, p.47-54, 2001.

18. GHOROGHCHIAN, J.; MENGHANI, M.; SALAHUDDIN, K. Use of microelectrodes in the detection of imipramine in biological fluids. Microchemical Journal, v. 45, p.62-67, 1992.

19. COSTA, J.A.C. da; MOYSÉS NETO, M.; VIEIRA NETO, O.M. Insuficiência renal aguda na terapia intensiva. Med online. [S.L.], v.2, n.6. 1999. Disponível em:<http://www.medonline.com.br/méd_ed/med6/ira.htm>. Acesso em: 26 jun. 2003.

20. SUN, Y.; YE, B.; ZHANG, W.; ZHOU, X. Simultaneous determination of dopamine and ascorbic acid at poly(neutral red) modified electrodes. Analytica Chimica Acta, v.363, p.75-80, 1998. 
21. ONI, J.; NYOKONG, T. Simultaneous voltammetric determination of dopamine and serotonin on carbon paste electrodes modified with iron (II) phthalocyanine complexes. Analytica Chimica Acta, v.434, p.9-12, 2001.

22. RAJ, C.R.; TOKUDA, K.; OHSAKA, T. Electroanalytical applications of cationic self-assembled monolayers: square-wave voltammetric determination of dopamine and ascobate. Bioelectrochemistry, v.53, p.153-191, 2001.

23. ZHAO, H.; ZHANG, Y.; YUAN, Z. Study on the electrochemical behavior of dopamine with poly(sulfosalicylic acid) modified glassy carbon electrode. Analytica Chimica Acta, v.441, p.117-122, 2001.

24. ZHANG, Y.Z.; JIN, G.Y.; WANG, Y.L.; YANG, Z.S.; Determination of dopamine in the presence of ascorbic acid using poly(acridine red) modified glassy carbon electrode. Sensors, v.3, n.10, p.443-450, 2003.

25. ADAMS, R.N. Electrochemistry at solid electrodes. In; MONOGRAPHS in electroanalytical chemistry and electrochemistry. New York: Marcel Dekker, 1969. 402p.

26. MOSES, P.R.; WIER, P.; MURRAY, R.W. Chemically modified tin oxide electrode. Analytical Chemistry, v.47, n.12, p.1882-1886, 1975.

27. PEREIRA, C.A.; SANTOS, S.A.; KUBOTA, L.T. Tendências em modificação de eletrodos amperométricos para aplicações eletroanalíticas. Química Nova, v.25. n.6A, p.1012-1021, 2002.

28. TALMANN, D.E.; PETERSEN, S.L. Composite eletrode for electroanalysis: principles and applications. Electroanalysis, v.2, p.499, 1990. 
29. CÉSPEDES, F.; MARTíNEZ-FÁBREGAS, E.; ALEGRETE, S. New materials for electrochemical sensing: I. Rigid conduting composites. Analytical Chemistry, v.15, p.296, 1996.

30. LUQUE, M.; RÍOS, A.; VALCÁRCEL, M. Validation of PVC-graphite composite electrodes for routine analytical work. Electroanalysis, v.11, p.1116, 1999.

31. MABBOTT, G.A.; An introduction to cyclic voltammetry. Journal of Chemistry Education, v.60, n.9, p.697-706, 1983.

32. CROW, D.R. Principles and applications of electrochemistry. London: Blackie Academic \& Profissional, 1994. p.221,216.

33. BRETT, A.M.O.; BRETT, C.M.A. Eletroquímica: princípios, métodos e aplicações. Coimbra: Oxford University Press, 1993. p.102-104.

34. SOUZA DE, D.; MACHADO, S.A.S.; AVACA, L.A. Voltametria de onda quadrada. Primeira parte: Aspectos teóricos. Química Nova, v.26, n.1, p.81-89, 2003.

35. RAMALEY, L.; KRAUSE, M.S.; Theory of square wave voltammetry. Analytical Chemistry, v.41, n.11, p.1362-1369, 1969.

36. LOVRIC, M. Square wave voltammetry of an adsorbed reactant. Journal of Electroanalytical Chemistry, v.248, p.239-253, 1988.

37. CLARE, B. W. Frontier orbital energies in quantitative structure-activity relationships: a comparison of quantum chemical methods. Theoretica Chimica Acta, v.87, p.415, 1994. 
38. KOROLKOVAS, A. Fundamentos da farmacologia molecular. Rio de Janeiro: Guanabara Dois, 1982. 783p.

39. SILVA DA, A.B.F.; ALVES, C.N.; MOLFETTA, F.A. A quantum chemM Structure: Theochem, v.577, p.187-195, 2002.

40. BRUNS, R. E.; GUADAGNINI, P. H.; SOUZA, A. A. Cargas atômicas em moléculas. Química Nova, v.19, p.148, 1996.

41. CASTILHO, M.; ALVES, C.N.; MAZO, L.H.; TABAK, M.; SILVA, A.B.F. DA Theoretical calculations on dipyridamole structure allow to explain experimental properties associated to electrochemical oxidation and protonation. Chemical Physics Letters, v.349, p.146-152, 2001.

42. MARONE, S.; ROZAS, I.; WEAVER, D.F. Theorical structural analyses of tricyclic neuroactive drugs: quantum pharmacologic descriptors for clustering anticonvulsant, antidepressant, and antipsychotic activities. Journal of Molecular Structure: Theochem, v.467, p.25-30, 1999.

43. SILVERSTEIN, R.M.; BASSLER, G.C.; MORRILL, T.C. Identificação espectrométrica de compostos orgânicos. 5. ed. Local: Guanabara Koogan, 1994, p. 3-7.

44. DOLE, M.; MACK, L.L.; HINES, R.L.; MOBLEY, R.C.; FERGUNSON, L.D.; ALICE, M.B. Molecular beams of macroions. Journal of Chemical Physics, v.49, n.5, p.2240-\&, 1968. 
45. YAMASHITA, M.; FENN, J.B. Electrospray ion-source - Another variation on the free-jet theme. Journal of Physical Chemistry, v.88, n.20, p.4451-4459, 1984. 46. MORAES, M.C.B.; LAGO, C.L. Espectrometria de massas com ionização por "electrospray"aplicada ao estudo de espécies inorgânicas e organometálicas. Quimica Nova, v.26, n.4, p.556-563, 2003.

47. OSER, B.L. Hawk's physiological chemistry. New Delhi: McGraw-Hill, 1966. p.350-352.

48. ZHANG, F.; YANG, L.; SHUPING, B.; LIU, J.; LIU, F.; WANG, X.; YANG, X.; GAN, N.; YU, T.; HU, J.; LI, H.; YANG, T. Neurotransmitter dopamine applied in electrochemical determination of aluminum in drinking waters and biological samples. Journal of Inorganic Biochemistry, v.87, p.105-113, 2001.

49. PARHAM, H.; ZARGAR, B. Determination of isosorbide dinitrate in arterial plasma, synthetic serum and pharmaceutical formulations by linear sweep voltammetry on a gold electrode. Talanta, v.55, p.255-262, 2001.

50. TOLEDO DE, R.A.; SANTOS, M.C.; HONÓRIO, K.M.; SILVA DA, A.B.F.; CAVALHEIRO, E.T.G.; MAZO, L.H. Use of the graphite polyurethane composite electrode for imipramine oxidation - mechanism proposal and electroanalytical determination. Analytical Letters. No prelo.

51. WEPSCHALL, R.H., SHAIN, I. Effects of adsorption of electroative species in stationary electrode polarography. Analytical Chemistry, v.39, p.1514-1527, 1967.

52. GOSSER JUNIOR, D.K. Cyclic Voltammetry: simulation and analysis of reaction mechanisms. New York: VCHP, 1993. p.98-99. 
53. LOVRIC, M.; LOVRIC, S.K.; MURRAY, R.W. Adsorption effects in square wave voltammetry of totally irreversible redox reactions. Electrochimica Acta, v.33, n.6, p.739-744, 1988.

54. INTERNATIONAL UNION OF PURE AND APPLIED CHEMISTRY. Harmonized guidelines for the in-house validation of methods of analysis (technical report). Disponível em: <http://www.iupac.org/divisions/V/501/draftoct19.pdf> Acesso em: 19 mar. 2005.

55. INSTITUTO NACIONAL DE METROLOGIA NORMALIZAÇÃO E QUALIDADE INDUSTRIAL. Orientações sobre validação de métodos de ensaios químicos DOQ - CGCRE - 008. Disponível em :<http://www.inmetro.gov.br/kits/doqcgcre008r01.pdf>Acesso em:15 fev. 2005.

56. BURNS, D.T.; DANZER, K.; TOWNSHEND, A. Recommendations for the use of the term "recovery" in analytical procedures. IUPAC Recommendations, p.1-5, 2001.

57. ULRICH, S.; MARTENS, J. Solid-phase microextraction with capillary gas-liquid chromatography and nitrogen-phosphorus selective detection for the assay of antidepressant drugs in human plasma Journal of Chromatography B, v.696, p.217-234, 1997.

58. TOLEDO DE, R.A.; SANTOS, M.C.; HONÓRIO, K.M.; SILVA DA, A.B.F.; CAVALHEIRO, E.T.G.; MAZO, L.H. Estudo eletroquímico e químico-quântico da oxidação do antidepressivo tricíclico amitriptilina. Química Nova, v.28, n.3, p.456-461, 205.

59. WANG, J. Analytical electrochemistry. New York: VCHP, 1994. p.161-169. 
60. TOLEDO DE, R.A.; SANTOS, M.C.; CAVALHEIRO, E.T.G.; MAZO, L.H. Determination of dopamine in synthetic cerebrospinal fluid by SWV with a graphitepolyurethane composite electrode. Analytical and Bioanalytical Chemistry, v.381, p. 1161-1166, 2005.

61. LOVRIC, M. Square wave voltammetry of an adsorbed reactant. Journal of Electroanalytical Chemistry, v.248, p.239-253, 1988.

62. WEN, X.L.; JIA, Y.H.; LIU, Z.L. Micellar effects on the electrochemistry of dopamine and its selective detection in the presence of ascorbic acid. Talanta, v.50, p.1027-1033, 1999.

63. DOWNARD, A.J.; RODDICK, A.D.; BOND, M.A. Covalent modification of carbon electrodes for voltammetric differentiation of dopamine and ascorbic acid. Analytica Chimica Acta, v.317, p.303-310, 1995.

64. DALMIA, A.; LIU, C.C.; SAVINELL, R.F. Electrochemical behaviour of gold electrodes modified with self-assembled monolayers with na acidic end group for selective detection of dopamine. Journal of Electroanalytical Chemistry, v.430, p.205-214, 1997.

65. ZHANG, L.; JIA, J.; ZOU, X.; DONG, S. Simultaneous determination of dopamine and ascorbic acid at an in-site functionalized self-assembled monolayer on gold electrode. Electroanalysis, v.16, p.1413-1418, 2004.

66. GHITA, M.; ARRIGAN, W.M. Dopamine voltammetry at overoxidised polyindole electrodes. Electrochimica Acta, v.49, p.4743-4751, 2004. 
67. THE EUROPEAN AGENCY FOR THE EVALUATION OF MEDICINAL PRODUCTS. Validation of analytical procedures: methodology. Disponível em:<www.emea.eu.int/pdfs/human/ich/038195en.pdf> Acesso em: 20 nov. 2005. 